\title{
Federal Geothermal Research Program Update Fiscal Year 2004
}

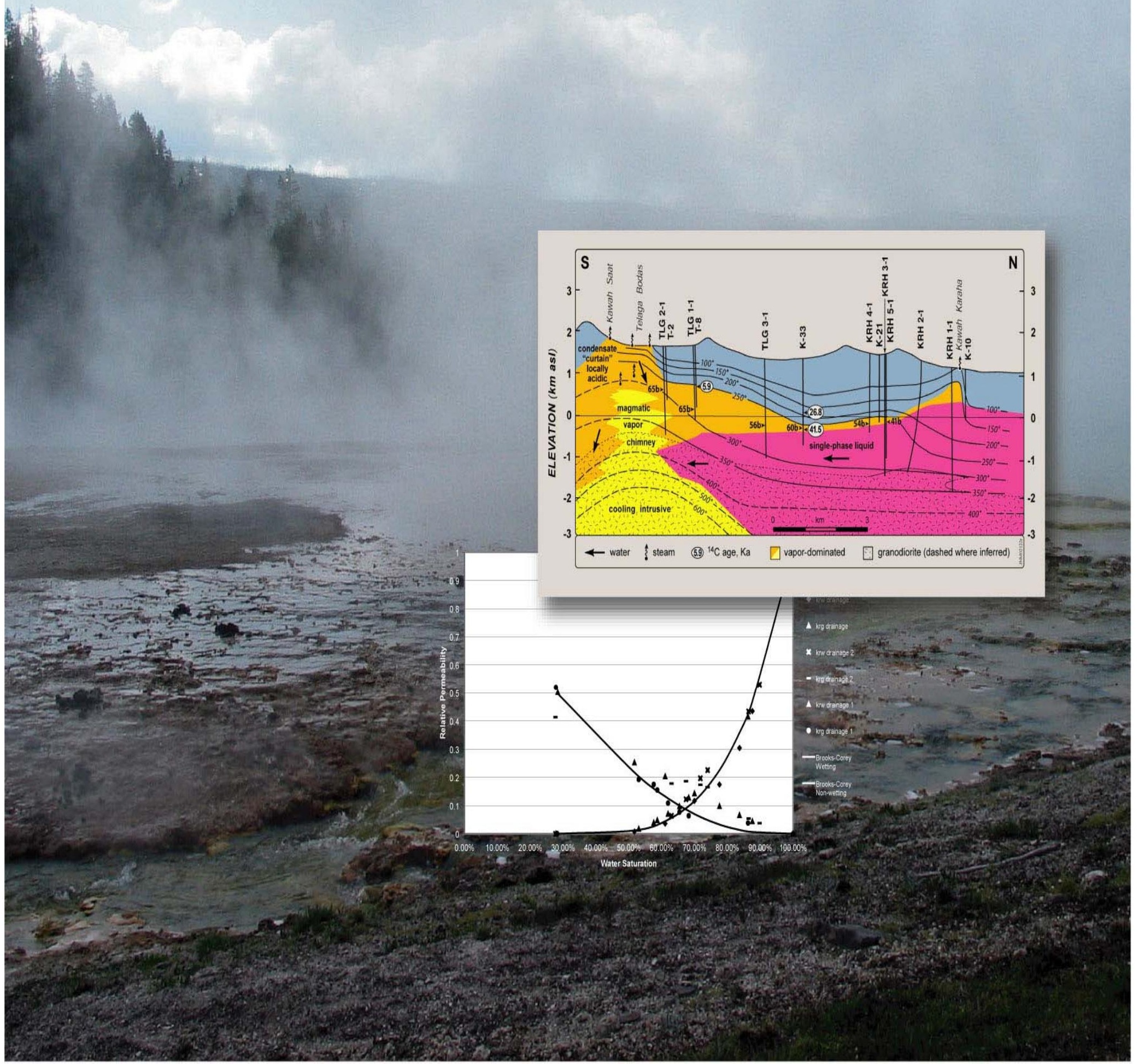


This information was prepared as an account of work sponsored by an agency of the U.S. Government. Neither the U.S. Government nor any agency thereof, nor any of their employees, makes any warranty, express or implied, or assumes any legal liability or responsibility for the accuracy, completeness, or usefulness of any information, apparatus, product, or process disclosed, or represents that its use would not infringe privately owned rights. References herein to any specific commercial product, process, or service by trade name, trademark, manufacturer, or otherwise, does not necessarily constitute or imply its endorsement, recommendation, or favoring by the U.S.

Government or any agency thereof. The views and opinions of authors expressed herein do not necessarily state or reflect those of the U.S. Government or any agency thereof. 


\section{CONTENTS}

SUMMARY vii

I. RESOURCE DEVELOPMENT; Raymond Fortuna, Technical Manager......................................... 1

Remote Sensing for Exploration and Mapping of Geothermal Resources; Calvin, W. .................... 3

Geology and Geophysics of Geothermal Systems; Nash, G. D. ............................................. 6

Localized Strain as a Discriminator of Hidden Geothermal Systems; Vasco, D. W...................... 10

Localized Strain as a Discriminator of Hidden Geothermal Resources; Foxall, W....................... 12

InSAR Ground Displacement Analysis; Oppliger, G........................................................ 16

Structural Controls, Alteration, Permeability and Thermal Regime of Dixie Valley from

New-Generation Mt/Galvanic Array Profiling; Wannamaker, P.E. ..................................... 20

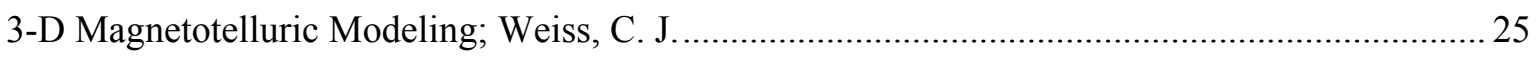

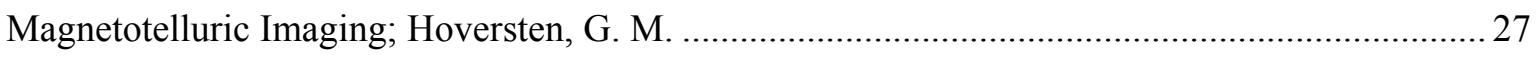

Western U.S. Geothermal Systems: Enhanced Data Acquisition and Inversion for

Electrical Resistivity Structure in Geothermal Exploration and Reservoir

Assessment; Wannamaker, P. E.

Characterization of 3D Fracture Patterns at The Geysers and Coso Geothermal Reservoirs by

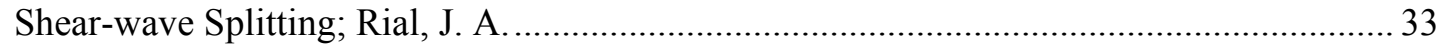

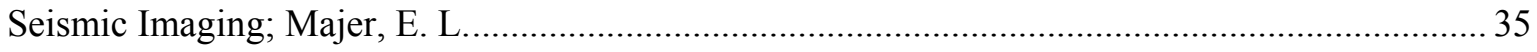

Assembling Crustal Geophysical Data for Geothermal Exploration in the Great

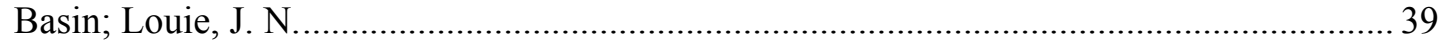

Technology for Increasing Geothermal Energy Productivity; Moller, N..................................... 41

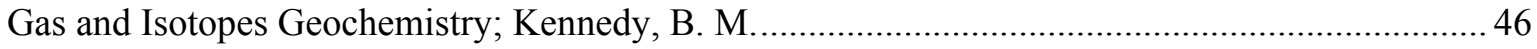

Design of Sampling Strategies to Detect $\mathrm{CO}_{2}$ Emissions From Hidden Geothermal

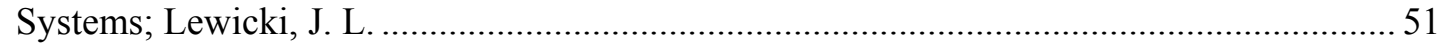

Geochemical Sampling of Thermal and Non-thermal Waters in Nevada; Shevenell, L.................55

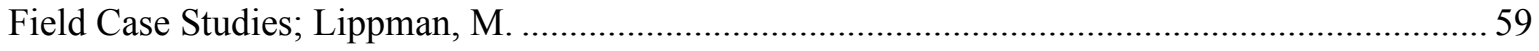

Regional Assessment of Exploration Potential for Geothermal Systems in The Great Basin

Using a Geographic Information System (GIS) - Part II; Coolbaugh, M. 61 
Characterization and Conceptual Modeling of Magmatically-Heated and Deep-Circulation,

High-Temperature Hydrothermal Systems in the Basin and Range and Cordilleran

United States; Hulen, J. B.

Improving Exploration Models of Andesite-Hosted Geothermal Systems; Moore, J. N.

Targeting of Potential Geothermal Resources in the Great Basin from Regional to

Basin-Scale Relationships Between Geodetic Strain and Geological

Structures; Blewitt, G

Dating of Young Igneous Rocks Associated with Geothermal Systems in the Great

Basin; Arehart, G. B. and Coolbaugh, M. F.

II. ENHANCED GEOTHERMAL SYSTEMS; Dr. Allan Jelacic, Technical Manager

Numerical Tools for Resource Management - TetGeo; Shook, G. M.

Studies of Geothermal Reservoir Dynamics; Pruess, K.

Reservoir Characterization for EGS and Hydrothermal Systems; Shook, G. M.

Analysis of Injection in Fluid Starved (EGS) Environments; Bloomfield, K. K.

Development of a Reservoir Geomechanics Model for Enhanced Geothermal

Systems; Ghassemi, A

Laboratory Measurements of Steam/Water Flow; Horne, R. N.

Geochemical Study of the Effects of Fluid Injection at EGS Sites; Kennedy, B. M.

Geologic and Geophysical Analysis of the Desert Peak-Brady Geothermal Fields:

Structural Controls on Geothermal Reservoirs in the Humboldt Structural

Zone; Faulds, J. E.

Prediction and Detection of Induced Fractures in EGS; Roberts, J. J.

High Temperature Borehole Televiewer; Kuszmaul, S. S.

MEQ Monitoring; Majer, E. L

III. SYSTEMS DEVELOPMENT; Raymond LaSala, Technical Manager 129

Materials Field Testing; Gawlik, K. 131

Advanced Cycles; Kutscher, C.

Advanced Heat Rejection; Kutscher, C.

Enhancement of Air-Cooled Condensers; Sohal, M. S.

Continual Removal of Non-condensable Gases for Binary Power Plant Condensers; Mohr, C.... 141 
Geothermal Plant Process Monitoring; Partin, J. K

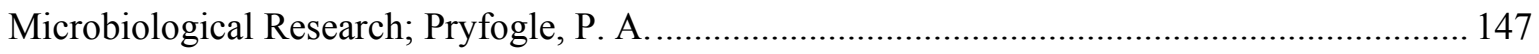

Geothermal Co-production of Silica and Other Commodities; Bourcier, W. L........................... 152

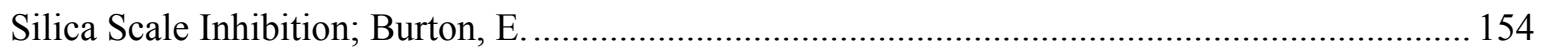

Investigation of Microbial Sulfur Oxidation for the Natural Abatement of Sulfides in Geothermal Cooling Tower Basins; Pryfogle, P. A....................................................... 158

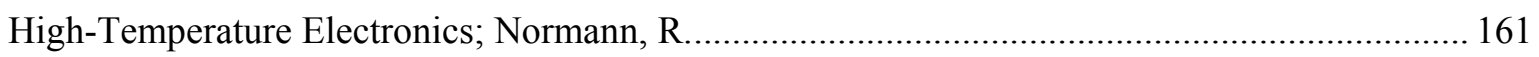

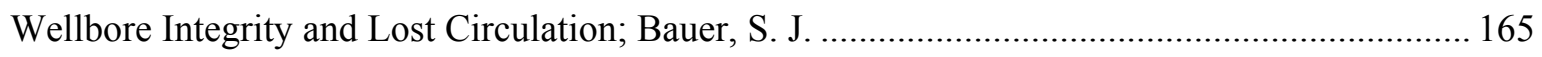

Hard-Rock Drill Bit Technology; Raymond, D. W. and Wise, J. L............................................ 169

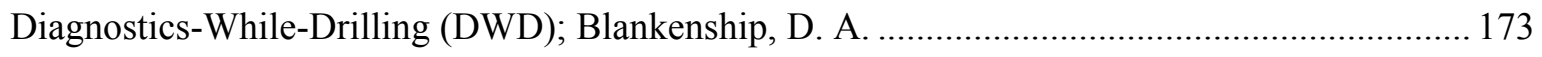

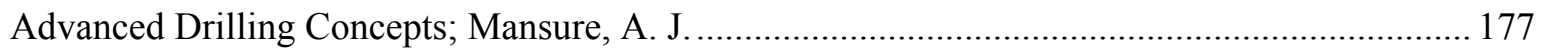

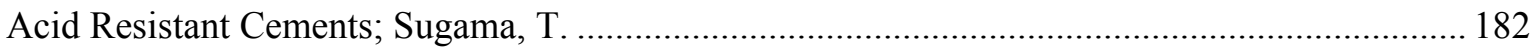

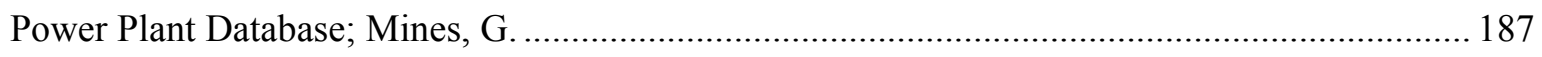

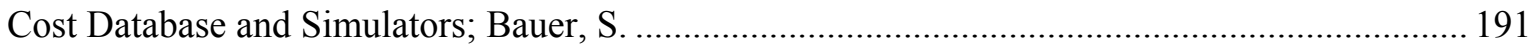

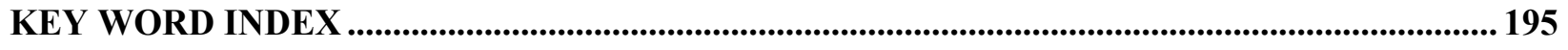

PRINCIPAL INVESTIGATORS ................................................................................................................. 199

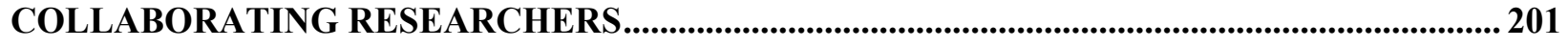

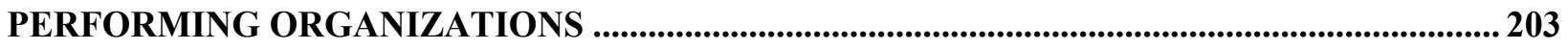




\section{SUMMARY}

\section{OVERVIEW}

The Department of Energy (DOE) and its predecessors have conducted research and development (R\&D) in geothermal energy since 1971. The Geothermal Technologies Program (GTP) works in partnership with industry to establish geothermal energy as an economically competitive contributor to the U.S. energy supply. Geothermal energy production, a $\$ 1.5$ billion a year industry, generates electricity or provides heat for direct use applications. The technologies developed by the Geothermal Technologies Program will provide the Nation with new sources of electricity that are highly reliable and cost competitive and do not add to America's air pollution or the emission of greenhouse gases. Geothermal electricity generation is not subject to fuel price volatility and supply disruptions from changes in global energy markets. Geothermal energy systems use a domestic and renewable source of energy.

The Geothermal Technologies Program develops innovative technologies to find, access, and use the Nation's geothermal resources. These efforts include emphasis on Enhanced Geothermal Systems (EGS) with continued R\&D on geophysical and geochemical exploration technologies, improved drilling systems, and more efficient heat exchangers and condensers.

The Geothermal Technologies Program is balanced between short-term goals of greater interest to industry, and long-term goals of importance to national energy interests. The program's research and development activities are expected to increase the number of new domestic geothermal fields, increase the success rate of geothermal well drilling, and reduce the costs of constructing and operating geothermal power plants. These improvements will increase the quantity of economically viable geothermal resources, leading in turn to an increased number of geothermal power facilities serving more energy demand. These new geothermal projects will take advantage of geothermal resources in locations where development is not currently possible or economical.

The Mission and Goal of the DOE Geothermal Technology Program are:

\section{Mission}

To work in partnership with U.S. industry to establish geothermal energy as an economically competitive contributor to the U.S. energy supply.

\section{Goal}

Reduce the levelized cost of generating geothermal power to $\$ 0.03$ to $\$ 0.05$ per kilowatt-hour by 2010

This Federal Geothermal Program Research Update for Fiscal Year 2004 reviews the accomplishments of DOE's Geothermal Program towards fulfilling the program mission and reaching program goals. The information contained in this Research Update illustrates how the mission and goals of the Office of Geothermal Technologies are reflected in each R\&D activity. The Geothermal Program, from its guiding principles to the most detailed research activities, is focused on expanding the use of geothermal energy.

\section{RESEARCH FOCUS}

In accordance with the mission and goals, the Geothermal Program serves two broad purposes: 1) to assist industry in overcoming near-term barriers by conducting cost-shared research and field verification that allows geothermal energy to compete in today's aggressive energy markets; and 2) to undertake fundamental research with potentially large economic payoffs. 
Since the inception of the Geothermal Program, the Federal government and private industry have worked closely together - in pursuing promising research directions, and in overcoming difficult technical barriers, to establish an extensive geothermal knowledge base. Over the past three decades, industry, in turn, has succeeded in creating an infrastructure that translates research results into marketplace applications. This DOE/industry partnership guides the DOE research program towards more costcompetitive power generation from geothermal resources. In addition, this partnership assesses the value of long-term research options. Private-sector inputs to DOE's planning process are critical to a logical, balanced strategy for the Geothermal Program.

This report uses the new Geothermal Technology Program structure. The majority of research projects are included under the program elements of Resource Development, Enhanced Geothermal Systems Technology and System Development. System Development includes the subsets of Heated Power Systems Research and Drilling Systems research. The Technology Deployment program element includes only a few research projects reported on here, and is also the element where the GeoPowering The West (GPW) and other GTP outreach projects are managed. GPW projects are not reported on in this research summary. The various program elements are introduced briefly below.

\section{Resource Development}

Resource Development research combines laboratory and analytical investigations with equipment development and field testing to establish practical tools for resource development and management. FY 2004 saw increased field work associated with water sampling, field mapping, setting up GPS stations, rock dating and collection electronic data. This field data is being analyzed and incorporated with laboratory results, into various models that provide new insights into areas including MT modeling, resistivity modeling, shear-wave splitting and fracture characterization, regional geologic settings and many other aspects of hydrothermal occurrences.

\section{Enhanced Geothermal Systems Technology}

Understanding and predicting fractures in geothermal reservoirs is key to finding hidden resources, designing new operations and enhancing existing ones. Researchers are using a combination of computer modeling, laboratory experiments and field experiments to investigate processes that enhance permeability in fractured reservoirs. Other efforts in the area of Enhanced Geothermal Systems include topics such as steam/water flow measurements, high temperature downhole instrumentation, injection of fluids into EGS systems, resource management modeling and geochemistry of hydrothermal systems.

\section{System Development}

System Development research during FY 2004 involved projects associated with both Heat and Power Systems, and Drilling.

Heat Power Systems research in FY 2004 focused on plant operations and how to improve power plant efficiencies. This research included studies of non-condensable gases, plant process monitoring, microbial research, scale inhibition and other areas that can ultimately help lower the cost of power produced from geothermal resources.

Drilling and completion of wells for exploration, production, and injection accounts for 20 to 40 percent of the cost of generating electricity from geothermal resources. One of the focuses of System Development is developing improved, economic drilling and completion technology for geothermal wells. Research conducted this year furthered the understanding of drill bit design and operation, cements and cementing processes used in high temperature geothermal applications. 
Several projects in FY 2004 addressed the costs associated with proving resources and producing geothermal power. These studies looked at factors such as total installed plant costs, trends in plant cost reduction, historical plant costs, economic modeling, and well and exploration costs.

Models for analyzing drilling and exploration costs as well as plant construction and operation costs are being developed. 


\section{RESOURCE DEVELOPMENT}




\section{Remote Sensing for Exploration and Mapping of Geothermal Resources}

Reporting Period: FY 2004 (October 1, 2003 to September 30, 2004)

DOE Grant/Contract \#: $\quad$ DE-FG36-02ID14311

Performing Organization: $\quad$ University of Nevada - Reno, Great Basin Center for Geothermal Energy

Principal Investigator: $\quad$ Wendy Calvin, (775) 784-1785, wcalvin@unr.edu

Collaborating Researchers: Mark Coolbaugh, UNR

DOE HQ Program Manager: Dr. Leland (Roy) Mink, (202) 586-5463, roy.mink@hq.doe.gov

DOE HQ Technical Manager: Raymond Fortuna, (202) 586-1711, raymond.fortuna@hq.doe.gov

DOE Funding Allocation: $\quad \$ 85 \mathrm{~K}(3 / 03$ to $9 / 04)$

Cost Share Funding: $\quad$ None in FY04

Project Objective: The work seeks to define surface identifiers of geothermal resources through analysis of remote sensing imagery to characterize mineral, vegetation, and thermal properties at known source regions to establish markers of potential in other areas. Geothermal identifiers include sinter, tufa (carbonate), hydrothermal alteration (clays, sulfates), vegetation stress due to near-surface saline waters, vegetation concentration near small surface seeps or springs, and thermal anomalies as mapped in both nighttime and corrected day/night imagery. The work responds to the need to identify new potential geothermal resource targets and map the geology and fault structures of these areas. New potential targets will be identified using the complementary signatures described above and geologic and fault mapping can be achieved using regional and local scale image information. This information can be used to determine high priority targets in existing resource areas and identify new targets for geothermal exploration and development. The project is expected both to identify new resource regions and bring down costs by helping to focus development in existing resource areas.

Background/Approach: Remote sensing has long been used as an exploration and site characterization tool. Applications have included mineral and petroleum exploration and development, hazard assessment, and targeting field intensive environmental remediation activities on the highest priority sites,. Wellestablished techniques in multispectral and hyperspectral analysis, coupled with new, state-of-the-art imagery from spaceborne and airborne sensor systems allows their direct and immediate application to problems in geothermal energy exploration and development. Recent improvement in the availability and quality of optical, near-infrared and thermal infrared imagery provides significant advantage for a multifaceted approach to identify geothermal resources and map geologic structures based on their surface expression. 
For our analysis we use a variety of multispectral (several wavelength channel) and hyperspectral (hundreds of wavelengths) data sets. These data sets are sensitive to surface mineralogy and lithology as well as surface temperature. Sinter, carbonate and hydrothermal alteration minerals, such as clays and sulfates, are identified by their unique spectral signatures from visible through infrared wavelengths. These materials are spatially mapped in the airborne and spaceborne imagery and field checked through field and laboratory spectral measurements as well as alternate methods of identification such as x-ray diffraction and thin section. Products of this work include spatial maps of various minerals and surface alteration, locations of thermal anomalies and synthesis of remotely sensed thematic and mineral identification maps with other field-based geologic maps and information. The data are georectified to standard projections so that they can be readily included in regional and site specific databases.

Status/Accomplishments: Work in FY04 concentrated on three primary tasks: 1) Providing detailed mineralogic mapping and relation to structure using hyperspectral data at Brady's, 2) Assessment and request of new multi-spectral imagery over sites of emerging interest (Buffalo Valley, Pyramid Lake, Fish Lake Valley), and 3) Continuing thermal anomaly mapping using higher spatial resolution imagery by from MASTER (a NASA airborne instrument). A fourth task, Exploratory work on the use of spectral mineralogy for rapid assessment of drill

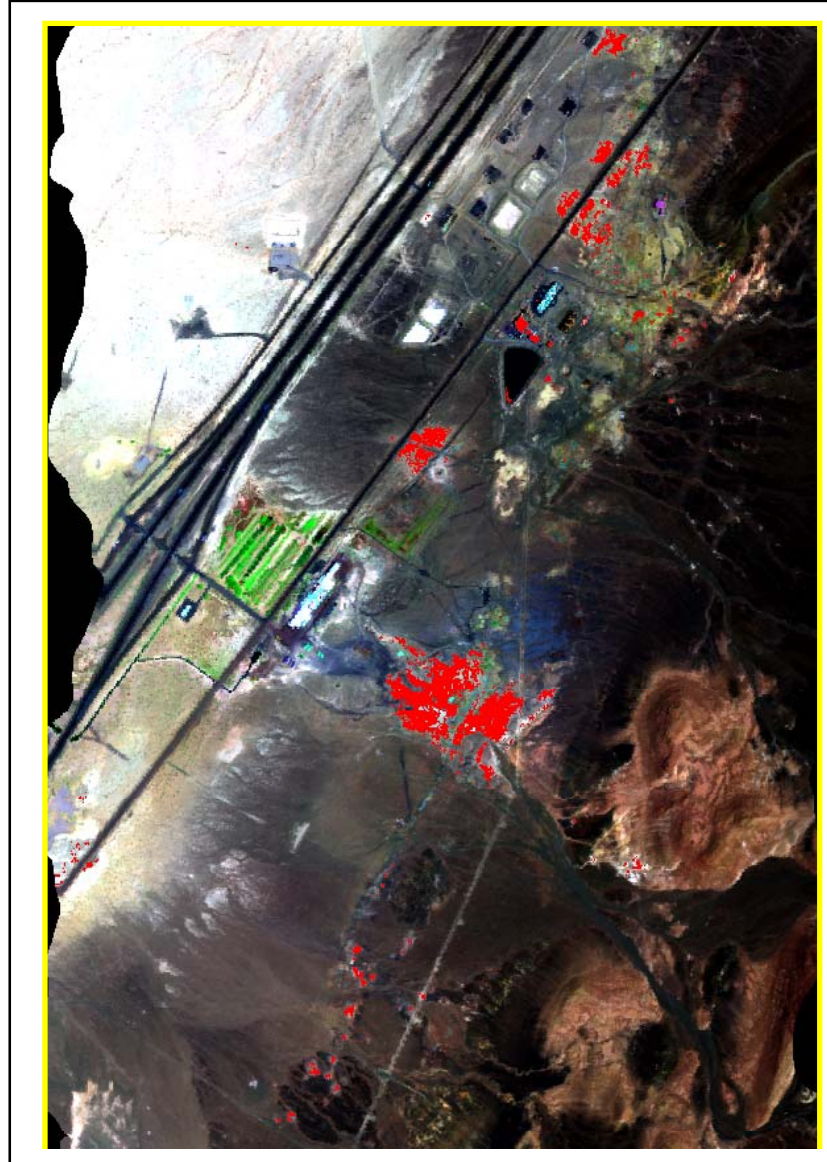

Figure 1. Portion of the hyperspectral data acquired at Bradys. Large deposits of sinter, mapped in red, are noted and mark an extension of the fault line south of the main plant. This map helped identify the location for further drilling at this site. core and cuttings was initiated based on a workshop held at DRI in December 2003.

This work extended our local scale studies from Steamboat into new areas. By comparing magmatic systems (Steamboat as recently inferred by geochemical studies) with extensional systems (Brady, Buffalo) we can begin to define surface alteration patterns and characteristics that may help distinguish these types of systems.

Task 1) Detailed analysis of hyperspectral imagery obtained in summer of 2003 over Brady's Hot Springs region was completed and validated (Figure 1). This analysis provided a local map of both sinter and tufa deposits surrounding the Ormat plant, identified fault extensions not previously recognized from field mapping and has helped constrain where to put additional wells that were drilled at the site.

Task 2) Initial analysis of Landsat and ASTER data for Buffalo Valley and Pyramid Lake was performed. Preliminary imagery in Buffalo/Jersey was provided to Ormat to guide their initial development. Pyramid Lake analysis provided an initial assessment used to support a proposal to the Paiute Tribe for full analysis and hyperspectral data acquisitions. That effort was funded through the tribe for FY05. 
Task 3) Concurrent analysis of shortwave and thermal data (MASTER flights) were delayed due to late arrival of additional funding. Flight request were approved and are pending for the FY05 flight season.

Task 4) Initial assessment of a variety of chip board cuttings and drill core from drill holes in the Desert Peak area was performed.

Reports \& Articles Published in FY 2004: "Possible extension of Brady's fault identified using remote mapping techniques”. C. Kratt, M. Coolbaugh, and W. Calvin, GRC Transactions, vol 27, 2003.

"Geothermal Exploration with Hyperspectral Data over Desert Peak, Nevada". C. Kratt, International Geoscience and Remote Sensing Symposium (IGARSS), Proceedings 2004.

"Spectral Analyses of Well Cuttings from Drillhole DP23-1, Desert Peak EGS area, Nevada - preliminary study of minerals and lithologies by infrared spectrometry", C. Kratt, W. Calvin, and S. Lutz, GRC, Transactions, vol 28, 2004.

Presentations Made in FY 2004: "Possible extension of Brady's fault identified using remote mapping techniques”. C. Kratt, GRC Morelia, Mexico, Oct 12-15, 2003.

"Geothermal Exploration with Hyperspectral Data over Desert Peak, Nevada". C. Kratt, IGARSS, Anchorage, AK, Sept 20-24, 2004.

"Spectral Analyses of Well Cuttings from Drillhole DP23-1, Desert Peak EGS area, Nevada - preliminary study of minerals and lithologies by infrared spectrometry", C. Kratt, GRC, Palm Springs, CA, Aug 30 Sept 1, 2004.

\section{Planned FY 2005 Milestones:}

Remote Sensing Summary paper for GSN Jan 05

Presentation of drill core study at Stanford Workshop Jan 05

Continuation proposal submitted to GBCGE

Feb 05

Thermal Anomaly Study of Bradys submitted to Geothermics Mar 05

Overview article of remote sensing for GRC Bulletin Apr 05 Presentation of Remote Sensing Summary at GSN May 05 Bradys work published in MS thesis by Kratt May 05 MASTER acquisitions of Buffalo, Gerlach area Jun 05 Initial analysis of MASTER Flights Aug 05 Landsat/ASTER analysis of new areas presented at GRC Sep 05 Bradys analysis submitted to Geothermics or RSE 


\section{Geology and Geophysics of Geothermal Systems}

Reporting Period: FY 2004 (October 1, 2003 to September 30, 2004)

DOE Grant/Contract \#: $\quad$ DEFG36001ID13891

Performing Organization: Energy \& Geoscience Institute 423 Wakara Way

Salt Lake City, UT 84108

Principal Investigator: Ｇregory D. Nash, (801) 585-3889, gnash@egi.utah.edu

Collaborating Researchers: Elizabeth Murphy: bmurphy@egi.utah.edu

William Pickles: pickles1@1lnl.gov

DOE HQ Program Manager: Dr. Leland (Roy) Mink, (202) 586-5463, roy.mink@hq.doe.gov

DOE HQ Technical Manager: Raymond Fortuna, (202) 586-1711, raymond.fortuna@hq.doe.gov

DOE Funding Allocation: $\quad \$ 164 \mathrm{~K}$

Cost Share Funding: $\quad \$ 0$

Project Objective: The overall objective of this multiyear project is to test new remote sensing data and emerging processing techniques, coupled with the advanced use of geographic information systems for data integration and interpretation, to determine their usefulness in geothermal exploration and system characterization. This effort directly relates to the DOE goal to increase the number of new domestic geothermal fields as the techniques tested in this study can be used to help define and refine exploration targets and locate blind geothermal systems. Many of the original objectives of this project were completed prior to FY 2004. Objectives for FY 2004 were to map mineralogy in Dixie Meadows, NV and thermal anomalies in Railroad Valley, NV. The first objective relates to the project goal of testing hyperspectral imagery for applications in soil-mineralogy mapping to detect hidden faults and buried geothermal phenomena. The second objective relates to testing satellite thermal infrared (TIR) data for locating thermal anomalies that may be related to blind systems. A third objective was testing ASTER multispectral data for small-scale mapping of the geology of the northern Silver Peak Range, Nevada near the Fish Lake Valley geothermal field.

Background/Approach: In order for the geothermal industry and production to grow in the United States new resources must be found. Remotely sensed data analysis offers a unique opportunity in exploration through its facilitation of (1) mineralogy mapping, (2) lithology mapping, (3) structural mapping, and (4) vegetation anomaly mapping over new targets. This is especially advantageous and cost-effective early in exploration as the information that is gleaned can be used to help direct further work. Geologic mapping in general can be expedited and subtle anomalous features, such as vegetation anomalies or buried geothermal phenomena that may reveal hidden permeable structures or blind systems, can be detected. 
The approach has been to acquire appropriate data, including multispectral, hyperspectra, and TIR, apply standard and unique processing and analysis techniques to meet the objectives, and to report the results in peer reviewed journals and at conferences.

Status/Accomplishments: All of the original objects of this project have been accomplished. Vegetalspectral analysis at Cove Fort-Sulphurdale, Utah was tested as a method of detecting hidden faults in exploration efforts. This effort proved to be successful and resulted in the Following published paper: Nash, G. D., J. N. Moore, and T. Sperry, 2003. "Vegetal-spectral anomaly detection at the Cove FortSulphurdale thermal anomaly, Utah, USA: implications for use in geothermal exploration," Geothermics, v. 32 , p. 109-130.

Hyperspectral data was also used to successfully map soil-mineral anomalies that are structurally related in Dixie Valley, Nevada. In the area of the power plant, $20 \mathrm{~m}$ spatial resolution AVIRIS data were used. For Dixie Meadows, Nevada, $3 \mathrm{~m}$ spatial resolution HyVista HyMap hyperspectral data was acquired in a cooperative effort with Dr. William Pickles of Lawrence Livermore National Laboratories. This work results in the following published papers detailing results:

Nash and Johnson (2004); Pal and Nash (2003); Pickles et al. (2003) - see Reports \& Articles Published in FY 2004 for full citations --; and

Nash, G. D. and G. Johnson, 2002, Soil Mineralogy Anomaly Detection in Dixie Valley, Nevada Using Hyperspectral Data, Proceedings: Twenty-Seventh Workshop on Geothermal Reservoir Engineering Stanford University, Stanford, California, January 28-30, 2001, SGP-TR-171.

TIR imagery was also tested for several uses in geothermal exploration including hydrologic modeling, heat-flow mapping, and thermal anomaly mapping. This work resulted in the following publications:

Dudley and Nash (2004) - see Reports \& Articles Published in FY 2004 for full citations --; and

Allis, R. G., S. Johnson, G. D. Nash, R. Benoit, 1999, A model for the shallow thermal regime at Dixie Valley Geothermal Field, Geothermal Resources Council Transactions, vol. 23, p. 493-498 .

Allis, R, G. Nash, S. Johnson, 1999, Mapping changes in surface thermal activity at Dixie Valley Geothermal Field, Nevada, Geothermal Resources Council Transactions, vol. 23, p. 499-504.

Other publications resulting for this project include:

Nash, G. D., 1999, GIS - the geospatial data IT paradigm for the next century: Awibengkok core example, in Geothermal Resources Council Transactions, vol. 23, p. 31-34.

Nash, G. D. and M. W. Hernandez, 2001, Cost-Effective Vegetation Anomaly Mapping for Geothermal Exploration, Proceedings: Twenty-Sixth Workshop on Geothermal Reservoir Engineering Stanford University, Stanford, California, January 28-30, 2001, SGP-TR-168.

Nash, G. D., 2001, Cost-effective use of GIS for tracer test data mapping and visualization, Geothermal Resources Council Transactions Vol. 25, p. 461-464.

Nemcok, M, J. McCulloch, G. Nash, and J. Moore, 2001, Fault Kinematics in the Karaha-Telaga Bodas, Indonesia, Geothermal Field: An Interpretation Tool for Remote Sensing Data, Geothermal Resources Council Transactions, Vol. 25, p. $411-415$. 
Nash, G. D., C. Kesler, and M. C. Adams, 2002, Geographic Information Systems: Tools for Geothermal Exploration; Tracers Data Analysis; and Enhanced Data Distribution, Visualization, and Management, Geothermal Resources Council Transactions, Vol. 26.

Nash, G. D. and G.W. Johnson, 2003. "Conceptualization and implementation of a tectonic geomophology study for geothermal exploration in the Great Basin, U.S.A.” Geothermal Resources Council Transactions vol. 27, 663-667.

As for the northern Silver Peak Range small-scale mapping effort, experiments in automated lithologic mapping using multispectral data were conducted in FY 2004 with limited success. This was done using Isodata cluster analysis. It is believed that different data processing may achieve better results in this regard.

The overall results of this project were successful and suggest that remote sensing can be an important tool in geothermal resource exploration and in better characterizing known geothermal systems. A summary of uses follows:

Hyperspectral data: In this project hyperspectral data has been found useful for (1) mineralogy mapping;

(2) mapping soil-mineral anomalies that may reveal faults and buried geothermal phenomena;

(3) mapping vegetation anomalies that may reveal hidden permeable faults that are in communication with a geothermal system (both airborne and field instruments are useful here); (4) lithology mapping; and (5) structural mapping. Evidence gained in this project also suggest that merging high spatial resolution panchromatic data $(\leq 1 \mathrm{~m})$ with high spatial resolution hyperspectral data $(\leq 5 \mathrm{~m})$ may produce imagery that is unmatched for use in geologic mapping.

Multispectral data: this data has been found to be useful for more generalized purposes, such as mapping undifferentiated hydrothermal alteration. This project has also produced results that suggest that medium spatial resolution multispectral data may be useful in detecting large vegetation anomalies that can be related to permeable structures in communication with geothermal systems, in medium to well vegetated areas. Multispectral data is the most cost-effective data for use in regional to semi-regional exploration efforts.

TIR data: thermal anomalies may be present over blind geothermal systems. The results of this project suggest that this type of data may be useful in mapping these anomalies. This could be accomplished over large areas in a cost-effective manner using ASTER TIR data. However, it is suggested that more local studies are needed, to corroborate the results of this and other limited studies, before regional studies are pursued.

This project has also reinforced the value of geographic information systems (GIS) in exploration efforts. GIS has enabled the visualization of data, storage and access of disparate data sets, and merging of data that would not be possible using any other technology. While CAD is preferred by some in geothermal exploration, it lacks a multitude of the functions facilitated with GIS.

Many of the publications generated by this project are available at http:/www5.egi.utah.edu.

\section{Reports \& Articles Published in FY 2004:}

Nash, G. D. and G. W. Johnson, 2004, Hyperspectral detection of geothermal system related soil mineralogy anomalies in Dixie Valley, Nevada: A tool for exploration, Geothermics, v. 33, issue 6, 695711. 
Nash, G. D., Murphy, E., and J. Umbriaco, 2004, Remote sensing for geothermal resource exploration and characterization: a summary of results 2000-2004, Geothermal Resources Council Transactions, $v$. $28,31-35$.

Pal, D. and G. D. Nash, 2003. "Mineralogic Interpretation Of Hymap Hyperspectral Data, Dixie Valley, Nevada, USA: Initial Results.” Geothermal Resources Council Transactions vol. 27, 669-672.

W. L. Pickles, G. D. Nash, W. M. Calvin, B. A. Martini, P. A. Cocks, T. Kennedy-Bowdin, R. B. MacKnight, E. A. Silver, D. C. Potts, W. Foxall, P. Kasameyer, A. F. Waibel, 2003, Geobotanical remote sensing applied to targeting new geothermal resource locations in the US Basin and Range with a focus on Dixie Meadows NV, Geothermal Resources Council Transactions, v. 27, 673-675.

Dudley, E.A. and G.D. Nash, 2003. "Using Thermal Infrared (TIR) Data to Identify Geothermal Anomalies." Geothermal Resources Council Transactions v. 27 645-647.

Presentations Made in FY 2004: A summary of the accomplishments of this project was presented at the 2004 Geothermal Resources meeting at Indian Wells, California. A poster was also presented at this meeting. Additionally, two presentations were delivered at the 2003 Geothermal Resources meeting at Morelia, Mexico.

Planned FY 2005 Milestones: Small-scaled geologic map of the northern Silver Peak Range. Final report to DOE as part of the EGI Western Geothermal Systems conclusion. 


\section{Localized Strain as a Discriminator of Hidden Geothermal Systems}

Reporting Period: FY 2004 (October 1, 2003 to September 30, 2004)

DOE Grant/Contract \#: $\quad$ 1.1.1.4

Performing Organization: $\quad$ Lawrence Berkeley Laboratory

Principal Investigator: $\quad$ D. W. Vasco, (510) 486-5206, dwvasco@lbl.gov

Collaborating Researchers: William Foxall, LLNL, (925) 424-3767

DOE HQ Program Manager: Dr. Leland (Roy) Mink, (202) 586-5463, roy.mink@hq.doe.gov

DOE HQ Technical Manager: Raymond Fortuna, (202) 586-1711, raymond.fortuna@hq.doe.gov

DOE Funding Allocation: $\quad \$ 75 \mathrm{~K}$

Cost Share Funding: None

Project Objective: To advance our fundamental knowledge of the relationship between regional geology, tectonics, and the formation, evolution, and operation of geothermal systems. Examination of the possibility of identifying candidate geothermal field sites using remotely sensed surface deformation data. A key component of this project is to better understand the relationship between regional strain, fluid flow and pressure changes in the subsurface, and surface deformation. This includes the interaction of existing faults and fracture zones and fluids in the subsurface.

If it proves possible to identify candidate geothermal field sites using remotely sensed surface deformation it would provide a very cost effective tool. Industry could use this tool to identify previously unknown resources. The improved understanding of fluid-fault/fracture interaction will be also be useful in optimizing geothermal production and in the modeling of geothermal systems.

Background/Approach: Most known geothermal resource areas have been explored and exploited, but little exploration targets undiscovered resources. Most fields and known resources in the Basin and Range province appear to be associated with active fault systems. Geodetic measurements, seismicity, geology, and remote sensing can be used to investigate whether localized perturbations in the magnitude and orientation of the regional strain field in relation to local fault geometry are associated with hydrothermal systems. If these methods are effective, they can then be used for identifying candidate sites for more detailed exploration for hidden geothermal resources. The observation aspect of this research focuses on the use of repeat-orbit synthetic aperture radar interferometry (InSAR), a satellite-based geodetic technique that has the potential of measuring surface strains on the order of $10^{-6}$ to $10^{-7}$ on a regional scale with a spatial resolution of 25 meters. This work is in collaboration with William Foxall of LLNL. We are exploring the advantages of stacking or averaging a large number of InSAR pairs in order to improved the accuracy of our InSAR-based strain measurements. The averaging provides estimates of observational 
uncertainties which are useful in assessing the significance of our estimates. In addition, through a collaboration with A. Ferretti of Politecnico di Milano, I am investigating the suitability of permanent scatterers for obtaining high precision estimates of regional strain. Permanent scatterers (PS) are objects which maintain their radar reflective characteristics over long periods of time. In addition, their reflectivity is not a strong function of the satellite view angle. Thus, orbits with differing geometry can be used to estimate surface deformation. Using identified PS it is possible to obtain surface velocity estimates with an accuracy of a few millimeters per year. In addition to improving the accuracy of surface deformation estimates, I am utilizing geodetic data to better understand the interaction between existing faults and fractures and fluids in the subsurface. Faults and fractures represent anomalous mechanical and hydrological zones of limited extent. The behavior of such regions can be difficult to comprehend using point measurements taken a particular times. The nearly continuous spatial coverage, provided by InSAR, is a valuable tool in monitoring fluid-fault interactions. Understanding fault-fluid interactions is critical in interpreting localized strain associated with a hidden geothermal system. The third component of this study involves dynamic fault modeling in the presence of fluids. Such modeling ties the surface deformation to geologic and hydrologic processes at depth. For this work I am collaborating with Professor Lane Johnson of U. C. Berkeley. We are implementing a state-variable dynamic fault model in the presence of fluids. Such a model will be useful in interpreting and predicting localized deformation in association with a geothermal system at depth. The expected products of this research are a set of tools for the detection of localized deformation. In addition, I am developing routines to model such localized deformation in terms of fluid-fault interaction. Several field studies will be conducted in order to validate the modeling. Such modeling will also be of use in understanding later geothermal production.

Status/Accomplishments: Recent work has focused on (1) collaborating with Alessandro Ferretti to use Permanent Scatterer (PS) InSAR data to infer strain at depth, (2) working with Lane Johnson to develop a dynamic faulting model, and (3) acquiring InSAR data for the region surrounding the Dixie Valley fault zone in collaboration with Dr. William Foxall of LLNL. The InSAR data have been processed and an initial interpretation of the results is ongoing. In particular, we have InSAR stacks for over twenty pairs of scenes. The use of PS data and the development of data processing techniques, such as stacking, is critical for imaging slowly varying regional strains over many years. Dr. Ferretti has developed an effective processing technique to identify permanent scatterers and observe their motion with sub-centimeter accuracy. (4) Studying the role that faults play in controlling flow in hydrothermal/magmatic systems I have completed a study of fault-fluid interaction at the Yellowstone caldera. I have also been working on leveling, GPS, EDM, and gravity data from Long Valley, California. The inversion of the deformation data has allowed us to show those faults which appear to be controlling flow at depth.

\section{Reports \& Articles Published in FY 2004:}

Vasco, D. W., and Ferretti, A., 2004. On the use of quasi-static deformation data to understand reservoir fluid flow, Geophysics, (in press).

\section{Presentations Made in FY 2004:}

Vasco, D. W., Karasaki, K, and Kishida, K., 2003. A coupled inversion of pressure and surface displacement, American Geophysical Union, Fall Meeting.

\section{Planned FY 2005 Milestones:}

Complete study of the use of geodetic data to image fluid-fault interaction May 05 Complete dynamic fault modeling in the presence of fluids 


\section{Localized Strain as a Discriminator of Hidden Geothermal Resources}

Reporting Period: FY 2004 (October 1, 2003 to September 30, 2004)

DOE Grant/Contract \#: $\quad$ W-7405-Eng-48

Performing Organization: Lawrence Livermore National Laboratory, Earth Sciences Division P.O. Box 808, Livermore, CA 94551-0808.

Principal Investigator: ～William Foxall, (925) 424 3767, bfoxall@1lnl.gov

Collaborating Researchers: Donald Vasco, LBNL; dwvasco@lbl.gov

Rob Mellors, San Diego State Univ; rmellors@geology.sdsu.edu

DOE HQ Program Manager: Dr. Leland (Roy) Mink, (202) 586-5463, roy.mink@hq.doe.gov

DOE HQ Technical Manager: Raymond Fortuna, (202) 586-1711, raymond.fortuna@hq.doe.gov

DOE Funding Allocation: $\quad \$ 175 \mathrm{~K}$

Cost Share Funding: none

Project Objective: The objectives of our research are to investigate the role that strain concentrations along active faults play in localizing geothermal resources in the western Basin and Range, and to develop and test techniques to identify hidden potential geothermal resources by detection of strain anomalies on a regional basis. This research is designed to meet the objectives of the Geothermal Program by providing cost effective regional exploration for new resources, which will lead to an increase in the overall supply of geothermal power and heat.

Background/Approach: Most producing geothermal fields and known geothermal resources in the Basin and Range province appear to be associated with Quaternary active fault systems, within which hydrothermal fluids are presumed to circulate from depth to relatively shallow production levels through high permeability fractures. DOE-funded research at Dixie Valley (Barton et al., Proc. $22^{\text {nd }}$ Stanford Workshop, 1997) indicates that hydraulically conductive fractures within the Stillwater fault zone are those that have orientations such that the fractures are critically stressed for normal shear failure under the regional stress field. Caskey and Wesnousky (Proc. $25^{\text {th }}$ Stanford Workshop, 2000) presented evidence that the geothermal field occupies a $10 \mathrm{~km}$-long gap between prehistoric Holocene ruptures of the fault segments on either side. Modeled Coulomb failure stress is high within the gap owing to the stress concentrations at the ends of the ruptures. These results suggest that a major contributing factor to the enhanced permeability at fault-hosted geothermal systems may be localized stress and strain concentrations within fault zone segments. This notion is generally consistent with the common occurrence of geothermal fields within fault offsets (pull-aparts) along strike-slip fault systems, where the local strain field has a large extensional component (e.g., Salton Sea and Coso). 
Geodetic measurements, seismicity, geology, and remote sensing can be used to investigate whether localized perturbations in the magnitude and orientation of the regional strain field are systematically associated with fault-hosted hydrothermal systems. The current focus of our research is to evaluate the utility of repeat-orbit synthetic aperture radar interferometry (InSAR) as a reconnaissance tool by testing its capability to detect localized strain anomalies directly. InSAR is a satellite-based geodetic technique that has the potential of measuring surface strains on the order of $10^{-6}$ to $10^{-7}$ on a regional scale with a spatial resolution of 25 meters. The basis for the technique is that the difference between the phases of the radar echos received from an imaging element (pixel) on the Earth's surface at nearby satellite positions during two different orbits is proportional (in part) to displacement of the pixel in the time interval between the two orbits. Mapping the phase changes produces an interferogram, which is processed to recover a map of surface deformation covering an area of approximately $100 \times 100 \mathrm{~km}$.

Our study is centered on the Central Nevada Seismic Zone and the Walker Lane belt of western Nevada, where both regional strain and much of the current geothermal production are concentrated. The broad geographical coverage afforded by InSAR allows us also to include adjacent areas of potential interest. Recent GPS studies indicate that the regional strain concentration correspond to surface displacement rates of a few $\mathrm{mm} /$ year across the $\sim 100 \mathrm{~km}$ width of each of these belts. Therefore, interferograms must span time intervals approaching ten years in order to capture sufficient cumulative deformation to be imaged by the InSAR. However, the signal/noise ratio (SNR) of interferograms in general degrades as the time interval spanned by the orbits increases. This is due to temporal phase decorrelation caused by subpixel displacements, resulting, for example, from plant growth, and changes in the reflective properties of the ground surface during the interval between the orbits. This means that the SNR achieved over these longer intervals precludes discrimination of subtle strain signatures on single-pair interferograms. We overcome this problem by stacking many single-pair interferograms of the same scene spanning different time intervals, which reinforces coherent, linearly increasing strain signals and minimizes the noise. An equally important function of stacking is to eliminate spurious signals on single-pair interferograms caused by tropospheric phase delays. The stack is constructed by summing the displacements, $d_{i}$, in the $N$ interferograms and normalizing by the sum of the interferometric time intervals, $T_{i}$, which produces a map of the average displacement rate $\left(\dot{d}=\sum^{N} d_{i} / \sum^{N} T_{i}\right)$ under the assumption of constant strain rate.

Status/Accomplishments: During FY05 we completed development of the automated InSAR processing procedure necessary to process the large number of radar scenes and interferogram pairs needed for stacking. We acquired synthetic aperture radar (SAR) data from 29 orbits of the European Space Agency ERS1/2 satellites (Track 217) for each of two contiguous frames $(2817,2835)$ covering the intersection of the CNSZ and Walker Lane (or, alternatively, the bifurcation of the Eastern California Shear Zone into the CNSZ and Northern Walker Lane). From these scenes 34 interferograms spanning time intervals ranging from 1 to 9 years during the period 1992-2001 were produced for each frame, of which 8 were rejected because of high noise caused by excessive baselines (separation between the orbits), possible snow cover in one of the scenes, or other reasons. We produced several stacks from different combinations of the remaining 26 interferograms. These include a stack of all 26 interferograms ( $\sum T=102$ years), and the stack shown in Fig 1, which comprises 15 interferograms (Frame 2817) that span individual time intervals less than four years ( $\sum T=35$ years $)$ during 1992-2000 and therefore have moderate to high SNR. We also produced stacks for the periods 1996-1999 and 1997-2001. The spatial resolution of the data in these stacks is approximately $80 \mathrm{~m}$. Fig. 1 also shows Quaternary active 
faults from the new USGS Quaternary Fault and Fold Database of the United States (Machette, et al., http://qfaults.cr.usgs.gov).
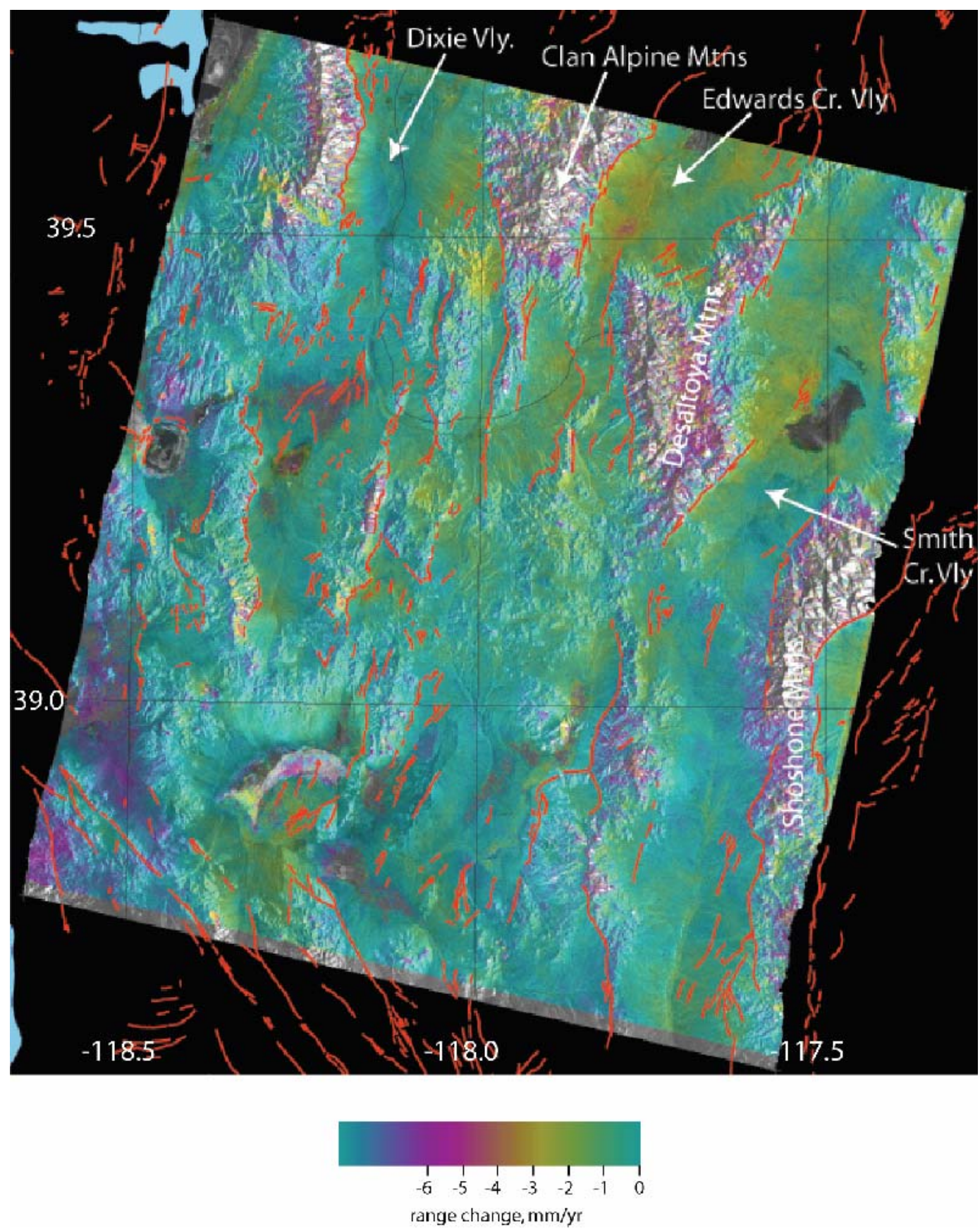

The general features in Figure 1 are seen in all of the stacks. Areas of decorrelation (low coherence) correspond to steep and forested range slopes and to salt or alkali marshes in the basins. Preliminary analysis of this interferogram indicates that the patches of relatively intense (green-yellow-orange) color in the vicinity of Edwards Creek Valley, Smith Creek Valley and Dixie Valley correspond to displacement rates of about 2-4 mm/yr towards the satellite. This is in general agreement with analysis of a smoothed, low-resolution interferogram stack by Gourmelen and Amelung (Eos v.85, AGU Fall Meeting, 2004), who detected a broad zone of deformation in this area that extends $\sim 100 \mathrm{~km}$ further to the 
north, and with GPS measurements. We are presently beginning detailed analysis of long- and, in particular, short-wavelength features on the interferogram stacks for the two frames and their relationships to active faults, seismicity and geothermal resources. This will include further data processing to enhance features at different spatial scales, and integration with GPS data.

\section{Reports \& Articles Published in FY 2004: None}

Presentations Made in FY 2004: None

Planned FY 2005 Milestones:

Final stack of existing scenes; preliminary stack of next 2 frames

Final integrated stack of all (4) frames

Jul 05

Integrated interpretation of InSAR and tectonic analyses 


\section{InSAR Ground Displacement Analysis}

Reporting Period: FY 2004 (October 1, 2003 to September 30, 2004)

DOE Grant/Contract \#: $\quad$ DE-FG36-02ID14311

Performing Organization: University of Nevada, Reno

Principal Investigator: ～Gary Oppliger, (775) 784-7056, oppliger@mines.unr.edu

Collaborating Researchers: Mark Coolbaugh

DOE HQ Program Manager: Dr. Leland (Roy) Mink, (202) 586-5463, roy.mink@hq.doe.gov

DOE HQ Technical Manager: Raymond Fortuna, (202) 586-1711, raymond.fortuna@hq.doe.gov

DOE Funding Allocation: $\quad \$ 28 \mathrm{~K}$

Cost Share Funding: $\quad$ \$6K salary match

Project Objective: This project is evaluating the utility of retrospective satellite radar interferometry (InSAR) ground displacement studies for characterizing geothermal reservoir responses to production. The objectives are to 1) demonstrate the recovery and application of retrospective Satellite Interferometric Synthetic Aperture Radar (InSAR) annual surface displacement histories for geothermal fields lacking surface displacement histories; 2) identify reservoir structural controls through integration of the displacement patterns with mapped geological and geophysical data; 3) chart measures of each reservoir's vs. displacement production sensitivity over time to define its progression toward production equilibrium.

This project supports increased utilization of geothermal resources in the Western United States by developing basic measurements and interpretations that will assist reservoir management and expansion at Bradys, Desert Peak and the Desert Peak EGS study area $(80 \mathrm{~km} \mathrm{NE}$ of Reno, Nevada) and will serve as a technology template for other geothermal fields.

This is a two year project initiated in October 2003 and planned for completion in September 2005.

Background/Approach: Incomplete knowledge of geothermal reservoir boundaries adds to the cost risks associated with field management, new development and exploration work. Commonly, groundwaterlevel and pressure data are highly insufficient to delineate the complete geothermal field and its response under production. In this context, ground displacement patterns mapped with InSAR promise to provide needed information on the extent of the reservoir system beyond the known field and on the effectiveness of fluid production and reinjection well patterns.

Minor surface displacement will occur as a consequence of the production of geothermal fluids even if the reservoir is deep and isolated from shallow groundwater. Reservoir volume change is largely driven by pressure reduction, which reduces the reservoir's compressive strength and allows subsidence of 
overlying strata into the reservoir, but reservoir contraction by cooling and possibly viscous drag from fluid flow also contribute. Where coupling into a shallow groundwater aquifer also occurs, surface displacements will contain additional contributions related to strain from the weight of deposits that have lost buoyant support and dehydration shrinkage of shallow clayey deposits. Because all of the above effects are linked to production they are not readily separated; however, they are collectively anticipated to define the system's primary fluid flow pathways.

InSAR observations at large capacity fields (Coso) have been reported, but no case studies have been undertaken on the more numerous middle capacity (10MW-50MW) fields, so our study seeks to demonstrate InSAR's value to this class of fields. The Bradys-Desert Peak Geothermal fields were selected because they have been the subject of several significant geologic investigations that will help place the results in context and the field operators have active field development programs that may be able to incorporate our results

The Bradys geothermal field lies along the northwest structural boundary between the low relief Hot Springs Mountains and Hot Springs Flats basin, about $80 \mathrm{~km}$ east-northeast of Reno, Nevada. The faultcontrolled reservoir is developed in permeable zones in Tertiary volcanic rocks in the hanging wall of the Bradys fault, a steeply dipping, north-northeast-striking fault with down-to-the-northwest normal displacement. Near the Bradys fault system, Mesozoic metasedimentary basement is overlain by 800 meters or more of Tertiary volcanic and sedimentary rocks. Basement structure and relief is suggested by surface gravity data (Figure 1). The Brady 21-MW dual-flash geothermal plant produces from three clusters of production wells (distributed over $\sim 1.4 \mathrm{~km}$ ) with an average depth of 930 meters and average fluid temperature of $\sim 156^{\circ} \mathrm{C}$. The plant has three clusters of injection wells (spaced over $7 \mathrm{~km}$ ) with an average injection fluid temperature of $\sim 114^{\circ} \mathrm{C}$.

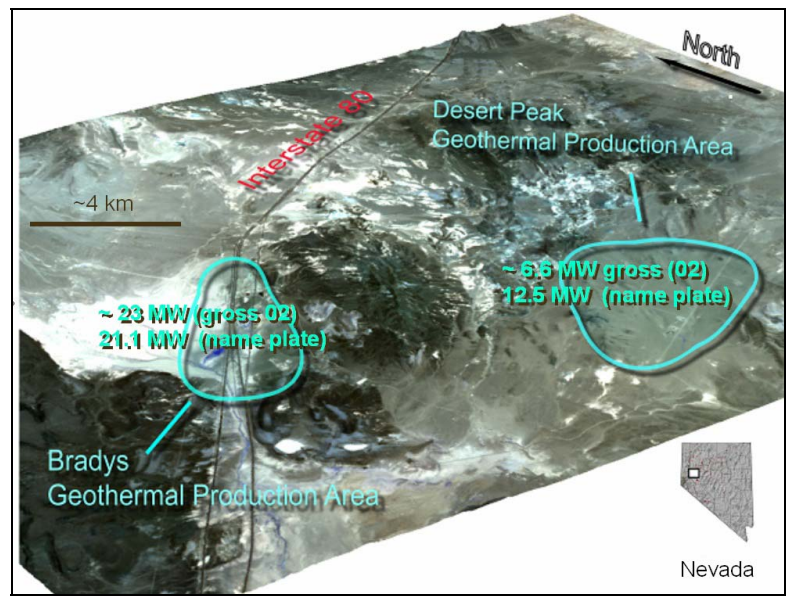

Bradys-Desert Peak Geothermal Fields Study Area

Status/Accomplishments: Raw format European Space Agency (ESA) ERS 1/2 satellite synthetic Aperture Radar (SAR) radar scenes acquired from 1992 through 2002 are being processed to measure the study area's time-dependent surface displacement patterns. Four of the ERS 1/2 SAR radar scenes used in FY04 were acquired through the Western North America InSAR (WinSAR) research consortium and additional scenes are being purchased from ESA. To create the required interferograms, we have configured an InSAR processing capability utilizing Jet Propulsion Laboratory's (JPL) Repeat Orbit Interferometry Package (ROI PAC) version 2.2.2 and ENVI post-processing tools. This processing work is in its mid-stages and will continue into FY05. Geothermal production summaries have been compiled to allow analysis of spatial and temporal changes to the reservoir. In FY05, existing surface geology and 
gravity defined basin geometries and structures from recent studies in the Bradys Desert Peak area will be combined with production data in a Geographic Information System (GIS) for comparisons with the derived InSAR patterns.

The first year results clearly demonstrate the practicality of the approach. The two presented interferograms, A and B in Figures 2 and 3, respectively cover 2.96 years (92-11-26 to 95-11-04) and 4.78 years (95-11-04 to 00-09-24), They reveal the first surface displacement feature reported for the Brady geothermal field. The discovery and delineation of this reservoir production signal is a significant technical result, which indicates InSAR may be useful over many mid-capacity geothermal fields. At the largest scale, the interferograms indicate that the Bradys active reservoir zone has strong hydrologic conductivity zone along a $7 \mathrm{~km}$ axis with a longer weaker deflation zone extending for $\sim 11$ $\mathrm{km}$ total. This is about $6 \mathrm{~km}$ more strike length than the field's surface manifestations (fumaroles and sinter). It is remarkable that although production is restricted to a span of $\sim 1.4 \mathrm{~km}$, the InSAR images delineate "structures" several kilometers up and down strike. If the extended reservoir strike length can be verified, the implications for future field development and improved reinjection may be significant. Although our preliminary analysis includes only four interferograms and limited production information, we are confident that our planned use of additional interferograms intervals and more detailed production patterns in FY05 will produce proportionally more detailed and useful results.

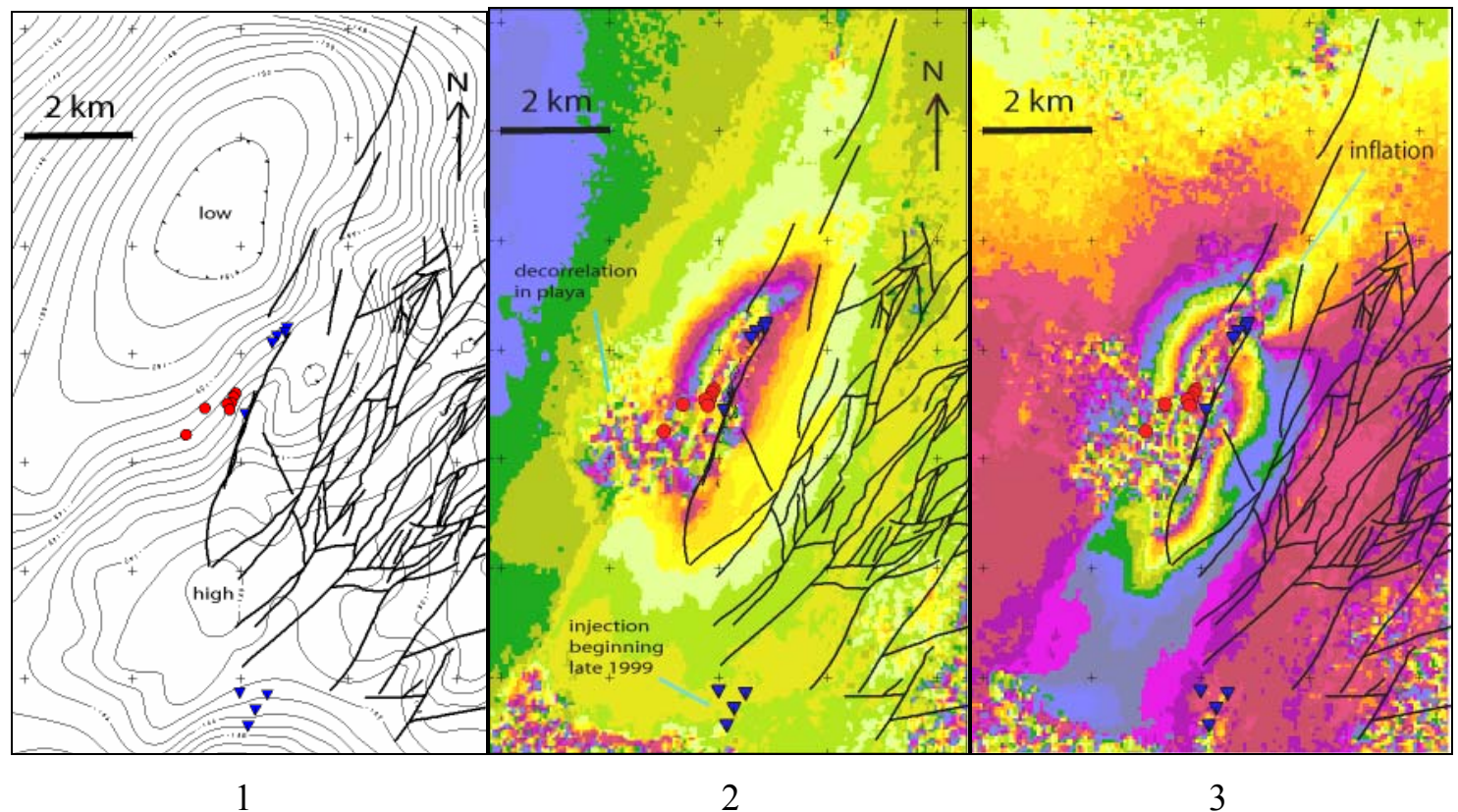

Figure 1: CBA gravity, 1 milligal contours, reflects structure and depth to Mesozoic basement.

Figure 2: Interferogram A - 2.9 years: 92-11-26 to 95-11-04.

Figure 3: Interferogram B - 4.8 years: 95-11-04 to 00-09-24. Each color represents $0.16 \mathrm{~cm}$ line-of-sight LOS distance change. A full color cycle is $2.83 \mathrm{~cm}$ LOS or $3.07 \mathrm{~cm}$ vertical. Surface faults: heavy black lines; Production wells: circles (red). Injection wells: triangles (blue). 


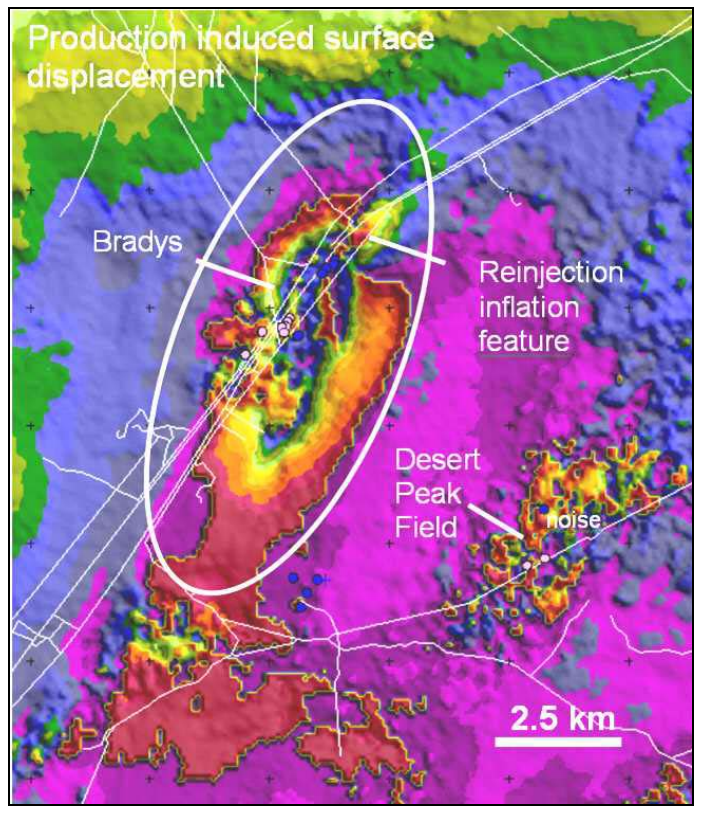

Figure 4: Interferogram B - 4.8 years: 95-11-04 to 00-09-24. This shaded surface displacement image more clearly depicts areas of surface inflation and deflation. Note the expression of the reinjection inflation feature. Each color represents $0.16 \mathrm{~cm}$ line-of-sight distance change. Full color cycle is $2.83 \mathrm{~cm}$ LOS or $3.07 \mathrm{~cm}$ vertical equivalent.

\section{Reports \& Articles Published in FY 2004:}

Oppliger, G., Coolbaugh, M., Foxall, W., 2004, Imaging structure with fluid fluxes at the Bradys geothermal field with satellite interferometric radar (InSAR): New insights into reservoir extent and structural controls. Annual Meeting, Palm Springs, CA., Aug. 29-Sep. 1, 2004, Geothermal Resources Council Transactions, v. 28. p 37-40.

\section{Presentations Made in FY 2004:}

Oppliger, G., Coolbaugh, M., Foxall, W., 2004, Imaging structure with fluid fluxes at the Bradys geothermal field with satellite interferometric radar (InSAR): New insights into reservoir extent and structural controls. Geothermal Resources Council, Annual Meeting, Palm Springs, California, Aug. 29Sep 1, 2004.

\section{Planned FY 2005 Milestones:}

Complete InSAR processing to obtain ground displacement time history Mar 05 Study relation of production to ground displacement (data modeling and analysis) 


\section{Structural Controls, Alteration, Permeability and Thermal Regime of Dixie Valley from New-Generation Mt/Galvanic Array Profiling}

Reporting Period: FY 2004 (October 1, 2003 to September 30, 2003)

DOE Grant No.: $\quad$ FG07-02ID14416

Performing Organization: University of Utah, Energy \& Geoscience Institute

423 Wakara Way, Ste 300, Salt Lake City, UT 84108

Principal Investigator: $\quad$ Philip E. Wannamaker, (801) 581-3547, pewanna@egi.utah.edu

Collaborating Researchers: N/A

DOE HQ Program Manager: Dr. Leland (Roy) Mink, (202) 586-5463, roy.mink@hq.doe.gov

DOE HQ Technical Manager: Raymond Fortuna, (202) 586-1711, raymond.fortuna@hq.doe.gov

DOE Funding Allocation: $\quad \$ 164 \mathrm{~K}$

Cost Share Funding: $\quad$ \$OK formally, but contractor Quantec Geoscience discounted survey by $15 \%$

Project Objective: A new-generation MT/DC array resistivity measurement system was applied at the Dixie Valley thermal area. Basic goals of the survey are 1), resolve a fundamental structural ambiguity at the Dixie Valley thermal area (single rangefront fault versus shallower, stepped pediment; 2), delineate fault zones which have experienced fluid flux as indicated by low resistivity; 3), image the disposition of resistive, possible reservoir formations in the subsurface; and 4), from a generic standpoint, investigate the capability of fully sampled electrical data for resolving subsurface structure. Broader project objectives include increasing the number of states with geothermal electric power facilities, reduced the levelized cost of generating power, and increase the power/heat energy supply for homes and businesses by improving exploration technology.

Background/Approach: Images of subsurface resistivity have suffered in resolution due to limited data type, inadequate data sampling, and non-optimal inversion approaches translating data to models. We have applied a new-generation array magnetotelluric/galvanic (MT/DC) system in a contiguous bipole deployment over three profiles at the Dixie Valley thermal area (Figure 1). As discussed by Madden (1971), MT is attuned to conductive structures primarily while the DC results improve resolution of resistive structures. This well-sampled data set is being analysed using a new inversion algorithm for resistivity image construction based on stabilization using a-priori constraints. A specific goal of the survey is to resolve a fundamental structural ambiguity at the Dixie Valley thermal area (single rangefront fault vs stepped pediment) (Blackwell et al., 1999; Smith et al., 2001, GRC Trans.). Data were obtained in year 1, analysis has taken place in year 2 and is ongoing. 


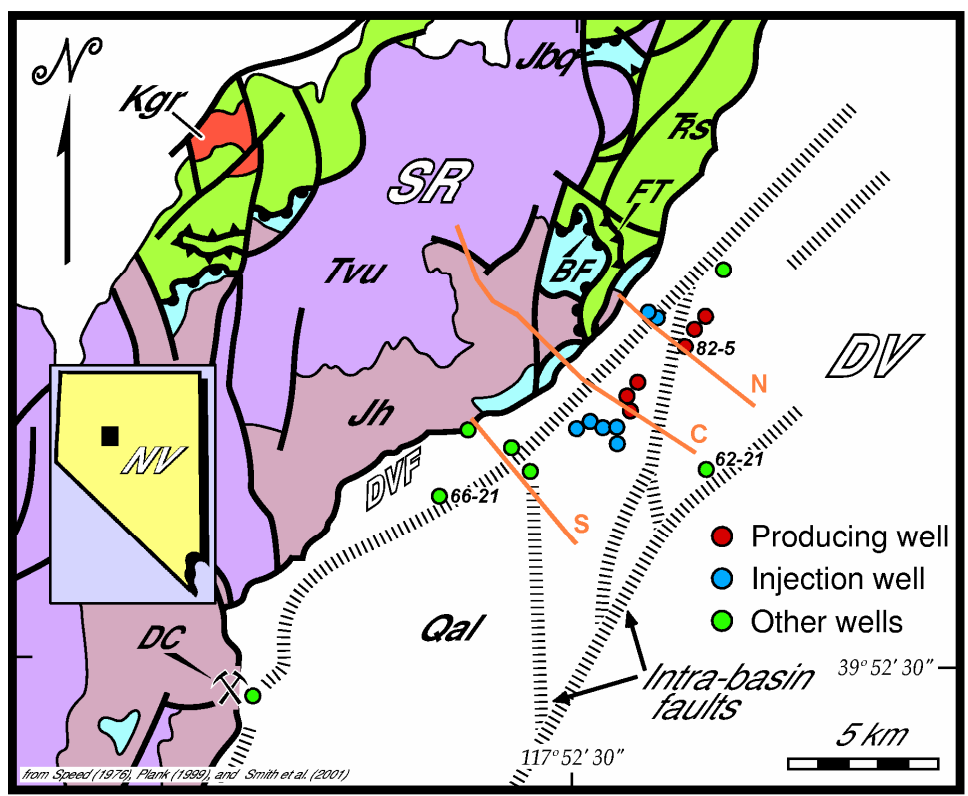

DIXIE VALLEY GEOTHERMAL SYSTEM
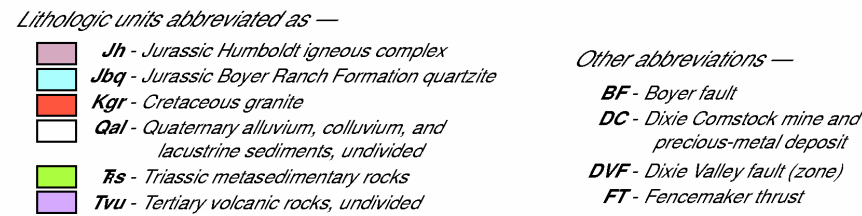

Figure 1. Simplified geological map of the Dixie Valley (DV)-Stillwater Range (SR) area surrounding the Dixie Valley thermal field. Orange lines show acquired contiguous MT/DC profiling through the system and adjacent fumarole fields. Lines are labeled $N$ (north), C (central) and S (southern). Original figure courtesy Jeff Hulen.

Status/Accomplishments: MT/DC surveying was carried out on three, 4-6 mile long profiles totaling 14 line miles, each crossing the Stillwater fault zone approximately at right angles (Figure 1). The acquisition was by contract to Quantec Geoscience, Inc., who recently developed the system for exploration problems in the mining industry. The frequency range of the MT data is $\sim 10 \mathrm{kHz}$ to $0.03 \mathrm{~Hz}$. These lines cross the Senator Fumeroles area, the Cottonwood Creek and main producing area, and the low-permeability region through the section 10-15 area. With array MT data, complete lateral sampling of the response is achieved through contiguous bipole deployment (Torres-Verdin and Bostick, 1992, Geophysics). In such a deployment, near-surface "static" distortions do not require qualitative correction but instead are included directly in the inversion process.

Our approach to the inversion of array MT data to yield resistivity cross sections is based on the a-priori, maximum likelihood estimates of Tarantola (1987, Elsevier) and utilizes the finite element platform of DeLugao and Wannamaker (1996, Geop. J. Int.). The approach applies just the smoothing implicit in the a-priori step estimate unlike the explicit smoothing of other EM inversion efforts. The a-priori damping factor is updated each iteration to achieve stabilization in terms of fundamental parameter correlations characteristic of the physics of diffusive EM (e.g., conductivity-dimension) rather than brute-force suppression of spatial derivatives. Also, the parameters defining the image grow both laterally and vertically with depth, thereby preserving the influence of individual parameters at the surface according to basic EM scaling, and thus stabilizing the parameter step and increasing depth of exploration. Inversion capability for joint MT/DC imaging including the induced polarization component has recently been completed under support of the Western U. S. Geothermal Systems contract (J. Hulen, P.I.). 
To date, an inversion of the MT data for the northern Senator Fumeroles line has been produced (Figure 2). High resistivities ( 1000 ohm-m) are seen under the Stillwater Range below $500 \mathrm{~m}$ depth and extending to the southeast under the pediment. Moderately high values $(\sim 100 \mathrm{ohm}-\mathrm{m})$ persist at rather shallow depths $(\sim 400 \mathrm{~m})$ from the topographic scarp where Senator fumeroles are located to a distance of about 1-1/2 km southeast just past well 38-32. Values of $100 \mathrm{ohm}-\mathrm{m}$ are more consistent with rock than alluvium (e.g., Ward et al., 1978, Geophysics), although alteration of the rock is a possibility. The alluvium of the main part of Dixie Valley is moderately conductive (10-25 ohm-m) in the upper $400 \mathrm{~m}$, and quite conductive in the 500-1000 m depth range $(<3 \mathrm{ohm}-\mathrm{m})$. A low resistivity limb dips upward from $\sim 1 \mathrm{~km}$ depth to the near-surface under well 38-32 near the west flank of Dixie Valley. Senator fumeroles itself does not exhibit a strong resistivity expression.

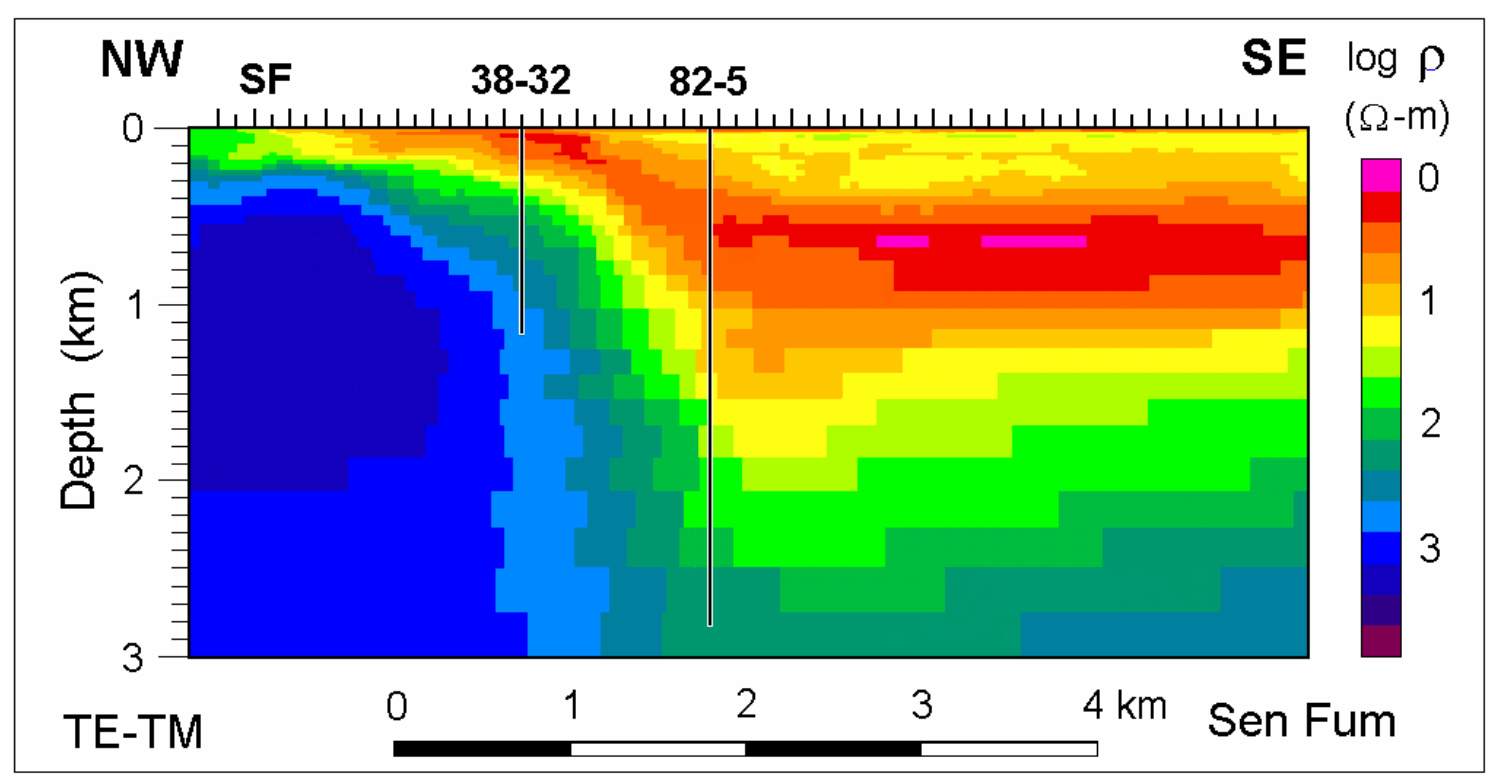

Figure 2. Electrical resistivity section for the northern $(N)$ profile of Figure 1 derived from 60 array MT sites taken with contiguous, $100 \mathrm{~m}$ long electric field bipoles. Tick marks are located at bipole centers. Bedrock-alluvium interface is interpreted to lie near the 70-100 ohm-m "contour". Senator fumeroles are denoted $S F$, and wells 38-32 and 82-5 are projected onto section.

The inversion to this point suggests that shallow basement rocks extend for a considerable distance to the southeast before plunging steeply down the main rangefront fault. It thus is more supportive of the multifault basement model than that of the single main fault (Blackwell et al., 1999, 2000). However, the structural interpretation remains somewhat non-unique: although Stillwater Range lithologies were intersected at a depth of $\sim 400 \mathrm{~m}$ in well $38-32$, near where the step in resistivity to values of $100 \mathrm{ohm}-\mathrm{m}$ or more occurs, an unknown amount of slide block material may exist over the main Dixie Valley rangefront fault here to complicate the structural framework (Johnson and Hulen, 2002, GRC Trans.). A particularly low resistivity zone flanks the interpreted main offsetting fault and may be due to alteration from geothermal fluid outflow and upflow. There also is a near-surface concentration of such intersected by well 38-32.

Lateral sampling uncertainties in data acquisition are removed by the contiguous bipole deployment, which helps to maximize the resolution of resistivity structure. Remote referencing and robust processing have generally yielded high quality data even in a field where power production has already been established. Incorporation of EM and galvanic data sets in principle should improve resolution of resistivity structure beyond that possible from either data set alone. Determining the structural framework 
at the Dixie Valley thermal area should improve thermal and reservoir models of the system. The project brings to geothermal exploration new technology developed recently within the mining industry, where the problem scales are similar. Quantec Geoscience is testing the joint inversion capability developed by the P.I. and has ported the MT component to a Beowulf cluster. We are very grateful to Caithness Energy Co. for access to the property and encouragement in the surveying.

New work this fiscal year included acquisition of 15 five-channel MT stations by contract in order to extend the effective length of the array profiles to the southeast. This is to gain better control on the lateral boundaries of the conductive Dixie Valley graben sediments and their effect on the inversion images. The location of these sites is given in Figure 3 . These new data are currently being merged with the array MT results and new inversion images will be produced.

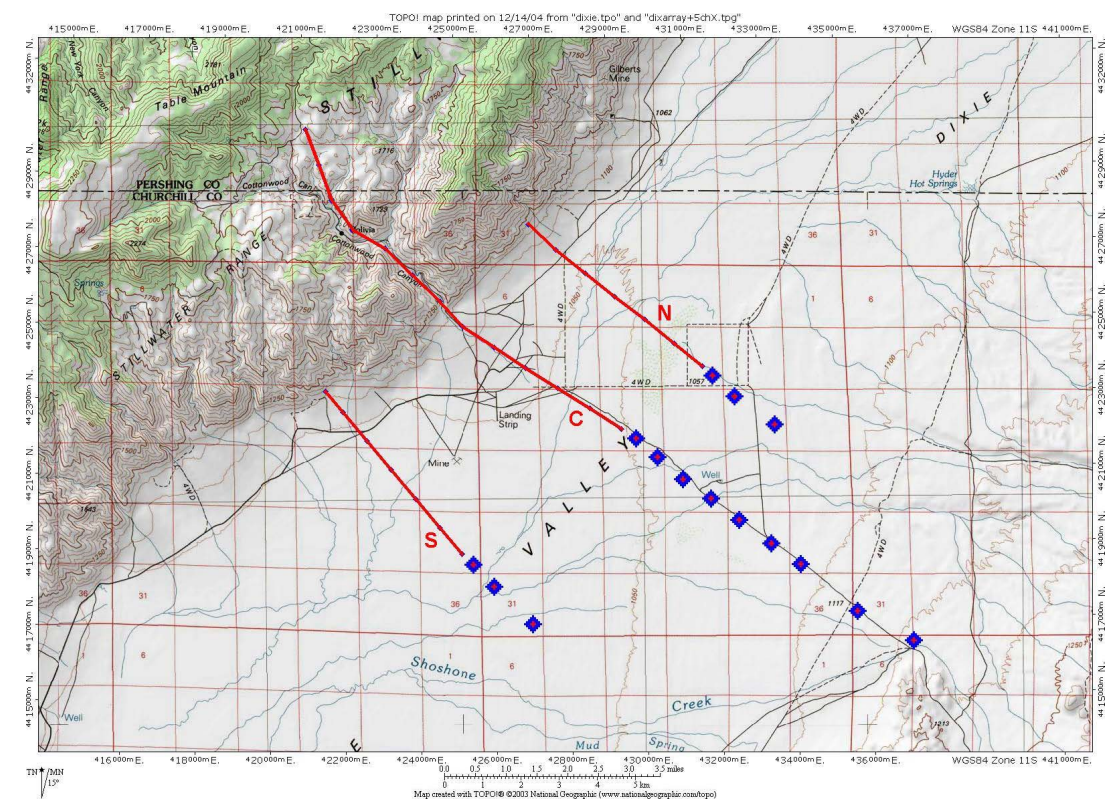

Figure 3. Shaded relief map showing location of contiguous MT/DC array profiles (red lines as in Figure 1) and their extension by discrete five-channel MT sites (blue diamonds).

\section{Reports \& Articles Published in FY 2004:}

Wannamaker, P. E., 2003, Initial results of magnetotelluric array surveying at the Dixie Valley geothermal area, with implications for structural controls and hydrothermal alteration, Geoth. Resour. Counc. Trans., 37-40.

Wannamaker, P. E., 2004, Magnetotelluric Array Surveying at the Dixie Valley Geothermal Area, with Implications for Structural Controls and Hydrothermal Alteration, Status of Geothermal Research at the Dixie Valley Geothermal System, Nevada, U.S. Dept of Energy report, edited by J. Renner, in prep., $10 \mathrm{pp}$.

\section{Presentations Made in FY 2004:}

Annual GRC meeting, Morelia, Mexico, October 12-15, 2003. 


\section{Planned FY 2004 Milestones:}

A one-year no-cost extension has been granted on this project. Thus, the present milestones are:

Complete MT inversions for other profiles.

Mar 05

Incorporate galvanic (DC) data into inversion models.

May 05

Complete and submit paper on survey results.

Aug 05 


\section{3-D Magnetotelluric Modeling}

Reporting Period: FY 2004 (October 1, 2003 to September 30, 2004)

DOE Grant/Contract \#: $\quad$ DE-AC04-94AL85000

Performing Organization: Sandia National Laboratories

Geothermal Research Department 6211

Albuquerque, New Mexico 87185-1033

Principal Investigator: Ｃhester J Weiss, (505) 284-6347, cjweiss@sandia.gov

Collaborating Researchers: N/A

DOE HQ Program Manager: Dr. Leland (Roy) Mink, (202) 586-5463, roy.mink@hq.doe.gov

DOE HQ Technical Manager: Raymond Fortuna, (202) 586-1711, raymond.fortuna@hq.doe.gov

DOE Funding Allocation: $\quad \$ 110 \mathrm{~K}$

Cost Share Funding: $\quad \$ 0$

Project Objective: Implement and further develop numerical modeling and interpretation tools developed at Sandia National Laboratories (SNL) for the analysis of magentotelluric (MT) data relevant to reconnaissance mapping and monitoring of enhanced geothermal systems (EGS).

Background/Approach: Modeling and interpretation of MT fields in EGS systems is an inherently complex computational problem, realistically tractable only on massively parallel computer systems or large cluster computers. Existing codes with this capability have previously been developed at SNL. However, increasing demands for computer resources within SNL as well as the onset of larger and more detailed datasets collected at EGS sites has required the examination of numerical methods for reducing this computational burden as much as possible. As such, "multi-grid" linear solvers for large sparse systems of linear equations have been investigated for their application in both the forward modeling and "inverse" or interpretation stages in MT analysis.

\section{Status/Accomplishments:}

1. Developed massively parallel multi-grid algorithms (collaborators at SNL-Livermore and Comp. Sci. at SNL-Albuquerque) for linear systems of equations.

2. Attendance at Geothermal resource council meeting in August 2004 to assess market and research trends in EGS technology, geophysical imaging of EGS systems, and DOE geothermal programmatic themes and objectives outside of FY 2004. 
3. Review and analysis of existing SNL modeling and interpretation software developed by previous PI for massively parallel computer systems at SNL.

4. Through leveraging of internal SNL R\&D funds, established groundwork for migration of existing modeling and interpretation software to mainstream, fully documented and laboratorysupported high-performance computing libraries and standards.

Due to movement of key staff to another laboratory, this activity as also been moved.

Reports \& Articles Published in FY 2004: N/A

Presentations Made in FY 2004: N/A

Planned FY 2005 Milestones: N/A 


\section{Magnetotelluric Imaging}

Reporting Period: FY 2004 (October 1, 2003 to September 30, 2004)

DOE Grant/Contract \#: $\quad$ DE-AC03-76SF00098

Performing Organization: Lawrence Berkeley National Laboratory

One Cyclotron Road

Berkeley, CA 94720

Principal Investigator: $\quad$ G. Michael Hoversten, (510) 486-4085, gmhoversten@lbl.gov

Collaborating Researchers: None

DOE HQ Program Manager: Dr. Leland (Roy) Mink, (202) 586-5463, roy.mink@hq.doe.gov

DOE HQ Technical Manager: Raymond Fortuna, (202) 586-1711, raymond.fortuna@hq.doe.gov

DOE Funding Allocation: $\quad \$ 67 \mathrm{~K}$

Cost Share Funding:

0

Project Objective: The project title derived from its inception. The project however moved from the application of MT on Kilauea in 2003 to the use of combined SP and conductivity mapping (MT) in 2004. The original objective stated in the 2004 AOP were: To conduct a time-lapse electrical conductivity and streaming potential (SP) monitoring experiment at a water injection well at the Geysers geothermal field to determine whether time-lapse changes in electrical conductivity and the streaming potential spectrum can be correlated with measured micro earth quake (MEQ) activity. If correlations between changes in electrical conductivity and/or the frequency spectrum of SP signals can be correlated with MEQ's, justification will exist for expanded laboratory experiments to establish a model to explain the link. This would allow development of new algorithms for flow pathway imaging based on spatial changes of electrical conductivity and SP. However, the project was awarded only half of the requested amount $(\$ 60 \mathrm{~K})$. This reduced budget allowed only enough for MT data acquisition (electrical conductivity mapping) but none for processing and interpretations. Therefore it was decided to switch operations from the Geysers to the Fort Bidwell Indian reservation, an opportunity that came up during 2004.

Background/Approach: Advances in three-dimensional (3D) electromagnetic (EM) numerical simulation, data acquisition systems, data processing techniques and electromagnetic noise cancellation techniques in the last 5 years mean that SP signals related to geothermal processes such as fluid flow and EM signals related to fluid saturation can be detected at levels several orders of magnitude below what was possible in the recent past. In addition these signals can now be interpreted with modeling in $3 \mathrm{D}$ at a level of complexity and integration with other data that could not be done even five years ago. These recent developments mean that techniques using EM energy and SP from fluid flow offer new potential to directly map fluid flow pathways within geothermal systems. 
The Fort Bidwell site presented a unique opportunity to test SP as a means of mapping flow pathways for geothermal systems. A series of existing wells were slated for flow tests in late 2004. This presented an opportunity to test whether or not the simultaneous measurements of streaming potential (SP) would show spatial correlation with mapped faults thought to control flow into the existing wells.

Status/Accomplishments: The beginning of 2004 saw the completions of the Kilauea MT experiment by the acquisition of an additional 45 MT stations on Kilauea. This work was originally slated for 2003 but was delayed due to donated equipment availability. This work was funded with $\$ 30 \mathrm{~K}$ of 2003 carry over money. The initial 2002 data was used in the preparation of two papers that were submitted to JGR for publication. It was suggested by the editors that the two papers be combined into one. The rewrite of the paper is under way. The 2004 data is scheduled for processing in the January-February time frame.

2004 funding received was $\$ 60 \mathrm{~K}$ as opposed to our initial request of $\$ 120 \mathrm{~K}$. As a result the proposed work laid out in the AOP was not achievable. We therefore decided to use the funds available to work at the Fort Bidwell Indian reservation where characterization work could be done at relatively low cost. We decided to perform a time lapse SP survey during a flow test of an existing hot well. A series of flow tests were planned using existing geothermal wells at Ft. Bidwell. We coordinated with Joe Laflure who is the contract geologist working with the owners of the property. In September 2004 two lines of electrodes were laid out approximately perpendicular to the strike of mapped faults near the well that was to be flowed. The SP on all 20 electrodes on the lines were monitored simultaneously for a short baseline period of a few hours prior to the flow test. This showed no appreciable change in the SP signal along the lines. Then the well was flowed for a period of 30 minutes. During the time the well was flowing, a time varying SP signal was observed on both lines in the vicinity of the major mapped fault that was thought to be the major conduit for waters into the well.

This initial feasibility test required roughly $\$ 30 \mathrm{~K}$ which leaves the remaining $\$ 30 \mathrm{~K}$ as carry over funding into 2005. We are coordinating a larger scale test at Ft. Bidwell for late January or early February 2005. During the second planned test we will recorded a baseline response over the faults for a period of two days and then perform a time lapse SP measurement where the flow pattern of the well will be periodic over 1 day followed by a second day of a periodic flow. The second experiment is designed to allow time domain correlation between the flow and the observed SP signals to verify that they are due to fluid movement in the faults that feed the well.

\section{Reports \& Articles Published in FY 2004:}

A JGR paper on the Kilauea MT interpretation is currently undergoing re-write.

\section{Presentations Made in FY 2004: None}

\section{Planned FY 2005 Milestones:}

1. Complete second time-lapse SP experiment at Fort Bidwell by Spring 2005.

2. If a time-lapse SP signal that is spatially coincident with known faults can be demonstrated to correlate in time with flow from the hot wells we will pursue the development and/or acquisition of a 3D transient coupled flow-SP modeling code.

3 If Milestone 1 is successfully completed we will endeavor to develop a 3D simulation model of the flow tests. 


\section{Western U.S. Geothermal Systems: \\ Enhanced Data Acquisition and Inversion for Electrical Resistivity Structure in Geothermal Exploration and Reservoir Assessment}

Reporting Period: FY 2004 (October 1, 2003 to September 30, 2004)

DOE Grant No.:

FG07-00ID13957

Performing Organization: University of Utah, Energy and Geoscience Institute 423 Wakara Way, Ste 300, Salt Lake City, UT 84108

Principal Investigator: $\quad$ Philip E. Wannamaker, (801) 581-3547, pewanna@egi.utah.edu

Collaborating Researchers: N/A

DOE HQ Program Manager: Dr. Leland (Roy) Mink, (202) 586-5463, roy.mink@hq.doe.gov

DOE HQ Technical Manager: Raymond Fortuna, (202) 586-1711, raymond.fortuna@hq.doe.gov

DOE Funding Allocation: $\quad \$ 160 \mathrm{~K}$

Cost Share Funding: $\quad \$ 0 \mathrm{~K}$

Project Objective: Since an increased fluid content due to fracturing, and the development of more conductive alteration minerals (clays, etc.), can give rise to an electrical resistivity contrast, our efforts are directed towards improving electromagnetic (EM) methods of probing. Broader project objectives include increasing the number of states with geothermal electric power facilities, reduced the levelized cost of generating power, and increase the power/heat energy supply for homes and businesses by improving exploration technology.

Background/Approach: Images of subsurface resistivity have suffered in resolution due to limited data type, inadequate data sampling, and non-optimal inversion approaches translating data to models. We have been developing multi-dimensional imaging software directed toward new-generation array magnetotelluric/galvanic (MT/DC) systems, which represents a generalized EM acquisition mode. We also have been working toward improving the quality and quantity of electrical geophysical data through development of a high-fidelity, in-house magnetotelluric system. Finally, we have been acquiring highquality MT field data to test models for controls on geothermal districts in the Great Basin.

Status/Accomplishments: Previous years' efforts have emphasized joint MT/DC data inversion for two dimensional resistivity models, applied to the Karaha geothermal system by Wannamaker et al. (2004a). We have initiated 3-D inversion this FY through a joint agreement with Y. Sasaki of Kyushu University. We are very fortunate to have been provided during the summer of FY04 with a copy of the Fortran source code for this inversion platform, the most recent incarnation of which is described by Sasaki (Earth Planets Space, 2004). It is our intention to greatly improve this approach through speeding of the 
laborious parameter sensitivities (Jacobians) by combining lumped cell integral equation and finite difference methods (Wannamaker and Sasaki, 2003, Proc. 3DEM-III Symp.). This is meant to achieve Jacobians in about the computational price of the forward problem, rather than 10's or 100's of times the forward problem as is currently the state for the stable Gauss-Newton direct approach. Initial results of our approach are quite promising. In Figure 1 are shown checks for a simple two-body situation with one inclined inhomogeneity over a deeper block-like structure.

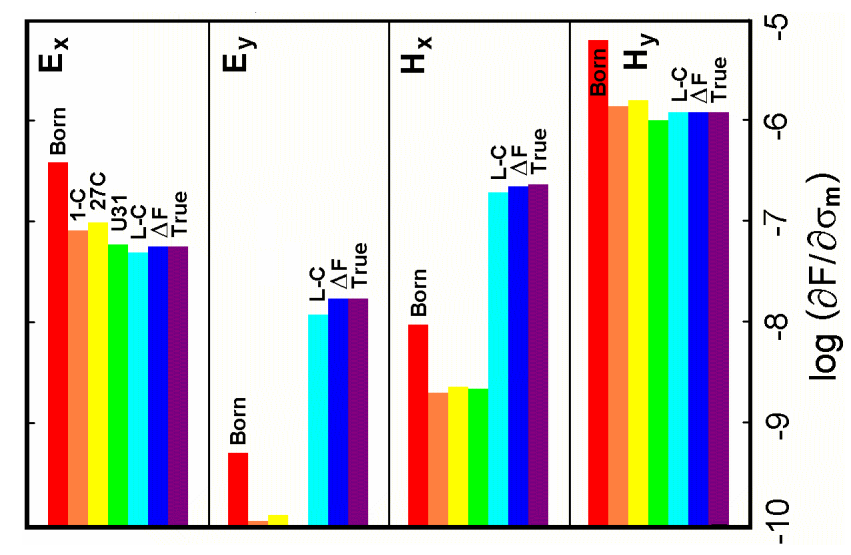

Figure 1. Jacobians of field quantities w.r.t. body conductivity $\sigma_{b m}$ via several approximations, for upper body outcropping $\left(d_{1}=0\right)$. Incident $E$ is along $x$-axis. $L-C$ is the lumped cell approximation we are pursuing. DelF is by finite differencing of two nearly equal structures. True is from analytic perturbation.

By the end of FY04, MT system development (Figure 2) was advanced primarily through completion of MT receiver interface cards, most analog signal conditioning cards, interconnect card and associated signal router cards, development of software for internal data communication and hardware control between the interface card and the channel cards. High-impedance measuring capability was described by Wannamaker et al. (2004b).

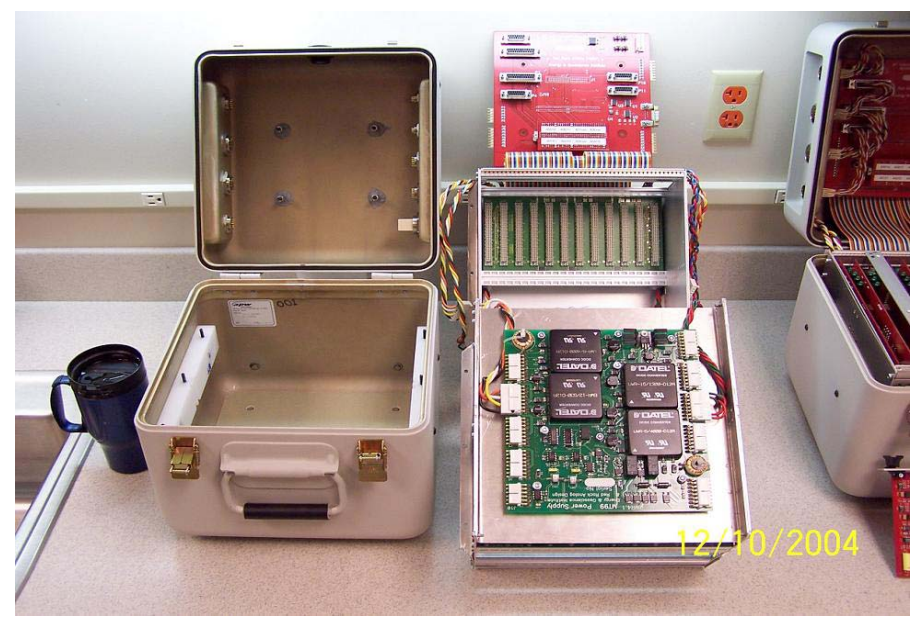

Figure 2. Display of principal hardware components of U Utah MT system nearing completion. Shown is main recording module containing analog conditioning, channel interconnect, and computer interface cards. Not shown are electric field preamp modules, GPS, radio modem and H-field (coil) junction box.

Under FY03 and FY04 funds, MT profiling was extended to the southeast and the northwest of the Dixie Valley thermal area, northwestern Nevada, as a testbed for inversion algorithms developed at EGI, and to explore fundamental controls on locations of high-temperature, Basin-Range geothermal systems 
(Figure 3). This is an intriguing region in that it lies within the extensive north-central Nevada seismic belt where seismicity is high and comparable to the fast-extending margins of the Great Basin (e.g., Bennett et al., 2003, Tectonics; Thatcher, 2003, Int. Geol. Rev.). This inference is supported by a marked increase in extension rates as evident in GPS geodetic surveying (op. cit.). However, it remains open to interpretation whether this increase occurs across a diffuse zone in NW Nevada, or a very sharp one (cf. Thatcher, 2003). The possibility of a concentrated thermal upwelling at this boundary in extension can perhaps best be assessed through resistivity structure according to depth to top of high mid-crustal conductivity. The degree of upwelling of isotherms as reflected in enhanced conductivity will be tested by comparing upper-middle crustal structure under the eastern and central Stillwater Range to that under the neighboring Clan Alpine Range across Dixie Valley, and the Humboldt Range across Buena Vista Valley. If positive results are obtained, this may constitute a regional exploration tool for concentrated heat flux in northwestern Nevada.

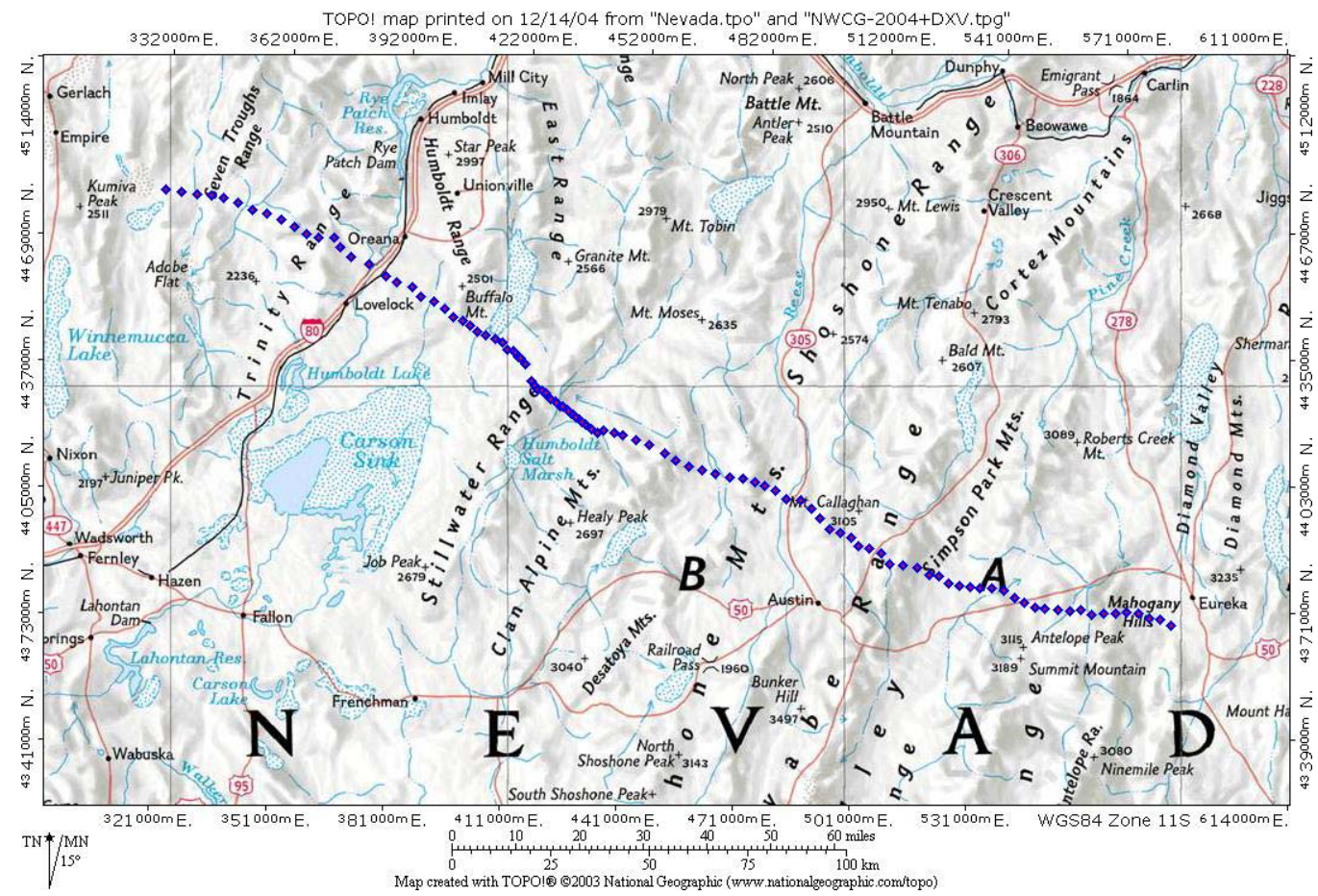

Figure 3. Shaded relief map of northwestern Nevada showing 100 sites of composite MT profiling centered on Dixie Valley thermal area. Maximal step in GPS spreading rates lies in northeast-southeast trend approximately along the Clan Alpine Range (Thatcher, 2003).

These data are undergoing analysis at the time of this writing. This includes editing, band averaging, and pseudosection construction. Subsequently, a two-dimensional inversion mesh will be constructed for derivation of a stabilized resistivity section using the in-house inversion code developed by the P.I. Wannamaker.

\section{Reports \& Articles Published in FY 2004:}

Wannamaker, P. E., 2003, Initial results of magnetotelluric array surveying at the Dixie Valley geothermal area, with implications for structural controls and hydrothermal alteration, Geothermal Resources Council Transactions, Morelia, Mexico, 37-40. 
Wannamaker, P. E., I. Raharjo, J. N. Moore, and R. Allis, 2004a, Magnetotelluric resistivity section and physical implications through the Telaga Bodas magmatic geothermal system, Indonesia, Geothermal Resources Council Transactions, Palm Springs, CA, 4 pp.

Wannamaker, P. E., J. A. Stodt, L. Pellerin, S. L. Olsen, and D. B. Hall, 2004b, Structure and thermal regime beneath South Pole region, East Antarctica, from magnetotelluric measurements, Geophys. J. Internat., 157, 36-54.

Presentations Made in FY 2004:

Formal presentations were not made on this specific material in FY04. Status of the U Utah MT system was presented at the annual EMSOC consortium meeting, Fall AGU Meeting, San Francisco, December 13, 2004.

\section{Planned FY 2004 Milestones:}

A six-month no-cost extension has been granted for this project, so the milestone dates are:

Finalize inversion of NW Nevada MT transect.

Mar 31/05

Present verification of integral equation/finite difference Jacobians.

Mar 31/05

Complete manuscript for submission on a-priori inversion approach in two dimensions.

Mar 31/05

Complete hardware construction of in-house MT field system.

Mar 31/05 


\section{Characterization of 3D Fracture Patterns at The Geysers and Coso Geothermal Reservoirs by Shear-wave Splitting}

Reporting Period: FY 2004 (October 1, 2003 to September 30, 2004)

DOE Grant No.:

Performing Organization:

Principal Investigator:

Collaborating Researchers:

DOE HQ Program Manager: Dr. Leland (Roy) Mink, (202) 586-5463, roy.mink@hq.doe.gov

DOE HQ Technical Manager: Raymond Fortuna, (202) 586-1711, raymond.fortuna@hq.doe.gov
University of North Carolina at Chapel Hill, Dept of Geological Sciences CB\#3315, Mitchell Hall, Chapel Hill, NC 27599

José A. Rial, (919) 966-4553, jar@email.unc.edu
Maya Elkibbi, Ming Yang, Victor Pereyra

DOE Funding Allocation: \$467K (Three years)

Cost Share Funding:

Project Objective: We apply our results from the processing of shear-wave splitting data to thoroughly describe subsurface fracture networks at The Geysers and Coso geothermal reservoirs. The project aims at developing a computer-based methodology to produce 3D maps of crack geometry, crack distribution, and crack density in fractured reservoirs. The latter crack parameters are crucial in determining directions of underground fluid flow as well as areas of increased permeability, essential in locating production targets. Due to the records time-span, we are also capable of tracking temporal changes in the general behavior of crack systems. The raw data for the project consists of seismographic recordings of microearthquakes (MEQ) detected over many years by arrays of sensors at both The Geysers and Coso. With the experience acquired in the processing and interpretation of these data in the past years, we have developed a novel computer technology (Matlab-based software) for the exploration, modeling and inversin of fractured reservoirs.

Background/Approach: A shear-wave propagating through rocks with crack-induced anisotropy splits into two waves, a fast one polarized parallel to the predominant crack orientation, and a slow one polarized perpendicular to it. For waves traveling within the shear-wave window of a given seismic station, the measured polarization direction $\delta$ of the fast shear wave typically parallels the strike of the predominant subsurface crack system regardless of its initial polarization at the source. Exceptions, however, have been discerned and carefully studied in the case of dipping cracks or when more than one crack system is involved. The time delay $\delta t$ between the arrival of the fast and the slow S-waves is proportional to the crack density, or number of cracks per unit volume. The analysis of split shear waves is thus a valuable technique to detect and map the main orientation and fracturing intensity in the subsurface. For the last few years we have studied and processed shear-wave splitting data in two seismically active, fracture-controlled environments, The Geysers (NW and SE Geysers) and Coso 
geothermal fields, California, using 16- and 14-station seismic arrays of 3-component, mostly down-hole instruments running at frequencies ranging from 400 to 480 samples/sec. From the analysis and processing of over 60,000 local micro-earthquakes, we have to date collected what is arguably the world's most complete set of high resolution, high quality shear-wave splitting observations.

Status/Accomplishments: This project ended officially on December 31, 2003. All the objectives of the proposal were accomplished. The final reports, Matlab software, all data and other deliverables were submitted to DOE in 2004.

\section{Reports \& Articles Published in FY 2004:}

Elkibbi, M.M. Yang and Rial, J.A. (2004), imaging Crack Systems in The Geysers with Shear-wave Splitting, Geothermal Res. Council Proc. Pp 780-800. (Best Paper Award).

Elkibbi, M. and Rial, J.A. (2004), Analysis of Shear-wave Splitting Observations at The Geysers, CA. Geophysical Journal International (in press).

Elkibbi, M., Yang, M., and Rial, J.A. Rial (2004): The Geysers Geothermal Field: Results from Modeling crack-induced Anisotropy. Geophysical Journal International (in press).

Yang, M. M. Elkibbi and J.A. Rial (2004): An Inversion Scheme to Model Subsurface Fracture Systems using Shear-wave Splitting Polarization and Delay Time Observations Simultaneously, Geophysical Journal International (in press).

Rial, J.A., M. Elkibbi and M. Yang (2004): Shear wave splitting as a tool for the characterization of geothermal fractured reservoirs: Lessons learned. Geothermics (In review).

Presentations Made in FY 2004:

Elkibbi, M.M. Yang and Rial, J.A. (2004), Imaging Crack Systems in The Geysers with Shear-wave Splitting, Geothermal Res. Council Proceedings, Indian Wells, CA. August 2004. 


\section{Seismic Imaging}

Reporting Period: FY 2004 (October 1, 2003 to December 31, 2003)

DOE Grant/Contract \#: $\quad$ DE-AC03-76SF00098

Performing Organization: Lawrence Berkeley National Laboratory

One Cyclotron Road, Berkeley

CA 94720

Principal Investigator: $\quad$ Ernest L. Majer, (510) 486-6709, elmajer@lbl.gov

Collaborating Researchers: Roland Gritto, rgritto@lbl.gov

Tom Daley, tmdaley@1bl.gov

DOE HQ Program Manager: Dr. Leland (Roy) Mink, (202) 586-5463, roy.mink@hq.doe.gov

DOE HQ Technical Manager: Raymond Fortuna, (202) 586-1711, raymond.fortuna@hq.doe.gov

DOE Funding Allocation: $\quad \$ 50 \mathrm{~K}$

Cost Share Funding: $\quad \$ 75 \mathrm{~K}$, In Kind, Seismic reflection data from Tuscarora geothermal field

Project Objective: The project objective includes the development and application of active seismic methods for improved understanding of the subsurface structure, faults, fractures lithology, and fluid paths in geothermal reservoirs. The knowledge of these properties will increase the reliability and reduce the risk of in-fill drilling associated with production and re-injection of spent geothermal fluids. Overall, the enhancement of underground fractures and the knowledge about subsurface flow will help in resource management by improving the accuracy of exploration targets, increasing the overall resource, and reducing the cost of geothermal production.

This objective is achieved by extending and adapting current seismic techniques to improve the capability for imaging surface features that control fluid flow in geothermal environments. While the objective of the work previous to FY2003 was concerned with the detection and location of faults and fractures based on an existing 3-D seismic data set collected at the Rye Patch geothermal reservoir, the current work was aimed at investigating how the presence of discrete models of fault and fracture zones can be detected and distinguished in seismic surface and borehole data.

Background/Approach: It is widely accepted that an increase in water circulation is needed to improve the efficiency of geothermal systems. Discrete faults with increased permeability present pathways for an increase in water flow. Similarly, zones of increased fracturing may constitute flow paths with even higher permeability depending on the fracture density. It is therefore desirable to detect and map faults and fracture zones and characterize their physical properties. Surface and borehole seismic imaging methods can generally be used to estimate these properties, but further development is needed for the application in geothermal areas. 
Seismic wave propagation in a homogeneously layered velocity model can lead to complicated wave fields even in the absence of structural features like faults or fracture zones. If these features are present, however, the seismic wave field becomes much more complicated and the seismic "foot print" of the fault/fracture zones may be masked and difficult to observe. Therefore, it is important to study the characteristics of seismic wave interaction with faults and fracture zones to establish typical patterns that can be recognized in seismic field data. General questions to investigate include the depth extent of faults. Is the seismic signature of blind faults (i.e., the fault planes don't break the surface) different from faults extending all the way to the surface? How can faults be distinguished from zones of high fracturing? Other parameters include the strike and dip as well as width of the fault or fracture zone. The fracture stiffness may be estimated from seismic waves, which could yield such important parameters as contact area or degree of mineralization within a fault or fracture. Numerical modeling of seismic wave interaction with faults and fracture zones is an important tool to investigate the physics of the problem and to develop new imaging methods to be applicable to geothermal areas.

Finite-difference modeling was used to simulate seismic wave propagation in a geothermal area with a layered velocity structure in the presence of different types of faults. The velocity model, the source and receiver geometries, as well as the source parameters were taken from previous studies at the Rye Patch geothermal reservoir. The parameters of the fault were modeled based on equivalent medium theory, where the orientation of the fault relative to the finite-difference grid and the fault stiffness are translated into elastic constants. The various investigated fault and fracture models represented weak structures with low isotropic stiffness or high compliance relative to the surrounding background medium.

\section{Status/Accomplishments:}

A suite of discrete fault and fracture models were investigated to study the foot-print of these features in seismic surface data. Faults with surface expression as well as blind faults were studied in addition to fracture zones. Shown in Figure $1 \mathrm{a}$ and $1 \mathrm{~b}$ are the modeled data from a hidden fault and the data from the 3-D Rye Patch study.

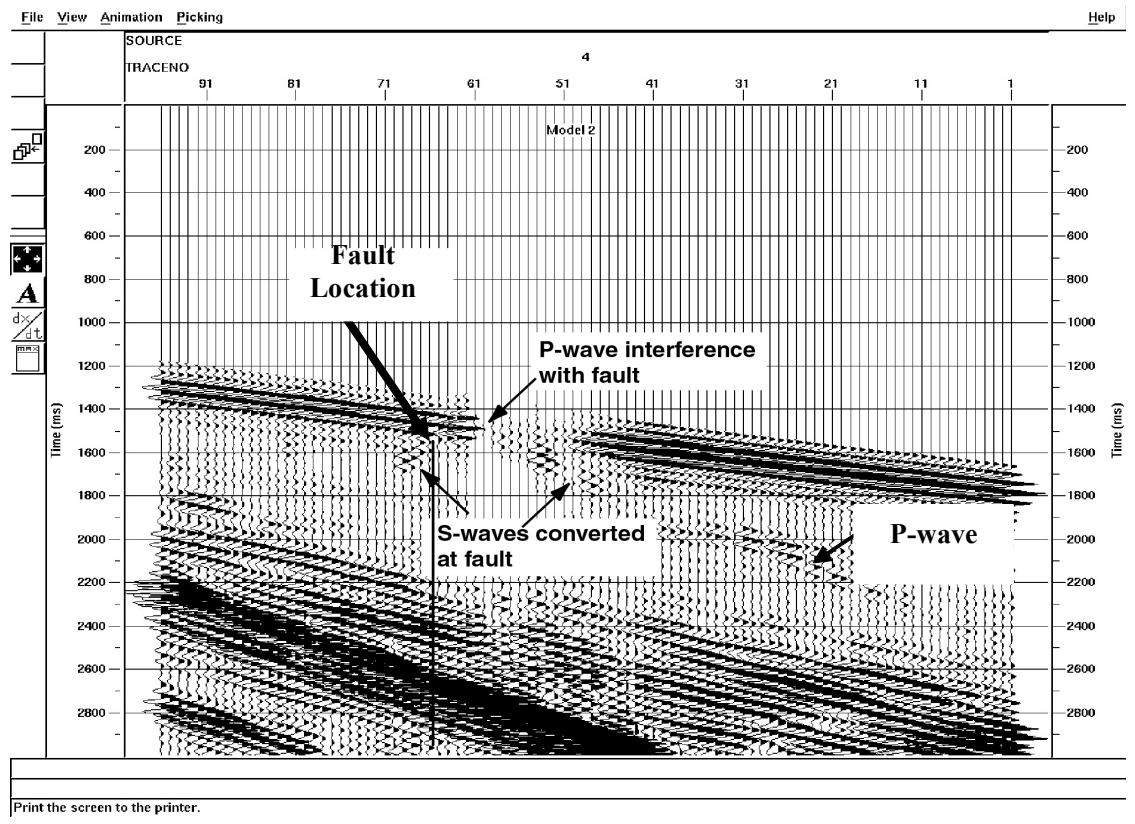

Figure 1a: Full elastic finite difference model of a hidden fault 


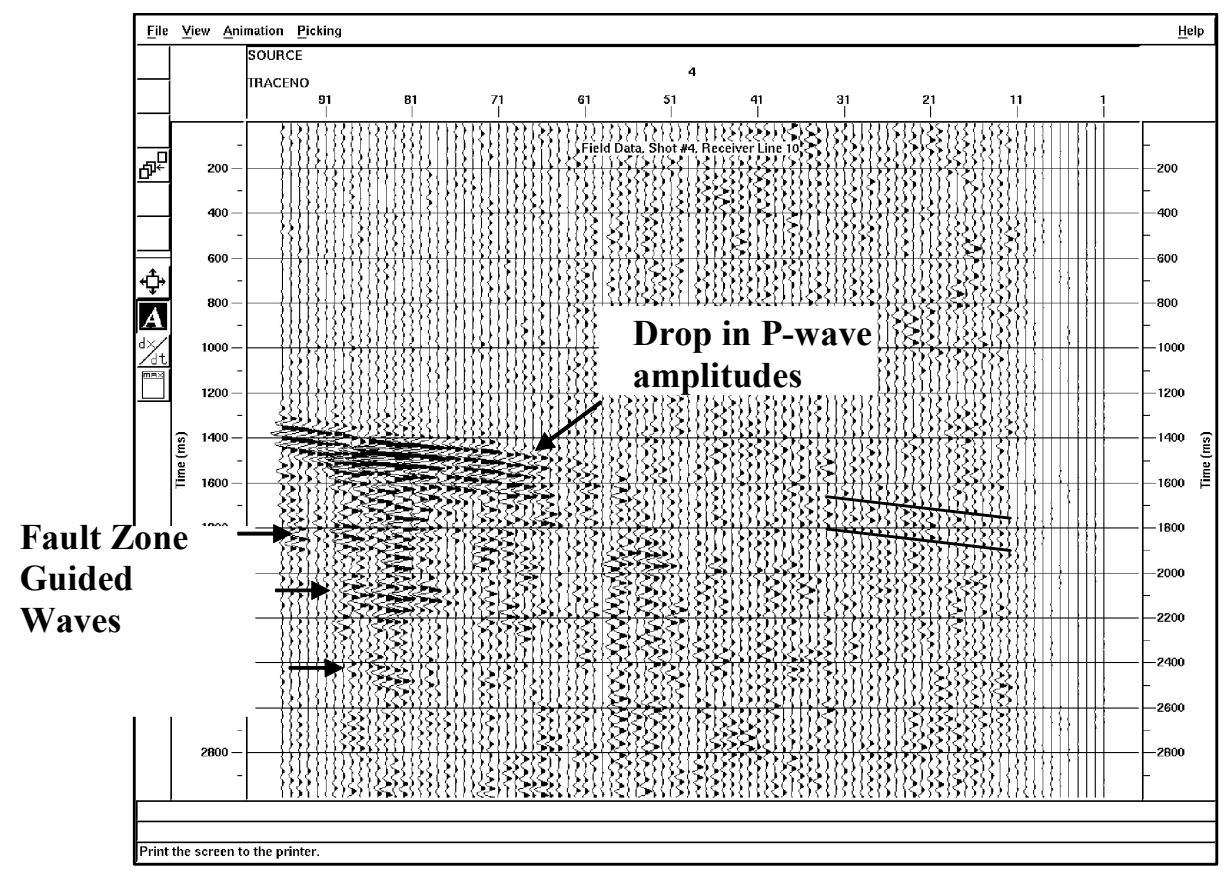

Figure 1b: Data from the Rye Patch 3-D seismic study

The results indicated that faults can be detected by single seismic lines, as long as the receivers are in the vicinity of the fault tip (within a distance of 2-3 wavelengths of the seismic waves). Faults terminating close to the surface leave a most pronounced seismic signature in the data by blocking the direct seismic (P) waves creating a seismic shadow along the receiver line behind the fault. At the same time wave conversion from P- to S-waves was observed. The apex of the converted waves in the seismograms indicated the location of the fault tip below the array. Blind faults have a diminished shadowing effect, because of wave front healing of the waves along their path from the fault tip to the receiver array. If the fault tip is to deep, the blocking effect may disappear. However, the conversion from P- to S-wave will still indicate the approximate location of the fault. Fracture zones are characterized by their guiding effect of seismic energy that can lead to advanced travel times relative to the propagating body waves that don't interact with the fracture zones. At the same time, converted S-waves can indicate the lateral extent of the fracture zone. Because of their characteristics, fracture zones can possibly be distinguished from faults in the subsurface. Furthermore, fault zone guided waves and multiple reflected waves within fracture zones that arrive at later times on seismograms are very distinct indicators for the presence of faults or fracture zones.

During the first month of FY2004 the results were prepared for a presentation given at the GRC 2004 Annual Meeting in Morelia, Mexico. The presentation won a "Best Paper Award" by GRC. The reminder of FY2004 was concerned with matching the numerical results to observations made from the seismic dataset recorded at the Rye Patch reservoir. The comparison showed that it is likely that the "Rye Patch" fault terminates within a few wavelength beneath the surface, and that it's location can be estimated from P-to-S converted waves. Furthermore, the fault acts as a wave-guide that facilitates the propagation of waves upwards from the basement through multiple scattering within its core. The results are written up for publication in Geothermics.

In early 2004 a second data area was included in the project. Shown in Figure 2 is the Hot Sulphur Springs in Northern Nevada. This is the subject of current investigation for installing a power plant. One of the critical issues is to accurately locate the faults at depth. In 2004, several 2-D seismic lines were run by the operating company. The location of these lines are shown in Figure 2. 


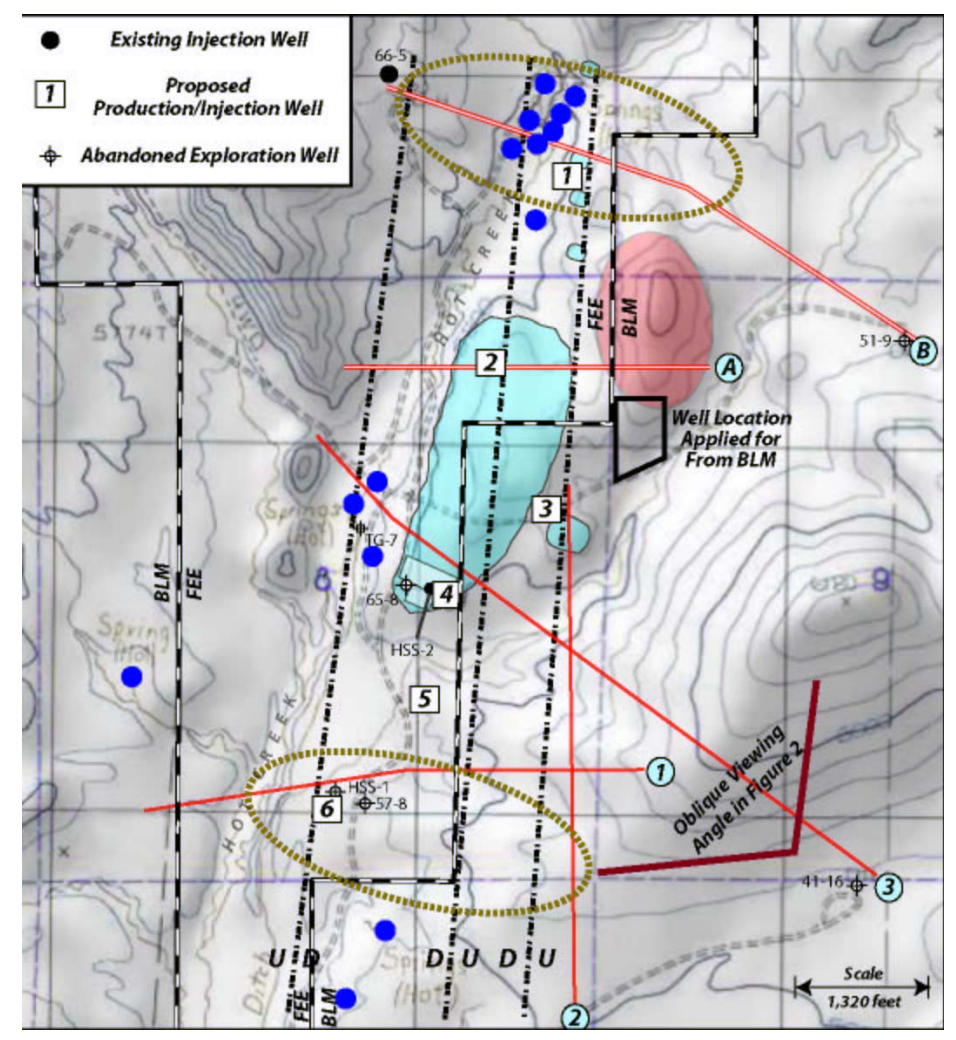

Figure 2 The Hot Sulphur Springs area in Northern Nevada.

In summary, the project generated intriguing results of seismic wave interaction with faults and fracture zones, which indicated that the foot-print of these features are clearly visible and often distinguishable in single seismic receiver lines. As a consequence, many previously collected 1-D and 2-D seismic data sets may still contain valuable information regarding the presence of blind faults. These data sets should be revisited, supported by numerical modeling activities, to determine the presence and approximate location of suspected subsurface faults. Although 3-D seismic surveys have to be conducted if the dip and the fault properties need to be determined in greater detail, the old data sets can reveal enough information about fault and fracture geometries that the 3-D surveys can be minimized, which can result in cost saving of more than $50 \%$.

\section{Presentations Made in FY 2004:}

Gritto, R.; Majer, E. L. (2003): Seismic methods for resource exploration in enhanced geothermal systems, Geothermal Resources Council Transactions, Vol. 27, pp. 223-226.

\section{Planned FY 2005 Milestones:}

Acquire seismic data from Cooksley geophysics, complete by 1st quarter Model data with full elastic solution, complete by end of $3 \mathrm{rd}$ quarter Provide recommendations on geologic drill targets, complete by end of $4^{\text {th }}$ quarter 


\section{Assembling Crustal Geophysical Data for Geothermal Exploration in the Great Basin}

Reporting Period: FY 2004 (October 1, 2003 to September 30, 2004)

DOE Grant/Contract \#: $\quad$ DE-FG36-02ID14311

Performing Organization: University of Nevada, Reno

Principal Investigator: ～John N. Louie, (775) 784-4219, louie@seismo.unr.edu

Collaborating Researchers: Mark F. Coolbaugh (UNR)

DOE HQ Program Manager: Dr. Leland (Roy) Mink, (202) 586-5463, roy.mink@hq.doe.gov

DOE HQ Technical Manager: Raymond Fortuna, (202) 586-1711, raymond.fortuna@hq.doe.gov

DOE Funding Allocation: $\quad \$ 84 \mathrm{~K}$

Cost Share Funding: $\quad \$ 18 \mathrm{~K}$

Purpose: This sub-project, continuing into a third year, is concerned with assembling a three-dimensional reference model of seismic velocity for the western Great Basin region of Nevada and eastern California. Exploration for hidden resources requires a realistic crustal and upper-mantle model to understand the deep sources of geothermal heat. In the western Great Basin, crustal properties and thickness are known only at wide spacing. With the more complete sampling of the crustal geophysical characteristics of geothermal resources in the Great Basin resulting from this study, geophysical measures can contribute to quantitative analyses of the associations between different geothermal indicators.

Objectives: The objective of this continuing sub-project, starting its third year, is to assemble a threedimensional reference model of crustal seismic velocity for the western Great Basin region of Nevada and eastern California. The resulting seismic velocity model consists of simplified rule-based representations of some of the region's crust to $50 \mathrm{~km}$ depth, and more detailed characterization of geothermal areas and sedimentary basins. With the resulting more complete sampling of the crustal geophysical characteristics of geothermal resources in the Great Basin, these measures are contributing to quantitative analyses of the associations between different indicators. Under the Great Basin Center for Geothermal Energy's goal "(1) Geothermal Resource Assessment and Exploration: B. Identification and Characterization of New Potential Geothermal Resource Targets," this project will contribute critical data toward the effective exploration for new geothermal resources. This project also assists the Center's goal to enhance the academic infrastructure and technical workforce in geothermal science and technology.

Work Scope: We have compiled velocity information from sources in the literature, results of previous seismic experiments and earthquake-monitoring projects, and data donated from mining, geothermal, and petroleum companies. We also collected (May 2002 and August 2004) two new crustal refraction profiles across western Nevada and the northern and central Sierra. These sections had not been well- 
characterized previously. About half of the first project year's budget was devoted to acquisition of seismic recording and computer equipment to support the collection of refraction data and dissemination of our results. This equipment was acquired two years ago and has been in constant use. More than two dozen graduate and undergraduate students from UNR have participated extensively in project activities, in capacities ranging from instrument deployment, through data analysis, to presentations at international professional meetings. A third regional refraction experiment is funded for the next project year. The seismic velocity model resulting from our selection of new and legacy data is available on the web at www.seismo.unr.edu/geothermal. We have made a final interpretation of the crustal thickness and velocity results gained during the May 2002 field project, which suggests very thin $(<25 \mathrm{~km})$ crust in a limited area of central Nevada near Battle Mountain, on the Humboldt Lineament. Interesting geochemical and GPS anomalies are also present in this area. We published a paper this year in the international technical journal Tectonophysics on these results:

J. N. Louie, W. Thelen, S. B. Smith, J. B. Scott, M. Clark, and S. Pullammanappallil, 2004, The northern Walker Lane refraction experiment: Pn arrivals and the northern Sierra Nevada root: Tectonophysics, 388, no. 1-4, 253-269. (Available on line at www.seismo.unr.edu/geothermal/walker.html)

Two presentations were delivered this year; each is available through www.seismo.unr.edu/geothermal:

John N. Louie, Aasha Pancha, Glenn P. Biasi, Weston Thelen, James B. Scott, Mark F. Coolbaugh, and Shawn Larsen, 2004, Tests and applications of 3-D geophysical model assembly: presented at the Great Basin and Range Evolution and Kinematics Workshop, Tahoe City, Calif., June 20-23.

John N. Louie, Weston Thelen, Shane B. Smith, Jim B. Scott, Matthew Clark, and Michelle Heimgartner, Mark Coolbaugh, Satish Pullammanappallil, 2004, Crustal thickness and seismic velocity in the Great Basin: presented at the Nevada Geothermal Conference, Reno, Nev., Nov. 5.

\section{Milestones:}

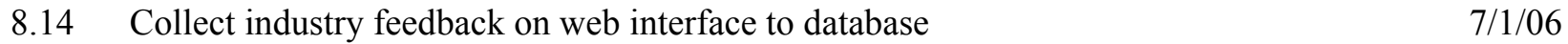

8.17 Make final changes to web database; deliver copy on CD/DVD 9/1/06

8.20 Report on model integration, web facilities 9/1/06

8.21 Publish journal paper on GoldStrike-Auburn refraction profile 9/15/04

8.22 Execute GoldStrike-Fresno refraction profile 8 8/29/04

8.23 Report on model integration, web facilities at Nevada geothermal conference $\quad 11 / 5 / 04$

8.24 Report preliminary results from GoldStrike-Fresno refraction 4/30/05

8.25 Execute GoldStrike-Las Vegas refraction profile 8/31/05

8.26 Report preliminary results from GoldStrike-Las Vegas refraction 4/30/06

Plans for Completion: Encompassed in milestones 8.17, 8.20, 8.24, 8.26.

\section{Subcontractors: None}

Partners: Seismic-velocity inversions have been carried out in collaboration with Dr. S.

Pullammanappallil of Optim LLC. The seismic velocity model from this sub-project has been contributed to the associated sub-projects of the GBCGE (PIs Shevenell, Coolbaugh) to assemble geographic databases of geothermal indicators. We continue to work in close concert with another project, sponsored by LLNL, which has developed a prototype velocity model assembler code. Additional seismic recorders were supplied for the refraction experiments by the NSF \& DOE-funded IRIS/PASSCAL Instrument Center at New Mexico Tech. 


\section{Technology for Increasing Geothermal Energy Productivity}

Reporting Period: FY 2004 (October 1, 2003 to March 14, 2004)

DOE Grant/Contract \#: $\quad$ DE-FG07-99ID13745/DE-FG36-99ID13745

Performing Organization: University of California, San Diego

Department of Chemistry \& Biochemistry 0340

9500 Gilman Drive; La Jolla, CA 92093

Principal Investigator: ～Dr. Nancy Moller, (858) 534-6374, nweare@ucsd.edu

Collaborating Researchers: Professor John Weare, Co-PI (jweare@ucsd.edu)

Dr. Christomir Christov (hhristov@chem.ucsd.edu)

DOE HQ Program Manager: Dr. Leland (Roy) Mink, (202) 586-5463, roy.mink@hq.doe.gov

DOE HQ Technical Manager: Raymond Fortuna, (202) 586-1711, raymond.fortuna@hq.doe.gov

DOE Funding Allocation: $\quad \$ 150 \mathrm{~K}$

Cost Share Funding: $\quad \$ 6,765$ Co-Principal Investigator Faculty Salary Exchange Program

Project Objective: Chemical problems, such as mineral sealing, injection incompatibilities, scaling and toxic gas emission, can significantly increase the costs of geothermal energy production. Future operations that exploit uncharacterized, deep heat sources and low permeability reservoirs face new problems involving very high temperature and pressure rock/water interactions. Therefore, the ability to predict the chemical behavior and energetics of hydrothermal heat sources and enhanced geothermal systems (EGS) as well as associated energy extraction processes would significantly promote the economical production and expanded use of geothermal energy. The overall objective of our research program is to provide the geothermal industry with easy-to-use computer modeling technologies that correctly predict resource and process chemistry for a wide array of operating conditions. Specific research goals are to: (1) develop models that describe the chemistry of geothermal resources and energy extraction processes for a wide range of composition (X), temperature $(\mathrm{T})$ and pressure $(\mathrm{P})$ variables; (2) develop new technology to model the complex chemistry of future deep, higher temperature and fluidlimited resources; (3) increase the understanding of the chemical interactions of geothermal fluids and injectates with reservoir rocks and during energy production; (4) develop internet based user interfaces and a web site that make the modeling technologies readily available and stimulate communication; (5) train students and advise professionals in reservoir and brine chemistry.

Our five-year grant (DE-FG07-99ID13745) started 3/18/99 and ended 3/14/04. During this final 5.5 month project period, building on the research foundation established in the prior years of this grant, the research goals are to complete several long-term research activities, to begin constructing a 
thermodynamic model of the important geothermal aluminum-silicate minerals and to make major improvements to our web site.

Background/Approach: Computer technologies that accurately predict geothermal chemistry - scaling, breakout, steam fractions, heat content, gas emission, phase co-existence, miscibility, $\mathrm{pH}$, formation temperatures, downhole brine concentrations - for a wide range of reservoir and production conditions can provide powerful tools to optimize energy production processes and decrease their costs. Since different regions of XTP space (e.g., subcritical and supercritical regions) display very different thermodynamic behaviors, construction of models to successfully treat these regions requires different theoretical approaches.

For current, relatively near surface geothermal operations $\left(\mathrm{T}<300^{\circ} \mathrm{C}\right)$, the major effect on the free energy of the hydrothermal fluids is from changes in solute concentrations and temperature. Successful equation of state (EOS) models for these systems must be able to accurately describe changes in the dissociation state of solutes as well as efficiently treat important mixing effects and solid-liquid-gas equilibria to high fluid concentration as a function of temperature. We have shown (e.g., Moller, Greenberg and Weare, 1999; Christov and Moller, 2004ab) that the semi-empirical expressions of Pitzer can provide a very accurate description of the free energy of highly complex aqueous systems to high brine concentrations and temperatures. Pressure corrections in this region for the compressible (but nearly ideal) vapor phase can be described by simple ideal gas mixing and, for higher pressure, a virial expansion in density. The Pitzer equations expand the excess Gibbs free energy of the solution phase to third virial coefficient terms in composition. An important feature of this modeling concept is the consistency that results from all properties being based on the free energy. The free energy is related to experimental data via the activity and osmotic coefficients, which can be calculated from analytic derivatives. At constant $\mathrm{T}$ and $\mathrm{P}$, the virial coefficients are specific functions of ionic strength with parameters to be evaluated from experimental data. These parameters also vary with temperature and pressure. The high accuracy of our Pitzer-type models is due to the use of a soundly based phenomenology and also to the heavy use of thermochemical measurements in the TP region of application for parameterization. These models summarize and evaluate large amounts of experimental data and, via their extrapolation and interpolation properties, expand the usefulness of these data.

Geothermal operations exploiting higher temperature $\left(\mathrm{T}>300^{\circ} \mathrm{C}\right)$ and pressure hydrothermal and fluidlimited heat sources can also undergo phase separation (e.g., flashing and miscibility) leading to large density and compositional changes. These conditions can be encountered during brine extraction and injection as well as during the evolution of the resource when brines are cycled through high TP regions. Therefore, a chemical model for high TP operations must be able to describe multiple phase geothermal processes and accurately reproduce XPVT properties in the supercritical region where the density of a system changes dramatically and continuously as a function of pressure. Another problem that must be addressed in modeling high TP geothermal systems is that the amount of experimental data available for model parameterization is significantly less than for subcritical systems.

In order to meet these challenges we generated new EOS phenomenologies that can treat high TP conditions. These are more closely related to first principle theory in order to decrease the demand for experimental data. We also developed new simulation technology to generate needed thermodynamic information from first principle theory. Since the various thermodynamic properties are related by differentiation or integration, the choice of representation (e.g., an EOS giving PVTX properties directly or an EOS based on the free energy and giving all other properties by differentiation) is somewhat arbitrary. We explored two approaches. One, applicable to moderately polar systems containing water but no salt, is based on the selection of an equation (EOS) for the pressure (compressibility) as a function of molar volume, temperature and composition. The second approach, applicable to supercritical aqueous salt systems, is based on the parameterization of a representation of the free energy as a function of molar 
volume, temperature and composition. Both approaches successfully produced models that could: (1) yield correct free energies for both the liquid and vapor densities and (2) treat the large changes in composition that can occur in phase separation processes (e.g., when highly saline brines are produced from fluids originally of low concentration). Scaling methods were developed to treat the very difficult critical region. With our new EOS frameworks and with molecular dynamics and Monte Carlo simulations, we have shown (e.g., Duan, Moller and Weare, 2003; In press publication, see below) that these models can reliably describe the chemistry, difficult to duplicate experimentally, encountered tapping the rich heat reserves located in deeper high TP and/or low fluid future resources.

Computer models summarize large amounts of experimental data, support innovative visualization techniques and are easily transferable. To facilitate technology transfer, we developed comprehensive user interfaces so that completed models can be bundled into application packages: TEQUIL (rock/water interactions, such as scaling and reservoir chemistry, as a function of composition for temperatures below $300^{\circ} \mathrm{C}$ ), GEOFLUIDS (multiple phase processes, such as flashing and miscibility, to very high T, P conditions) and GEOHEAT (in progress: heat characteristics, such as enthalpies, of complex mixtures) These packages can be easily accessed on our interactive web site (geotherm.uscd.edu).

Status/Accomplishments: FY04 included the 5.5 month continuation of our DOE grant DE-FG0799ID13745 grant from 10/01/03 to 3/14/04 (termination date). Grant project goals were completed.

Liquid density brine models: Progress made in the FY04 period includes:

- $\quad$ Finalization and publication (Geochimica Cosmochimica Acta, publications listed below) of manuscripts describing a $\mathrm{pH}$ and temperature dependent model of acid/base reactions in the H-Na$\mathrm{K}-\mathrm{Ca}-\mathrm{OH}-\mathrm{Cl}-\mathrm{HSO}_{4}-\mathrm{SO}_{4}-\mathrm{H}_{2} \mathrm{O}$ system.

- $\quad$ Completion of a $\mathrm{pH}$ and temperature dependent model of carbonate solid-liquid equilibria in the $\mathrm{Na}-\mathrm{K}-\mathrm{Ca}-\mathrm{H}-\mathrm{HCO}_{3}-\mathrm{CO}_{3}-\mathrm{OH}-\mathrm{H}_{2} \mathrm{O}-\mathrm{CO}_{2}(\mathrm{~g})$ system. A paper describing the sodium and potassium carbonate systems is in preparation. Validation and testing of calcium parameterization is continuing.

- Parameterization of the $\mathrm{H}_{4} \mathrm{SiO}_{4}{ }^{\circ}-\mathrm{H}_{3} \mathrm{SiO}_{4}{ }^{-}-\mathrm{NaCl}-\mathrm{KCl}-\mathrm{CaCl}_{2}-\mathrm{H}_{2} \mathrm{O}$ system to high temperature.

- Making substantial progress modeling the highly complicated aqueous chemistry of aluminum as a function of $\mathrm{pH}$ and temperature by beginning the addition of hydroxide reactions to our preliminary model of the $\mathrm{H}-\mathrm{Al}-\mathrm{Cl}-\mathrm{H}_{2} \mathrm{O}$ system. These activities are by necessity carried out incrementally and several projects started in previous grant years were completed in FY03-04. They significantly expand the compositional flexibility of our variable temperature $\left(0-250^{\circ} \mathrm{C}\right)$ TEQUIL modeling technologies and substantially increase the applicability of this modeling package to describe the chemistry of geothermal resources and energy extraction. Note also that in this grant we proposed to initiate modeling aluminum interactions and to build the foundation necessary to add the hydrothermal alumino-silicate mineral interactions to the TEQUIL modeling technologies. Our new DOE grant (DE-FG36-04GO14300, start date 10/1/04) continues this project (see FY05 milestones).

Advanced modeling technologies for high T, P conditions (In FY04 this project was funded by grants from other agencies.): Under DOE grant DE-FG07-99ID13745 we explored new technologies to model the complex chemistry of future deep, higher temperature, pressure and fluid-limited resources. The system $\mathrm{Na}, \mathrm{K}, \mathrm{Ca}, \mathrm{Mg}, \mathrm{Cl}-\mathrm{H}_{2} \mathrm{O}$ includes the major salt components of most high TP natural fluids. We now have accurate EOS models of the $\mathrm{MgCl}_{2}$ - and $\mathrm{CaCl}_{2}-\mathrm{H}_{2} \mathrm{O}$ binaries to add to our previous high TP EOS model of the NaCl-KCl- $\mathrm{H}_{2} \mathrm{O}$ system. However, we could not find any high TP experimental data for $\mathrm{MgCl}_{2}$ and $\mathrm{CaCl}_{2}$ mixtures. After examining various molecular level approaches, we have found that the EOS technology can provide qualitatively correct information about salt water solutions that is useful for 
understanding deep high T, P reservoir behavior. Using this information, we developed an empirical approach based on classical mixing rules and now have a mixing model for the $\mathrm{MgCl}_{2}-\mathrm{CaCl}_{2}-\mathrm{H}_{2} \mathrm{O}$ system (Duan, Moller and Weare, to be submitted publication (a) listed below). Very non ideal behavior is predicted, but the lack of data for this system, makes it impossible to tell whether this non ideal behavior is real. Therefore we temporarily suspended the EOS approach and concentrated on direct molecular simulation. Progress made in the FY04 period includes:

- $\quad$ Parameterization of molecular level potentials using first principle simulation of the properties of Cl- in water solutions for use in molecular simulations of high TP fluids.

- Use of molecular dynamics simulations to quantitatively predict vapor-liquid equilibria in binary and ternary systems for high TP conditions (Duan, Moller and Weare, in press publication and to be submitted publication (b) listed below).

Technology transfer: In FY03-04 we made substantial progress improving our geotherm.ucsd.edu web site. The navigation, visual appearance and flexibility of the site were improved off site. In the FY04 period we:

- $\quad$ added these web site improvements to the server;

- $\quad$ improved notification of user communications on web site;

- $\quad$ initiated improvements to web site documentation.

\section{Reports \& Articles Published in FY 2004:}

Christov C. and Moller N. (2004a) Chemical equilibrium model of solution behavior and solubility in the $\mathrm{H}-\mathrm{Na}-\mathrm{K}-\mathrm{OH}-\mathrm{Cl}-\mathrm{HSO}_{4}-\mathrm{SO}_{4}-\mathrm{H}_{2} \mathrm{O}$ system to high concentration and temperature. Geochim. Cosmochim. Acta 68, 1309-1331.

Christov C. and Moller N. (2004b) Chemical equilibrium model of solution behavior and solubility in the $\mathrm{H}-\mathrm{Na}-\mathrm{K}-\mathrm{Ca}-\mathrm{OH}-\mathrm{Cl}-\mathrm{HSO}_{4}-\mathrm{SO}_{4}-\mathrm{H}_{2} \mathrm{O}$ system to high concentration and temperature. Geochim. Cosmochim. Acta 68, 3717-3739.

Duan Z., Moller N. and Weare J. H. (2003) Equation of state for the $\mathrm{NaCl}-\mathrm{H}_{2} \mathrm{O}-\mathrm{CH}_{4}$ system: Phase equilibria and volumetric properties above 573K. Geochim. Cosmochim. Acta 67, 671-680.

Duan Z., Moller N. and Weare J. H. Gibbs ensemble simulations of vapor/liquid equilibrium using the flexible RWK2 water potential. Journal of Physical Chemistry, (In press).

Duan Z., Moller N. and Weare J. H. Equations of state for the $\mathrm{CaCl}_{2}-\mathrm{H}_{2} \mathrm{O}$ and $\mathrm{MgCl}_{2}-\mathrm{H}_{2} \mathrm{O}$ systems for high temperatures and pressures. To be submitted for publication (a), Geochim. Cosmochim. Acta.

Duan Z., Moller N. and Weare J. H. Gibbs ensemble Monte Carlo simulation of vapor/liquid and metastable liquid/liquid phase equilibria in the $\mathrm{CO}_{2}-\mathrm{CH}_{4}-\mathrm{N}_{2}$ system. To be submitted for publication (b), Geochim. Cosmochim. Acta.

Other Activities: Reviewed manuscripts submitted to a number of journals in Physical Chemistry and Geoscience and the Journal of the American Chemical Society.

Reviewed proposals for various DOE programs and the National Science Foundation.

Reviewed proposals requesting computer time for various national supercomputer centers.

Member (Professor John Weare) of DOE Fundamental Science Directorate Review Committee, Pacific

Northwest National Laboratory, June 1-5, 2004. Wrote report on the computational capabilities of PNNL. 
Planned FY 2005 Milestones: Our five-year grant (DE-FG07-99ID13745) ended 3/14/04. However, our new DOE geothermal grant (DE-FG36-04GO14300) started October 1, 2004. Objective of projects carried out under the new grant include the construction a hydrothermal mineral data base and solution models for hydrothermal fluids within the system $\mathrm{H}-\mathrm{Al}-\mathrm{Na}-\mathrm{K}-\mathrm{Ca}-\mathrm{OH}-\mathrm{Cl}-\mathrm{SO}_{4}-\mathrm{H}_{2} \mathrm{O}-\mathrm{SiO}_{2}$. Many of the hydrothermal minerals found in geothermal reservoir rocks have compositions in this system. Examples are $\mathrm{NaAlSi}_{3} \mathrm{O}_{8}$ (Albite), $\mathrm{CaAl}_{2} \mathrm{Si}_{4} \mathrm{O}_{10} \bullet(\mathrm{OH})_{4}$ (Wairakite), Quartz $\left(\mathrm{SiO}_{2}\right)$, etc. The solubility of aluminum silicate minerals is determined by the activity of the species in solution via dissolution reactions and the chemical equilibrium constants for the dissolution reactions. In FY05 we will continue our efforts, initiated under DOE grant DE-FG07-99ID13745, to construct an accurate $\mathrm{pH}$ dependent model of the aqueous chemistry of aluminum to high temperature. Aluminum aqueous chemistry is highly complicated. Several hydrolysis species exist, their abundance varying with $\mathrm{pH}$ and temperature. Using data obtained by the Oak Ridge National Laboratory, with DOE funding, and other data in the literature we will construct a $\mathrm{pH}$ and temperature dependent model $\left(0-150^{\circ} \mathrm{C}\right)$ of the $\mathrm{H}-\mathrm{Na}-\mathrm{K}-\mathrm{Al}-\mathrm{OH}-\mathrm{Cl}-\mathrm{H}_{2} \mathrm{O}$ system. This model will be the first to collect these data into one consistent package, thereby greatly increasing the application of these many recent measurements. 


\section{Gas and Isotopes Geochemistry}

Reporting Period: FY 2004 (October 1, 2003 to September 30, 2004)

DOE Grant/Contract \#: $\quad$ DE-AC03-76SF00098

Performing Organization: Lawrence Berkeley National Laboratory

One Cyclotron Road, Berkeley, CA 94720

Principal Investigator: $\quad$ B. Mack Kennedy, (510) 486-6451, bmkennedy@lbl.gov

Collaborating Researchers: $\quad$ M. C. van Soest, Lisa Shevenell (UNR)

DOE HQ Program Manager: Dr. Leland (Roy) Mink, (202) 586-5463, roy.mink@hq.doe.gov

DOE HQ Technical Manager: Raymond Fortuna, (202) 586-1711, raymond.fortuna@hq.doe.gov

DOE Funding Allocation: $\quad \$ 150 \mathrm{~K}$

Cost Share Funding: $\quad \sim 20 \%$ in kind - field access, assistance in sampling, data access.

Project Objective: To develop new and apply existing geochemical and isotopic techniques for assessing existing and finding new geothermal systems. Develop new methods to delineate the presence of subsurface temperature anomalies associated with fluid and permeability and improve identification of productive and non-productive systems. Enhance existing numerical simulators to take full advantage of the available geochemical, geophysical and geologic information.

Background/Approach: To assist the geothermal industry in finding, developing and operating geothermal fields we must acquire (1) a more thorough understanding of known geothermal resources and (2) new innovative techniques for finding new and sometimes "hidden" geothermal systems. The project will take an integrated approach using geophysical, geochemical, geologic, and remote sensing techniques as potential tools for expanding exploration capabilities for U.S. geothermal industries. The chemical characterization of fluids in a geothermal reservoir is essential for assessment and realizing optimum utilization of the resource. The isotopic composition of elements in fluids provide a quantitative measure of material balance, therefore isotopes are extremely powerful in unraveling fluid histories and tracing fluid flow. Conservative elements, such as the noble gases ( $\mathrm{He}, \mathrm{Ne}, \mathrm{Ar}, \mathrm{Kr}$, and $\mathrm{Xe}$ ) are extremely useful because they preserve isotopic information related to initial conditions and sources.

Status/Accomplishments: During FY04, we concentrated on two primary projects. The first was a detailed study of helium isotope systematics throughout Dixie Valley and the inter-relationship between the Dixie Valley geothermal reservoir and local hydrology. The second is the construction of a helium isotope "map" of the Basin and Range and surrounding areas to evaluate the utility of helium isotopes as a regional exploration tool.

1. Dixie Valley 
Helium isotopic compositions in production wells of the Dixie Valley Geothermal Field range from 0.70 $0.76 \mathrm{Ra}$ and are elevated relative to that expected for radiogenic production in the crust $(0.02-0.10 \mathrm{Ra})$ indicating that as much as $\sim 7.5 \%$ of the helium and $\sim 10-15 \%$ of the heat in the fluids from the Dixie Valley geothermal reservoir is mantle-derived. Due to a lack of geologic and geophysical evidence for current or recent magmatic activity and the inability of older magma systems to sustain high enough ${ }^{3} \mathrm{He} /{ }^{4} \mathrm{He}$ ratios, the most viable source for the mantle ${ }^{3} \mathrm{He}$ is fluid transport up through the Stillwater Range Front fault system; a system which appears to be in direct communication with the mantle. Using a simple one-dimensional steady-state fluid flow model, the helium content and isotopic composition imply vertical fluid flow rates from the deeper source of $\sim 7 \mathrm{~mm} / \mathrm{yr}$, corresponding to a ${ }^{3} \mathrm{He}$ flux of $\sim 10^{4}$ atoms $\mathrm{m}^{-2} \mathrm{sec}^{-1}$. Assuming the system is in steady state with respect to both heat and helium transport through the crust, the calculated ${ }^{3} \mathrm{He}$ flux is $\sim 30 \mathrm{x}$ lower than expected if the anomalous Dixie Valley heat flux (80$90 \mathrm{~mW} \mathrm{~m}^{-2}$ ) is driven by mantle partial melting and underplating. If the heat-helium system has not attained a steady state, then initiation of mantle melting and heat-helium transport through the crust must have begun no later than 20-30 million years ago. Alternatively, due to probable mixing with other non ${ }^{3} \mathrm{He}$-enriched fluids, the simple 1D flow model has underestimated fluid flow rates through the fault system by as much as a factor of $\sim 30$.

The fluid samples from the Dixie Valley geothermal field have the highest helium isotopic compositions $(\mathrm{R} \sim 0.8 \mathrm{Ra})$ and helium enrichment factors $\left[\mathrm{F}\left({ }^{4} \mathrm{He}\right) \sim 200\right]$ in Dixie Valley (Figure 1). The high temperature fluids $\left(270^{\circ} \mathrm{C}\right)$ are produced from fractures along the valley bounding Stillwater Range Front fault system. The helium compositions of springs and wells throughout the valley that are not in direct communication with the Stillwater Range Front fault, are a mixture of this deep fluid with a younger less ${ }^{4} \mathrm{He}$ and ${ }^{3} \mathrm{He}$-enriched groundwater $\left[\mathrm{R}<0.35 \mathrm{Ra}, \mathrm{F}\left({ }^{4} \mathrm{He}\right)<5\right]$, as indicated by the dashed line in Figure 1 . The exceptions to the simple mixing trend are fumaroles (SE and Senator Fumaroles) and Dixie Meadows hot spring (located $\sim 30 \mathrm{~km}$ southwest of the geothermal field), which have helium isotopic compositions that are indistinguishable from the geothermal field and, therefore are not effected by shallow groundwater. These features are all located along the range front fault, implying that the Stillwater fault, at least along the section from the geothermal field southwest to Dixie Meadows, is a fast path for vertical fluid flow that is unencumbered by local hydrology affecting fluids further out in the valley. If so, the geothermal potential of the Stillwater fault system may be significantly greater than the 6-8 km long system presently under production. Furthermore, the other features in the valley, which plot along the mixing line in Figure 1, although influenced by local hydrology, also

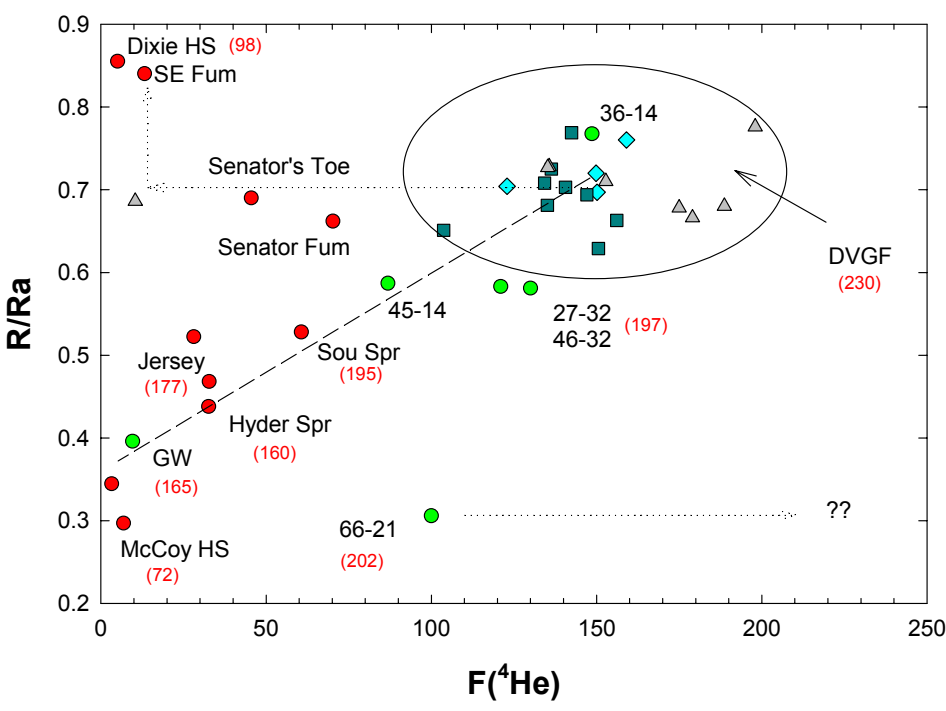

Figure 1: Dixie Valley helium trends contain a fluid component indistinguishable from the geothermal/Stillwater fault fluid. Whether or not this implies an additional deeper pervasive geothermal system needs to be further evaluated. 
The Basin and Range Province in western North American is characterized by an anomalous thermal gradient, high heat flux, and volcanism and extensional tectonics that have varied in time and space over the past $\sim 30$ million years. This confluence of geology has created a vast region of exceptionally high potential for geothermal energy development. Beginning $\sim 8$ million years ago and continuing to the present, magmatism has migrated to the margins of the basin and NW-SE extension, characterized by high angle block faulting, dominates in the northwestern and central Basin and Range. Within the Province two types of geothermal resource have been identified: magma hosted and "extensional". Concentrated along the margins of the Basin and Range, the magma hosted systems (e.g. Steamboat, Long Valley, Coso, and Roosevelt) mine heat from cooling magma bodies emplaced in the shallow crust and are similar to the numerous magma hosted systems throughout the world. However, the extensional geothermal systems, which are found throughout the Basin and Range and may constitute the largest geothermal potential, are nearly unique to this region. Very little is known, except in general terms, about the origin and development of these systems or what drives their spatial and temporal distribution with respect to regional and local tectonic history.

Early models developed to explain the anomalous high Basin and Range heat flow invoked large scale regional under-plating of mantle derived melts. This would induce a high regional ${ }^{3} \mathrm{He}$ flux across the crust-mantle boundary and on average it would be expected that helium isotope ratios in surface fluids would be uniformly high across the Basin and Range, reflecting the regional high flux. More recent models that restrict current mantle melting to localized regions along the margins of the Basin and Range and are more consistent with the distribution and age of current and recent volcanism in the Basin and Range. The heat flow anomalies in the remainder of the Basin and Range are, therefore, related to crustal thinning, older melting events, and/or more recent areas of local small scale mantle melting (e.g. Figure 2a).

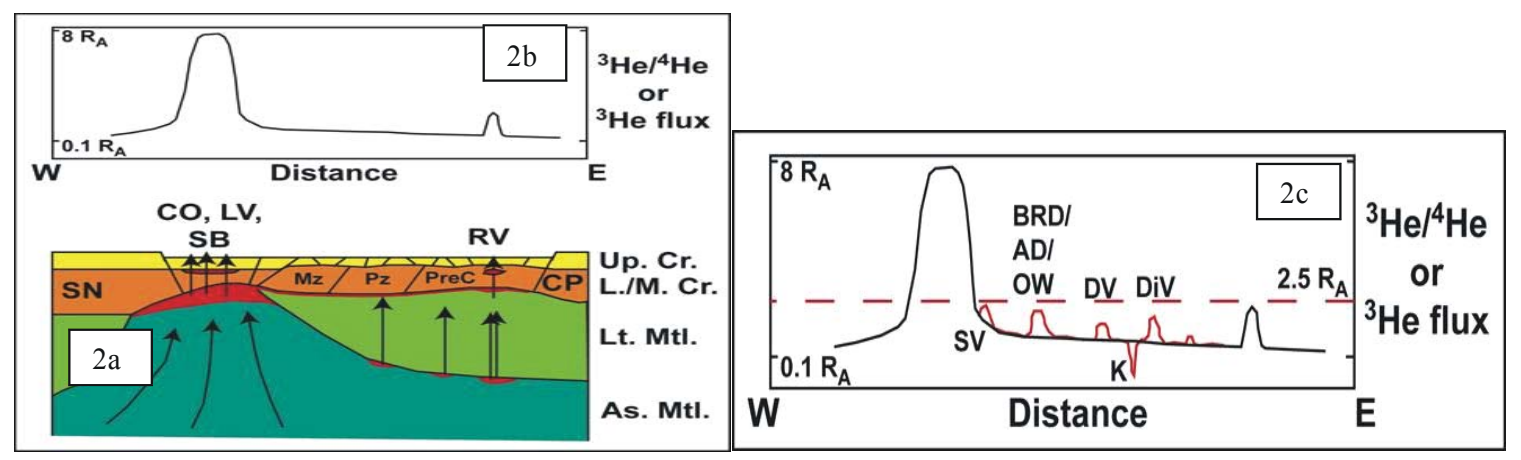

Figure 2: Basin and Range magmatism and helium isotope models (a and b) compared to regional data $(c)$.

A theoretical helium isotope profile that might be associated with the more recent models is shown in Figure $2 \mathrm{~b}$. High, mantle-like, helium isotope ratios are confined to the regions of current large scale mantle melting and under-plating where the ${ }^{3} \mathrm{He}$ flux will be the greatest. Away from this zone, the helium isotope ratios decrease rapidly as the flux of mantle ${ }^{3} \mathrm{He}$ declines. Current localized magmatism like that observed at Roosevelt, Utah (RV in Figure 2a) may generate local elevated helium isotope ratios compared to its surroundings. However, the size of the mantle derived magma batch, the amount of crustal interaction, the age of the crust it interacts with, and time since the last fresh mantle derived 
magma was added to the system will determine the magnitude of the helium isotope ratio enrichment compared to its surroundings.

Preliminary results of a regional helium isotope study appear to conform to the more recent models, as depicted in Figure $2 \mathrm{~b}$. Fluids from the western margin of the Basin and Range, a region characterized by current volcanic activity, have helium isotope ratios as high as $\sim 6 \mathrm{Ra}$ (Figure 2c). Moving away from these areas, helium isotope ratios decrease rapidly to 'background' values of around $0.6 \mathrm{Ra}$, and then gradually decrease toward the east to low values of $\sim 0.1 \mathrm{Ra}$ at the eastern margin of the Basin and Range. Superimposed on this general regional trend are features which have elevated helium isotope ratios $(0.8$ $2.1 \mathrm{Ra}$ ) compared to the local background (Figure 2c). Spring geochemistry and local geology indicate that these "He-spikes" are not related to current or recent magmatic activity, suggesting that the spikes may reflect localized zones characterized by deep permeable pathways and high vertical fluid flow rates. Our detailed study of one of these deep permeable pathways (Dixie Valley and the Stillwater Range Front Fault system), has demonstrated that the deep permeable pathways are confined to the range front normal faults characteristic of the extensional regime in the Basin and Range. However, not all range front fault systems transmit fluids with a mantle signature, implying that not all have deep permeable pathways.

The role played or necessity of deep permeable pathways in the development of a viable geothermal resource in the Basin and Range is not well understood. Perhaps mapping of geochemical and isotopic information into a tectonic and geophysical context will add to our understanding of these systems. For instance, the Dixie Valley geothermal system, which is one of the most productive extensional geothermal systems in the Basin and Range and which produces fluids from an identified deep permeable pathway, is situated in a transition region between a zone of slow extension rates to the east and accelerating extension to the west. The relevance of the transition region to the location of the geothermal system is unknown. To facilitate future exploration and the evaluation of geothermal resource potential, the relevance of this and similar issues must be addressed and understood.

\section{Reports \& Articles Published in FY 2004:}

Kennedy, B.M. and van Soest, M.C. (2004) A helium isotope perspective on the Dixie Valley, Nevada hydrothermal system. To be submitted to Geothermics (presently undergoing in-house review).

Evans, W.C., van Soest, M.C., Mariner, R.H., Hurwitz, S., Ingebritsen, S.E., Wicks, C.W., and Schmidt, M.E. (2004). Magmatic intrusion west of the Three Sisters, central Aregon, USA: the perspective from spring geochemistry. Geology, v32, no.1, 69-72, LBNL\# 53877. (role: supervisor, consultant, reviewer).

Van Soest, M.C., Evans, W.C., Mariner, R.H., and Schmidt, M.E. (2004). Chloride in hot springs of the cascade volcanic arc - the source puzzle. In Water-Rock Interaction (WRI-11), Wanty, R.B. and Seal II, R.R. (eds.), 209-213, LBNL\# 55553.

\section{Presentations Made in FY 2004:}

van Soest, M.C., Kennedy, B.M., and Dobson, P. (2004). Helium isotopes in hot springs and (hot) wells of the Basin and Range; a progress report. $29^{\text {th }}$ Workshop on Geothermal Reservoir Engineering, Stanford University, Jan. 26-28, 2004.

Kennedy, B.M. and van Soest, M.C. (2004). Helium isotopes in hot springs and (hot) wells of the Basin and Range. EarthScope GreatBreak Workshop, Tahoe City, CA., June, 2004 (invited poster).

\section{Planned FY 2005 Milestones:}

Complete and submit manuscript on Dixie Valley 
Complete sampling and analyses of fluids from Basin and Range Geothermal Plants

Initiate detailed sampling program of one or two selected Basin and Range

valley's with known helium isotope anomalies

Sep 05 


\section{Design of Sampling Strategies to Detect $\mathrm{CO}_{2}$ Emissions From Hidden Geothermal Systems}

Reporting Period: FY 2004 (October 1, 2003 to September 30, 2004)

DOE Grant/Contract \#: $\quad$ DE-AC03-76SF00098

Performing Organization: Lawrence Berkeley National Laboratory, Earth Sciences Division 1 Cyclotron Rd., Berkeley, CA 94020

Principal Investigator: $\quad$ Jennifer L. Lewicki, (510) 495-2818, jllewicki@lbl.gov

Collaborating Researchers: Curtis M. Oldenburg, B. Mack Kennedy

DOE HQ Program Manager: Dr. Leland (Roy) Mink, (202) 586-5463, roy.mink@hq.doe.gov

DOE HQ Technical Manager: Raymond Fortuna, (202) 586-1711, raymond.fortuna@hq.doe.gov

\section{DOE Funding Allocation: \$27K}

Cost Share Funding: $\quad$ None

Project Objective: This project investigates the potential for $\mathrm{CO}_{2}$ detection and monitoring in the nearsurface environment to serve as a tool to discover hidden geothermal systems. We target $\mathrm{CO}_{2}$ due to (1) its abundance in geothermal systems, (2) its moderate solubility in water, and (3) the wide range of technologies available to monitor $\mathrm{CO}_{2}$ in the near-surface environment. However, monitoring in the near surface for $\mathrm{CO}_{2}$ derived from hidden geothermal reservoirs is complicated by the large variation in $\mathrm{CO}_{2}$ fluxes and concentrations arising from natural background biological and hydrologic processes. We address these complications and develop an integrated monitoring and analysis strategy for geothermal $\mathrm{CO}_{2}$ detection based on the following components: (1) numerical simulation of geothermally derived $\mathrm{CO}_{2}$ flow and transport in the vadose zone and atmospheric surface layer, (2) analysis of the sources and magnitudes of background $\mathrm{CO}_{2}$ concentrations and fluxes in the near-surface, (3) compilation and analysis of the measurement capabilities and cost effectiveness of available technologies for $\mathrm{CO}_{2}$ detection, and (4) Bayesian statistical analysis of background biological and geothermal $\mathrm{CO}_{2}$. Results of the study are expected reduce the time and cost associated with exploration for geothermal systems.

Background/Approach: Most commercial geothermal projects have been developed near previously known resources, for example, near hot springs or areas of historic use. Also, the majority of hydrothermal systems with obvious surface expressions in the U.S. have already been explored for geothermal development potential. Discovery of new geothermal systems will therefore require exploration of areas where the reservoirs are either hidden or lie at greater depths than presently known reservoirs. As a result, research must be geared toward the development of novel exploration techniques to locate these new geothermal resources. Here, we define "hidden" geothermal systems as those systems above which hydrothermal surface features (e.g., hot springs, fumaroles, elevated ground temperatures, hydrothermal alteration) are lacking. Emissions of moderate to low solubility gases (e.g., $\left.\mathrm{CO}_{2}, \mathrm{CH}_{4}, \mathrm{He}\right)$ 
may be one of the primary near-surface signals from these systems. Detection of anomalous gas emissions related to hidden geothermal systems may therefore be an important tool to discover new resources.

We focus our investigation on the detection and monitoring of $\mathrm{CO}_{2}$ in the subsurface and above ground in the near-surface environment as a tool to discover hidden geothermal systems because (1) $\mathrm{CO}_{2}$ is the major non-condensable gas present in geothermal reservoirs, (2) due to its moderate solubility in water, $\mathrm{CO}_{2}$ from volcanic-hydrothermal sources tends to migrate to the near-surface in the gaseous phase in equal or greater proportion than dissolved in the aqueous phase in groundwater, and (3) a broad range of technologies are available to monitor $\mathrm{CO}_{2}$ in the near-surface environment. Importantly, however, $\mathrm{CO}_{2}$ is produced in the near surface by a variety of biological processes, and monitoring of $\mathrm{CO}_{2}$ from hidden geothermal reservoirs will involve monitoring a system with large variation in $\mathrm{CO}_{2}$ fluxes and concentrations arising from natural biological and hydrologic processes. The detection of anomalous $\mathrm{CO}_{2}$ will therefore require searching for potential geothermal $\mathrm{CO}_{2}$ anomalies, likely of small magnitude, over areas of tens of $\mathrm{km} 2$ or more within the naturally varying background $\mathrm{CO}_{2}$ fluxes and concentrations.

The objective of this project is to investigate geothermal $\mathrm{CO}_{2}$ monitoring in the near surface as a tool to discover hidden geothermal reservoirs. A primary goal of this project is to develop an approach that places emphasis on cost and time-efficient near-surface exploration methods and yields results to guide and focus more cost-intensive geophysical measurements, installation of deep wells, and geochemical analyses of deep fluids. To this end, we present (1) the physical properties of $\mathrm{CO}_{2}$ key to its transport in the near-surface environment, (2) model simulations of geothermal $\mathrm{CO}_{2}$ migration and seepage that highlight fundamental features of these processes, (3) a discussion of the processes that affect natural background $\mathrm{CO}_{2}$ fluxes and concentrations within which anomalous geothermal $\mathrm{CO}_{2}$ must be discerned, (4) technologies that are currently available or will be potentially available in the future to monitor $\mathrm{CO}_{2}$ migration and seepage in the near surface, and (5) strategies based on integrated field measurements, numerical simulations, and statistical analyses to detect geothermal $\mathrm{CO}_{2}$ seepage fluxes and concentrations within the naturally varying background fluxes and concentrations.

Status/Accomplishments: The LBNL Report that describes the results of this project, summarized below, is currently in review.

1. Physical properties of $\mathrm{CO}_{2}$ key to its transport in the near-surface environment: The flow and transport of $\mathrm{CO}_{2}$ at high concentrations will be controlled by its high density, low viscosity, and high solubility in water relative to air. Carbon dioxide is a dense and inviscid gas relative to air and will therefore tend to be mobile and sink due to buoyancy effects. However, because $\mathrm{CO}_{2}$ and other gases in the near surface are fully miscible, no significant density segregation is expected to occur in gas mixtures unless there is relative flow between the gas and liquid water. This flow may cause more soluble $\mathrm{CO}_{2}$ to preferentially dissolve in groundwater and leave behind a gas mixture enriched in the less soluble components. If groundwater pressure decreases and/or temperature increases, exsolution may occur, releasing $\mathrm{CO}_{2}$ back to the gas phase.

2. Numerical model simulations of geothermal $\mathrm{CO}_{2}$ migration and seepage in the near-surface environment: We use the simulator T2CA, a research module of TOUGH2, to model coupled subsurface and atmospheric surface layer gas flow and transport. T2CA retains the fundamental porous media flow and transport capabilities of TOUGH2, and models five components (water, brine, $\mathrm{CO}_{2}$, a gas tracer, and air) under isothermal or non-isothermal conditions. The main advance in T2CA is the implementation of a simple atmospheric transport and dispersion capability for dilute gases. The geologic framework of the model hidden geothermal system we consider is based loosely on an arid basin and range system like the Dixie Valley geothermal system, only without any surface manifestations. Within this system, we model the migration of $\mathrm{CO}_{2}$ resulting from a range of geothermal source $\mathrm{CO}_{2}$ fluxes emitting from the top of a conductive fault, located near the water table. Results show that $\mathrm{CO}_{2}$ concentrations can reach very high 
levels in the shallow subsurface even for relatively low geothermal source $\mathrm{CO}_{2}$ fluxes (e.g., Figure 1). However, once $\mathrm{CO}_{2}$ seeps out of the ground into the atmospheric surface layer, surface winds are effective at dispersing $\mathrm{CO}_{2}$ seepage.
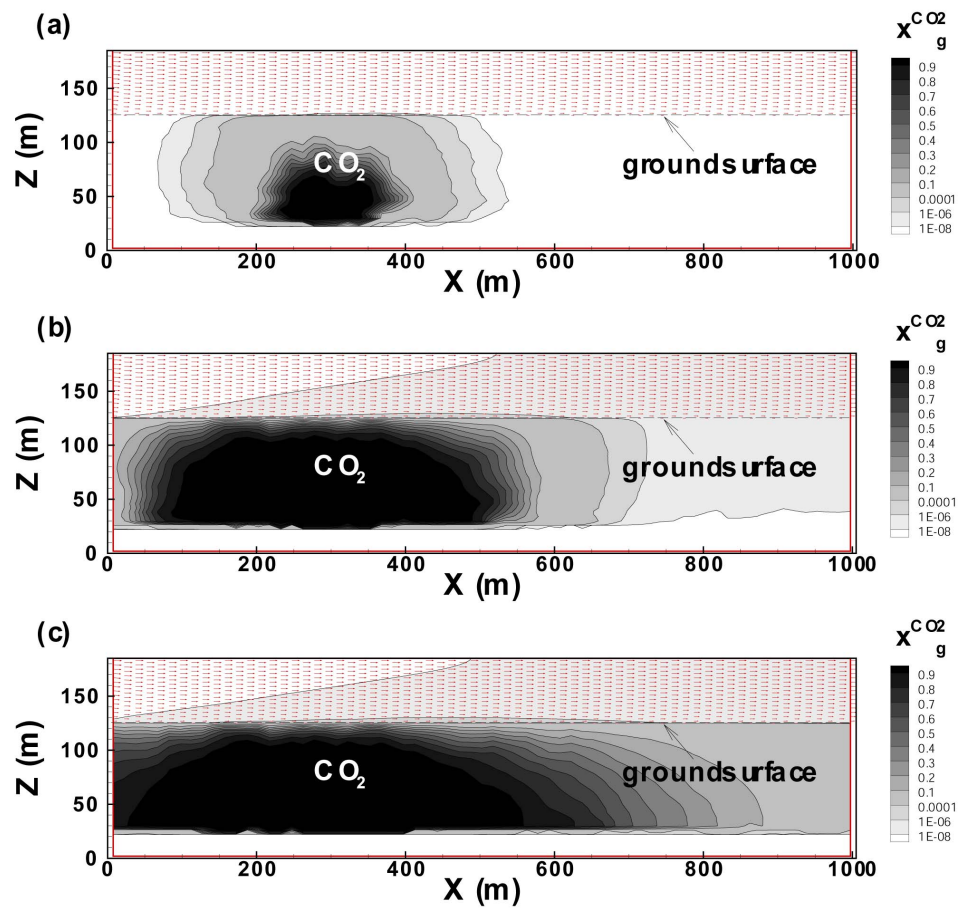

Figure 1. Coupled $\mathrm{CO}_{2}$ subsurface migration and surface-layer mixing at (a) 1, (b) 10, and (c) 200 years after $\mathrm{CO}_{2}$ migration begins for wind velocity of $3 \mathrm{~m} \mathrm{~s}^{-1}$.

3. Processes that affect natural background $\mathrm{CO}_{2}$ : In natural ecological systems in the absence of geothermal gas emissions, near-surface $\mathrm{CO}_{2}$ fluxes, concentrations, and carbon isotopic compositions are primarily controlled by uptake by photosynthesis, production by root respiration, microbial

decomposition of soil/subsoil organic matter, groundwater degassing, and exchange with the atmosphere. We discuss the natural spatial and temporal variability of $\mathrm{CO}_{2}$ fluxes, concentrations, and carbon isotopic compositions in the near surface arising from these background processes. We then compare these signals to those expected from migration of geothermal $\mathrm{CO}_{2}$ into the near-surface environment.

4. Technologies to monitor $\mathrm{CO}_{2}$ migration and seepage in the near surface: Available technologies for monitoring $\mathrm{CO}_{2}$ in the near-surface environment include (1) the infrared gas analyzer (IRGA) for measurement of concentrations at point locations, (2) the accumulation chamber (AC) method for measuring soil $\mathrm{CO}_{2}$ fluxes at point locations, (3) the eddy covariance (EC) method for measuring net $\mathrm{CO}_{2}$ flux over a given area, (4) hyperspectral imaging of vegetative stress resulting from elevated $\mathrm{CO}_{2}$ concentrations, and (5) light detection and ranging (LIDAR) that can measure $\mathrm{CO}_{2}$ concentrations over an integrated path. Technologies currently in developmental stages that have the potential to be used for $\mathrm{CO}_{2}$ monitoring include tunable lasers for long distance integrated concentration measurements and microelectronic mechanical systems (MEMS) that can make widespread point measurements. We assess each of these technologies in the context of measurement detection limit and error, spatial and temporal scale of measurement, availability, and cost of operation.

5. Integrated field measurement, modeling, and statistical analysis strategies to detect geothermal $\mathrm{CO}_{2}$ : To address the challenge of detecting potentially small-magnitude geothermal $\mathrm{CO}_{2}$ emissions within the 
natural background variability of $\mathrm{CO}_{2}$, we propose an approach that integrates available detection and monitoring methodologies with statistical analysis and modeling strategies. This approach is summarized as follows: Within the area targeted for geothermal exploration, point measurements of soil $\mathrm{CO}_{2}$ fluxes and concentrations using the $\mathrm{AC}$ method and a portable IRGA, respectively, and measurements of net surface flux using EC should be made. Also, the natural spatial and temporal variability of surface $\mathrm{CO}_{2}$ fluxes and subsurface $\mathrm{CO}_{2}$ concentrations should be quantified within a background area with similar geologic, climatic, and ecosystem characteristics to the area targeted for geothermal exploration. Bayesian and geostatistical analyses of data collected from both areas should be used to guide sampling strategy, discern spatial patterns that may be indicative of geothermal $\mathrm{CO}_{2}$ emissions, and assess the presence (or absence) of geothermal $\mathrm{CO}_{2}$ within the natural background variability with a desired confidence level. Once measured $\mathrm{CO}_{2}$ concentrations and fluxes have been determined to be of anomalous geothermal origin with high statistical confidence, more expensive vertical subsurface gas sampling and chemical and isotopic analyses can be undertaken. Integrated analysis of all measurements will determine definitively if $\mathrm{CO}_{2}$ derived from a deep geothermal source is present, and if so, the spatial extent of the anomaly.

Further geophysical measurements, installation of deep wells, and geochemical analyses of deep fluids can then be guided and focused by the results of the near surface $\mathrm{CO}_{2}$ monitoring program.

\section{Reports \& Articles Published in FY 2004:}

\section{Presentations Made in FY 2004:}

Planned FY 2005 Milestones: While funding for this project does not extend into FY2005, the following will be accomplished:

Publication of LBNL Report

Dec 04

Presentation and publication of results at Stanford Geothermal Workshop

Jan 05

Submission of results for review to peer-reviewed journal

Apr 05 


\section{Geochemical Sampling of Thermal and Non-thermal Waters in Nevada}

Reporting Period: FY 2004 (October 1, 2003 to September 30, 2004)

DOE Grant/Contract \#: $\quad$ DE-FG36-02ID14311

Performing Organization: University of Nevada, Reno

Principal Investigator: ～～Lisa Shevenell, (775) 784-1779, 1shevenell@charter.net

Collaborating Researchers: Larry Garside

DOE HQ Program Manager: Dr. Leland (Roy) Mink, (202) 586-5463, roy.mink@hq.doe.gov

DOE HQ Technical Manager: Raymond Fortuna, (202) 586-1711, raymond.fortuna@hq.doe.gov

\section{DOE Funding Allocation: $\$ 60 \mathrm{~K}$ \\ Cost Share Funding: $\quad \$ 16 \mathrm{~K}$}

Project Objective: The objective of this project is to obtain geochemical data from springs (and some wells) for which data are not publicly available, or for which the analyses are incomplete, poor, or nonexistent. With these data, geothermometers are being calculated and a preliminary assessment of the geothermal potential and ranking of the sampled areas is being conducted using the new geochemical data. Objectives changed slightly in 2004. Samples are now being collected at sites identified by other components of the Center's geothermal research as having high potential for geothermal development. These samples are being collected to support more detailed work and assessment at those sites. (e.g., Buffalo Valley and Rawhide-Fairview Peak).

Background/Approach: There are more than 350 known geothermal systems in Nevada. At least $30 \%$ of these systems do not have modern, complete water analyses, with analyses for many of these from only one spring in a group of springs. Often it is not known from which spring in a group the sample was taken or if the sampled spring was from the highest temperature spring in that group. Additional data are available from a previously digitized database containing all springs and wells on 7.5' quadrangles. From these digitized site locations, there are $\approx 1000$ springs for which a location is known, but for which there are no available temperature (or chemical) measurements. Although many of these sites are within known geothermal areas and are located near springs for which temperature and/or geochemical data are available, many of these sites are not so located and require evaluation before the geothermal potential of the area can be adequately assessed. A sampling team was assembled including collaborators at Lawrence Berkeley National Laboratory (Thijs van Soest and B. Mack Kennedy).

Status/Accomplishments: We continued to revise and update the text of Bulletin 91 (Thermal Waters of Nevada, by Garside and Schilling, 1979) with information in the published literature and data collected from field visits to the selected sites between 2002 and 2004. Newly collected data were shared with 
numerous entities, including geothermal consultants and geothermal companies to assist them in their efforts to identify new geothermal prospects for more extensive exploration.

A field sheet and photo database continued to be constructed with all field data being captured. Additional entries and changes and error corrections were conducted on the Access database containing all data generated in this work as well as over 7000 entries from historical data.

Topographic maps were searched for all springs (thermal and otherwise) on any topographic map within the broad area of geothermal anomalies identified by the GIS and GPS projects in the Buffalo Valley area and the Fairview Peak-Rawhide area. These sites were evaluated to determine sampling priorities. The focus of the sampling program was changed somewhat to support the activities of the other exploration projects. Samples have been collected at Buffalo Valley and are planned to be collected near Fairview Peak.

Data were received for sites that were selected for ${ }^{14} \mathrm{C}$ analysis. Literature searches and research was conducted on using ${ }^{14} \mathrm{C}$ to date groundwaters in order to become familiar with the latest developments in this field.
A poster was prepared highlighting the geochemical data collected, and the associated database and website being constructed. The title of the poster was "Nevada Geothermal Resources Database and Web Site", and it was presented at the Western States Renewable Energy Summit to in Reno, NV on October 8, 2003. A PowerPoint presentation for the annual GRC meeting in Morelia, Mexico was prepared, and presented by a colleague (Chris Sladek). This presentation summarized sampling and results to date.

An extensive QA process was initiated to assure that good data are being obtained on fluid samples from the NBMG analytical lab. Sample splits were sent to DRI, LANL (Goff), USGS (Mariner), and Thermochem to assist in comparing lab results. In addition, numerous analyses were run at different dilutions using new and different standards. Results of this $Q A$ process were evaluated and all analyses were re-run as a result of identification of analytical problems. Revised, corrected data were provided by the lab and imported into the Access database.

Sladek spent time constructing and testing a temperature gradient probe and he logged several wells at Rye Patch, comparing his results to those obtained by David Blackwell (SMU). He and Coolbaugh also spent several days learning and using an iPAQ-GPS unit to map sinters at several sites. Sladek also worked on data base issues, ${ }^{14} \mathrm{C},{ }^{3} \mathrm{H}$ sample submittals, and a digital water (spring and well) sample sheet for the iPAQ (with Shevenell and Coolbaugh). He got a master location list set up for using on GPS units and for the National Geographic Topographic map program, which should be a help in the field in the future. Some of this work is related specifically to the geochemistry portion of the project, whereas others benefit numerous projects (e.g., learning iPAQ and the Topo map program).

Sladek attempted to sample additional sites in the Gerlach area, but was unsuccessful at some sites due to locked gates. However, samples were successfully collected at several other areas in Washoe and Elko Counties.

A full suite of geothermometers was calculated for all samples with sufficient data in the Access database (including new data generated in this project). A tally of data completeness was made for each of the geothermal power plant sites to assist with an evaluation of the utility of various geothermometers at these sites. Relatively few samples were available that were complete and had good charge balances at each power plant. To assist with the geothermometer evaluation, NBMG information office files were searched 
for logs, temperatures, depths, etc. of production wells at each of the power plants. Tables and plots of data were constructed from which data are being evaluated. Geothermometers were evaluated using power plant data as controls. Geochemical modeling was conducted to determine if more rigorous methods than traditional geothermometer calculations improve temperature estimates. Geochemical modeling of the power plant data was evaluated. Early results indicate these more time consuming calculations do not appreciably improve subsurface temperature estimates.

Using the Access database, errors on NBMG Map 141 were identified, solutions researched, and errors were fixed. The new map was printed and re-posted on the web site. We published a revision to Map 141, showing geothermal spring and well locations in Nevada, as a Nevada Bureau of Mines and Geology Map.

The technician (Sladek) that was doing the sample collection moved on to other projects. Hence, we initiated paperwork to hire a replacement, to be shared between Shevenell, Blewitt, and a separately funded geothermal project. Sampling has been suspended and analyses are being completed on previously collected water samples.

\section{Reports \& Articles Published in FY 2004:}

Coolbaugh, M., and Shevenell, L., 2004. A method for estimating undiscovered geothermal resources in Nevada and the Great Basin. Geothermal Resources Council Transactions, v. 28 (Best Paper Award): 13-18.

Coolbaugh, M., Zehner, R., Kreemer, C., Blackwell, D., Oppliger, G., Sawatzky, D., Blewitt, G., Pancha, A., Richards, M., Shevenell, L., Raines, G., Johnson, G., and Minor, T., in review. Preliminary geothermal map of the Great Basin, Western United States. Nevada Bureau of Mines and Geology Map.

Shevenell, L., and L. Garside, 2004. Nevada Geothermal Resources, revised. Nevada Bureau of Mines and Geology Map 141.

Shevenell, L., Coolbaugh, M., Faulds, J., Oppliger, G., Calvin, W., Louie, J., Blewitt, G., Kratt, C., Arehart, G., Sladek, C., Lechler, P., and Garside, L., 2004. Accomplishments at the Great Basin Center for Geothermal Energy. Geothermal Resources Council Transactions, v. 28: 47-52.

Shevenell, L., Coolbaugh, M., Faulds, J., Oppliger, G., Calvin, W., Louie, J., Blewitt, G., Kratt, C., Garside, L., Arehart, G., Sladek, C., and Lechler, P. 2005. Accomplishments at the Great Basin Center for Geothermal Energy. Abstract submitted to the 2005 Geological Society of Nevada meeting.

\section{Related Reports:}

Shevenell, L., and L. Garside, 2004. Quarterly progress report to DOE on the Project: Nevada Geothermal Resources Database and Web Site, October 1-December 30, 2003, 3 p. January 15, 2004.

Shevenell, L., 2004. Quarterly progress report to DOE on the Project: Expanding Geothermal Resource Utilization in Nevada through Directed Research and Public Outreach, October 1-December 30, 2003, $19 \mathrm{pp}$ (with contributions from six other PI's on research grants). January 30, 2004.

Shevenell, L., 2004. Great Basin Center for Geothermal Energy Contributions to U.S. Energy Security. Submitted to DOE January 5, 2004, 1 p. 
Shevenell, L., and L. Garside, 2003. Quarterly progress report to DOE on the Project: Nevada Geothermal Resources Database and Web Site, January 1-March 31, 2004, April 15, 2004, 3 p.

Shevenell, L., and L. Garside, 2003. Quarterly and final report to DOE on the Project: Nevada Geothermal Resources Database and Web Site, April 1-June 31, 2004, July 15, 2004, 4 p.

Shevenell, L., 2004. Quarterly progress report to DOE on the Project: Expanding Geothermal Resource Utilization in Nevada through Directed Research and Public Outreach, January 1-March 30, 2004, 19 pp (with contributions from six other PI's on research grants). April 30, 2004.

Shevenell, L., 2004. Quarterly progress report to DOE on the Project: Expanding Geothermal Resource Utilization in Nevada through Directed Research and Public Outreach, April 1-June 30, 2004, 8 pp (Management and Geochemistry sections). July 30, 2004.

Shevenell, L., 2004. Quarterly progress report to DOE on the Project: Expanding Geothermal Resource Utilization in Nevada through Directed Research and Public Outreach, July 1-September 30, 2004, 8 pp (Management and Geochemistry sections). October 30, 2004.

\section{Presentations Made in FY 2004:}

Coolbaugh, M.F. and Shevenell, L.A., 2004, A method for estimating undiscovered geothermal resources in Nevada and the Great Basin: Proceedings, Annual Meeting; GRC; Palm Springs, CA, Aug. 29-Sep. 1, 2004.

\section{Planned FY 2005 Milestones:}

1. Hire new spring sampling technician \& student assistant $\quad$ Feb 2005

2. Complete Phase 3 spring sampling

Oct 2005

3. Complete Phase 3 water analyses

Dec 2005

4. Complete geothermometer and mixing calculations

Apr 2006

5. Complete final report evaluating geothermal potential of sites

Sep 2006

6. Provide data and preliminary results to industry and others

ongoing 


\section{Field Case Studies}

Reporting Period: FY 2004 (October 1, 2003 to September 30, 2004)

DOE Grant/Contract \#: $\quad$ DE-AC03-76SF00098

Performing Organization: Lawrence Berkeley National Laboratory

One Cyclotron Road, Berkeley, CA 94720

Principal Investigator: $\quad$ Marcelo Lippmann, (510) 486-5035, mjlippmann@lbl.gov

Collaborating Researchers:

DOE HQ Program Manager: Dr. Leland (Roy) Mink, (202) 586-5463, roy.mink@hq.doe.gov

DOE HQ Technical Manager: Raymond Fortuna, (202) 586-1711, raymond.fortuna@hq.doe.gov

DOE Funding Allocation: $\quad \$ 174 \mathrm{~K}$

Cost Share Funding:

Project Objective: The goal of the project is to collect, disseminate and document the results of exploration, evaluation and development activities carried out, especially in geothermal areas outside the U.S.A., with special emphasis on Enhanced Geothermal System (EGS) project. The information will be useful in the planning and design phase of EGS activities by U.S. Industry. The overall goal is to provide insight on activities carried out by different groups in their efforts to increase the fluid and heat output of given geothermal field by way of hydraulic fracturing and/or re-injection of spent geothermal fluids or of waters of different origin (e.g. treated sewage and surface waters).

Background/Approach: The project had two main thrusts, (1) to collect and disseminate existing data on completed and on-going projects, and (2) to acquire additional information not readily available in publications.

In the open-file technical literature and in company files there is a wealth of information on foreign EGS projects. From these data sets one will be able to learn about the successes and failures during different stages of an EGS program. LBNL will search for existing publications, papers/reports in print and contact technical personnel involved in on-going EGS projects.

Status/Accomplishments: This on-going project has collected a large set of publications on EGS activities, particularly in foreign geothermal fields, continues to search for news on current projects and on plans for future EGS activities. Information has been e-mailed to DOE and U.S. geothermal organizations like the Geothermal Energy Association, the Geothermal Resources Council and DOE contractors.

Reports \& Articles Published in FY 2004: None 


\section{Presentations Made in FY 2004: None}

\section{Planned FY 2005 Milestones:}

1. Technical Review paper to be presented at the 30th Stanford University Workshop on Geothermal Reservoir Engineering (Stanford, California, January 31-February 2, 2005).

2. Updated Summary Review paper to be presented at the GRC 2005 Annual Meeting (Reno, NV, September 25-28, 2005). 


\section{Regional Assessment of Exploration Potential for Geothermal Systems in The Great Basin Using a Geographic Information System (GIS) - Part II}

Reporting Period: FY 2004 (October 1, 2003 to September 30, 2004)

DOE Grant/Contract \#: $\quad$ DE-FG36-02ID14311

Performing Organization: University of Nevada, Reno

Principal Investigator: $\quad$ Mark F. Coolbaugh, (775) 784-1415, mfe@unr.nevada.edu

Collaborating Researchers: Rick Zehner (GBCGE), Gary Raines (USGS), Lisa Shevenell (NBMG), Tim Minor (DRI), Don Sawatzky (UNR), Gary Oppliger (UNR)

DOE HQ Program Manager: Dr. Leland (Roy) Mink, (202) 586-5463, roy.mink@hq.doe.gov

DOE HQ Technical Manager: Raymond Fortuna, (202) 586-1711, raymond.fortuna@hq.doe.gov

DOE Funding Allocation: $\quad \$ 92 \mathrm{~K}$

Cost Share Funding: $\quad 0$

Project Objective: The objective is to generate new exploration targets for both conventional and EGScapable geothermal systems by analyzing regional data in a GIS. Digital geothermal data will be made available to industry and researchers on a web site. Relationships among the data will be explored using spatial statistical analysis, and regional assessments and predictive maps of geothermal potential will be made. Compared to the prior year, in which research focused on Nevada, this year's research has expanded to cover the Great Basin.

Background/Approach: Unlike most geothermal systems in the world, those in the Great Basin usually lack close connections to young silicic volcanism, making them more challenging to locate. A deep water table can also conceal their locations, by making it difficult for thermal fluids to reach the surface where they can be observed as hot springs. Fortunately, many types of evidence provide clues as to where such geothermal systems might be found. These include the location and orientation of Quaternary faults, crustal strain rates derived from GPS stations, heat-flux anomalies, anomalous groundwater chemistry, earthquakes, young volcanism, gravity geophysics, and hydrothermal alteration. A GIS can be used to draw these diverse types of information together, assess correlations, and identify regions of greater exploration potential, based not only on where geologic conditions are favorable, but also on a determination of which areas have not been fully explored.

As this GIS database is made available to industry, researchers, and the public via a web site, the efficiency of exploration and research efforts will be improved. Redundancies of collecting the same data will be reduced, and exploration can be focused into areas having the greatest potential. Much of the data 
useful for predicting "conventional" geothermal systems can also be used for assessing potential EGS resources.

The research has been divided into five primary tasks: 1) Acquisition of digital data; 2) Data analysis with spatial statistics; 3) Identification of new geothermal targets; 4) Posting the geothermal GIS on the web; and, 5) Collaboration to optimize results. Correlations among the data will be explored using weights-ofevidence and other statistical techniques, using ArcView ${ }^{\circledR}$ and/or ArcGIS ${ }^{\circledR}$. Predictive maps of regional geothermal potential will be generated for the Great Basin, and specific locations warranting more detailed, follow-up investigations will be identified. $50 \%$ of the manpower is dedicated to posting geothermal data on the web in a format allowing for selective extraction, overlaying, and viewing of data using ArcExplorer ${ }^{\circledR}$ or similar "freeware", and downloading from an FTP site.

Status/Accomplishments: The following sub-projects were either completed or are in progress:

1. Preliminary map of favorability for undiscovered geothermal systems in Nevada: Regional geothermal favorability maps would be more useful if they could be combined with other indices that measure the "degree of exploration" or "ability of geothermal systems to remain concealed". In other words, some areas may have high geothermal favorability, but extensive drilling may have already identified most geothermal systems; thus few additional systems are likely to be found. Ideal areas for exploration will have high geothermal favorability, few existing drill holes and wells, and a geological setting permissive for concealed geothermal systems (lack of surface expression). A new geothermal map of Nevada was produced (Coolbaugh and Shevenell, 1994) that combined a geothermal favorability index (based on 5 evidence layers and a logistic regression model) with a "degree of exploration" index (based on drilling), and an index measuring the ability of geothermal systems to remain concealed (based on depth to water table). This preliminary map demonstrates how a GIS can be used to help quantify undiscovered geothermal resources in unexplored areas, and some of the methodology employed may prove useful in a more formal reassessment of geothermal resources for the United States, such as may be conducted by the USGS. This preliminary map of undiscovered resource potential for Nevada (Coolbaugh and Shevenell, 2004) has identified a number of areas with good grass-roots potential, including portions of the northern Carson Desert, Pyramid Lake Paiute Reservation, the Smoke Creek Desert, Buffalo Valley, and an alkali flat southeast of Rawhide, Nevada.

2. Preliminary geothermal potential map of the Great Basin: A preliminary geothermal potential map of the Great Basin (see presentation section below, Coolbaugh et al., 2004c) was presented on Nov. $5^{\text {th }}, 2004$ (just after the FY 2004 reporting period) at a geothermal workshop at the Great Basin Center for Geothermal Energy, University of Nevada, Reno. It is mentioned here because much of the preparatory evidence maps and a draft version of the map were produced during FY 2004. This map provides a higher spatial resolution of geothermal favorability for the Great Basin than has been previously available, and it is based on several new types of regional geological and geophysical maps not previously available in a compiled, digital format. These new data layers include: a) crustal strain rates derived from GPS stations (Geoff Blewitt, Corné Kreemer); b) improved resolution heat flux and temperature gradient maps (David Blackwell, Maria Richards); c) long-term crustal strain rates based on slip rates along Quaternary faults (USGS compiled database, Corné Kreemer); d) a combined gravity and topographic elevation gradient map (Gary Oppliger, Catherine Helm-Clark); and e) earthquakes (Aasha Pancha). Information on the map allows the viewer to separately assess the potential for extensional-type geothermal systems and magmatic-heated geothermal systems. The locations of hot springs, temperature gradient wells, Quaternary faults, Quaternary silicic volcanic vents, geothermal power plants, and KGRAs are also shown. This map will be published through the Nevada Bureau of Mines and Geology in FY 2005.

3. Map of depth to water table in the Great Basin: A map of the depth to the water table in basins and valleys of the Great Basin was completed by Tim Minor of the Desert Research Institute, Reno, Nevada, 
in March, 2004. This map can be used to help assess where sub-surface geothermal resources may remain hidden beneath deep water tables, because hot springs are less likely to form when the water table is deep. The map is based on approximately 65,000 well records from the NWIS (National Water Information System) maintained by the USGS. Water depths were interpolated from the well data in 73 separate basins or grouped basins.

4. Structural Controls on Great Basin geothermal systems: A database describing the structural orientation of faults controlling geothermal fluid flow in the Great Basin was compiled and added to the geothermal GIS and analyzed spatially and statistically (Coolbaugh et al., 2003). The resulting patterns are being used to help develop a regional structural model for geothermal systems in the Great Basin (Faulds et al., 2004), in which right-lateral motion along the Walker Lane splays into an evolving set of northeast-striking extensional faults in northwestern Nevada and southeastern Oregon. This regional structural model shows promise for explaining the location of high-temperature geothermal systems in the interior of the Great Basin, and for helping to predict the orientation of fluid-controlling structures in individual geothermal systems.

5. Digital GIS-based field mapping: A fully digital field-based system for mapping geothermal features with pocket PCs (iPAQ) was developed, and put to use mapping geothermal features at the Salt Wells geothermal system in western Nevada (Coolbaugh et al., 2004). Surface geothermal features at the Bradys Hot Springs geothermal system were also mapped, using hand-held GPS units. Silicification at Salt Wells was found to be much more widespread than any previous maps indicated, providing support for the relatively high ( $\sim 175 \mathrm{deg}$. C) geothermometer temperatures found there. This suggests that a relatively high temperature geothermal reservoir may exist at depth, with temperatures higher than those found in shallow drill-holes near the surface. The distribution of surface silicification provides important clues to the location of faults and geological formations that may control geothermal fluid flow. The development of this digital mapping system enables data to be gathered in the field at greater speed and higher accuracy than possible with traditional methods. Because the data, including written field descriptions, is entered in digital format in the field, the time involved with keyboard data entry and digitization into an office GIS is minimized.

6. Development of digital data and interactive map section of the web site of the Great Basin Center for Geothermal Energy: The Great Basin Center web site at http://www.unr.edu/Geothermal was extensively modified during FY 2004 to include new spatial data and expanded features to view and download that data. Late in FY 2003 migration of the first batch of geothermal GIS spatial data to the web site was completed. This included an interactive map using ArcIMS software which facilitates the interactive viewing, selecting, and downloading of spatial data and metadata. The web site was moved over to the Keck Library at UNR in the summer of 2004 when it became apparent that the greater hardware resources there would facilitate continued expansion of the web site with a lower maintenance cost. Once set up at the Keck Library, development of the interactive maps portion of the GBCGE web site intensified and several maps containing Great Basin spatial data were published. In addition, the first of a number of sitespecific geothermal databases developed by INEEL was received for posting on the GBCGE web site; it covers Railroad Valley, and a preliminary interactive map of Railroad Valley became operational end of the second quarter. In mid-summer 2004, a dedicated GIS assistant research scientist (Rick Zehner) was hired, and a major expansion of data on the web site occurred. Pages were added for downloading regional and projects-scale data and metadata, and the amount of spatial data made available on the site vastly increased, including the project-scale geothermal data from Railroad Valley, Nevada provided by INEEL. Additional interlinks were added to improve navigation. Improvements were made to the interactive maps section, and the groundwork was laid to migrate the spatial data to a relational database (ArcSDE) on a fast server, which should significantly improve retrieval times for large grids and images. 


\section{Reports \& Articles Published in FY 2004:}

Coolbaugh, M.F., 2003, The Prediction and Detection of Geothermal Systems at Regional and Local Scales in Nevada using a Geographic Information System, Spatial Statistics, and Thermal Infrared Imagery: Ph.D. dissertation, Reno, Nevada, University of Nevada, Reno, USA, 172 p.

Coolbaugh, M.F. and Shevenell, L.A., 2004, A method for estimating undiscovered geothermal resources in Nevada and the Great Basin: Proceedings, Annual Meeting, Palm Springs, CA, Aug. 29-Sep. 1, 2004, Geothermal Resources Council Transactions, v. 28, p. 13-18.

Coolbaugh, M.F., Sawatzky, D.L., Oppliger, G.L., Minor, T.B., Raines, G.L., Shevenell, L.A., Blewitt, G., and Louie, J.N., 2003, Geothermal GIS coverage of the Great Basin, USA: Defining regional controls and favorable exploration terrains: Proceedings, Annual Meeting, Morelia, Mexico, Oct. 12-15, 2003, Geothermal Resources Council Transactions, v. 27, p. 9-13.

Coolbaugh, M.F., Sladek, C., and Kratt, C., 2004, Digital mapping of structurally controlled geothermal features with GPS units and pocket computers: Proceedings, Annual Meeting, Palm Springs, CA, Aug. 29-Sep. 1, 2004, Geothermal Resources Council Transactions, v. 28, p. 321-325.

Faulds, J.E., Coolbaugh, M., Blewitt, G., and Henry, C.D., 2004, Why is Nevada in hot water? Structural controls and tectonic model of geothermal systems in the northwestern Great Basin: Proceedings, Annual Meeting, Palm Springs, CA, Aug. 29-Sep. 1, 2004, Geothermal Resources Council Transactions, v. 28, p. 649-654.

Shevenell, L., Coolbaugh, M., Faulds, J., Oppliger, G., Calvin, W., Louie, J., Blewitt, G., Kratt, C., Arehart, G., Sladek, C., Lechler, P., and Garside, L., 2004, Accomplishments at the Great Basin Center for Geothermal Energy: Proceedings, Annual Meeting, Palm Springs, CA, Aug. 29-Sep. 1, 2004, Geothermal Resources Council Transactions, v. 28, p. 47-51.

\section{Presentations Made in FY 2004:}

Coolbaugh, M.F. (and Shevenell, L.A.), 2004a, Overview of Nevada's geothermal resources: presentation to the Alaska-Nevada Trade Mission, Reno, Nevada; sponsored by the Nevada Division of Minerals, Peppermill Hotel, Reno, Nevada, June 9-11, 2004.

Coolbaugh, M.F. (and Shevenell, L.A.), 2004b, A method for estimating undiscovered geothermal resources in Nevada and the Great Basin: Basin and Range I Session, Annual Meeting, Palm Springs, CA, Aug. 29-Sep. 1, 2004.

Coolbaugh, M.F., (and Sawatzky, D.L., Oppliger, G.L., Minor, T.B., Raines, G.L., Shevenell, L.A., Blewitt, G., and Louie, J.N.), 2003a, Geothermal GIS coverage of the Great Basin, USA: Defining regional controls and favorable exploration terrains: Basin and Range Session, Annual Meeting, Morelia, Mexico, Oct. 12-15, 2003.

Coolbaugh, M. (and Raines, G., Sawatzky, D., Blewitt, G., Bedell, R., Shevenell, L., Minor, T., and Taranik, J.), 2003b, Predicciónes regiónales para buscar a las aguas termales subterráneas en Nevada USA con análisis espacial por medio de SIG (sistemas de información geográficos); presentation to the Institute for Scientific and Technological Research of San Luis Potosi, San Luis Potosi, Mexico, Oct. 17, 2003. 
Coolbaugh, M. (and Faulds, J., Blewitt, G., and Henry, C.), 2004a, Geothermal Activity: Another Clue for Unraveling Recent Great Basin Tectonics: presentation at GreatBreak Earthscope Workshop; in conjunction with Nevada Seismological Laboratory; Tahoe City, CA., June 21-23, 2004.

Coolbaugh, M.F. (and Sladek, C., and Kratt, C.), 2004b, Digital mapping of structurally controlled geothermal features with GPS units and pocket computers: Exploration - New Fields Session, Annual Meeting, Palm Springs, CA, Aug. 29-Sep. 1, 2004.

Coolbaugh, M.F. (and Zehner, R., Kreemer, K., Blackwell, D., Oppliger, G., Sawatzky, D., Blewitt, G., Pancha, A., Richards, M., Helm-Clark, C., Shevenell, L., Raines, G., Johnson, G., and Minor, T.), 2004c, Preliminary Geothermal Potential Map, Great Basin; presentation at Great Basin Center for Geothermal Energy November 5, 2004 Workshop.

Shevenell, L. (and Coolbaugh, M., Faulds, J., Oppliger, G., Calvin, W., Louie, J., Blewitt, G., Kratt, C., Arehart, G., Sladek, C., Lechler, P., and Garside, L.), 2004, Accomplishments at the Great Basin Center for Geothermal Energy: Basin and Range I Session, Annual Meeting, Palm Springs, CA, Aug. 29-Sep. 1, 2004.

\section{Planned FY 2005 Milestones:}

Creation of 2nd year predictive maps of geothermal potential for Great Basin: 


\section{Characterization and Conceptual Modeling of Magmatically-Heated and Deep-Circulation, High-Temperature Hydrothermal Systems in the Basin and Range and Cordilleran United States}

Reporting Period: FY 2004 (October 1, 2003 to September 30, 2004)

DOE Grant/Contract \#: $\quad$ DE-FG07-00ID13891

Performing Organization: Energy and Geoscience Institute (EGI), University of Utah 423 Wakara Way, Suite 300, Salt Lake City, UT 84108

Principal Investigator: ～Jeffrey B. Hulen, (801) 581-8497, jhulen@egi.utah.edu

Collaborating Researchers: Joseph N. Moore, Gregory D. Nash, Michal Nemcok, Susan J. Lutz (EGI); Denis L. Norton (Geologist/Geochemist, Stanley, ID); Dennis Kaspereit, Brian Berard, Todd van de Putte (CalEnergy Operating Corporation, Calipatria, CA); Stuart Johnson (ORMAT International, Inc., Reno, NV); John Deymonaz (Fish Lake Green Power Corporation, Dyer, NV).

DOE HQ Program Manager: Dr. Leland (Roy) Mink, (202) 586-5463, roy.mink@hq.doe.gov

DOE HQ Technical Manager: Raymond Fortuna, (202) 586-1711, raymond.fortuna@hq.doe.gov

DOE Funding Allocation: $\quad \$ 260 \mathrm{~K}$

Cost Share Funding:

None, although surface and subsurface samples and datasets supplied for this work (without restriction) by the above-named corporations cost several tens of millions of dollars to obtain, and could be considered (although informally) "in-kind" contributions.

Project Objective: (1) Refine and develop new geological, geochemical, geophysical, and numerical (i.e., mathematical) models for well-drilled existing U.S. geothermal fields (carefully chosen as exemplary of broader regions of the west); (2) provide a published record of the results of this work as a means of assisting the domestic geothermal industry to apply these models for risk-reduced and more cost-effective exploration and development; (3) begin transferring knowledge and understanding gained by working on the exemplary study systems to advance and encourage implementation of the Enhanced Geothermal System (EGS) concept; (4) maintain and augment the world-class EGI Geothermal Sample Library as an international repository and study center for geothermal cores, cuttings, and other materials, and as a vital R\&D resource for the entire geothermal community.

Background/Approach: Utilizing a wealth of formerly proprietary subsurface samples and datasets for exemplary high-temperature western U.S. geothermal systems, develop and publish detailed and refined new conceptual and numerical hydrothermal-history models of fundamental scientific import but, more 
importantly, of use to geothermal explorationists and developers as they seek to enhance and expand the nation's vital renewable-energy resource base. Model development encompasses examination and evaluation of drill cuttings and cores along with organization, analysis, and synthesis of surface and subsurface corporate databases. Methods employed in model development include geologic mapping, geologic logging of cores and cuttings, evaluation of geophysical well logs, geochemical analysis, fluidinclusion microthermometry, stable and radiogenic isotope analysis, radiometric age dating, computer modeling of hydrothermal histories and current developmental state of predictive capabilities for locating productive thermal-fluid aquifers or equally permeable zones suitable for reservoir-fluid restoration and pressure support through injection. Begin the process of evaluating the cumulative results of this research project with respect to applications in the emerging discipline of EGS.

Status/Accomplishments: (1) Discovered, and characterized in detail, what would likely be a mineable lead-zinc-silver orebody (if not at temperatures $>200^{\circ} \mathrm{C}$ ) in the southern Salton Sea geothermal field; modeled the means by which these incipient ores (multi-ounce silver per ton, several per cent each lead and zinc) were precipitated in the geothermal system still active here. The characterization and modeling, employing the approach summarized above, yielded new insights into the architecture and evolution of the system, particularly its upper reaches (in this area, to as shallow as $300 \mathrm{~m}$ at $200^{\circ} \mathrm{C}$ ), and provide new constraints for field operators seeking to exploit shallow hot reservoir compartment yielding as much as several hundred thousand $\mathrm{lb} / \mathrm{hr}$ brine plus steam. "Ground preparation" for zinc mineralization involved (and may still be involving) wholesale hydrothermal dissolution of diagenetic calcite cement from fluvial sandstone differing little if any from such units anywhere in the Salton Trough. Taken to extremes, this process, effected by hot, initially acidic reservoir brines, yields loose sand prone to flow copiously on its own into wellbores. Operators planning future hydraulic stimulation of potential reservoir-sand bodies throughout this region must take the positions, geometries, and potential responses of these "flowing sands" carefully into account. Our research at the Salton Sea field in general, and in the region of the oregrade $\mathrm{Pb}-\mathrm{Zn}-\mathrm{Ag}$ mineralization in particular, has greatly improved understanding of these special sand bodies' geometry, extent, texture, and complex diagenetic and hydrothermal evolution.

(2) Confirmed and further characterized a km-scale massive gravity-slide block partially hosting the Dixie Valley geothermal system. On the basis of this find, and on prior work done at the Cove Fort/Sulfurdale (UT) geothermal system by J. Moore (EGI) and others, as well as at the Comstock and Bullfrog epithermal precious-metal deposits (NV), began considering the multiple ways that low-angle faults, landslides, rock avalanches, and allied phenomena in extensional tectonic environments might exert control on deep-circulation geothermal systems in general. This concept was developed into a full-blown proposal for further EGS-oriented, DOE-funded geothermal research following the close of the present grant as of March 31, 2005.

(3) Discovered a hitherto unmapped regional-scale low-angle detachment fault in Oligocene ignimbrites within and around the Emigrant geothermal area in Fish Lake Valley, NV. The detachment fault, which likely predates inception of current geothermal activity here, is actually a tabular zone up to $20 \mathrm{~m}$ thick separating lower-plate non-welded ignimbrite from its upper-plate, densely welded counterpart. Although the upper and lower plates alike are minimally altered and mineralized, the detachment-fault zone itself sheared and slickensided gouge and breccia - is commonly silicified, brightly hematite-stained, and cut by multiple generations of silica, and calcium-manganese carbonate veinlets. The detachment zone was clearly a major regional (at least $25 \mathrm{~km}^{2}$ ) aquifer in a fossil ( $\left.\sim 6 \mathrm{Ma}\right)$ geothermal system here. Analogous features could readily channel thermal-fluid flow in modern deep-circulation systems.

(4) Along those lines, discovered preliminary but compelling evidence that the Steamboat geothermal system (NV) could be developed beneath and partially within an imbricated system of low-angle faults and gravity-slide blocks. The topography of the Steamboat Hills shows a typically hummocky "landslidelike" morphology, and an old open-pit lead-silver mine at the crest of the hills was excavated entirely 
without dynamite or other explosives. Moreover, the producing thermal-fluid aquifers at Steamboat are distinctly subhorizontal features, commonly associated with unusual secondary mineralogies and lithologic assemblages. This hypothesis, which could have major implications for geothermal exploration and development here and throughout the Great Basin, will be tested as part of a second EGS-oriented DOE geothermal grant to the Principal Investigator, said research to commence in the fall of 2004.

Reports \& Articles Published in FY 2004: Much of the fiscal year has been devoted to preparing a series of five culminating manuscripts detailing the results of this four-year research project and to be submitted to a variety of appropriate peer-reviewed journals. Funding complications attending transition of research oversight from DOE-Idaho Falls to DOE-Golden led to delays in this process. The five manuscripts, now nearing completion, will be submitted as detailed in the corresponding FY2003 annual for this project, but instead of the originally suggested dates will be tendered at or near the conclusion of a no-cost extension at the end of March 2005. Working titles and authors for the in-progress papers are as follows:

Hulen, J.B., Norton, D.L., Moore, J.N., Kaspereit, D., and Berard, B., 2005, The Salton Sea geothermal field, California - geologic framework, hydrothermal evolution, and a current conceptual model: To be submitted to Geothermics.

Hulen, J.B., Norton, D.L., and Dutrow, B.L., 2005, Stratigraphic, structural, mechanical,, thermal, and geochemical controls on vein-hosted and stratabound $\mathrm{Pb}-\mathrm{Zn}-\mathrm{Ag}$ mineralization in the southern Salton Sea magmatic-hydrothermal system, Imperial Valley, California: To be submitted to The American Journal of Science.

Hulen, J.B., Moore, J.N., and Norman, D., 2005, A possible "Creede-type" vein-hosted and stratabound argentiferous high-grade lead-zinc deposit in the Salton Sea geothermal field, California: To be submitted to Economic Geology.

Hulen, J.B., Norton, D.L., Moore, J.N., et al., 2005, A generic conceptual model for magmatically-heated, high-temperature geothermal systems in the Great Basin and Cordilleran United States: To be submitted to Geothermics.

Hulen, J.B., and Johnson, S.D., 2005, "Deep-circulation” geothermal systems along high-angle fault systems in the greater Basin and Range province, western United States: To be submitted to Geothermics.

Hulen, J.B., and Berard, B., 2005, A stack of multiple and deeply-buried rhyolite domes, flows and tuffs in the Salton Sea pull-apart zone - Implications for magmatic and hydrothermal evolution of the nascent continental rift southern California: To be submitted to The Journal of Volcanology and Geothermal Research.

The following paper was presented and published in FY 2004:

Hulen, J.B., Norton, D.L., Moore, J.N., and Kaspereit, D., 2004, Epithermal Pb-Zn-Ag mineralization in an active, high-temperature geothermal system, the Salton Sea geothermal field, California: Geothermal Resources Council Transactions (Palm Springs, CA), 10 p.

\section{Presentations Made in FY 2004:}

Hulen, J.B., Norton, D.L., et al., 2004 - See immediately above 
Hulen, J.B., 2004, Structure, stratigraphy, alteration, and mineralization in the Salton Sea geothermal field, California (invited presentation): Utah State University, Distinguished Lecture Series, October 25, 2004.

\section{Planned FY 2005 Milestones:}

Submittal of the first five (of six) manuscripts listed under "Reports and Articles" Submittal of the sixth manuscript so listed above Mar-Apr 05 Delivery of Final Technical Report to DOE 


\section{Improving Exploration Models of \\ Andesite-Hosted Geothermal Systems}

Reporting Period: FY 2004 (October 1, 2003 to September 30, 2004)

DOE Grant/Contract \#: $\quad$ DEFG3600ID13891

Performing Organization: Energy and Geoscience Institute, University of Utah

Principal Investigator: ～Joseph N. Moore, (801) 585-6931, jmoore@egi.utah.edu

Collaborating Researchers: Dr. Rick Allis (Utah Geological Survey), Dr. Patrick Browne (University of Auckland); Dr. Carol Bruton (LLNL); Dr. Bruce Christensen (Institute of Geological and Nuclear Sciences, N.Z.); Mr. Jeffrey Hulen (EGI); Ms. Susan Lutz (EGI); Dr. Dallas Mindenhall (Institute of Geological and Nuclear Sciences, New Zealand); Michal Nemcok (EGI); Dr. David Norman (New Mexico Tech), Mr. Tom Powell (Thermochem, Inc); Dr. James Stimac (Philippine Geothermal Inc. (Unocal))

DOE HQ Program Manager: Dr. Leland (Roy) Mink, (202) 586-5463, roy.mink@hq.doe.gov

DOE HQ Technical Manager: Raymond Fortuna, (202) 586-1711, raymond.fortuna@hq.doe.gov

\section{DOE Funding Allocation:}

Cost Share Funding:

Project Objective: Conceptual models provide the basis for essentially all geothermal exploration and development. They assist in locating and ranking the most prospective geothermal fields, predicting reservoir characteristics and siting the first test holes. These models are continually refined as new information is obtained from drilling and scientific studies. Ultimately these refined models provide the basis for field development and the predication of the geothermal field's long-term behavior.

Background/Approach: This project focuses on geothermal systems associated with active andesitic volcanoes. Volcanic-hosted systems occurring principally along the margins of the Pacific Ocean within the "Pacific ring of fire" host most of the world's high temperature geothermal fields. Within the western U.S., the Cascades hold great potential for the discovery of large geothermal systems, but this province remains largely unexplored. Current drilling and exploration activities at Medicine Lake, CA and Meager Mountain, B.C., nevertheless, provide a clear indication of the significance of this province to the geothermal development.

The studies being conducted address the need for reducing the risks associated with geothermal exploration and development through a better understanding of the fundamental nature and geology of volcanic-hosted resources. The key to developing better exploration models lies in detailed investigations of individual systems and the recognition of both common and dissimilar features. The approach we are 
using is to characterize the petrology, geochemistry and fractures in core and cuttings samples and then integrate these data with measured downhole temperatures and pressures and with the compositions of the reservoir fluids. Our investigations represent cooperative efforts with the Karaha-Bodas Co. LLC (a subsidiary of Caithness Energy) at Karaha-Telaga Bodas, Indonesia and with Philippine Geothermal Inc. (a subsidiary of Unocal) at Bulalo, Philippines.

The research has focused on nine key questions specifically raised by the geothermal industry:

1. Why did these systems form where they did?

2. What surface and subsurface exploration techniques might best be used to find and map these systems?

3. What controls the permeability structure of these systems?

4. How can production and injection wells be located to minimize the risk of failure due to lack of permeability?

5. How does the permeability change as the geothermal system matures?

6. What are the sources of the fluids, how did they evolve, and how can the processes that affected their compositions be recognized?

7. What are the ages of the systems?

$8 \quad$ How and why do vertically extensive vapor-dominated regimes form?

9. What is the influence of magmatic activity on these systems?

Status/Accomplishments: During FY 04, work was completed on the mineral, rock and fracture distributions in 4 core holes and 4 deep rotary drilled production tests (Fig. 1). The samples represent a total footage of more than $16 \mathrm{~km}$. All of the rock and mineral data, downhole temperature measurements, locations of lost circulation zones, deviation surveys, surface fracture distributions and topography has now been mapped in three dimensions using the computer program Petrel.

Previous ${ }^{14} \mathrm{C}$ dating of organic matter contained in lake beds from a depth of $\sim 1000 \mathrm{~m}$ in well T-8 and extensive hydrothermal alteration of the rocks at shallower depths had indicated that the modern geothermal system formed recently, within the last 6000 years. Decompression of the system at $4200 \mathrm{y}$ $\mathrm{BP}$ during formation of the crater on Gallungung Volcano, $5 \mathrm{~km}$ south of Telaga Bodas, triggered the formation of the modern vapor-dominated region. This event was marked by the deposition of chalcedony throughout the field. Meteoric waters are presently entering the system at depth, recharging the system. Water entering from the top of the system consists of various proportions of acidic condensate and rainfall. As the water descends, anhydrite and calcite are deposited, sealing the shallow fractures. This mineral deposition resulted in downward growth of the cap rock and a reduction in shallow permeabilities.

Temperature and mineral distributions suggest the granodiorite, which shows little alteration, provides the heat driving the geothermal system. The overlying rocks consist primarily of tuffaceous deposits and lava flows, ranging mainly from dacite to andesite in composition. Few dikes were encountered in the wells. Although the granodiorite was not penetrated in the southern part of the field, the presence of tourmaline in TLG 1-1 and 2-1 suggests intrusive rocks lie at relatively shallow depths within a few hundred meters 
of the well bottoms. Magnetotelluric surveys define a vertical low resistivity pipe-like feature (vapor chimney in Fig. 1) beneath the lake and a cap of low resisitivity rocks above the steam reservoir. The low resistivities are thought to reflect the presence of clay minerals at shallow depths and hot saline acidic waters at greater depths along the hot margins of the chimney.

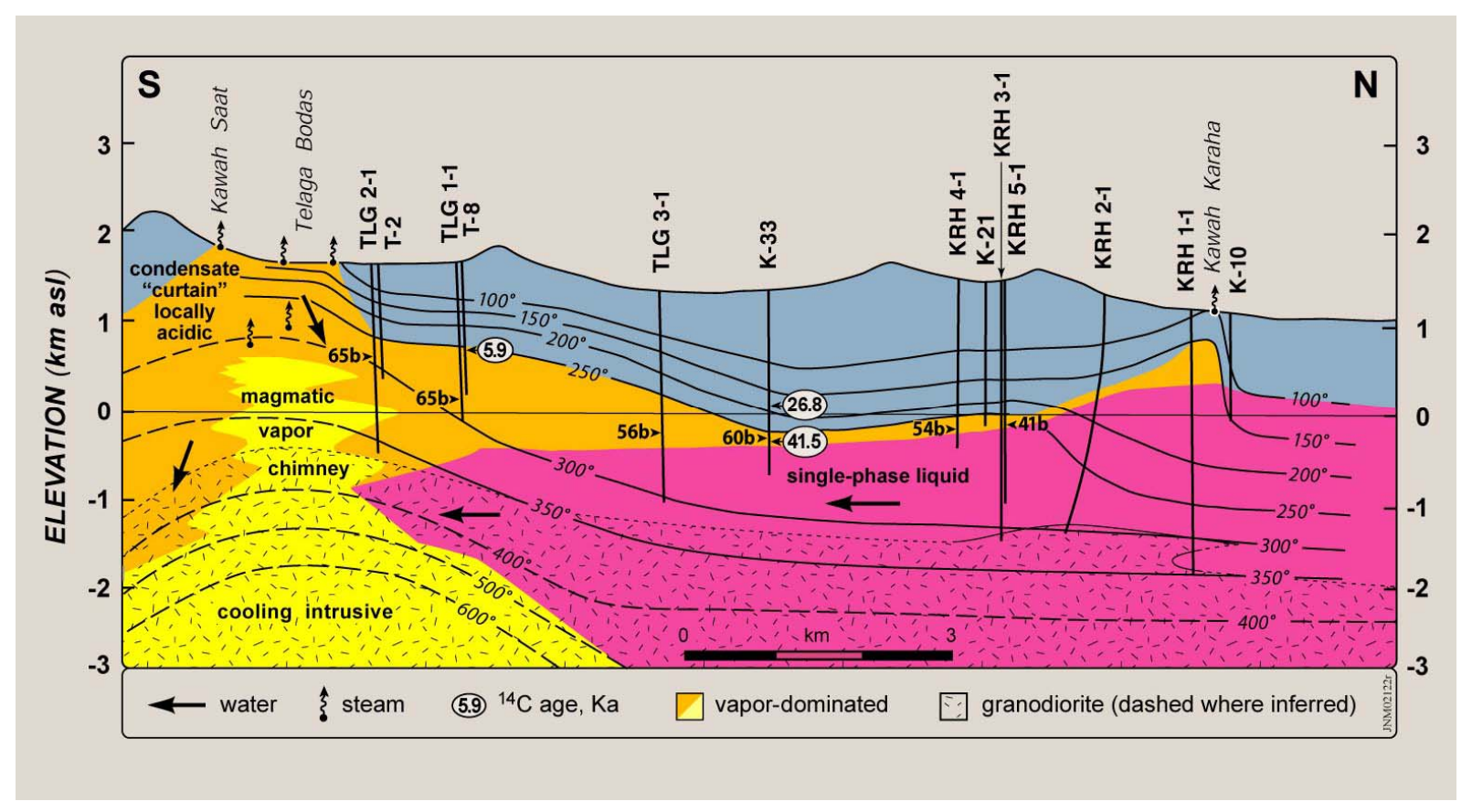

Fig. 1. North-south cross section showing measured temperatures, pressures and main hydrologic regimes. Telaga Bodas is an acidic lake, Kawah Saat and Kawah Karaha are fumarole fields. Wells TLG 2-1, T-2, TLG 1-1, T-8, TLG 3-1, K-33, K-21 and KRH 2-1 have been studied in detail.

Fractures encountered in the core samples where analyzed to determine their kinematics, their relative ages and their relationship to specific stages of mineral deposition. Examination of fracture wall structures show that the orientation of the stress field has remained stable since the fractures formed. This is an important conclusion because it indicates that fault kinematics in the geothermal field can be predicted from present-day stress data and fracture geometries. We have recognized a systematic change in the local stress regime with depth. Normal faults, tensile fractures, sinistral and dextral strike-slip faults and oblique sinistral and dextral strike-slip faults with a normal component of displacement occur in the caprock. In contrast, normal and tensile fractures are dominant in the reservoir. The change from a strike slip to extensional stress regime reflects the increase in overburden thickness, which causes a change in the principal stress magnitudes but not in their orientation. Extensional fractures improve reservoir quality. Thus the stress regime appears to play a strong role in reservoir behavior.

Productive and nonproductive fractures can be distinguished on the basis of their calculated tendencies to slip and dilate and on their ability to withstand resolved normal stresses. These characteristics provide information on a fracture's tendency to reactivate, its ability to transmit fluids and its response to hydrofracturing. The majority of the productive fractures were among those that were most prone to dilate or slip. The best productive fractures are tensile fractures and normal faults with strikes roughly perpendicular to the minimum compressive stress, which trends $98^{\circ}$. Ideally oriented fractures have strikes of $\sim 8^{\circ}$ and steep dips. These fractures have a tendency to achieve maximum possible apertures. However, there is no apparent relationship between fracture density and fluid entries. Fracture densities of 5 per $10 \mathrm{~m}$ characterize both productive and nonproductive zones. 


\section{Reports \& Articles Published in FY 2004:}

Hulen, J., Norton, D., Moore, J. and Kasperit, D., 2004. Epithermal vein-hosted and stratbound Pb-Zn mineralization in an active hydrothermal system: The southern Salton Sea Geothermal field, California: GRC Transactions, v. 28, p. 415-424.

Lynne, B.Y., Campbell, K.A., Moore, J.N. and Browne, P.R.L., 2004, Rapid diagenesis of siliceous sinter (opal-A to quartz) over 1900 years at Opal Mound, Roosevelt Hot Springs, Utah, U.S.A.: New Zealand Geothermal Workshop, v. 26, in press.

Moore, J., Bruton, C. and Powell, T., 2004, Wairakite: A potential indicator of fluid mixing: GRC Transactions, v. 28, 495-498.

Nemčok, M., Moore, J. N., Allis, R., McCulloch, J., 2004, Fracture development within a stratovolcano: the Karaha-Telaga Bodas geothermal field, Java volcanic arc. In: The initiation, propagation, and arrest of joints and other fractures (Engelder, T. and Cosgrove, J. eds.): Geological Society of London, Special Publication 231, p. 223-242.

Norman, D. and Moore, J., 2004, Evidence for deep flowing cool recharge solutions at the NE part of the Coso geothermal field from clay minerals and fluid inclusion gas analysis: GRC Transactions, v. 28, p. 669-674.

Wannamaker, P., Raharjo, I., Moore, J. and Allis, R., 2004, Magnetotelluric resistivity section and physical implications through the Telaga Bodas magmatic geothermal system, Indonesia: GRC Transactions, v. 28, p. 369-371.

Presentations Made in FY 2004: Papers listed in the preceding section were presented at the annual meetings of the Geothermal Resources Council and the Stanford Reservoir Engineering Conference.

\section{Planned FY 2005 Milestones:}

Complete fracture analysis integrating surface and subsurface data 


\section{Targeting of Potential Geothermal Resources in the Great Basin from Regional to Basin-Scale Relationships Between Geodetic Strain and Geological Structures}

Reporting Period: FY 2004 (October 1, 2003 to September 30, 2004)

DOE Grant/Contract \#: $\quad$ DE-FG36-02ID14311 (AOP number is 1.1.4.8)

Performing Organization: University of Nevada, Reno,

Mail Stop 178

Reno NV 89557

Principal Investigator: $\quad$ Geoffrey Blewitt, (775) 784-6691 ext. 171, gblewitt@unr.edu

Collaborating Researchers: None

DOE HQ Program Manager: Dr. Leland (Roy) Mink, (202) 586-5463, roy.mink@hq.doe.gov

DOE HQ Technical Manager: Raymond Fortuna, (202) 586-1711, raymond.fortuna@hq.doe.gov

DOE Funding Allocation: $\quad \$ 125 \mathrm{~K}$

Cost Share Funding: $\quad \$ 26 \mathrm{~K}$

Project Objective: The objectives of this project are to assess the use of inter-seismic crustal strain rates derived from GPS-stations as an exploration tool for non-magmatic high-temperature geothermal systems, and to use this technique to target potential geothermal resources in the Great Basin. Two potential target areas were identified in year one (FY03) by regional-scale studies: (1) the area spanned by Buffalo Valley, Jersey Valley, Pleasant Valley, which is currently unexploited, and (2) as control areas, the Brady's/Desert Peak Hot Springs geothermal area which last year was investigated using geophysics and structural tectonics methods by the Great Basin Center for Geothermal Energy (P.I., Jim Faulds), and the Dixie Valley geothermal production area. An augmentation of FY04 funding (\$40K) also allowed for the Northern Walker Lane to be studied spanning the region from the Sierra Nevada to the Brady's/Desert Peak area. As reported below, this task has covered far more area than originally proposed at no additional cost to this project; therefore, we hereby revise our objectives upwards to produce a high resolution map of strain covering the entire region from the Sierra Nevada to Battle Mountain at the northeastern extreme, and to Austin at the southeastern extreme.

Background/Approach: It is well known that geothermal systems in the Great Basin are associated with recent or active faults. However not all young faults in the Great Basin have been mapped because many of them are covered by Quaternary sediments, and fault offsets are not always evident. Hot springs will not always reveal the locations of underlying geothermal systems along these faults when the water table is deep or when laterally flowing aquifers are present. These basin-scale studies would allow for identification and characterization of active faults, in terms of strain rate and style of strain. For example, 
there is already a significant indication that trans-tensional systems (such as step-overs in strike-slip faults) are key potential target areas in non-magmatic settings in the Basin and Range.

Our approach is to use GPS. The GPS positioning measurements are required to have sufficient accuracy $(\sim 1 \mathrm{~mm})$ and be of sufficient density (station distances of $\sim 15 \mathrm{~km})$ to resolve the strain field associated with basin-scale structures. To meet the accuracy requirement, for FY04 we installed a new network of permanent GPS monuments attached to bedrock or volcanic outcrops, which are re-visited several times per year, providing several weeks of data from each site occupation. The monuments are custom designed to allow for easy re-mounting of the GPS antenna on each site visit to precisely the same physical location ( $<<1 \mathrm{~mm}$ tolerance). GPS equipment (purchased, tested, and customized under this grant) is transported by a field technician between sites to cover the entire station network, by 1-2 fieldwork days per week on average. Every quarter, the P.I. produces a time series of daily station positions accurate to millimeters. After 1.5 years of operation (end of FY05) the time series will be sufficiently long that a preliminary estimate of station velocities is possible, which will allow us to assess the level of error versus that predicted by the specification model. After 2.5 years of operation (end of FY06), the velocity estimates will be sufficiently precise to use them as input to a strain-rate model, and infer strain-rates on active quaternary faults. A spatial correlation study will then allow us to infer the characteristics of the strain field that indicate favorable conditions for geothermal fields, which could be used (along with other indicators) to enhance future prospecting.

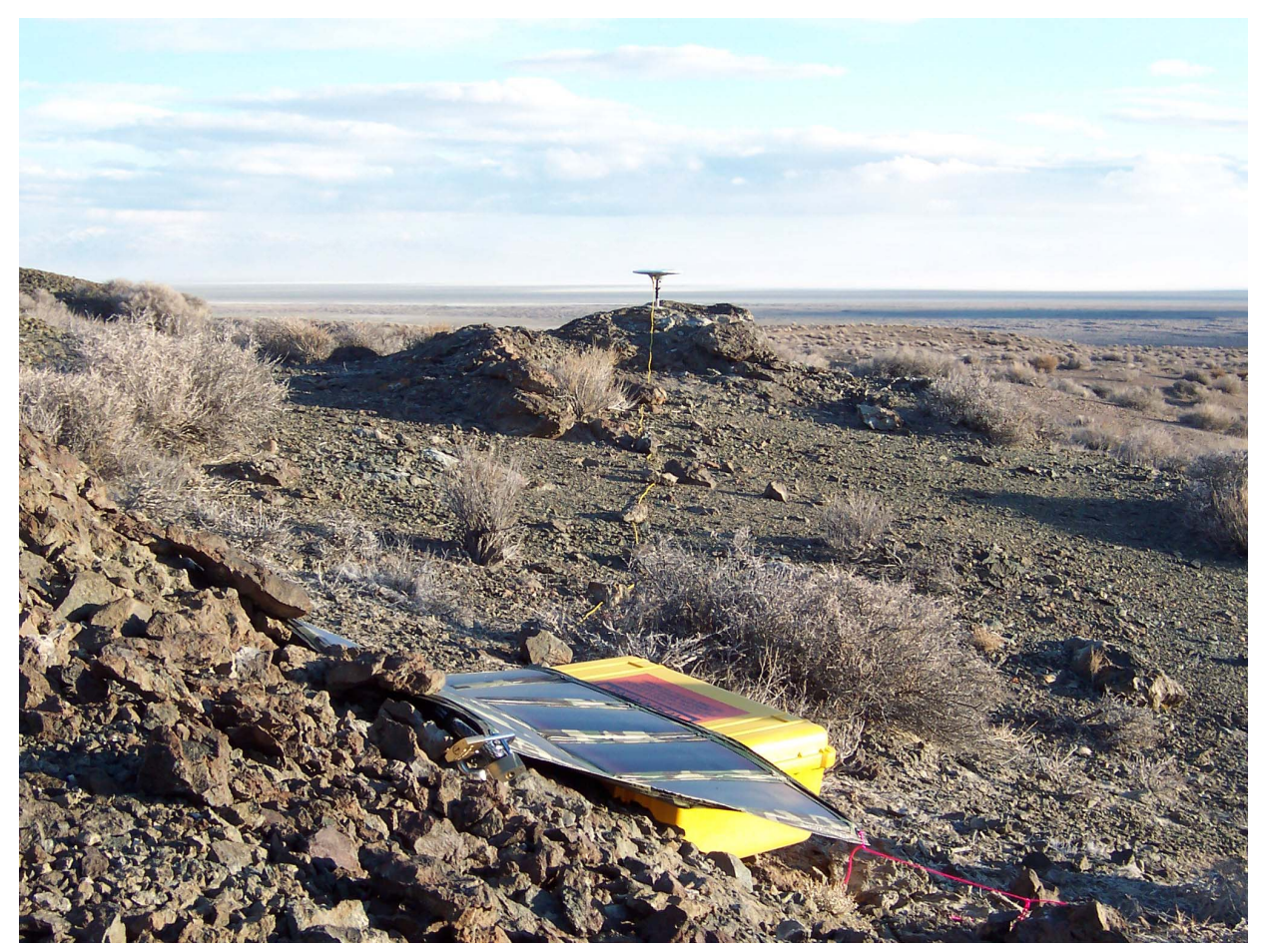

Figure 1: GPS station "MOPU” installed on the northwestern edge of the Carson sink, northern Nevada. The antenna can be quick-released from a permanent stainless steel monument. The yellow box contains the GPS receiver and controller and is padlocked to an eyebolt epoxied into the rock for security. The flexible 30-W solar panel charges an $80 \mathrm{~A}$-hr battery, allowing for continuous operation, even if covered by snow for up to 10 days.

Status/Accomplishments: In FY04, this task exceeded expectations in that a total of 56 GPS stations were established covering a much broader area than originally proposed, at no additional cost (as compared to the 20-40 stations originally proposed). This included additional coverage to the south of the 
Carson Sink, Edwards Creek Valley, Antelope Valley (near Austin), Granite Springs Valley, and the Lower and Upper Valleys of the Humboldt River (near Lovelock). The stations were monitored by 34 GPS receivers (19 of which were funded by this project, plus 15 by other funds not formally included in the cost sharing) that were rotated to cover all sites, so that each station records data regularly throughout the year. This newly installed network was named "MAGNET," which stands for "Mobile Array of GPS for NEvada Transtension." Transtension is the style of strain in the Earth's crust that we have so far identified as "candidate" positive indicator of geothermal fields, and is characterized by the sum of shear strain (corresponding to solid body deformation) and dilatational strain (corresponding to expansion in surface area).

For purposes of initial error assessment we have successfully produced our first time-series solutions for GPS station positions, which indicate that weekly-averaged positions are indeed repeatable at the millimeter level, and that we are on track to deliver accurate strain maps by FY06. Also in FY04, other already-established GPS stations in the region were analyzed and the results were used to update our strain-rate map originally produced in FY03. This updated strain-rate solution was then used as part of a comprehensive geothermal map of the Great Basin that was first revealed at a Geothermal Conference held in Reno, October 2005 (see references below).

At the time of reporting (December 2004), more than 5,000 files of 24-hour continuous GPS station data have been collected, organized, processed, and reduced to station position time series from the MAGNET network. In FY05 we plan to continue operation of the network, and before the end of the year produce a preliminary station velocity solution for the entire network. These velocities will be used to compute a preliminary strain rate tensor map and to assess the level of errors. By the end of FY06, we predict that the strain rates will be of sufficient accuracy and spatial resolution to be at the level required to discriminate hypotheses from each test area on the relationship between crustal strain and non-magmatic geothermal potential, and to indicate new promising areas for geothermal exploration.

\section{Reports \& Articles Published in FY 2004:}

Faulds, J.E., M. Coolbaugh, G. Blewitt, and C.D. Henry, Why is Nevada in hot water? Structural controls and tectonic model of geothermal systems in the northwestern Great Basin: Geothermal Resources Council Transactions, p. 649-654., 2004.

Shevenell, L., M. Coolbaugh, J. Faulds, G. Oppliger, W. Calvin, J. Louie, G. Blewitt, C. Kratt, G. Arehart, C. Sladek, P. Lechler, and L. Garside, Accomplishments at the Great Basin Center for Geothermal Energy. Geothermal Resources Council Transactions, v. 28: 47-52, 2004.

Shevenell, L., Arehart, G., Blewitt, G., Calvin, W., Coolbaugh, M., Faulds, J., Lechler, P., Louie, J., Oppliger, G., Expanding geothermal resource utilization in Nevada, 2003 Annual Report, Department of Energy, Jan 2004.

Shevenell, L., Arehart, G., Blewitt, G., Calvin, W., Coolbaugh, M., Faulds, J., Lechler, P., Louie, J., Oppliger, G., Expanding geothermal resource utilization in Nevada, Quarterly Progress Report, Department of Energy, Jan 2004.

Shevenell, L., Arehart, G., Blewitt, G., Calvin, W., Coolbaugh, M., Faulds, J., Lechler, P., Louie, J., Oppliger, G., Expanding geothermal resource utilization in Nevada, Quarterly Progress Report,

Department of Energy, Apr 2004. 
Shevenell, L., Arehart, G., Blewitt, G., Calvin, W., Coolbaugh, M., Faulds, J., Lechler, P., Louie, J., Oppliger, G., Expanding geothermal resource utilization in Nevada, Quarterly Progress Report, Department of Energy, Jul 2004.

News article in "Nevada Geothermal Update," Nevada Division of Minerals, Mar 2004.

News article in "Nevada Geothermal Update,” Nevada Division of Minerals, Sep 2004.

DOE's Geoscience news release on new GPS network for geothermal research, Feb 2004.

\section{Presentations Made in FY 2004:}

Blewitt G., Semi-permanent GPS station design for high resolution, high accuracy strain monitoring in the Basin and Range, poster presentation at the UNAVCO 2004 Annual Meeting, p. 23, Boulder, Colorado, held Feb 25-27,2004.

Blewitt, G., M. Coolbaugh, W. Holt, R. Bennett, J. Davis, A map of current tensor strain rate in the Basin and Range from GPS, poster presentation at EarthScope GreatBREAK Workshop, Tahoe City, California, held June 21-23, 2004.

Blewitt, G., Geodesy in the Great Basin: Highlights and Challenges, invited plenary talk at the EarthScope GreatBREAK Workshop, Tahoe City, California, held June 21-23, 2004.

Blewitt, G., "GPS and strain analysis at UNR," presented to Department of Energy Yucca Mountain Project, Summerlin, NV, May 2004.

Coolbaugh, M.F., J. Faulds, G. Blewitt, C. Henry, Geothermal Activity: Another clue for unraveling recent Great Basin tectonics, EarthScope GreatBREAK Workshop Abstracts, Tahoe City, California, held June 21-23, 2004.

Faulds, J.E., M. Coolbaugh, G. Blewitt, and C.D. Henry, Why is Nevada in hot water? Structural controls and tectonic model of geothermal systems in the northwestern Great Basin: talk presented at the Geothermal Resources Council Conference, Palm Springs, Sep 2004.

Faulds, J., M. Coolbaugh, C. Henry, and G. Blewitt, Why is Nevada in hot water? Relations between plate boundary motions, the Walker Lane, and geothermal activity in the northern Great Basin, Geological Society of America Abstracts with Programs, Vol. 36, No. 4, p. 27, 2004.

Faulds, J., C. Henry, G. Blewitt, M. Coolbaugh, The northern Walker Lane, northwestern Great Basin: A youthful part of the North American-Pacific transform margin, EarthScope GreatBREAK Workshop Abstracts, Tahoe City, California, held June 21-23, 2004.

Kreemer, C., G. Blewitt, W.C. Hammond, and M.F. Coolbaugh, A new strain rate model for the Great Basin and its application to tectonic and geodynamic studies, Eos Trans., AGU 85(47), Fall Meet. Suppl., Abstract G31D-06 INVITED, 2004.

Hammond, W.C., W. Thatcher, and G. Blewitt, Crustal deformation across the Sierra Nevada-northern Walker Lane, Basin and Range transition, Western United States measured with GPS, 2000-2004, Eos Trans., AGU 85(47), Fall Meet. Suppl., Abstract G31D-07, 2004. 
Shevenell, L., M. Coolbaugh, J. Faulds, G. Oppliger, W. Calvin, J. Louie, G. Blewitt, C. Kratt, G. Arehart, C. Sladek, P. Lechler, and L. Garside, Accomplishments at the Great Basin Center for Geothermal Energy, talk presented at the Geothermal Resources Council Conference, Palm Springs, Sep 2004.

Planned FY 2005 Milestones:

Produce initial velocity solution for the MAGNET network Sep 05

Updated strain-rate map of the Great Basin showing style and magnitude of strain Sep 05

Publication of results at Geothermal Resource Council Conference

Sep 05 


\section{Dating of Young Igneous Rocks Associated with Geothermal Systems in the Great Basin}

Reporting Period: FY 2004 (October 1, 2003 to September 30, 2004)

DOE Grant/Contract \#: $\quad$ DE-FG36-02ID14311

Performing Organization: University of Nevada, Reno

Principal Investigators: $\quad$ Greg B. Arehart, Mark F. Coolbaugh, (775) 784-1415, arehart@unr.edu

Collaborating Researchers: Terry Spell (UNLV)

DOE HQ Program Manager: Dr. Leland (Roy) Mink, (202) 586-5463, roy.mink@hq.doe.gov

DOE HQ Technical Manager: Raymond Fortuna, (202) 586-1711, raymond.fortuna@hq.doe.gov

DOE Funding Allocation: $\$ 71 \mathrm{~K}$

Cost Share Funding:

Project Objective: The objective is to examine in more detail the temporal relationships between geothermal systems and young spatially-associated igneous rocks. There are a number of active geothermal systems in the interior and on the margins of the Great Basin that occur near mafic extrusive igneous rocks, as elucidated from county geological maps of Nevada and Utah as well as from personal observations. The goal of this research is that of acquiring and dating samples of these young igneous rocks. We have focused on known productive or potentially-productive systems because subsurface data are available on these areas and, therefore, we have a better knowledge of their geology and geochemistry.

Background/Approach: The vast majority of producing geothermal systems (i.e., those that produce electrical power) around the world are associated with active magmatic provinces; heat associated with recent magmatic activity is thought to drive fluid convection. In contrast, the geothermal systems in the Great Basin appear to be of two types: magmatic-driven (similar to most other geothermal systems globally) and extensional (driven by deep circulation in a region of high heat flow). Magmatic-driven systems in the Great Basin can be identified by their geochemical signature (Arehart et al., 2002) and their spatial association with young rhyolites. These systems appear to be localized on the margins of the Great Basin. In contrast, extensional systems occur primarily in the interior of the Great Basin, and do not appear to be associated with young rhyolites. However, extensional systems do correlate with the presence of young basaltic volcanism 1.5 Ma or less in age (Coolbaugh et. al, 2002). Much of this basaltic volcanism consists of volumetrically minor cinder cones and lavas whose presence is thought to indicate regions of active extensional tectonism: such tectonism is a favorable environment for the formation of high-temperature geothermal systems. 
It has been shown empirically in the Great Basin and elsewhere that magmatic-type systems have a higher temperature gradient with depth and are, therefore, potentially more productive targets. Consequently, the presence of young $(<1.5 \mathrm{Ma})$ siliceous volcanic rocks should be considered a positive indicator of the exploration potential of geothermal systems. The presence of young basaltic rocks $(<1.5 \mathrm{Ma})$ is considered a positive indicator for the occurrence of extensional geothermal systems, as these basaltic rocks may utilize similar pathways in extended or extending crust.

\title{
Status/Accomplishments:
}

We have collected $92 \%$ of the proposed samples ( 22 of 24 ) even though we are only into the third month of the second year of funding, considering the three-month delay in receiving year-two funds. The field samples from year-one collection were submitted over nine months ago for radioisotopic dating by the laboratory of Dr. Terry Spell at the University of Nevada, Las Vegas. Analytical work (dating of firstround samples) has been delayed at UNLV because of a sample backlog in that laboratory and some apparent confusion at the reactor. Following is the text of an email received from Terry Spell on November 29, 2004. As of this writing (Dec 20), we have still not received any geochronological data from the laboratory.

\begin{abstract}
Hello Greg,
Below are Kathy's comments regarding your samples in the lab. In short, all but 3 of those should be analyzed before everyone heads out for the holidays (about 4 weeks from now). 3 of them were in a tube that was returned from the reactor unirradiated, and will go back out in the next package this week - those will be run in January. Apologies for the time these have taken, our sample processing backlog just exploded about a year ago and we still have not caught up. It didn't help that our furnace was down for repairs for about a month recently.
\end{abstract}

Terry

Because of these delays, we have not yet received any analytical data results. However, we expect to be able to make up these delays in during 2005 so that all results will be obtained and the evaluation report completed by the end of the second year of funding, which has been extended through the end of September, 2005. We are considering whether to submit samples from year-two sampling to another lab and are contacting other labs to determine whether a more timely turnaround is possible.

Nevertheless, our field investigations have identified several interesting volcanic occurrences of potential quaternary age that have not been fully documented or dated. If some of these occurrences prove to be of Quaternary age, they could significantly expand the distribution of known young volcanic rocks in the interior of the Great Basin, and increase the apparent correlation between those young rocks and hightemperature geothermal activity. Those new occurrences include a previously undated basalt exposure at Lone Rock in the northern Carson Desert, a potential young maar eruption crater north of the Stillwater geothermal field, and a very fresh unaltered rhyolite pumice deposit northwest of Soda Lake. In addition, a series of samples have been taken in the Roosevelt, UT area to assess a possibly extensive zone of thermal age resetting in the Mineral Mountains batholith. Such mineral resetting has not been fully investigated and could be used to help identify new geothermal centers that have no corresponding surface eruption features. 


\section{Reports \& Articles Published in FY 2004:}

Shevenell, L., Coolbaugh, M., Faulds, J., Oppliger, G., Calvin, W., Louie, J., Blewitt, G., Kratt, C., Arehart, G., Sladek, C., Lechler, P., and Garside, L., 2004, Accomplishments at the Great Basin Center for Geothermal Energy: Proceedings, Annual Meeting, Palm Springs, CA, Aug. 29-Sep. 1, 2004, Geothermal Resources Council Transactions, v. 28, p. 47-51.

\section{Presentations Made in FY 2004:}

Shevenell, L. (Coolbaugh, M., Faulds, J., Oppliger, G., Calvin, W., Louie, J., Blewitt, G., Kratt, C., Arehart, G., Sladek, C., Lechler, P., and Garside, L.), 2004, Accomplishments at the Great Basin Center for Geothermal Energy: Basin and Range I Session, Annual Meeting, Palm Springs, CA, Aug. 29-Sep. 1, 2004.

\section{Planned FY 2005 Milestones:}

Completion of sample collection

March 05

Completion of mineral separates for group 2

May 05

Completion of dating measurements for group 2

July 05

Posting of dates on GBC website

August 05

Completion of final report discussing research results September 05

Submit paper for publication December 05 


\section{ENHANCED GEOTHERMAL SYSTEMS}




\section{Numerical Tools for Resource Management - TetGeo}

Reporting Period: FY 2004 (October 1, 2003 to September 30, 2004)

DOE Grant/Contract \#:

Performing Organization: Idaho National Engineering and Environmental Laboratory Applied Earth Sciences PO Box 1625, Idaho Falls, ID 83415-2107

Principal Investigator: $\quad$ G. Michael Shook, (208) 526-6945, Mike.Shook@inl.gov

Collaborating Researchers: Dr. John Doherty, Watermark Numerical Computing John Pritchett, SAIC

DOE HQ Program Manager: Dr. Leland (Roy) Mink, (202) 586-5463,roy.mink@hq.doe.gov

DOE HQ Technical Manager: Dr. Allan Jelacic, (202) 586-6054, allan.jelacic@ee.doe.gov

DOE Funding Allocation: $\quad \$ 250 \mathrm{~K}$

Cost Share Funding: $\quad \$ 75 \mathrm{~K}$

Project Objective: The objective of this project is to develop a suite of new numerical tools for use in geothermal reservoir management. In particular, we are developing numerical models and interfaces that couple the geothermal reservoir model TETRAD with SAIC's geophysical codes and the inverse model PEST. The various models' capabilities are summarized below.

- Tet $^{-1}$ is a Parameter Estimation (aka, inverse model or automatic history match) version of TETRAD. It is designed to estimate reservoir parameters from inverse modeling of reservoir data alone.

- TetGeo is a version of TETRAD which is coupled to SAIC's geophysical models. TetGeo writes output files that are subsequently used as input to the geophysical models. The added model output adds constraints to the history match process (i.e., use production history and geophysical survey results to estimate reservoir parameters).

- $\quad \mathrm{TetGeo}^{-1}$ will be an inverse version of TetGeo, and will be completed by mid-FY05. This inverse model uses both reservoir and geophysical models in the parameter estimation process. The model will be tested for use in both reservoir characterization and field management, and exploration.

Because TETRAD is used by all domestic geothermal companies, it was selected for use in this project. It should be noted, however, that, as most of the software developed herein only interfaces with TETRAD (i.e., is not imbedded), adding these new tools to other geothermal models is straightforward.

Background/Approach: The approach taken in this project is to enhance the suite of numerical tools available to the geothermal industry for reservoir management. As the most widely used reservoir model by the domestic geothermal industry, TETRAD was identified as the reservoir model core. New software 
and program interfaces are being written to couple TETRAD to other codes in order to enhance the effectiveness of reservoir modeling. Specific programs are discussed in more detail below.

The public domain inverse model PEST (Parameter ESTimation) was identified as the most appropriate inverse engine to couple to TETRAD. Because TETRAD is proprietary, care must be taken to preserve the developer's interest. PEST operates only on input/output files, modifying input parameters as it minimizes the differences between model output and field observations. PEST furthermore treats the forward model (TETRAD in this case) in a "batch mode" sense. Two advantages come from this. First, the proprietary nature of the code is preserved. More importantly, however, the method is readily expanded to include numerous forward models (e.g., TETRAD followed by geophysical models). The flexibility of the PEST code, and the ability to add more model instructions, make it an ideal candidate for this project.

Interfaces have been written to generate an output file from a TETRAD run that is subsequently used as input to SAIC's geophysical models. Conceptually, this "post processing" is similar to plotting production histories from a reservoir model to compare the simulated history with the observed. In reality, of course, the geophysical models are appreciably more complex than simple post processing implies. The models that are being coupled to TETRAD include Microgravity, DC Resistivity, SP, and MT codes (Pritchett, 2000). This is the only task that requires modifications to TETRAD in order to generate the output file.

Given the discussion above regarding the flexibility of the inverse engine PEST and the ability to generate multiple sets of field observations by running both reservoir and geophysical models, the logical next step of this project is to create an inverse model that operates on both reservoir and geophysics data. Because of the care taken in developing Tet-1 (most importantly the flexibility and freedom to include multiple forward models) and the existence of a coupled reservoir + geophysics code (TetGeo), writing this model, TetGeo-1, is expected to be a relatively straightforward matter. It was started in FY04, and will be completed in FY05. Should additional geophysical models become available (e.g., seismic models), further code modifications to TETRAD will be performed to include these new capabilities. The model will be available for field testing by interested operators in mid-FY05.

Status/Accomplishments: All software and program interfaces have been completed for creating Tet ${ }^{-1}$ and TetGeo. The goal of the coding was to maintain the flexibility of TETRAD input structure - for example, permeability can be defined in more than five different ways - while still ensuring invariant input formats required by Tet ${ }^{-1}$. Version 1 of Tet $^{-1}$ assumed parameter constancy over some region. Version 2 of Tet-1 allows this "regional constancy" as well, but adds geostatistical methods for parameter estimation. For example, a permeability field can be estimated from a set of user-defined "pilot points," the geostatistical description of the field (e.g., an autocorrelogram), and kriging. Regularization of the field ensures that heterogeneity is introduced only as needed to achieve a match between observed and modeled behavior (Doherty, 2004).

We have also begun evaluating the use of data interpretation in the inversion process. Preceding analyses or direct measurements on site can be included as "prior information," that act as further constraints on the parameter estimation process. For example, a tracer test might be used to estimate permeability in a given field. However, we can also use test interpretations (e.g., mean residence times, flow and storage geometries, etc.) as additional observations. While this improves the ratio of observations-to-estimated parameters, there is nevertheless a strong tendency to attempt to estimate more parameters than are supported by the number of independent observations. This can be overcome in PEST through the use of Singular Value Decomposition (Doherty, 2004). In SVD mode PEST estimates only as many parameters as is supported by the data. Another crucial feature in PEST is the linear analysis of predictive uncertainty. It is this tool that will allow us to achieve our ultimate goal: to determine specifically which tools (and related interrogation volumes) best reduce uncertainty in the conceptual model and model 
predictions, which offered redundant information, and which offer little or no return on investment. These results will allow for succinct and robust field characterization for responsible field management.

$\mathrm{Tet}^{-1}$ was field-tested using a tracer test conducted by INEEL scientists. Tracer was injected in three wells, over 3 distinct intervals, and extracted from 18 extraction wells. Very limited estimates of permeability and porosity were available for the initial parameter estimates. The geostatistical properties of the aquifer were likewise unknown. We made a series of inverse model runs that considered different statistical properties of the aquifer (correlation length, variance in permeability, etc.), and achieved an excellent match of much of the data. The two figures below are examples of what were considered "good" matches (Figure 1) vs. "bad" matches (Figure 2). The analysis suggests the aquifer is highly heterogeneous with a very short correlation length. We continue using the dataset if FY05 to study the effect of adding test interpretation as prior information as discussed above.

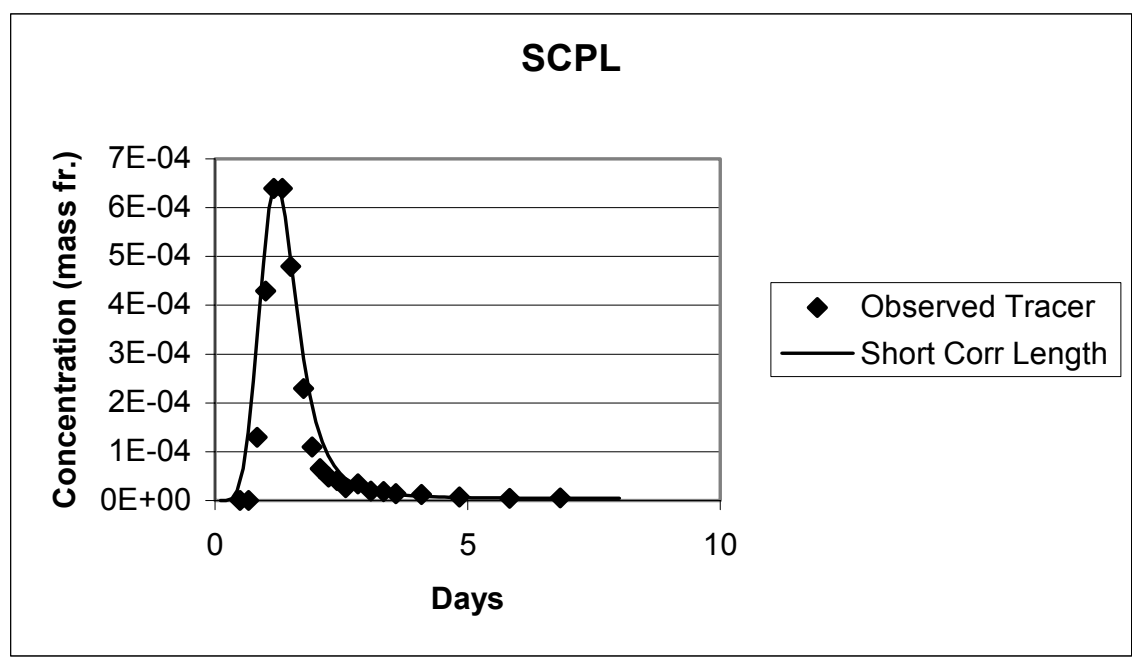

Figure 1. History match of Well SCPL using Tet ${ }^{-1}$. This match is excellent.

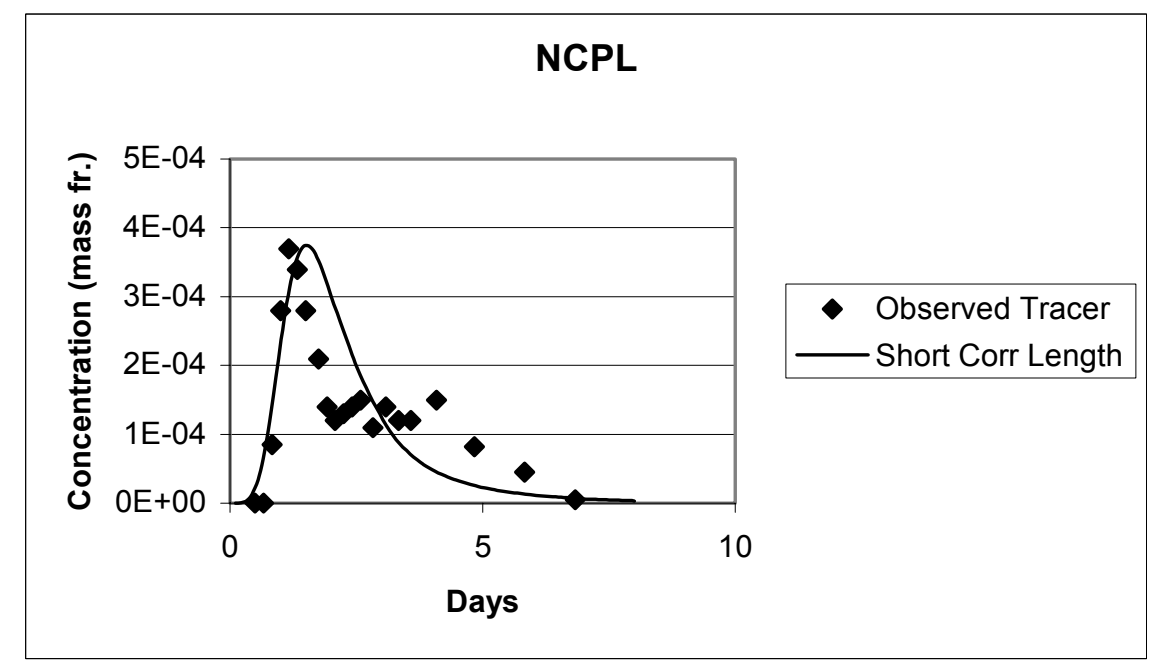

Figure 2. History match of Well NCPL using Tet ${ }^{-1}$. While not a bad match of tracer data, this well is among the worst - likely due to the scatter in the observed data itself. 
The geophysical models were also used in FY04 in an exploration test. A "hidden" geothermal reservoir with Basin and Range characteristics was first simulated in the native state. The resource was hidden in the sense that no surface manifestation was associated with the reservoir. Using the modeled, native state properties of the reservoir, the geophysical codes were used to determine the feasibility of finding such hidden resources with electrical methods (Pritchett, 2004). Results of the study show that, for hidden resources, low frequency MT and SP surveys provide direct evidence of a circulating geothermal system. Results of such surveys can be combined with other field information using inverse modeling (e.g., with TetGeo-1) to characterize the subsurface quantitatively. The cost of such a study (including the field surveys) is likely less than the cost of a single deep discovery well.

Version 2 of Tet $^{-1}$ was released in FY04 to interested geothermal operators (Unocal, Caithness, and CalEnergy all have copies of the code). Reports on the use of geophysics for exploration are on the INEEL web page. New versions of $\mathrm{Tet}^{-1}$ and $\mathrm{TetGeo}^{-1}$ will be distributed to interested users, and training will be made available (pending industry requests).

\section{Reports \& Articles Published in FY 2004:}

Shook, G.M. and J.E. Doherty, 2004, “Tet ${ }^{-1}$ v.2: New features and capabilities," INEEL report, distributed to Tet-1 users.

Pritchett, J.W., July 2004, "Finding Hidden Geothermal Resources in the Basin and Range using Electrical Survey Techniques, a Feasibility Study," SAIC-04/1031 under contract to INEEL.

\section{Presentations Made in FY 2004:}

Shook, G.M., March 2004, "INEEL Geoscience Activities," Geothermal Program Review, LBNL, Berkeley, Ca.

\section{Planned FY 2005 Milestones:}

Release of $\mathrm{Tet}^{-1}$, version 3 . 


\section{Studies of Geothermal Reservoir Dynamics}

Reporting Period: FY 2004 (October 1, 2003 to September 30, 2004)

DOE Grant/Contract \#: $\quad$ DE-AC03-76SF00098

Performing Organization: Lawrence Berkeley National Laboratory

One Cyclotron Road, Berkeley, CA 94720

Principal Investigator: $\quad$ Karsten Pruess, (510) 486-6732, K_Pruess@lbl.gov

Collaborating Researchers: Tianfu Xu, Chao Shan, Nicolas Spycher, Eric Sonnenthal

DOE HQ Program Manager: Dr. Leland (Roy) Mink, (202) 586-5463, roy.mink@hq.doe.gov

DOE HQ Technical Manager: Dr. Allan Jelacic, (202) 586-6054, allan.jelacic@ee.doe.gov

DOE Funding Allocation: $\quad \$ 180 \mathrm{~K}$

Cost Share Funding: None

Project Objective: Improve fundamental understanding and engineering methods for geothermal systems, with increasing emphasis on EGS systems. Improve techniques for characterizing and controlling reservoir conditions and processes through new modeling and monitoring techniques based on "active" tracers and chemically and mechanically coupled processes.

Background/Approach: Current reservoir simulation codes include only rudimentary capabilities for chemical and mechanical interactions between rocks and fluids. To maintain and improve productivity and sustainability of geothermal systems, industry needs more accurate and comprehensive simulation capabilities that can incorporate geochemical and geomechanical information and processes.

\section{Status/Accomplishments:}

The major emphasis of our work in FY04 has been in two areas, (1) reactive chemical transport modeling, and (2) tracer testing in hot fractured rock (HFR) reservoirs.

\section{Reactive Chemical Transport}

The outstanding accomplishment was the completion of the TOUGHREACT code, which caps a multiyear effort that in addition to receiving geothermal support was also funded by research programs in geologic sequestration of greenhouse gases and geologic disposal of high-level nuclear wastes. TOUGHREACT is a numerical simulation program for chemically reactive non-isothermal flows of multiphase fluids in porous and fractured media. The program is written in Fortran 77 and was developed by introducing reactive chemistry into the multiphase flow code TOUGH2. Interactions between mineral assemblages and fluids can occur under local equilibrium conditions or kinetic rates. The gas phase can 
be chemically active. Precipitation and dissolution reactions can change formation porosity and permeability, and can also modify the unsaturated flow properties of the rock.

TOUGHREACT has been transferred to DOE's Energy Science and Technology Software Center (ESTSC) in Oak Ridge, TN, where it is available for licensing. The code is distributed with a comprehensive user's guide that includes sample problems addressing geothermal reservoirs and hydrothermal systems, nuclear waste isolation, groundwater quality, sequestration of carbon dioxide in saline aquifers, and supergene copper enrichment (Xu et al., 2004b). Code installation instructions are available in a READ.ME file.

As the TOUGHREACT code was nearing completion, our efforts shifted more towards applications, chiefly to studying mineral precipitation and dissolution effects in geothermal production-injection systems. Detailed modeling of reinjection at Unocal's Tiwi field, Philippines, was able to quantitatively explain injectivity loss in terms of silica scaling, and provided guidance for injecting in a manner that would avoid such scaling (Xu et al., 2004a). A study of a flow-through hot dry rock system that was patterned after the European HDR project at Soultz explored modification of water chemistry to simultaneously avoid calcite precipitation and clay swelling (Xu and Pruess, 2004).

\section{Tracer Testing in HFR Systems}

To be commercially viable and sustainable, energy production from hot dry rock (HDR) and hot fractured rock (HFR) reservoirs must achieve adequate and predictable rates of heat transfer from matrix rocks of low permeability to fluids circulating in the fracture network. The crucial parameter determining the capacity and longevity of such reservoirs is the area available for heat transfer, i.e., the interface area between fractures and matrix rocks. There are currently no methods available for determining this interface area in the field. We are evaluating the feasibility of determining heat transfer area by means of tracer tests.

The basic effect that may allow such determination is diffusive exchange of solutes between fractures and the adjacent rock matrix. When a slug of solute tracer migrates through a fracture, some of it will diffuse into the rock matrix, and subsequently, when the concentration gradient reverses after the slug has passed, will diffuse back into the fractures (Fig. 1). This back-diffusion provides a characteristic signature in the tracer breakthrough curves (BTCs), namely, a long tailing period. Tracer concentrations in the tail of the BTC increase with increasing fracture-matrix interface area (equivalently, decreasing fracture spacing; see Fig. 2). This effect has been observed and was found useful for gas phase tracers in vapor-dominated systems. A obstacle against applications to liquid-phase systems is posed by the fact that solute diffusivities in the aqueous phase are orders of magnitude smaller than gas phase diffusivities, so that the tails will be too weak to be practically useful. We have addressed this problem by considering sorbing tracers. Reversible sorption, e.g. by means of surface complexation, causes tails in BTCs to become stronger. Remarkably, as far as impacts on BTCs in the fractures are concerned, the effects of reversible sorption are completely equivalent to an increase in effective diffusivity. More quantitatively, if in the rock matrix solutes diffuse with diffusivity $\mathrm{D}$ and are subject to reversible sorption characterized by a "retardation factor" R, then the BTC in the fractures is identical to what would be obtained for an enhanced diffusivity D' = DR without retardation (Pruess et al., 2004; see Fig. 3). 


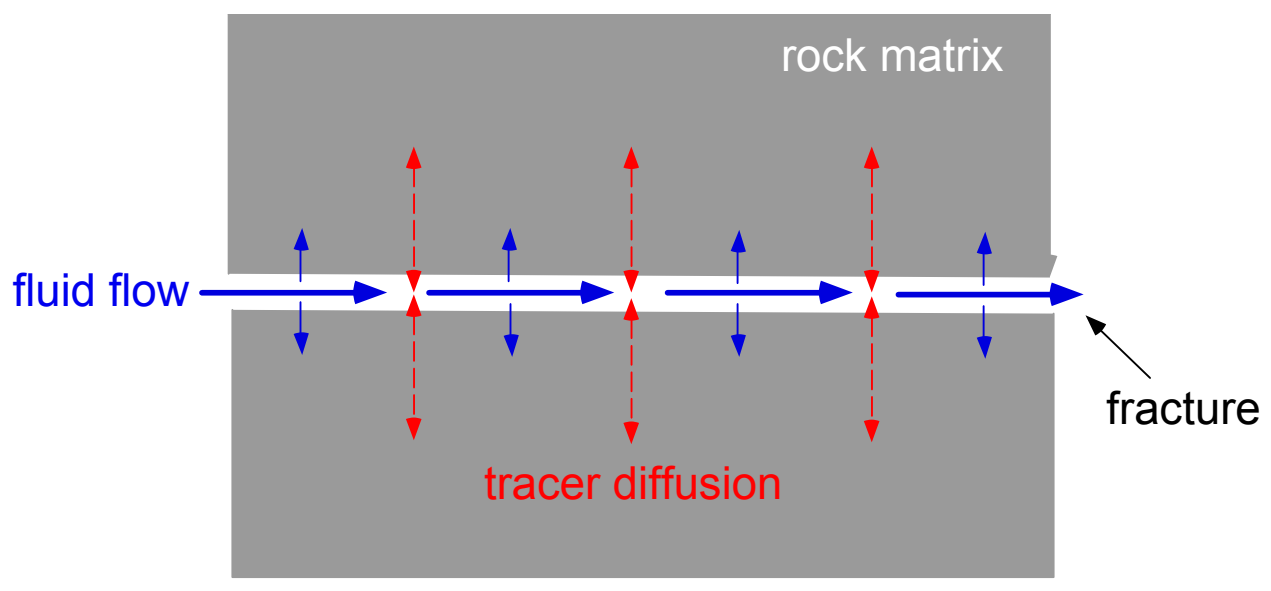

Figure 1. Schematic of tracer migrating down a fracture, subject to diffusive exchange with the rock matrix.

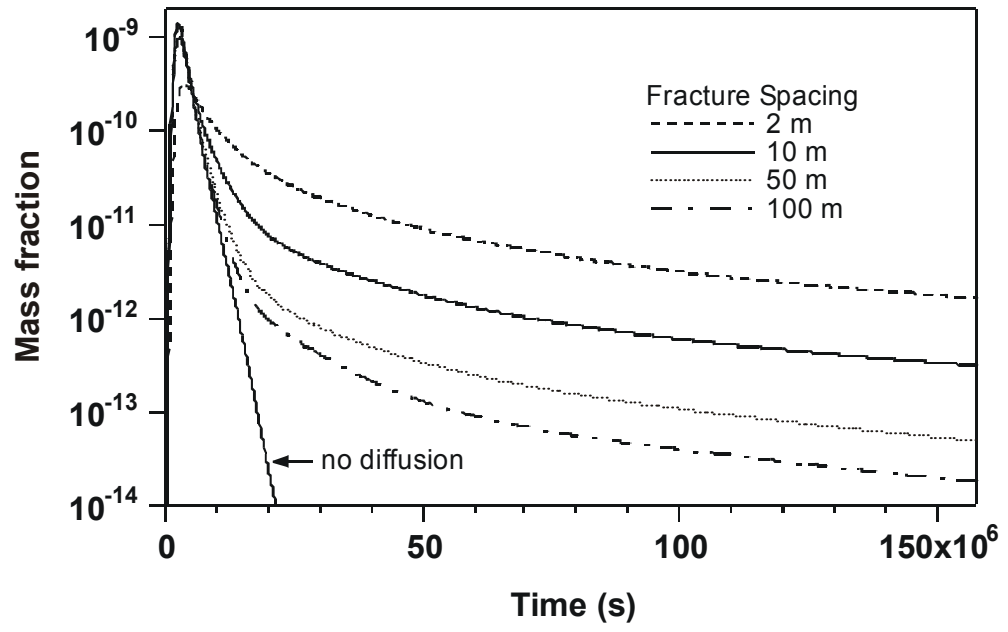

Figure 2. Dependence of tracer BTCs on fracture spacing (Pruess et al., 2004).

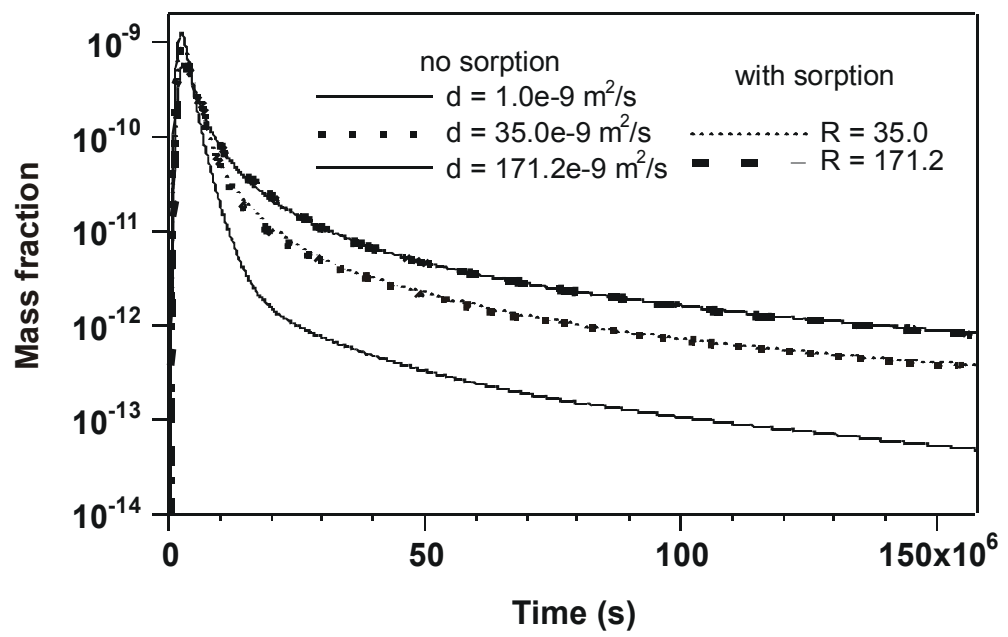

Figure 3. Comparison of tracer BTCs for different diffusivities with those including sorption effects. 


\section{Reports \& Articles Published in FY 2004:}

Kiryukhin, A., T. Xu, K. Pruess, J. Apps and I. Slovtsov. Thermal-Hydrodynamic-Chemical (THC) Modeling Based on Geothermal Field Data, Geothermics, Vol. 33, No. 3, pp. 349 - 381, doi:10.1016/j.geothermics.2003.09.005, 2004. (LBNL-55514)

Pruess, K. Special Issue: Selected papers from the TOUGH Symposium 2003, Berkeley, 12-14 May, 2003 - Preface, Geothermics, Vol. 33, No. 4, pp. 399 - 400, August 2004.

Pruess, K. The TOUGH Codes-A Family of Simulation Tools for Multiphase Flow and Transport Processes in Permeable Media, Vadose Zone J., Vol. 3, pp. 738 - 746, 2004. (LBNL-53630)

Pruess, K., T.V. Heel and C. Shan. Tracer Testing for Estimating Heat Transfer Area in Fractured Reservoirs, Lawrence Berkeley National Laboratory Report LBNL-55091, May 2004.

Pruess, K. and T. Xu. Numerical Simulation of Reactive Flow in Hot Aquifers (book review), Geothermics, Vol. 33, pp. 213 - 215, doi:10.1016/j.geothermics.2003.08.006, 2004. (LBNL-55513)

Shan, C. and K. Pruess. EOSN - A New TOUGH2 Module for Simulating Transport of Noble Gases in the Subsurface, Geothermics, Vol. 33, No. 4, pp. 521 - 529, August 2004. (LBNL-52431)

Todaka, N., C. Akasaka, T. Xu and K. Pruess. Reactive Geothermal Transport Simulation to Study the Formation Mechanism of Impermeable Barrier between Acidic and Neutral Fluid Zones in the Onikobe Geothermal Field, Japan, J. Geophys. Res. Solid Earth, Vol. 109(B5):5209, doi: 10.1029/2003JB002792, May 2004. (LBNL-52493)

Todaka, N., C. Akasaka, T. Xu and K. Pruess. Reactive Geothermal Transport Simulations to Study Incomplete Neutralization of Acid Fluid Using Multiple Interacting Continua Method in Onikobe Geothermal Field, Japan, Lawrence Berkeley National Laboratory Report LBNL-55433, June 2004.

Todesco, M., J. Rutqvist, G. Chiodini, K Pruess and C. Oldenburg. Modeling of Recent Volcanic Episodes at Phlegrean Fields (Italy): Geochemical Variations and Ground Deformation, Geothermics, Vol. 33, No. 4, pp. 531 - 547, August 2004. (LBNL-53603)

$\mathrm{Wu}, \mathrm{Y}$.S. and K. Pruess. A physically based numerical approach for modeling fracture-matrix interaction in fractured reservoirs, Lawrence Berkeley National Laboratory Report LBNL-55004, May 2004.

Wu, Y.S., L. Pan and K. Pruess. A Physically Based Approach for Modeling Multiphase Fracture-Matrix Interaction in Fractured Porous Media, Advances in Water Resources, Vol. 27, pp. 875 - 887, 2004. (LBNL-54749)

Xu, T., Y. Ontoy, P. Molling, N. Spycher, M. Parini and K. Pruess. Reactive Transport Modeling of Injection Well Scaling and Acidizing at Tiwi Field, Philippines, Geothermics, Vol. 33, No. 4, pp. 477 491, August 2004a. (LBNL-53991)

Xu, T., E. Sonnenthal, N. Spycher and K. Pruess. TOUGHREACT User's Guide: A Simulation Program for Non-isothermal Multiphase Reactive Geochemical Transport in Variably Saturated Geologic Media, Lawrence Berkeley National Laboratory Report LBNL-55460, September 2004b. 
$\mathrm{Xu}, \mathrm{T}$. and K. Pruess. Numerical Simulation of Injectivity Effects of Mineral Scaling and Clay Swelling in a Fractured Geothermal Reservoir, Lawrence Berkeley National Laboratory Report LBNL-55113, May 2004.

\section{Presentations Made in FY 2004:}

Xu, T., E. Sonnenthal, N. Spycher and K. Pruess. Using TOUGHREACT to Model Reactive Fluid Flow and Geochemical Transport in Hydrothermal Systems, presented at GRC Annual Meeting, Morelia, MI, Mexico, October 2003.

$\mathrm{Xu}, \mathrm{T}$. and K. Pruess. Numerical Simulation of Injectivity Effects of Mineral Scaling and Clay Swelling in a Fractured Geothermal Reservoir, presented at GRC Annual Meeting, Reno, NV, August 2004.

\section{Planned FY 2005 Milestones:}

Complete analysis of tracer migration in HFR systems

Demonstrate the use of water chemistry for controlling injectivity in EGS systems

Evaluate feasibility of mitigating corrosive gases in vapor-dominated systems

Sep 05

Benchmark mechanically coupled simulation codes

Apr 05 


\section{Reservoir Characterization for EGS and Hydrothermal Systems}

Reporting Period: FY 2004 (October 1, 2003 to September 30, 2004)

DOE Grant/Contract \#:

Performing Organization: Idaho National Engineering and Environmental Laboratory Applied Earth Sciences

PO Box 1625, Idaho Falls, ID 83415-2107

Principal Investigator: Ｇ. Michael Shook, (208) 526-6945, Mike.Shook@inl.gov

Collaborating Researchers: Dr. Gary A. Pope, gpope@mail.utexas.edu

DOE HQ Program Manager: Dr. Leland (Roy) Mink, (202) 586-5463, roy.mink@hq.doe.gov

DOE HQ Technical Manager: Dr. Allan Jelacic, (202) 586-6054, allan.jelacic@ee.doe.gov

DOE Funding Allocation: $\quad \$ 330 \mathrm{~K}$

Cost Share Funding:

Project Objective: Tracer testing is one of the most powerful reservoir characterization methods. Appropriately designed tracer tests yield information such as reservoir volume and geometry, fluid velocities and thermal sweep efficiency. Geothermal tracer test analysis is currently handicapped by insufficient tracer selection criteria and poor understanding of the information available from tracer test analysis. This project enhances the utility of tracer testing by addressing the following needs:

- $\quad$ Develop a complete list of tracer candidate selection criteria to enable quantitative analysis of tracer tests, including necessary tracer selection protocol.

- Demonstrate reservoir properties that can be estimated from a well-designed tracer test.

- $\quad$ Develop the analytical and numerical tools to estimate reservoir properties.

Enhanced Geothermal Systems (EGS) are unconventional geothermal fields, usually lacking either sufficient permeability or water. Successful energy extraction from such fields would increase the regional distribution of EGS. We have evaluated a number of engineered designs for improved energy extraction from atypical geothermal fields.

These project objectives directly address the Geoscience Program goals in several ways. First, tracer test analysis can provide estimates of reservoir geometry, flow paths, fluid and thermal velocities, etc. These parameters are critical for improving reservoir management, thereby reducing the levelized cost of geothermal power. The interpretation methods being developed in this project also have direct application in EGS characterization. Matrix-fracture surface areas, fracture geometries, and thermal velocities in fractured media can all be calculated from tracer tests. Improved characterization methods for EGS also 
supports the Geothermal Program goals by enhancing the regional distribution of geothermal power generation.

Background/Approach: A large number of tracer tests have been conducted in the geothermal industry in the last decade; however, analysis of such tests remains largely qualitative. Interpretation methods developed previously at INEEL show that reservoir volume and fluid and temperature velocities can be estimated in heterogeneous (but porous) media. That work is being extended to more complex cases of fractured media. Two-phase or vapor phase tracer tests have proven much more difficult to analyze, in large part due to the complexities of phase partitioning, variable heats of vaporization, and adsorption. These difficulties must be overcome in order to develop methods for interpreting tracer tests in two-phase or superheated, fractured geothermal reservoirs. New methods for estimating geothermal reservoir geometry, including fracture geometry and surface area, are also required to improve reservoir management.

Wellbore heat exchangers (WBHX) have recently been promoted as an additional means of energy extraction in fluid starved systems. In order to evaluate the WBHX concept and other, innovative well development and completions, we have conducted a series of parametric studies to evaluate their potential to contribute to energy production from engineered and fluid starved systems.

The approach being taken in this project is a combination of analytical and numerical. For tracer test interpretations we infer the properties from the form of the conservation equations themselves. For example, the ratio of fluid - to - temperature velocities can be determined directly from the equation describing the conservation of energy. A properly-interpreted tracer test yields fluid velocity, so thermal velocities are readily estimated. In some cases, however, analytic solutions to the governing equations are difficult or impossible to obtain, and so numerical simulations are conducted.

Status/Accomplishments: An INEEL external report was released in early FY-04 on tracer testing and test analysis. The report summarizes steps that are required to successfully implement and interpret a tracer test in the field. The report includes discussions appropriate tracer test goals, laboratory tests required to ensure the tracer has the required properties, field deployment, and an extensive discussion of test analysis methods. The report is being modified in length for submittal to Geothermics in early FY05.

A detailed parametric study of WBHX was completed in FY04. The detailed study was summarized in an INEEL external report; that report was subsequently shortened and submitted to Geothermics for publication. The manuscript has been accepted for publication, and will appear in early FY05. The parametric study evaluated the effect of wellbore depth and geometry, regional heat flux and rock properties, fluid injection rates, and other parameters on power generation potential. A "Best Case" scenario was developed that used optimal parameters from the sensitivity study. Those parameters are summarized in Table 1. The ideal work history for the best case is shown in Figure 1 below. Ideal work rate assumes perfect conversion of thermal energy to electric power. As seen in the figure below, WBHX is not capable of producing $200 \mathrm{kWe}$ for an extended period of time. Using realistic power conversion rates, the WBHX cannot produce $50 \mathrm{kWe}$.

Analytical studies have focused on methods to estimate additional reservoir properties from tracer tests in fractured media. This work is an extension of methods previously developed for porous media (Shook, 2001), but applies equally well in fractured media. The concepts are based on analysis of tracer flow paths (streamlines) that are independent of the medium (fractured or porous). Most recently, these concepts were used to develop a method of estimating flow geometry in fractured media (Shook, 2003). In FY04 we have extended the method to estimating fracture-matrix surface area. This surface area is crucial for heat transfer in EGS and hydrothermal systems, so estimates are of paramount importance. 
Table 1. Best Case well geometry and other parameters.

Well Geometry

Parameters

Tubing inner diameter $-76.2 \mathrm{~mm}$ (3.0 in.)

Basal Heat Flux $-0.1 \mathrm{~W} / \mathrm{m} 2$

Tubing outer diameter $-88.9 \mathrm{~mm}$ (3.5 in.)

Formation Thermal conductivity $-1.89 \mathrm{~W} / \mathrm{m}^{\circ} \mathrm{C}$

Insulation outer diameter - $101.6 \mathrm{~mm}$ (4.0 in.)

Formation volumetric heat capacity $-1,875.7 \mathrm{~kJ} / \mathrm{m} 3 .{ }^{\circ} \mathrm{C}$

Casing inner diameter $-578.0 \mathrm{~mm}$ (22.75 in.)

Working fluid volumetric heat capacity $-4,187 \mathrm{~kJ} / \mathrm{m} 3 .{ }^{\circ} \mathrm{C}$

Casing outer diameter - $593.7 \mathrm{~mm}$ (23.375 in.)

Wellbore diameter $-660.4 \mathrm{~mm}$ (26.0 in.)

Insulation Thermal Conductivity $-0.07 \mathrm{~W} / \mathrm{m}^{\circ} \mathrm{C}$

Well depth $-5,593 \mathrm{~m}$

Circulation rate $-6.3 \times 10-3 \mathrm{~m} 3 / \mathrm{s}$

Surface temperature $-26.7^{\circ} \mathrm{C}$

Bottomhole temperature $-350^{\circ} \mathrm{C}$

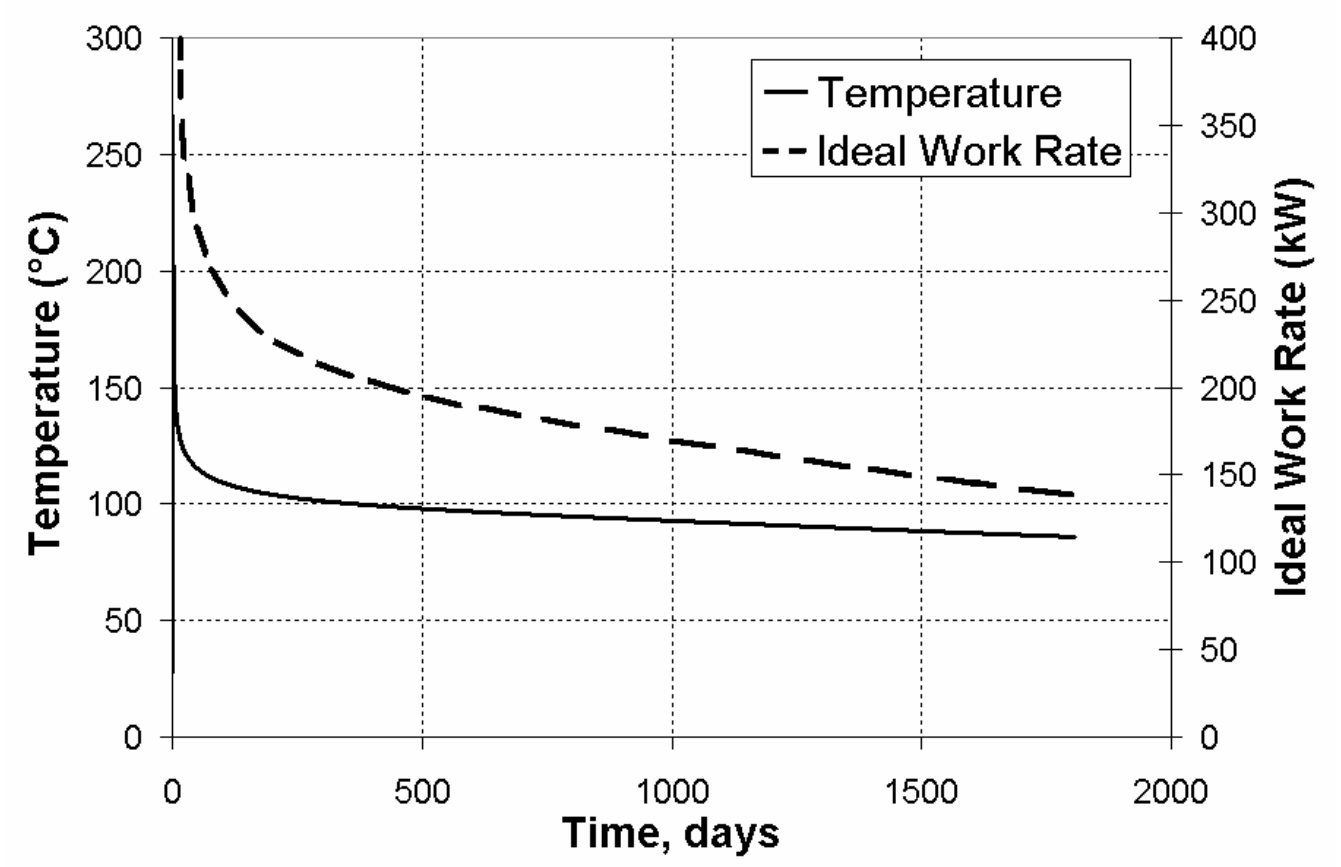

Figure 1. Ideal work history.

The method can be described as follows. If a conservative tracer is injected along with an adsorbing tracer, the two tracers will have different residence times in the medium. The conservative tracer flows with the velocity of the liquid (uw). The adsorbing tracer spends some of its time flowing, and some stationary (adsorbed). The adsorbing tracer velocity can be written as:

$\mathrm{v}_{\text {Ads }}=\frac{\overrightarrow{\mathrm{u}}_{\mathrm{w}}}{\varphi} \cdot \frac{\varphi \rho_{\mathrm{w}}}{\varphi \rho_{\mathrm{w}}+(1-\varphi) \rho_{\mathrm{s}} \frac{\partial \mathrm{C}_{\mathrm{s}}}{\partial \mathrm{C}_{\mathrm{w}}}}=\frac{\overrightarrow{\mathrm{u}}_{\mathrm{Cons}}}{\varphi} \cdot \frac{1}{1+\frac{(1-\varphi) \rho_{\mathrm{s}} \frac{\partial \mathrm{C}_{\mathrm{s}}}{\partial \mathrm{C}_{\mathrm{w}}}}{\varphi \rho_{\mathrm{w}}}}=\frac{\overrightarrow{\mathrm{u}}_{\mathrm{w}}}{\varphi} \cdot \frac{1}{1+\mathrm{D}}$ 
By calculating the mean residence times (via moment analysis; Shook, 1999) of the two tracers, the retardation factor $\mathrm{D}$ can be determined as

$$
\frac{\overline{\mathrm{t}}_{\mathrm{Ads}}}{\overline{\mathrm{t}}_{\mathrm{Cons}}}=1+\mathrm{D}
$$

The retardation term is a product of specific surface area and the slope of the tracer adsorption isotherm. By measuring the adsorption isotherm in the laboratory, surface area can be estimated directly.

The method has been tested numerically on several relatively simple, fractured geothermal reservoirs. In all cases simulated, the surface area estimated from tracer tests agreed very well with the input values. Of course, there remains additional work required to deploy this method in the field. For example, identifying a tracer with the appropriate adsorptive characteristics is instrumental to the method's success. The WBHX report was widely disseminated within the geothermal community. All tracer interpretation methods have been developed in spreadsheet applications. The spreadsheets have been distributed to approximately 10 geothermal groups worldwide. Feedback from the companies is used to make the application more user-friendly and robust. INEEL will continue to distribute and support tracer test interpretation applications for the geothermal community.

\section{Reports \& Articles Published in FY 2004:}

Shook, G.M., S.L. Ansley, and A. Wylie, "Tracer Testing Methods: Test Design and Implementation, Tracer Selection, and Interpretation Methods," INEEL report 03-01466, Jan. 2004.

Maxfield, B.T., D.M. Ginosaur, and G.M. Shook, "Evaluation of Perfluorocarbons as Geothermal Tracers," Geothermics, in press.

Nalla, G., G.M. Shook, G.L. Mines, and K.K Bloomfield, "Parametric Sensitivity Study of Operating and Design Variables in Wellbore Heat Exchangers," Trans, 29th Stanford Workshop on Geothermal Reservoir Engineering, Jan. 2004.

Nalla, G., G.M. Shook, G.L. Mines, and K.K Bloomfield, "Parametric Sensitivity Study of Operating and Design Variables in Wellbore Heat Exchangers," INEEL report 03-01433, May 2004.

Nalla, G., G.M. Shook, G.L. Mines, and K.K Bloomfield, "Parametric Sensitivity Study of Operating and Design Variables in Wellbore Heat Exchangers," accepted for publication, Geothermics.

Shook, G.M., "Estimating Fracture Surface Area from Tracer Tests: Mathematical Formulation,” Trans., Geothermal Resources Council, Vol. 28, Sept. 2004.

Nalla, G. and G.M. Shook, "Engineered Geothermal Systems using Advanced Well Technology," Trans., Geothermal Resources Council, Vol. 28, Sept. 2004.

\section{Presentations Made in FY 2004:}

Nalla, G., G.M. Shook, G.L. Mines, and K.K Bloomfield, "Parametric Sensitivity Study of Operating and Design Variables in Wellbore Heat Exchangers," Trans, 29th Stanford Workshop on Geothermal Reservoir Engineering, Jan. 2004. 
Shook, G.M., "Estimating Fracture Surface Area from Tracer Tests: Mathematical Formulation," Trans., Geothermal Resources Council, Vol. 28, Sept. 2004.

Nalla, G. and G.M. Shook, "Engineered Geothermal Systems using Advanced Well Technology," Trans., Geothermal Resources Council, Vol. 28, Sept. 2004.

\section{Planned FY 2004 Milestones:}

Publish Tracer Test Protocol and Interpretation article in reviewed journal Mar 05 Extend tracer methods for thermal velocity estimates to superheat conditions Aug 05

Complete tracer interpretation methods for fractured media

Aug 05 


\section{Analysis of Injection in Fluid Starved (EGS) Environments}

Reporting Period: FY 2004 (October 1, 2003 to September 30, 2004)

DOE Grant/Contract \#: $\quad$ DE-AC07-99ID13727

Performing Organization: Idaho National Engineering and Environmental Laboratory

Principal Investigator: $\quad$ K. Kit Bloomfield, (208) 526-5250, Kevin.Bloomfield@inl.gov

Collaborating Researchers: G. Mike Shook, INEEL

DOE HQ Program Manager: Dr. Leland (Roy) Mink, (202) 586-5463, roy.mink@hq.doe.gov

DOE HQ Technical Manager: Dr. Allan Jelacic, (202) 586-6054, allan.jelacic@ee.doe.gov

\section{DOE Funding Allocation:}

Cost Share Funding:

Project Objective: A controlling economic factor in geothermal power generation is the efficient use of the working fluid: injected water. In either hydrothermal or engineered geothermal systems, water is injected to increase energy extraction via improved thermal sweep efficiency. The processes of heat transfer from reservoir rock to the injected fluid and effects of contaminants on generation efficiency, are complex and coupled processes. The level of complexity generally requires numerical simulation as a tool to evaluate optimizing injection usage. This project uses numerical modeling to evaluate energy recovery and power generation efficiency for various hydrothermal and engineered geothermal systems.

Background/Approach: The objective of this project at its most basic level is to use numerical modeling and analytic solutions to evaluate optimal methods of energy extraction and power generation efficiency for various reservoir descriptions. By evaluating a variety of injection conditions in hydrothermal systems, we expect to identify relationships between power generation efficiency and location and volume of injectate used. A prototype resource model is a resource that varies from crystalline rock with no permeability that fractures could theoretically be artificially induced, to a resource with matrix properties. Test cases are provided for testing the influence varying matrix permeability properties have on produced fluid temperatures. The influence of matrix permeability will be defined further by calculating effective heat transfer area and volume increases as permeability increases. Temperature histories are evaluated for available energy to aid in plant sizing issues that will arise in the design and development phases of an Enhanced Geothermal System (EGS). The tools and methods presented here will be instrumental for EGS. Other operational targets addressed in this project include energy recovery in enhanced, or engineered, geothermal systems.

These objectives support the Geothermal Program objectives in a number of ways. Evaluating means of increasing generation efficiency via injection optimization reduces the levelized cost of geothermal 
power. Heat transfer studies in dry EGS environments can lead to an increase in the regional distribution of geothermal power production.

Status/Accomplishments: To study the heat transfer of one fracture and effects of matrix properties on heat transfer the model was constrained to one injector and one producer 1000 meters apart. The initial temperature of the model is $225^{\circ} \mathrm{C}$. The production fluid was intended to produce at a rate of 600 thousand kilograms per hour at $150^{\circ} \mathrm{C}$ after ten years of production (consistent with a power generation of $5 \mathrm{MWe}$ ). From these parameters an effective surface area of a single fracture 2-D model could be determined analytically. For simplicity, the model consisted of a one-dimensional plug flow through a rectangular fracture.

Consider a plane wall as one side of the fracture. The problem may be treated as one dimensional in y, and we are interested in the temperature variation with position in time, $\mathrm{T}(\mathrm{y}, \mathrm{t})$. The heat equation for transient conduction in a semi-infinite solid of one plane wall for the fracture is given by:

$$
T p=T r+(T i-T r) \operatorname{efrc}\left(\frac{K r A}{\rho w c w Q \sqrt{\alpha t}}\right)
$$

From temperature histories the above analytical solution can be used to determine the surface area that the injected fluid contacted in the reservoir rock. To determine the effects of matrix permeability on heat transfer a 2-D numerical model was constructed. The base case was one fracture with a permeability of one darcy adjacent to one micro darcy matrix or six orders of magnitude difference in permeability. It was determined that $54 \times 10^{6}$ square meters was required to return $150^{\circ} \mathrm{C}$ fluid after ten years of production. Then the matrix permeability was increased in orders of magnitude and the results are given in Figure 1.

\section{Temperature Histories}

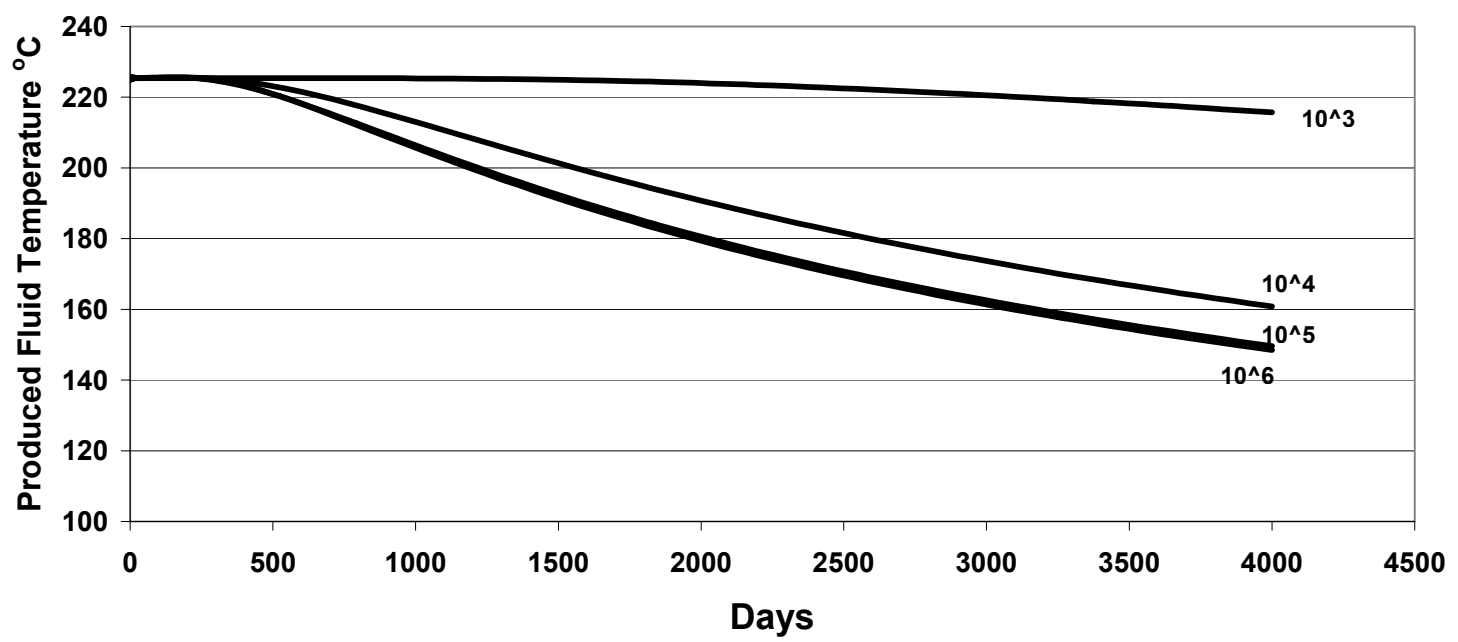

Figure 1. Temperature histories of different orders of magnitude difference between fracture and matrix permeability. 
Reports \& Articles Published in FY 2004: Nalla, G., Shook G.M., Mines G. L., Bloomfield K. K. 2004, Parametric Sensitivity Study of Operating and Design Variables in Wellbore Heat Exchangers, Stanford Geothermal Program Proceedings and internal report.

Presentations Made in FY 2004: Nalla, G., Shook G.M., Mines G. L., Bloomfield K. K. 2004, Parametric Sensitivity Study of Operating and Design Variables in Wellbore Heat Exchangers, Stanford Geothermal Program Proceedings

Planned FY 2005 Milestones:

Submit journal article for publication Apr 05

Publication of results at Geothermal conference 


\section{Development of a Reservoir Geomechanics Model for Enhanced Geothermal Systems}

Reporting Period: FY 2004 (October 1, 2003 to September 30, 2004)

DOE Grant/Contract \#: $\quad$ DE-AC07-99ID13727

Performing Organization: University of North Dakota

Department of Geology and Geological Engineering

Box 8358

Grand Forks, ND 58202

Principal Investigator: $\quad$ Ahmad Ghassemi, (701) 777-3213, ahmadghassemi@mail.und.nodak.edu

Collaborating Researchers: Alexander Cheng, University of Mississippi

DOE HQ Program Manager: Dr. Leland (Roy) Mink, (202) 586-5463, roy.mink@hq.doe.gov

DOE HQ Technical Manager: Dr. Allan Jelacic, (202) 586-6054, allan.jelacic@ee.doe.gov

DOE Funding Allocation: $\$ 75 \mathrm{~K}$

Cost Share Funding: $\quad \$ 24 \mathrm{~K}$

Project Objective: The purpose of this work is to develop a reservoir geomechanics and fracture propagation model for estimating the stress state and fracture distribution for use in reservoir characterization and development plans. The work will help in a priori determination of suitable target zones, drilling risks and alternatives, and assessment of stimulation by hydraulic fracturing. The proposed geomechanics model will be developed through rock mechanics research and development activities for EGS in a 3 year period.

Background/Approach: Cracks and fractures are the major pathways for fluid flow and provide the necessary heat exchange surfaces; they also play a significant role in many other aspects of geothermal energy extraction such as wellbore stability and hydraulic stimulation. As a result, delineation of fractured zones and possible fluid accumulation and flow within a reservoir, and understanding of artificial fracture behavior is necessary. These can be achieved by an integrated (field work and numerical modeling) investigation of the geomechanics history of the reservoir and the stress conditions leading to and resulting from the formation of fractures, fracture networks, and faults. Fracture distribution is largely controlled by stress, which in turn depends on rock rheology, natural discontinuities such as faults, poroelastic, and thermal stresses. The quantification of the stress state is also important in other aspects of reservoir development, namely optimum drilling trajectory, borehole instability and fluid loss which adversely impact economic drilling of geothermal wells; and hydraulic fracturing. 
The approach involves enhancement of the current 2D fracture propagation model to allow analysis of thermal stresses while considering rock inhomogeneities, generation of fracture networks, and fracture interactions, and fracture slip; three-dimensional analysis of natural fracture response; development of a 2D poro-viscoelastic finite element model with damage mechanics for predicting zones of fluid accumulation and deformation-induced fluid flow and migration. The geomechanics model will allow: prediction of the in-situ stress distribution as well as the pore fluid pressure and temperature; prediction of fracture zones as well as fracture type and orientation associated with reservoir deformation; the development of a state-of-the-art porothermoelastic wellbore stability model will assist in planning drilling operations (reducing costs), and hydraulic fracturing for future reservoir development. The models will be applied in a quantitative geomechanics study of the Coso geothermal field.

Status/Accomplishments: The project is moving on 3 thrusts. The poro-viscoelastic finite element model (FEM) has been developed and will need to be improved/calibrated for application. A 2D fracture propagation model has been improved to allow analysis of thermal stresses while considering rock inhomogeneities, fracture interactions, and fracture slip. The transient version is under development. Development a poro-thermoelastic wellbore stability model based on analytical solutions was moved from year 2 to year one. The Initial phase of the work has been completed. The three-dimensional analysis of natural fracture response to cooling has been moved to the second year.

\section{Reports \& Articles Published in FY 2004:}

1. Simakin, A. \& Ghassemi, A. 2004. Modeling deformation of partially melted rock using a poroviscoelastic rheology with dynamic power law viscosity, Tectonophysics (in press).

2. Simakin, A., and Ghassemi, A. 2004. A visco-poroelastic model with strain-history dependent rheology: application to geomechanics. 6th North American Rock Mechanics Symposium. Houston, TX.

3. Ghassemi, A., and Zhang, Q. 2004. A Transient Fictitious Stress Boundary Element Method for Porothermoelastic Media. J. Engineering Analysis with Boundary Elements. 28/11, 1363-1373.

4. Ghassemi, A. 2004. The Effects of the Magma Body on the Dynamics of Deformation in the Coso Geothermal Field. Quarterly Report: NDRM-INEEL04-03.

5. Ghassemi, A. 2004. A visco-poroelastic model with strain-history dependent rheology. Quarterly Report: NDRM-INEEL04-01.

6. Ghassemi, 2004. Coupled liquid flow and heat conduction in a propagating fracture network (part 1). Quarterly Report: NDRM-INEEL04-02.

\section{Presentations Made in FY 2004:}

A visco-poroelastic model with strain-history dependent rheology: application to geomechanics. $6^{\text {th }}$ North American Rock Mechanics Symposium. Houston, TX. 


\section{Planned FY 2005 Milestones:}

Implement a damage mechanics model in the 2D poro-viscoelastic finite element model and application to the geomechanics of the Coso geothermal field

Apr 05

Test and finalize thermoelastic fracture model

Apr 05

Study 2D fracture network in Coso and characterize its current state with respect to slip

Aug 05

Three-dimensional analysis of natural fracture response to injection cooling

Sep 05 


\section{Laboratory Measurements of Steam/Water Flow}

Reporting Period: FY 2004 (October 1, 2003 to September 30, 2004)

DOE Grant/Contract \#: $\quad$ DE-FG36-02ID14418

Performing Organization: $\quad$ Stanford University

Principal Investigator: $\quad$ Roland N. Horne, (650) 723-9595, horne@stanford.edu

Collaborating Researchers: Kewen Li

DOE HQ Program Manager: Dr. Leland (Roy) Mink, (202) 586-5463, roy.mink@hq.doe.gov

DOE HQ Technical Manager: Dr. Allan Jelacic, (202) 586-6054, allan.jelacic@ee.doe.gov

DOE Funding Allocation: $\quad \$ 163 \mathrm{~K}$

Cost Share Funding:

Project Objective: The focus of the project is to determine the fundamental flow properties of boiling steam/water transport in geothermal reservoirs, in order to better predict the performance of those reservoirs under exploitation. The properties measured will be used by industry in simulation of the reservoir performance during project design. Increasing the certainty in forecasting reservoir performance will result in better development decisions and a reduction in energy recovery cost towards the target of 3 to 5 cents $/ \mathrm{kWh}$.

Background/Approach: Steam/water relative permeability and capillary pressure are important properties for geothermal reservoir engineering, in that they have a major influence on the performance of geothermal reservoirs under development. All numerical simulations of geothermal reservoir performance require the input of relative permeability and capillary pressure values, yet actual data on these parameters have not been available. Hence we are developing methods to measure relative permeability and capillary pressure in actual geothermal rock that is low permeability and fractured.

Steam-water relative permeability and capillary pressure are important parameters, yet are rather poorly understood. The deficiency in the understanding of steam-water flow properties is due primarily to the great difficulty in conducting experiments in boiling flow, since phase transfer makes it hard to account for the individual rates of flow.

Using our existing steady-state CT method, we can measure steam/water relative permeability and capillary pressure in rock with permeability above $1 \mathrm{md}\left(10^{-13} \mathrm{~cm}^{2}\right)$. We can obtain the in-situ fluid saturation simultaneously. For geothermal rock with permeability smaller than $1 \mathrm{md}\left(10^{-13} \mathrm{~cm}^{2}\right)$, the steady-state CT method still works but it would take an extremely long time to conduct the experiments. Our first proposed approach is to measure the curves in real fractured geothermal rocks, by making the measurements in separate sections. We have concluded from our experimental data that steam/water 
relative permeability follows the Corey type of behavior and steam/water capillary pressure follows the Brooks-Corey model. We can measure the end-point steam/water relative permeability and saturation in the geothermal rock with permeability smaller than $1 \mathrm{md}$ using our existing steady-state CT method or a direct weighing method developed. Then the whole curve of steam/water relative permeability can be obtained using the Corey model and the capillary pressure curve can be obtained using the Brooks-Corey model.

Our second method is to measure steam/water relative permeability in fracture models. The apparatus shown in Fig. 1 is installed in a temperature-controlled air-bath. Distributions of pressure and temperature in the fracture model are measured. Saturation can be measured by digital video analysis. The flow rates of steam and water are measured using an optical device installed at the outlet of the model. Finally, the steam/water relative permeability in fractures can be calculated using Darcy's law.

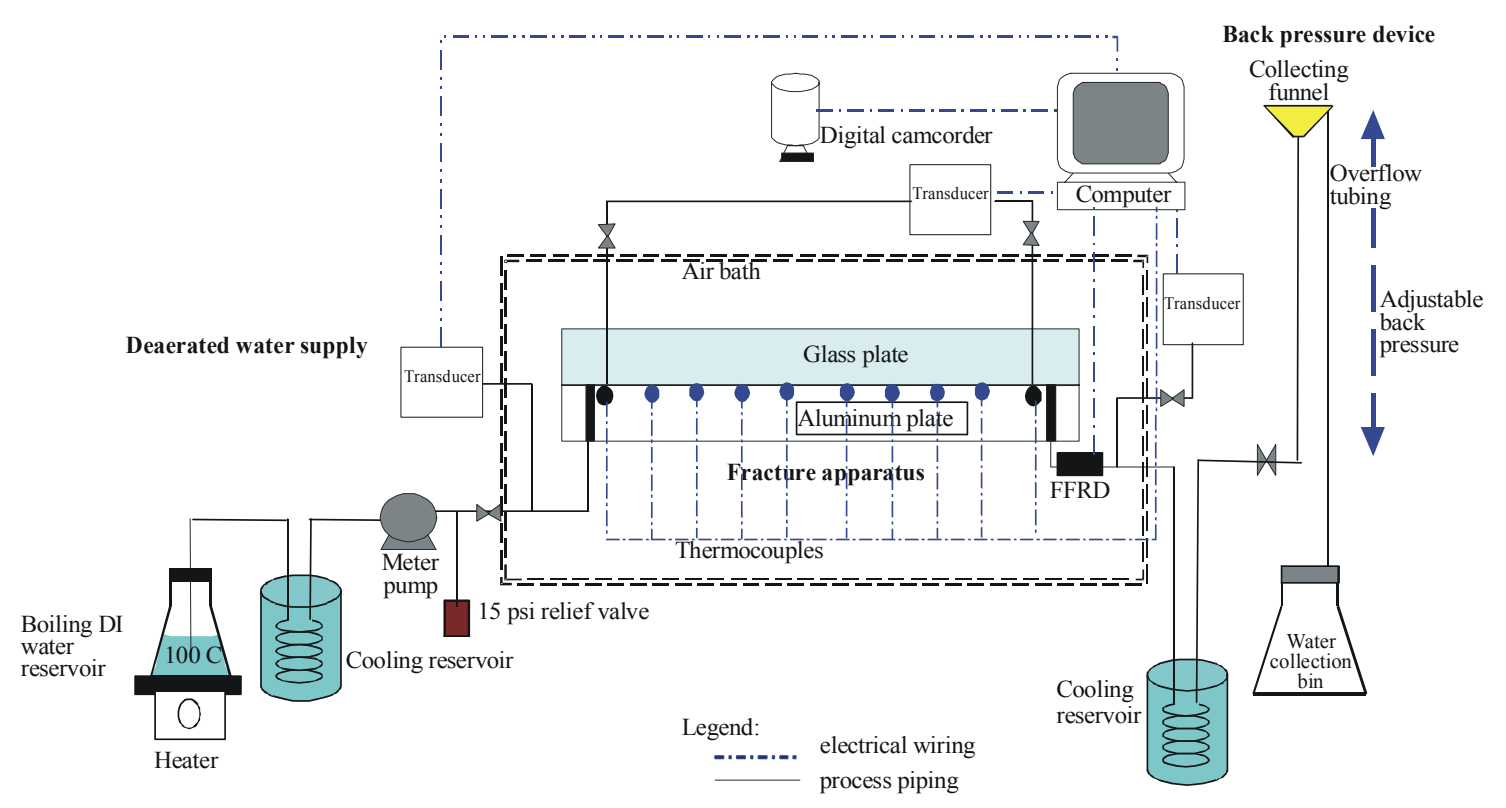

Figure 1: Process flow diagram for steam-water experiment.

Status/Accomplishments: In this study, we have suggested an alternative approach to describe the twophase relative permeability behavior in rough-walled fractures based on the two-phase flow structures. This approach lumps the microscale physical mechanism (viscous and capillary forces) into an apparent observable parameter, channel tortuosity, which was found to dominate the reduction of the relative permeabilities from the values that would be expected based on the X-curve. Three artificial fractures, smooth-walled, homogeneously rough-walled and randomly rough-walled, were studied to represent distinct surface geometry and heterogeneity. The experimental results from these three fractures could be described successfully by the proposed model. Furthermore, we found that the magnitude of the channel tortuosity increases when the heterogeneity of the fracture surface increases. Although only three simplified fractures were studied and the relationship between the flow-based heterogeneity and the channel tortuosity is not fully developed yet, we were able to derive an empirical model generalized from all channel tortuosities from these three fractures. This model can represent the current experimental data as well as observations from earlier studies with good agreement, as shown in Figure 2. 


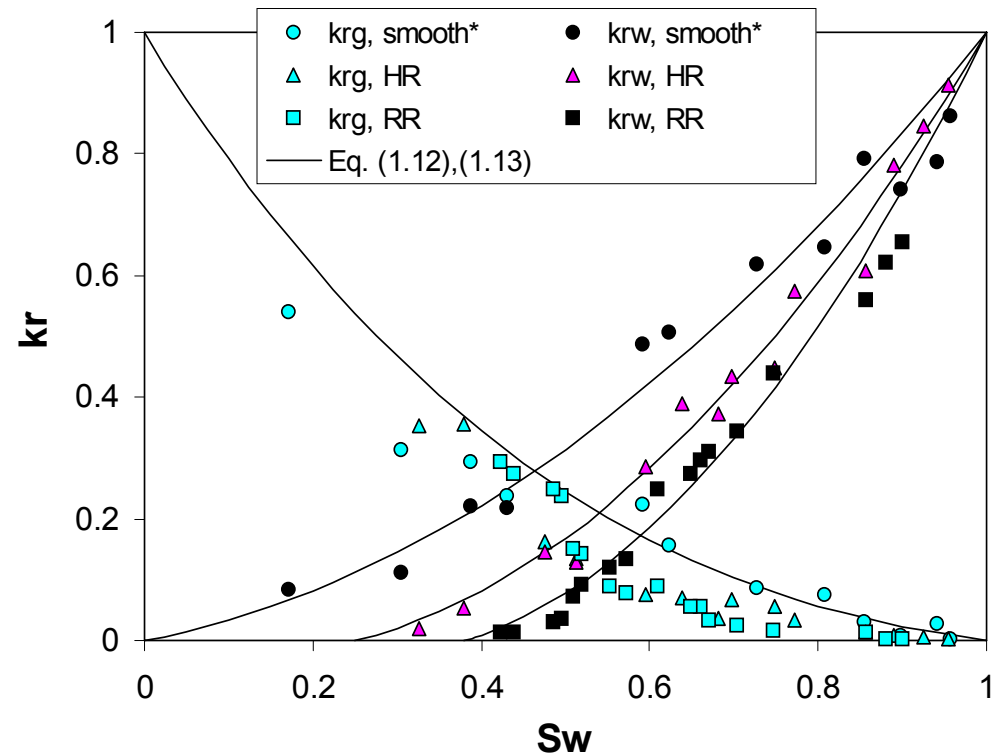

Figure 2: Comparison of the experimental steam/water relative permeabilities with tortuous-channel model for the smooth-walled, homogenously rough (HR) and randomly rough (RR) fractures. The $S_{w r}$ values for HR and $R R$ fractures are 0.25 and 0.39 respectively determined from the experiments.

In the rock experiments, using Darcy's Law and assuming the ideal gas equation, effective permeability data were calculated at different saturation points. As in a usual steady-state relative permeability measurement, saturation was altered by adjusting relative injectivity, which is basically the ratio between the flow rates of brine and nitrogen entering the system. The results of the preliminary relative permeability experiment are presented in Figure 3.

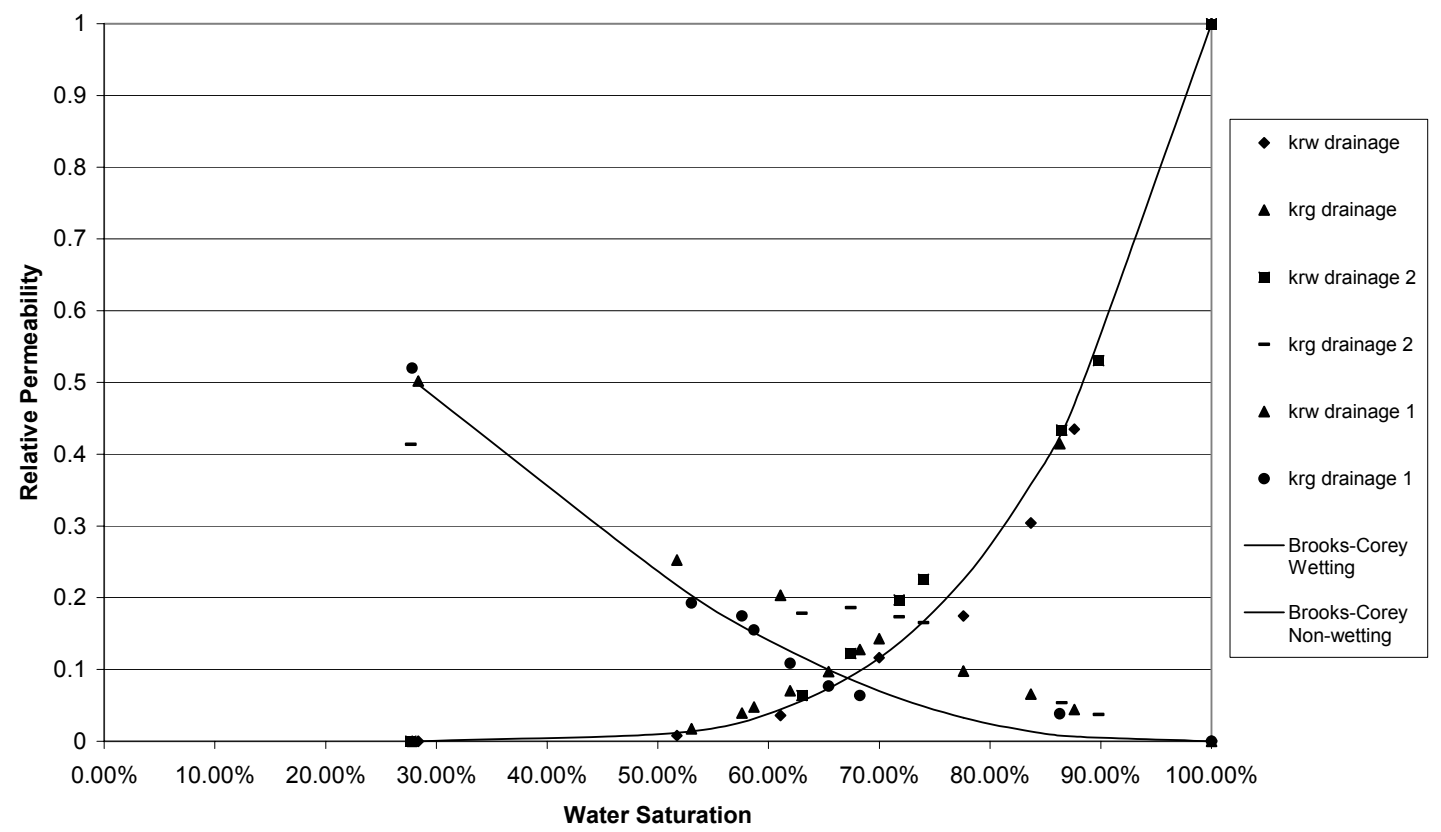

Figure 3. Nitrogen-Water Drainage Relative Permeability in Berea Sandstone 
Figure 3 shows a summary of three drainage relative permeability experiments done with Nitrogen and $1 \% \mathrm{NaCl}$ solution in Berea sandstone. To explain the legend, krw drainage, krg drainage, krw drainage 1 and krg drainage 1 were done with an improved core holder, constructed this year. The general trend of the results seen in Figure 3 is in agreement with earlier studies, confirming the correct functioning of the new apparatus. Plotted against a semiempirical model, the results can be observed to generally follow the Brooks-Corey model (with $\lambda=2$ ).

The preliminary experiments have been used to test the new coreholder with Berea sandstone, through which fluids flow easier and faster than in geothermal rocks. In the next phase, the rock experiments will be conducted with real fractured geothermal rocks.

\section{Reports \& Articles Published in FY 2004:}

Chen, C.Y., Horne, R.N., and Fourar, M.: "Experimental Study of Liquid-Gas Flow Structure Effects on Relative Permeabilities in a Fracture", Water Resour. Res., Vol. 40, No. 8, August 2004.

Li, K. and Horne, R.N.: "Steam-Water and Air-Water Capillary Pressures: Measurement and Comparison," J. of Canadian Petroleum Technology (July 2004), V.43, No. 7.

Li, K. and Horne, R.N.: "An Analytical Scaling Method for Spontaneous Imbibition in Gas-Water-Rock Systems," SPEJ (September 2004), 9(3).

Li, K. and Horne, R.N.: "Experimental Study of Gas Slippage in Two-Phase Flow," SPEREE (December 2004).

\section{Presentations Made in FY 2004:}

Chen, C.Y., Li, K. and Horne, R.N.: "Experimental Study of Phase Transformation Effects on Relative Permeabilities in a Fracture," SPE 90233, presented at the 2004 SPE Annual Technical Conference and Exhibition, Houston, TX, U.S.A., 26-29 September 2004.

Reyes, J.L.P., Chen, C.Y., Li, K. and Horne, R.N.: Calculation of Steam and Water Relative Permeabilities Using Field Production Data, with Laboratory Verification, 2004 Geothermal Resources Council meeting, Palm Springs, CA

Chen, C.Y., Horne, R.N., and Fourar, M.: Experimental Study of Two-Phase Flow Structure Effects on Relative Permeabilities in a Fracture, Proceedings of 29th workshop on Geothermal Reservoir Engineering, Stanford University, Stanford, California, January 26-28, 2004

\section{Planned FY 2005 Milestones:}

Presentation of fracture study at World Geothermal Congress $\quad$ Apr 05

Completion of fracture experiments

Completion of fractured geothermal rock experiments 


\section{Geochemical Study of the Effects of Fluid Injection at EGS Sites}

Reporting Period: FY 2004 (October 1, 2003 to September 30, 2004)

DOE Grant/Contract \#: $\quad$ DE-AC03-76SF00098

Performing Organization: $\quad$ Lawrence Berkeley National Laboratory

One Cyclotron Road, Berkeley, CA 94720

Principal Investigator: $\quad$ B. Mack Kennedy, (510) 486-6451, bmkennedy@lbl.gov

Collaborating Researchers: $\quad$ M. C. van Soest, Jennifer Lewicki, Mich Stark/Joe Beall (Calpine Corp.)

DOE HQ Program Manager: Dr. Leland (Roy) Mink, (202) 586-5463, roy.mink@hq.doe.gov

DOE HQ Technical Manager: Dr. Allan Jelacic, (202) 586-6054, allan.jelacic@ee.doe.gov

DOE Funding Allocation: $\quad \$ 100 \mathrm{~K}$

Cost Share Funding: $\quad \sim 40 \%$ in kind - field access, assistance in sampling, data access.

Project Objective: To determine the geochemical effects of production and increased injection in steam wells of the Aidlin and other northern Geysers areas.

Background/Approach: The Northern Geysers has a wide range of reservoir temperatures and steam compositions. In general, compared to the Southern Geysers, the steam is high and variable in gas and ${ }^{18} \mathrm{O}$ concentrations and contains variable concentrations of corrosive $\mathrm{HCl}$ that requires mitigation. At the margins of the presently producing field, gas and chloride concentrations and downhole temperatures increase indicating the presence of a high temperature reservoir which may also extend under the production area. The Aidlin field is an outlier of the main Geysers and contains the highest gas and $\mathrm{HCl}$ except for the now shutin Coldwater Creek field that was studied by the PIs of this project in 1993-4. In 1997 and 2002 in collaboration with Calpine, the operators of most of The Geysers, baseline surveys of noble gas isotopes were made of Aidlin well samples. In 2002 the baseline survey was expanded to include a complete suite of analyses of steam from selected representative Northern Geysers wells for analyses of noble gas isotopes, carbon isotopes in $\mathrm{CO}_{2}$ and $\mathrm{CH}_{4}$, water isotopes (LBNL) and standard gas chemistry (Thermochem). The increase of water available for injection afforded by the connection of the Santa Rosa wastewater pipeline will allow production of steam from greater depths and further toward the field margins. Our objective is to monitor the impact of increased injection with respect to high noncondensable gas and $\mathrm{HCl}$ mitigation and shifts in reservoir composition reflecting changes in fluid source.

\section{Status/Accomplishments:}

The results of the 1997 and 2002 sampling campaign indicate a significant shift in the noble gas composition of the Aidlin production fluids (Figure 1). The Aidlin field is thought to contain a significant contribution from the "High Temperature Reservoir" (HTR) that is characteristic of the Northwest 
Geysers. An earlier study of the Coldwater Creek field demonstrated a well defined compositional difference between the fluids produced primarily from the HTR and those produced from the "Normal Temperature Reservoir" (NTR). Most notably the HTR is characterized by much higher helium concentrations (defined by the slopes of the mixing lines in Figure 1) than observed in the NTR fluids. Between 1997 and 2002, the compositions of the Aidlin production fluids shifted from low helium concentrations to higher NTR-like compositions. We have yet to observe helium compositions similar to that in the Coldwater Creek HTR. At present, we have too little data to explain the shift in terms of injection and/or changes induced by production. A third sampling campaign was recently completed. Future sampling may be conducted quarterly, depending on the outcome of the 2004 analyses.

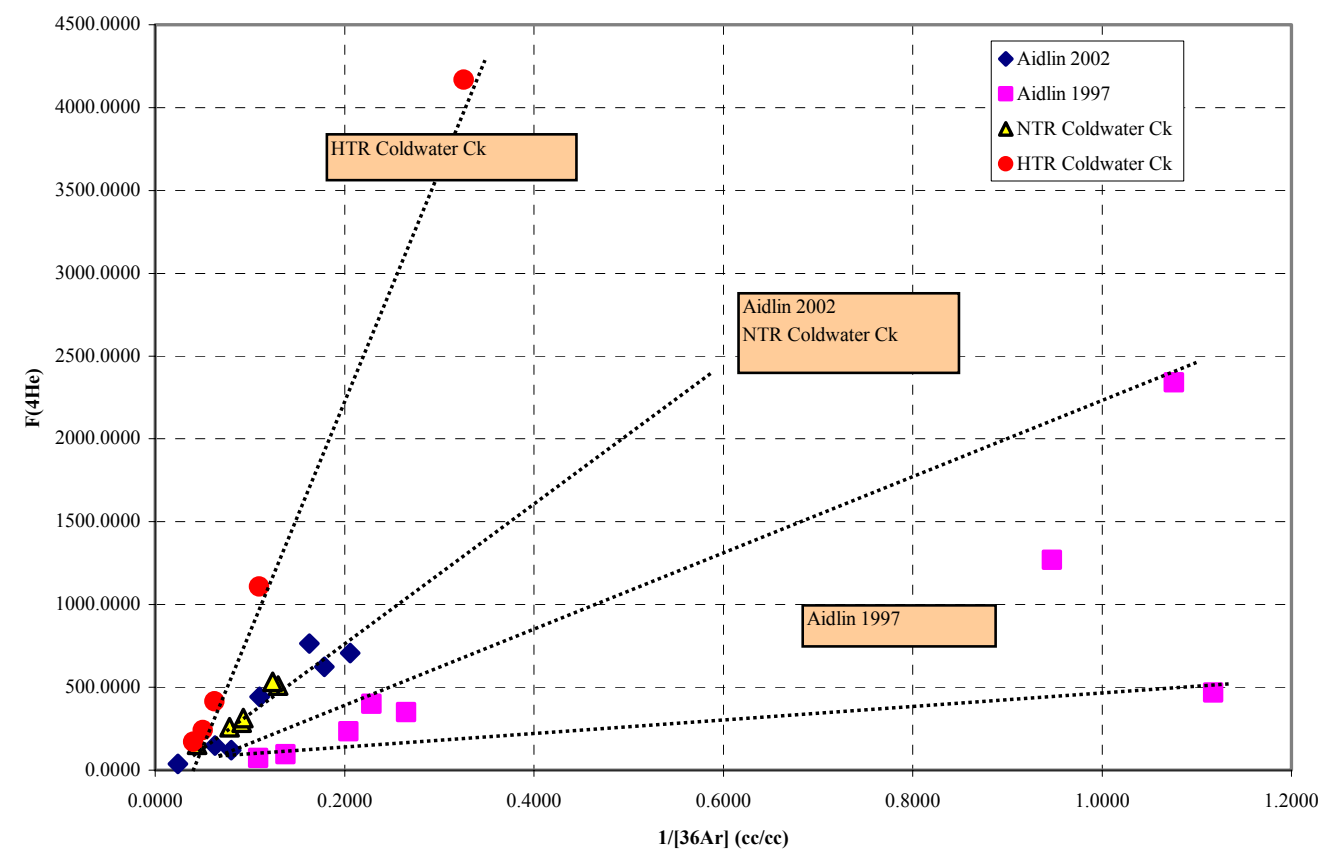

Figure 1: $F\left({ }^{A} \mathrm{He}\right)$, the helium enrichment factor defined as the $\left[\left({ }^{4} \mathrm{He}{ }^{\beta 6} \mathrm{Ar}\right)_{\text {sample }} /\left({ }^{4} \mathrm{He} e^{\beta 6} \mathrm{Ar}\right)_{\text {air }}\right]$, vs the inverse $\left[{ }^{36} \mathrm{Ar}\right]$ concentration in $\mathrm{cc} / \mathrm{cc}$, which is proportional to the $\mathrm{CO}_{2}{ }^{36} \mathrm{Ar}$ ratio. In this figure, the greater the slope of a mixing line the greater the helium enrichment.

Our initial survey of other areas of the northern Geysers has not found any helium enrichments of the same magnitude as Coldwater Creek HTR fluids. However, several wells along the northwest edge of the Ottoboni Ridge area have compositions not unlike the NTR, suggesting a possible HTR influence (Figure 2). These wells are also characterized by relatively higher ${ }^{3} \mathrm{He} /{ }^{4} \mathrm{He}$ ratios, indicative of a higher proportion of magmatic gas. The remaining wells have helium concentrations similar to that found at Aidlin in 1997. 


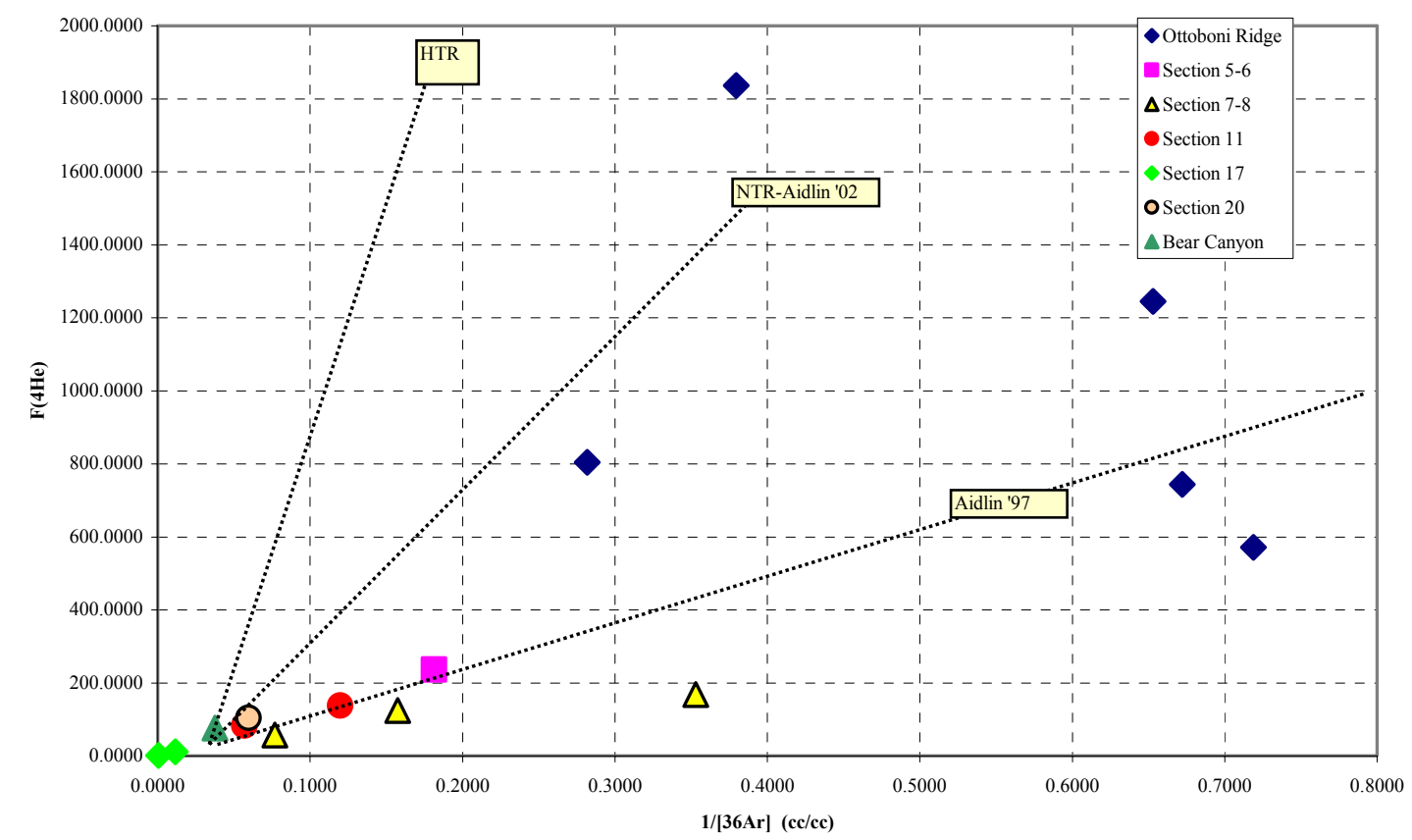

Figure 2: Same as Figure 1. Data from 2002 sampling campaign of the northern Geysers area.

We have just completed a second field wide sampling campaign in which the same wells sampled in 1997 and 2002 were re-sampled. In addition to samples collected for noble gas, $\mathrm{CO}_{2}, \mathrm{CH}_{4}, \mathrm{~N}_{2}$, and steam isotopic compositions, a selected set of wells were also sampled for ${ }^{14} \mathrm{C}$ analyses. The Santa Rosa waste water injection fluid will be characterized by modern ${ }^{14} \mathrm{C}$, whereas indigenous reservoir fluids will have only "dead" carbon providing an additional tool for tracing and monitoring the geochemical impact of increased injection.

\section{Reports \& Articles Published in FY 2004:}

No official reports or articles were published in 2004. The data was informally presented to Calpine representatives.

Presentations Made in FY 2004:

See above.

\section{Planned FY 2005 Milestones:}

Complete analyses of 2004 sampling campaign Mar 05

Initiate quarterly sampling of the Aidlin Field, if necessary

Present results of 2004 sampling campaign to Calpine Apr 05

Present results at Geothermal Resource Council Meeting 


\section{Geologic and Geophysical Analysis of the Desert Peak-Brady Geothermal Fields: Structural Controls on Geothermal Reservoirs in the Humboldt Structural Zone}

Reporting Period: FY 2004 (October 1, 2003 to September 30, 2004)

DOE Grant/Contract \#: $\quad$ DEFG36-02ID14311

Performing Organization: Nevada Bureau of Mines and Geology, University of Nevada, Reno

Principal Investigator: J James E. Faulds, (775) 784-6691, ext. 159, jfaulds@unr.edu

Collaborating Researchers: Larry Garside, Gary Oppliger, and Rasool Anooshehpoor

DOE HQ Program Manager: Dr. Leland (Roy) Mink, (202) 586-5463, roy.mink@hq.doe.gov

DOE HQ Technical Manager: Dr. Allan Jelacic, (202) 586-6054, allan.jelacic@ee.doe.gov

\section{DOE Funding Allocation: $\$ 38 \mathrm{~K}$ \\ Cost Share Funding: $\quad \$ 16 \mathrm{~K}$}

Project Objective: The major goals of this project are to 1) characterize links between thermal reservoirs and individual structural and stratigraphic features, 2) better define the boundaries of the geothermal reservoirs in the Desert Peak-Brady fields, and 3) elucidate the late Cenozoic 3D strain and stress fields.

The Desert Peak geothermal field may ultimately serve as a prototype for identification of blind resources elsewhere in the northern Great Basin, particularly in the Humboldt structural zone. This project is relevant to applied research areas, including 1) inventory of existing geothermal resources in GIS context (Part 1A), 2) geologic mapping and fault characterization (1B), and 3) assessment of controls of reservoir boundaries $(2 \mathrm{~B})$.

Background/Approach: A broad region of high heat flow, the Battle Mountain heat-flow high, covers much of northern Nevada and includes an ENE-trending zone of faults. This zone of faulting and high heat flow has been referred to as the Humboldt structural zone (HSZ). Most major geothermal fields in northern Nevada occur along NNE-striking faults in or near the HSZ. The abundance of producing fields and regional extent of the heat flow anomaly indicate high potential for discovering additional geothermal reservoirs. Despite the economic significance of the HSZ, few detailed investigations have been conducted on its Cenozoic stratigraphic and structural framework. How structures and strata control geothermal resources in the HSZ are generally poorly understood. Our integrated structural and geophysical investigation of the Desert Peak-Brady geothermal fields in the Hot Springs Mountains of western Nevada has significant potential for characterizing the structural setting (strain and stress fields) and controls on geothermal reservoirs in the HSZ. Of developed fields, some of the best exposures of faults and folds occur in the Desert Peak-Brady fields. Our research complements an ongoing EGS study by ORMAT and GeothermEX and builds on our completed work in the area. 
This study involves: 1) expansion of detailed mapping (1:24k scale) to include remaining parts of the northern Hot Springs Mountains, 2) more thorough stratigraphic-structural analyses, 3) acquisition of additional gravity data, 4) a micro-earthquake (MEQ) study, and 5) continuation of the GIS compilation. The mapping and structural-stratigraphic analyses will better delineate the late Cenozoic 3D strain-stress fields and further elucidate relations between faults, strata, and geothermal reservoirs. The gravity work will further constrain the subsurface geometry of major faults and configuration of the Tertiary-basement contact. The MEQ survey will discern the subsurface geometry of faults and fractures that channel fluids.

Status/Accomplishments: Major accomplishments in FY2004 include the following.

1. Publication of Geologic Map: The Phase I geologic map and cross section were finalized for publication as a Nevada Bureau of Mines and Geology Open-File Report (Faulds and Garside, 2003). The Phase I map includes $\sim 70 \mathrm{~km}^{2}$ of detailed geologic mapping between the EGS Desert Peak study area on the east and Brady geothermal field on the west.

2. New Geologic Mapping: Detailed geologic mapping was completed in critical parts of the northern Hot Springs Mountains, including areas near the Brady geothermal plant and Desert Queen Mine. Geologic mapping of $\sim 13 \mathrm{~km}^{2}$ was completed in areas both north and south of the Brady Plant. In addition, thin sections of samples collected previously were examined in more detail. To the south of the Brady Plant, hot spring sinter, overlying linear tufa ridges and opaline replacement features in sedimentary rocks suggest that the Brady fault zone can be continued at least $1 \mathrm{~km}$ farther south than shown on our preliminary map (Faulds and Garside, 2003). Farther south, any evidence of the fault is concealed by Lake Lahontan beach gravels. Mapping also suggests that the Brady fault has more than one strand, at least north of the Brady Plant. Detailed geologic mapping of $\sim 15 \mathrm{~km}^{2}$ in the Desert Queen area (just north of the EGS site) included analysis of faults, joints, and veins cutting the only exposure of Mesozoic basement in the area. Two major joint and vein sets were observed in these rocks. Charactering the structural framework of the basement rocks is important, because the Ormat-GeothermEx EGS project at Desert Peak intends to generate a geothermal reservoir in the Mesozoic basement. In addition, the geothermal aquifer at the Desert Peak field resides in Mesozoic basement.

3. Enhanced Gravity Study: Collection of planned new data points, final processing, and multi-survey integration were completed for the gravity investigation. This year's gravity observations (170 stations) were distributed around the perimeter of last year's coverage (368 stations) and were directed at definition of regional basement structure in the area surrounding the northern Hot Springs Mountains. The combined multi-year gravity observation data set of 538 stations was terrain corrected and processed to complete Bouguer anomalies using uniform reduction parameters. The new gravity map was distributed to the project team on $8 / 06 / 04$. The enhanced data set will facilitate interpretation of several critical features, including the lateral extent of major fault zones controlling geothermal activity at Brady's and Desert Peak, geometry and overall extent of structural basins (e.g. Hot Springs Flat basin in the hanging wall of the Brady fault), and geometric relations between various basins and major fault zones.

4. Two-Dimensional Gravity Model: A 2-D gravity model was completed for the published cross section. The gravity model and geologic cross-sections are in good agreement over most of the profile. Although uncertainties in actual bulk rock densities limit the reliability of the model, the results indicate that a broad gravity high centered in the northern Hot Springs Mountains results from a thick section of basalts within the Tertiary section (as shown in the cross section) rather than from relatively shallow basement. However, the gravity modeling does suggest that pre-Tertiary basement may be 400 meters deeper than shown in the cross section over a $3 \mathrm{~km}$ horizontal distance just east of the Brady's Field. The models and results were shared with Brady's-Desert Peak stake-holders at Ormat and GeothermEx.

5. Drill Core Analysis: Analysis of core from Tertiary strata was completed for 8 wells in the Brady's and Desert Peak areas. The major goal of this work was to elucidate subsurface structural features in the 
northern Hot Springs Mountains. The core provides a wealth of information concerning the stratigraphic and structural framework of the area and will be instrumental in better defining the subsurface structure and stratigraphy, particularly around the Brady field. For example, the core has already permitted firm correlation of unexposed Miocene strata in the Brady's area with that near Desert Peak. This will permit better estimates of displacement magnitude on faults, particularly the Brady fault zone. In addition, it appears as though several unexposed Oligocene tuffs found in the core correlate with regionally extensive units found throughout much of western and central Nevada. The core data indicate that the northern Hot Springs Mountains contain one of the thickest known sequences $(>700 \mathrm{~m})$ of ash-flow tuff in the region. This demonstrates that the Oligocene tuff section accumulated in a deep paleovalley etched into Mesozoic basement. We are curious whether the paleovalley could be indirectly related to geothermal activity, perhaps by providing a relatively impermeable cap and linear channelway for deeply circulating fluids (?). Several samples were collected from each core for petrographic and geochronologic analyses. In our analysis of the core, we discovered that cuttings from multiple wells were stored outside and therefore deteriorating significantly due the effects of weather. Ormat allowed us to retrieve what was salvageable, and these cuttings now reside at the Nevada Bureau of Mines and Geology. Eventually, we intend to thoroughly analyze these cuttings (similar to our analysis of the core) in order to further enhance our understanding of the subsurface in the northern Hot Springs Mountains.

6. Regional Tectonic Model: Data from the Desert Peak-Brady's fields and other geothermal systems in the Great Basin were synthesized in order to characterize structural controls and develop a tectonic model for such systems. Geothermal systems are most common in the northwestern Great Basin and are generally controlled by NNE-striking normal faults. The abundance of geothermal systems in this region probably results from a transfer of dextral shear in the Walker Lane to normal-fault systems in the Basin and Range province. Enhanced extension favors deep circulation of aqueous solutions along faults oriented perpendicular to the WNW-trending extension direction. The northwestern terminus of the transform boundary between the Pacific and North American plates is fundamentally responsible for this transfer of strain. These findings were presented at both the GRC meeting in Palm Springs and GSA Cordilleran Section meeting in Boise.

7. Geochronology: Mineral separates of 4 volcanic units were prepared for radiogenic dating and sent to the Geochronology Lab at New Mexico Tech for analysis. These include some of the oldest and youngest volcanic units in the area. Dates for these units will help to constrain the timing of extension and volcanism within the northern Hot Springs Mountains. The samples were sent to the lab in December 2003, but results were delayed by equipment problems at New Mexico Tech. Dates are now expected in February 2005. In addition, mineral separates were completed in 2004 for eight samples collected from the core. Dates from these samples will provide critical age control for the well data.

8. Microearthquake Study: Nine portable stations consisting of RefTek 72A digital recorders and 3component L-22 seismometers were deployed for analysis of micro-earthquakes. Since May 2004, 13 local micro-earthquakes have been recorded on three or more stations. The first eleven events were recorded during the second week of June 2004. Preliminary epicenters have been located for these events. Only two other events were recorded by October 5, 2004. These two events have not yet been located. The data have been sent to Optim for determining hypocenter location and possible focal mechanisms. The micro-earthquake study has been compromised slightly by continued drilling at the Brady's and Desert Peak fields. Because of the recent Parkfield earthquake, the L22 sensors used in this experiment were removed on 5 October 2004 and sent back to PASSCAL Instruments. We substituted 8 UNR sensors to continue the monitoring. We plan to remove all stations by late November or early December 2004.

9. Cross-Section Software Packages: Two software packages were acquired with funds from an internal UNR grant for facilitating construction and retro-deforming detailed cross sections of the northern Hot Springs Mountains. A graduate student (Ben Delwiche) was assigned to learning and mastering the 
software. Detailed cross sections typically require more than 3 days of work. Utilization of these software packages may significantly reduce this time commitment, thereby facilitating production of multiple cross sections and fence diagrams of the geothermal fields. This will ultimately enhance 3-D visualization of the fields.

\section{Reports \& Articles Published in FY 2004:}

Faulds, J.E., Coolbaugh, M., Blewitt, G., and Henry, C.D., 2004, Why is Nevada in hot water? Structural controls and tectonic model of geothermal systems in the northwestern Great Basin: Geothermal Resources Council Transactions, p. 649-654.

Faulds, J.E., and Garside, L.J., 2003, Preliminary geologic map of the Desert Peak - Brady geothermal fields, Churchill County, Nevada: Nevada Bureau of Mines and Geology Open-File Report 03-27.

Faulds, J.E., Garside, L.J., and Oppliger, G.L., 2003, Structural analysis of the Desert Peak-Brady geothermal fields, northwestern Nevada: Implications for understanding linkages between northeasttrending structures and geothermal reservoirs in the Humboldt structural zone: Geothermal Resources Council Transactions, v. 27, p. 859-864.

Faulds, J.E., Coolbaugh, M., Henry C.D., and Blewitt, G., 2004, Why is Nevada in hot water? Relations between plate boundary motions, the Walker Lane, and geothermal activity in the northern Great Basin: Geological Society of America Abstracts with Programs, v. 36, no. 4, p. 27.

Coolbaugh, M., Faulds, J.E., Blewitt, G., Henry, C.D., 2004, Geothermal activity: another clue for unraveling recent Great Basin tectonics: Earthscope/NSF Great Basin Symposium, Lake Tahoe, California, June 21-23.

\section{Presentations Made in FY 2004:}

Why is Nevada in hot water? Structural controls and tectonic model of geothermal systems in the northwestern Great Basin: Geothermal Resources Council Meeting, Palm Springs, California (September 2004).

Why is Nevada in hot water? Relations between plate boundary motions, the Walker Lane, and geothermal activity in the northern Great Basin: Geological Society of America Cordilleran Meeting, Boise, Idaho (May 2004).

Structural and geophysical analysis of the Brady and Desert Peak geothermal fields, western Nevada: Implications for structural controls on geothermal fields in the northern Great Basin, Nevada Petroleum Society monthly meeting (January 2004).

Structural analysis of the Desert Peak-Brady geothermal fields, northwestern Nevada: Implications for understanding linkages between northeast-trending structures and geothermal reservoirs in the Humboldt structural zone: Geothermal Resources Council Meeting, Morelia, Mexico (October 2003).

\section{Planned FY 2005 Milestones:}

Complete paleomagnetic study 
Phase 2 geologic map + cross sections

Mar 05

Compile geometry and kinematics of faults-folds

Mar 05

Integrate geochronologic-geochemical data with strat columns and geologic map

Mar 05

Expand map of subsurface faults-bedrock relief and 3D computer model

of gravity inferred bedrock surface

Mar 05

Digitization of new geologic map

Mar 05

3D subsurface model of northern Hot Springs Mountains

Mar 05

Digital copy of MEQ events and P- and S-wave phase arrival information

Mar 05

Locations, depth, focal mechanisms, cross-sections of MEQ hypocenters

Mar 05

Publication of results at Geothermal Conference

Sep 05 


\section{Prediction and Detection of Induced Fractures in EGS}

Reporting Period: FY 2004 (October 1, 2003 to September 30, 2004)

DOE Grant/Contract \#: $\quad$ W-7405-Eng-48

Performing Organization: Lawrence Livermore National Laboratory 7000 East Avenue, P.O. Box 808, Livermore, CA 94551

Principal Investigator: ～Jeffery J. Roberts, (925) 422-7108, roberts17@1lnl.gov

Collaborating Researchers: Steve Carlson, Russ Detwiler (LLNL), Ann Robertson-Tait (GeothermEx), Christy Morris (Ormat)

DOE HQ Program Manager: Dr. Leland (Roy) Mink, (202) 586-5463, roy.mink@hq.doe.gov

DOE HQ Technical Manager: Dr. Allan Jelacic, (202) 586-6054, allan.jelacic@ee.doe.gov

DOE Funding Allocation: $\quad \$ 200 \mathrm{~K}$

Cost Share Funding: $\quad$ In-kind: Ormat - Desert Peak Core, well logs, test data

Project Objective: To determine what physical and chemical properties of rocks and fluids control permeability evolution of induced fractures in geothermal fields, to suggest optimal strategies for sustaining permeability, to identify measurements to determine the spatial extent and aperture of fractures, and to apply this knowledge in support of DOE EGS experiments.

Background/Approach: The development of Enhanced Geothermal Systems (EGS) depends on the creation of permeable fractures. Once fractures are created, the success of the program depends on maintaining and enhancing permeability. Sustaining fracture permeability will depend on many variables including rock type, fluid chemistry, temperature, local stress field, fracture strain rate, and the proximity of natural fractures to the well bore. This work supports two Geoscience objectives of the DOE Geothermal Program: 1) Enhance our understanding of the mechanical, thermal and chemical evolution of natural and induced fractures, and 2) Improve methods of fracture detection and characterization.

Our approach is to perform laboratory experiments designed to assess the evolution of permeability and the geochemical attributes of induced fractures in geothermal environments. Quantitative assessment of permeability evolution on artificial and natural fractures as a function of effective stress, fluid chemistry, and temperature will be used to plan injection schemes in EGS field projects. Results will be reported at GRC and directly to industry partners. The results are generally applicable to EGS sites composed of intermediate intrusives and granitic host rocks.

Status/Accomplishments: Fluid flow experiments are being conducted on quartz monzonite core retrieved from depths of about $1 \mathrm{~km}$ at the Desert Peak East EGS site in Churchill County, Nevada. The experimental goals are to observe the evolution of fracture permeability during injection at geothermal 
pressure and temperature conditions and to elucidate the controlling mechanisms. Thus far we have successfully conducted experiments at a confining pressure of $5.5 \mathrm{MPa}$, pore pressures of $1.38 \mathrm{MPa}$ or $2.07 \mathrm{MPa}$ and temperatures of $167-169^{\circ} \mathrm{C}$; conditions representative of some potential EGS systems. Additional experiments exploring EGS parameter space are planned. A schematic example of an EGS injection region is shown in Figure 1 that illustrates differing environments accessible experimentally.

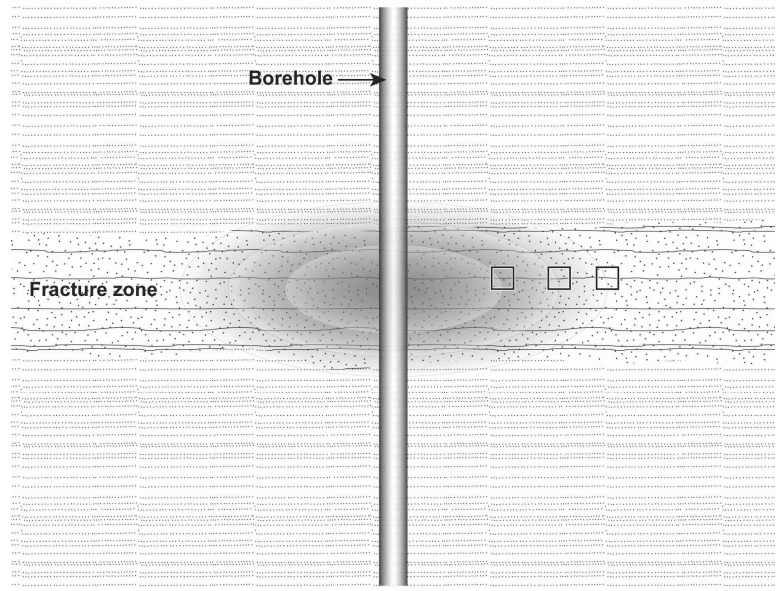

Figure 1. Schematic of EGS injection region showing different environments that can be accessed experimentally: flow rate, temperature and water/rock interaction vary away from the injection borehole.

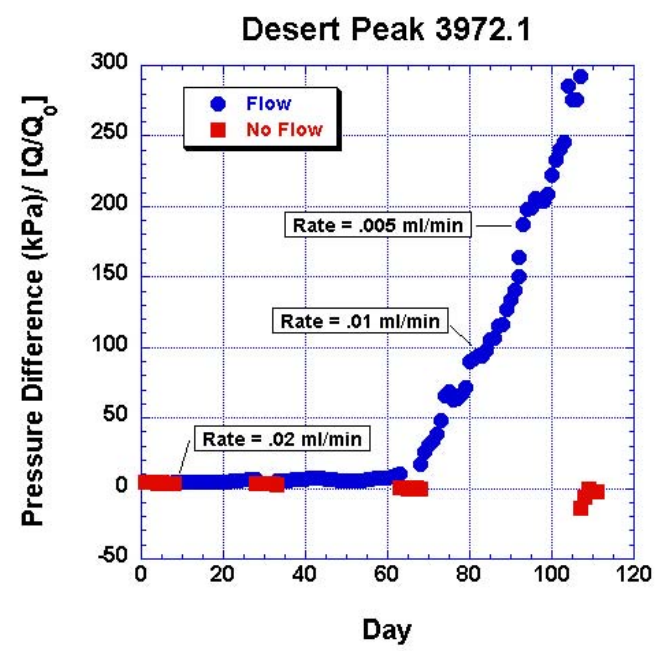

Figure 2. Evolution of fracture permeability during experiment DP3972.1. Over the course of the experiment differential pressure is observed to increase. Lower flow rates were necessary in the latter stages of the experiment to remain in the range of differential pressure instrumentation.

Saline water representative of spent geothermal brine at Desert Peak has been used as the injection fluid. Changes in fracture permeability were noted in experiments with flow through an artificial fracture at constant flow rates between 0.02 to $0.005 \mathrm{ml} / \mathrm{min}$ over a period of several weeks. Evidence for permeability evolution is provided by changes in differential pore pressure at constant flow and by changes in effective hydraulic aperture calculated from the variable flow rate data (Figure 2). The differential pressure measurements indicate that fracture permeability of core from the Desert Peak EGS site is changing in response to fluid injection. For one sample, DP 3972.1, pressure difference during constant flow at $166^{\circ} \mathrm{C}$ approximately doubled in 45 days. An effective hydraulic aperture of $18.6 \mu \mathrm{m}$ was calculated for specimen DP 3972.2. The effective hydraulic aperture for specimen DP 3972.1 fell from $14.2 \mu \mathrm{m}$ prior to flow to $9.0 \mu \mathrm{m}$ after about three weeks of flow. Thus far, all experiments have shown a decline in hydraulic aperture.

Electrical resistivity measurements of the core during the experiments have proven to be a sensitive indicator of changing fracture attributes and fluid ionic content. Electrical resistivity is observed to rise (conductivity decreases) during flow and fall during no-flow intervals, reflecting changes in the ionic content of the pore fluid. The decrease in electrical resistivity during no-flow intervals is attributed to higher ionic content of the pore fluid due to mineral dissolution. The resistivity increase during flow may result from the loss of ions downstream (and out of the specimen) or from precipitation along the fracture surfaces.

Surface characterization by use of profilometry is being utilized to determine quantitative changes that take place during the flow experiments. The surface prior to the experiment is shown in Figure 3. After flow the surfaces are again characterized (Figure 4). Observable features include the development of 
channels and a decrease in overall fracture roughness. Variograms indicate that the pre-flow fracture surfaces have more small-wavelength variation than the post-flow surface (Figure 5). Additional work using fracture surface profilometry will enable estimates of changing aperture. We will also attempt to correlate regions of the largest changes with specific mineralogy.

These preliminary experiments form the basis for a more focused effort to understand the effects of temperature and injection fluid chemistry on changing fracture permeability. Future experiments will include more detailed study of the fluid geochemistry and mineral dissolution and how the fracture aperture is affected in an EGS environment.
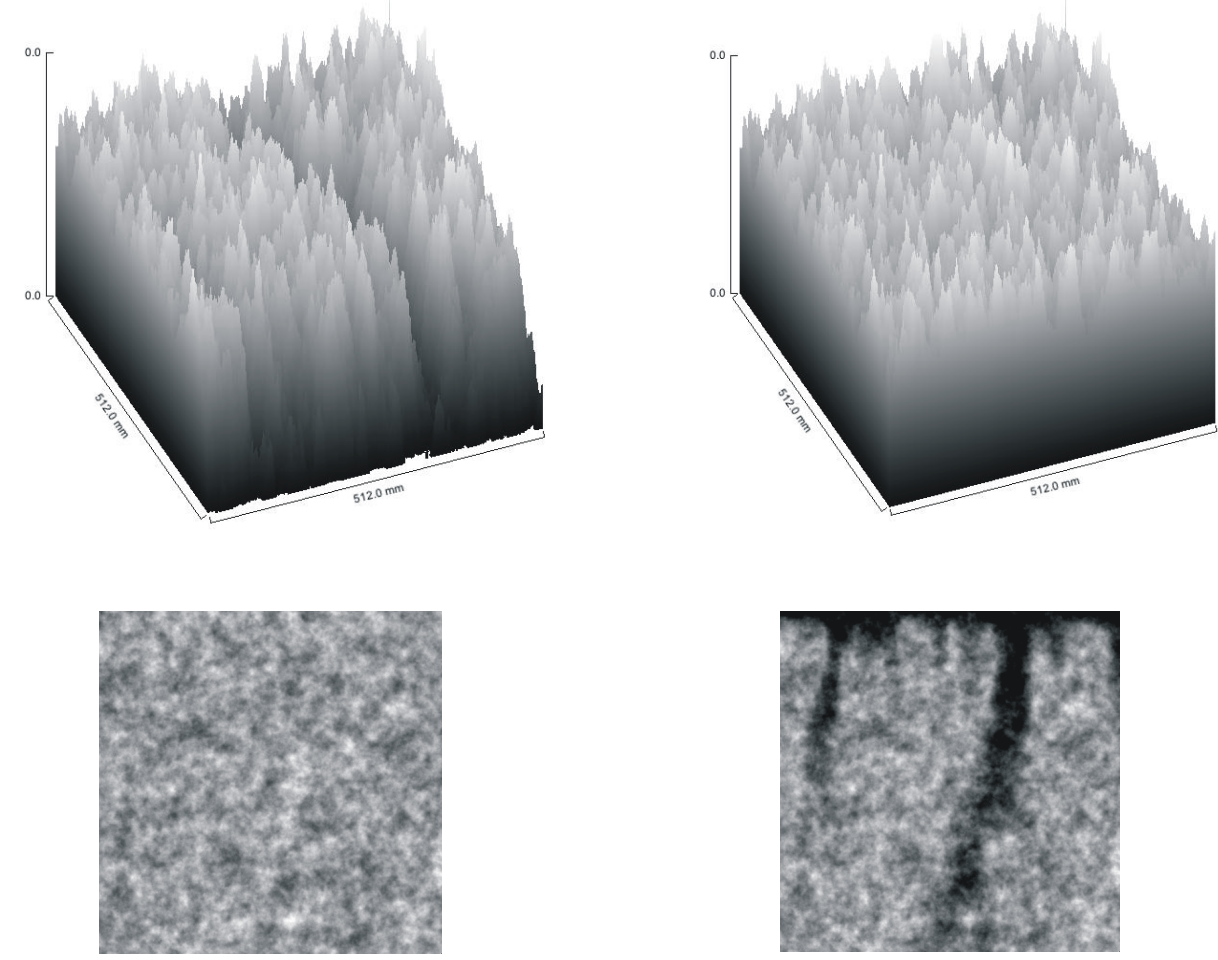

Figure 4. Surface profiles of fracture surface pre-flow (a, left) and post flow (b, right). Scale is vertically exaggerated in $3 D$ representations. Note development of channel in the post-flow image. 


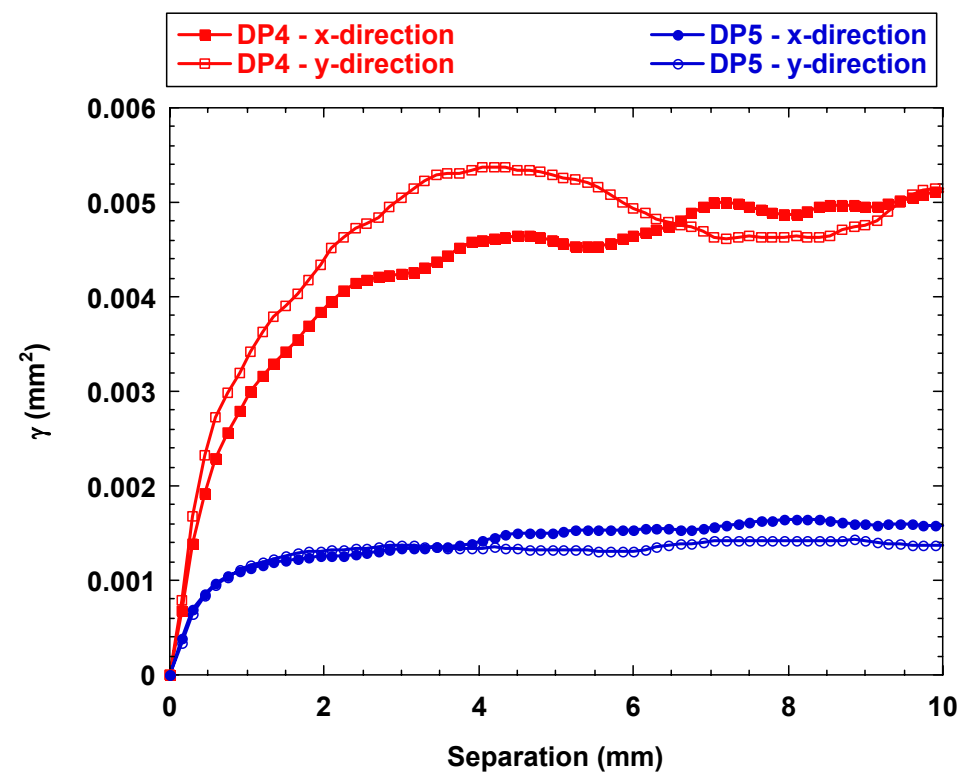

Figure 5. Variogram of half the average squared difference in peak height of a pair of points $(\gamma)$ versus point separation shows significant differences in pre- and post-flow surfaces. Squares denote pre-flow measurements and circles are post-flow measurements for $x$-direction (open symbols) and $y$-direction (closed symbols). More small wavelength variability exists for the pre-flow surface.

\section{Reports \& Articles Published in FY 2004:}

Carlson' S.C., J.J. Roberts, R.L. Detwiler, E.A. Burton, A. Robertson-Tait, C. Morris, P. Kasameyer, 2004, Fracture Permeability Evolution in Rock from the Desert Peak EGS Site, Geothermal Resources Council Trans., v. 28, p. 279-284.

\section{Presentations Made in FY 2004:}

Carlson'S.C., J.J. Roberts, R.L. Detwiler, E.A. Burton, A. Robertson-Tait, C. Morris, P. Kasameyer, Fracture Permeability Evolution in Rock from the Desert Peak EGS Site, Geothermal Resources Council, Annual Meeting, Palm Springs, CA, Aug. 30-September 2, 2004 (presented by J. Roberts)

Detwiler, R.L., S. Ezzedine, and H. Rajaram, Dissolution of single fractures: The role of aperture variability and reactive fluid flow on permeability evolution, DOE Basic Energy Sciences Symposium on Flow and Transport: Characterization and Modeling from Pore to Reservoir Scales, Gaitherburg, MD, Sept. 24-25, 2004.

\section{Planned FY 2005 Milestones:}

Complete design of thermal fracture experiment and test design

Dec 2004

Complete fracture permeability evolution experiments with silica-free fluids

May 2005

Complete set of thermal fracture experiments and report results at 2005 GRC

Aug. 2005 


\section{High Temperature Borehole Televiewer}

Reporting Period: FY 2004 (October 1, 2003 to September 30, 2004)

DOE Grant/Contract \#: $\quad$ DE-AC04-94AL85000

Performing Organization: Sandia National Laboratories

Geothermal Research Department 6211

Albuquerque, New Mexico 87185-1033

Principal Investigator: $\quad$ Scott S. Kuszmaul, (505) 844-5401, sskuszm@sandia.gov

Collaborating Researchers: Steve Bjornstad, stevenbjornstad@navy.mil

Steve Hickman, hickman@usgs.gov

DOE HQ Program Manager: Dr. Leland (Roy) Mink, (202) 586-5463, roy.mink@hq.doe.gov

DOE HQ Technical Manager: Dr. Allan Jelacic, (202) 586-6054, allan.jelacic@ee.doe.gov

DOE Funding Allocation: $\quad \$ 0 \mathrm{~K}$ (completed with limited carryover)

Cost Share Funding: $\quad$ \$200K direct funding received from Naval Air Warfare Weapons Station

Project Objective: This project is funded jointly by DOE's Geothermal Technology Program and Naval Air Weapons Geothermal Program Office. The geothermal industry has a critical need for the type of formation and fracture information available from low temperature borehole imaging televiewers. Unfortunately, these tools will not survive in the high temperature environments typically encountered in geothermal wells. The goal of the High Temperature Borehole Televiewer project is to upgrade an existing conventional low temperature televiewer to operate at high temperature in order to provide data to enhance the understanding of underground fractures.

The system will be deployed by the U.S. Geological Survey (USGS) to perform fracture imaging at the Coso Geothermal field as part of the Enhanced Geothermal System (EGS) technology demonstration. The purpose of the EGS project is to develop and demonstrate new EGS techniques to improve the productivity of the Coso Geothermal field.

Background/Approach: A feasibility study was initiated to investigate the viability of developing a $+300{ }^{\circ} \mathrm{C}$ High Temperature Borehole Televiewer that could be deployed by the USGS at the Coso Geothermal field to perform fracture imaging in order to demonstrate the required techniques for improving productivity.

Early project emphasis consisted of conducting a market survey to identify and evaluate the technology utilized in existing low temperature borehole televiewers with the expectation that one of these commercially available systems could be readily upgraded to operate at high temperature. Our preference 
was for a system that was domestically available from a manufacturer that also provides field services to the geothermal industry and was willing to market the new borehole televiewer system. An evaluation matrix was developed to aid our selection process of potential suppliers. The template contained categories chosen to permit comparison of the three leading companies that offer borehole televiewers. The assessment clearly indicated that Mount Sopris Instrument Company was best suited to upgrade their borehole televiewer to high temperature.

The design approach used was based on a configuration that allowed the electronics and software to be reused without major modifications. This design method would be achieved by inserting the printed circuit boards with embedded software in a Dewar to prevent exposure to high temperatures. Also, we required that the surface system functionality not need modified due to the limited budget. The majority of the design effort would then concentrate on mechanically redesigning the tool nose and related components that are exposed to the $+300{ }^{\circ} \mathrm{C}$ wellbore fluids. A new motor, transducer, mirror, and associated components rated at $+300{ }^{\circ} \mathrm{C}$ will need to be developed.

Status/Accomplishments: The initial full-scale field test of the newly designed ABI85 acoustic head integrated with a previously designed ABI88 cartridge was conducted at Coso well 58A-10 on 1/9/04. System imaging at high temperature and mechanical centralization were to be confirmed. Problems imaging at maximum temperature were encountered when the 4.33 " diameter tool got stuck at 7450 feet in the 6.125 " diameter open hole. The temperature at this limited depth was only $170{ }^{\circ} \mathrm{C}$, which was not high enough to provide a valid high temperature stress test of the system. It was concluded that a 3-month schedule slip was warranted to enable the centralizers to be reconfigured and autoclave testing performed to verify performance at high temperature.

ALT undertook a series of autoclave tests during February 2004 that exposed a fully assembled acoustic head to temperatures of $300^{\circ} \mathrm{C}$ at pressures of $10,000 \mathrm{psi}$ as required by the contract. This testing revealed a tendency of the system imaging sensitivity to decrease during and after excursions to high-temperature and high-pressure environments. To resolve this issue, a series of videoconferences was conducted with the transducer designer TNO TPD, ALT, and Sandia. As a result of these meetings the operating parameters of the autoclave testing was altered to eliminate boiling the oil in the tool head and the head was redesigned to include a venting orifice to relieve any pressure differential between the transducer and the backing material. Further testing confirmed that the system imaging sensitivity returned to normal after excursions to high-temperature and high-pressure environments.

Integration testing of the ABI85HT system components continued throughout the summer of 2004 in preparation for full system test at Coso. The dewar flasks were manufactured and successfully evacuation tested, the centralizers were redesigned to provide the necessary stiffness to keep the tool centered in the open hole at a 15-degree deviation from the vertical, and the motor drive torque was tested at various pressure and temperature profiles.

This effort resulted in two complete ABI85 systems being delivered to Coso for an October 2004 final acceptance field test. The reconfigured centralizers permitted the tool to be deployed past the previous obstruction encountered in Coso well 58A-10 to a total depth of 10,200 feet. Good images were acquired at this depth at temperatures exceeding $235^{\circ} \mathrm{C}$ and thus contractual delivery requirements were deemed completed. The ABI85 systems will remain in place at Coso in preparation for the deepening of the EGS well 34-9RD2.

The commercially available ABI85HT borehole televiewer system now offers the geothermal industry a $50^{\circ} \mathrm{C}$ increase from the previous $225^{\circ} \mathrm{C}$ limit to the new $275^{\circ} \mathrm{C}$ and above limit at which open-hole borehole caliper and structural information can be acquired. 
Reports \& Articles Published in FY 2004: There were no articles published but the research was documented in the following reports.

1. TNO TPD detailed the results of their autoclave test to verify the stability of the transducer used on the ABI85HT acoustic head, internal memo reference DII-MEM-040000, February 4, 2004.

2. ALT detailed the selection of the oil to use in the ABI85HT acoustic head in "Report on Evaluation of the Acoustic Performance of the ABI85HT Tool and Comparison of Galden and Morlina Oil", July 12, 2004.

3. ALT detailed the results of their full-scale autoclave test to verify ABI85HT acoustic head functionality in the report "Autoclave Testing of ABI85HT Acoustical Heads in Paris, July 2004", July 2004.

4. ALT detailed the results of their test of the ABI85HT tool in a cool well in the report "ABI85HT Head Field Testing Chateaurenard, August 2004”, August 2004.

5. ALT detailed the results of their additional autoclave testing to verify final ABI85HT acoustic head configuration in the report "ABI85HT Report of the Autoclave Test of the 23rd August", August 23, 2004.

6. USGS detailed the results of their quality check on ABI85 orientation data in the report "Notes on Preliminary Findings of ABI85 QA: Orientation Errors", December 2004 (FY05).

Presentations Made in FY 2004: No presentations were given at external open meetings.

Planned FY 2005 Milestones: Project completed November 2004. 


\section{MEQ Monitoring}

Reporting Period: FY 2004 (October 1, 2003 to December 31, 2003)

DOE Grant/Contract \#: $\quad$ DE-AC03-76SF00098

Performing Organization: Lawrence Berkeley National Laboratory, One Cyclotron Road, Berkeley, CA 94720

Principal Investigator: $\quad$ Ernest L. Majer, (510) 486-6709, elmajer@lbl.gov

Collaborating Researchers: John Peterson, jepeterson@lbl.gov

DOE HQ Program Manager: Dr. Leland (Roy) Mink, (202) 586-5463, roy.mink@hq.doe.gov

DOE HQ Technical Manager: Dr. Allan Jelacic, (202) 586-6054, allan.jelacic@ee.doe.gov

DOE Funding Allocation: $\quad \$ 200 \mathrm{~K}$

Cost Share Funding:

$\$ 50 \mathrm{~K}$, In kind, station support and maintenance from Calpine and NCPA, \$92K, California Energy Commission, Grant for initial station installation of main Geysers Array

Project Objective: To use microearthquake (MEQ) monitoring to intelligently manage the effects of fluid injections and optimize the production for Enhanced Geothermal Systems. Continue monitoring Geysers area and correlating the seismicity to reservoir production parameters as a function of injection and withdrawal rates. Circulate data to the public and scientific community through the USGS and UC Berkeley Northern California Data Center. Analyze the data to link seismicity to reservoir dynamics.

Background/Approach As the global demand for energy increases it is obvious that geothermal must and will play a significant part in meeting this demand. Exploitation of deep resources such as Geothermal will need manipulation of the deep geological setting to release the trapped heat resource. One of the environmental as well as scientific issues that must be addressed is the effect and role of seismicity in managing geothermal resources. Seismicity is currently being used as a reservoir management tool, but is it is also becoming a negative issue with some of the communities surrounding geothermal fields. Seismic events in the magnitude 2 and above range have raised concern to the residents near certain fields for not only their individual but cumulative effect. In particular, the general public's perception is that this induced seismicity may cause damage to structures on the surface, similar to that caused by "natural" earthquakes. A general concern by industry is that not enough human resources have been invested in trying to answer some of the questions associated with it. For example, how and why do they occur and can we devise any procedures to reduce them. A large amount of knowledge and experience exists and needs to be synthesized.

Economically viable geothermal systems must have adequate heat, fluids, and permeability in sufficient quantity. All three of these imply a dynamic system where if one perturbs the system through either 
injection or withdrawal the in-situ stresses will become unbalanced (they may already may be in many areas) causing an increase in failure rates and possible seismicity rates. In some geothermal areas if one increases the injection rate MEQ activity increases. This may be a small or large increase depending on the existing in-situ stresses, amount of net fluid removal, chemical reactions in the permeable pathways, subsidence, pressure changes, the size of the faults/connectivity, and the rate of fluid

injection/withdrawal. The initial part of this project is focused at The Geysers. The Geysers California field is about to undergo a significant injection program, which is aimed at enhancing the lifetime and production of the field. A question that must be answered when one is using sustained injection to enhance production is, can one intelligently manage injection to minimize the effect of earthquake activity. If one injects too fast, in the wrong areas, etc, seismicity may increase and potentially cause damage to the wells and power plants, but may also be of concern to nearby communities. LBNL has had a long history of MEQ monitoring at a variety of geothermal areas. The work started at the Geysers in the 1970 's and has continued on and off until the present. Currently LBNL in conjunction with Calpine and NCPA installed and is operating a 23-station state-of-the-art array over the entire field. This work was funded by the California Energy Commission (PIER) (\$600K) to collect background and initial data from the Santa Rosa wastewater injection project. The data collection started in May of 2003 and will continue until the end of December of 2003 (CEC grant ends). The data are collected and sent to LBNL and then USGS. The locations, and waveform data are saved and sent to the Northern California Data center at the Berkeley Seismographic Station. Injection is planned to expand as the wastewater volume increases over the years. A critical question that is being addressed is how this injection will affect the seismicity, what does it imply for injection strategy, and how will it impact the local community as well as field operations. In short how does one evaluate and manage the risk associated with injection and seismicity.

The northwest Geysers is a prime candidate for EGS due to the very high heat content. Injection is one of the few economic means to mine this heat. The current array does not extend to this area. Needed is background seismicity data for this area and an understanding of how expansion affects the entire system. This is a unique opportunity to obtain the data before injection and increased production begins. The work in FY 2004 will expand the current array at The Geysers by adding 5 more stations to cover the next planned expansion of the Geysers to the NW. Background data will be collected along with the rest of The Geysers and analyzed relative to production and injection rates, volumes, and location of injection/ production. Locations of MEQ's, source mechanisms, rates of seismicity, rates of energy release, and magnitudes of the events will be calculated and correlated with known faults and geology. To address the issue of MEQ's and injection/production a time history must be built up. Questions such as the maximum expected event, how does one-change injection rates and location, as well as questions regarding balance of risk versus overall production will be addressed. Estimates of fault dimensions versus maximum expected magnitudes, cumulative energy release versus rate of release (many small versus few big).

Status/Accomplishments: The seismic array was expanded in 2004 to include the Aidlin plant area (Figure 1). This was in preparation for the injection in this area from excess water due to increased rainfall that occurs in the winter in this area (usually Nov-March).

Monitoring was interrupted in early September of 2004 due to a 12,000-acre wildfire that swept through the Geyser SE area. All stations were down because the internet wires were damaged that connected the station and one of the two central sites that converted the data that was being sent to Berkeley. The array was reconfigured by October of 2004 and operations were resumed in the NW Geysers, but the SE part of the array is still down awaiting resumption of power and Internet service to this part of the array. It is anticipated that the resumption of power and Internet service will be accomplished by CalPine by early January of 2005.

In terms of analysis of the data, the seismicity has been increasing over time. Notable is the upswing in early 2003, right after the injection increased by 11,000,000 gal/day in the northern section of the field 
due to the water from Santa Rosa. However, the amount of energy increase over the same time period is actually constant or slightly decreasing! This is implying the system as a whole may be at its energy release limit, or it will take a much larger injection to increase energy output due to seismicity. There may be several explanations.

1. There is an upper limit on fault length thus limiting energy release at the upper range.

2. Most of the events are occurring on pre-existing faults, no new fractures are being created.

3. The injection rate is not high enough or, is not correlated to energy release.

In any case, as we learn more about the seismicity we may be able to control it. Aidlin is an excellent opportunity to perform these studies due to the fact that it is a relatively "virgin" injection zone.

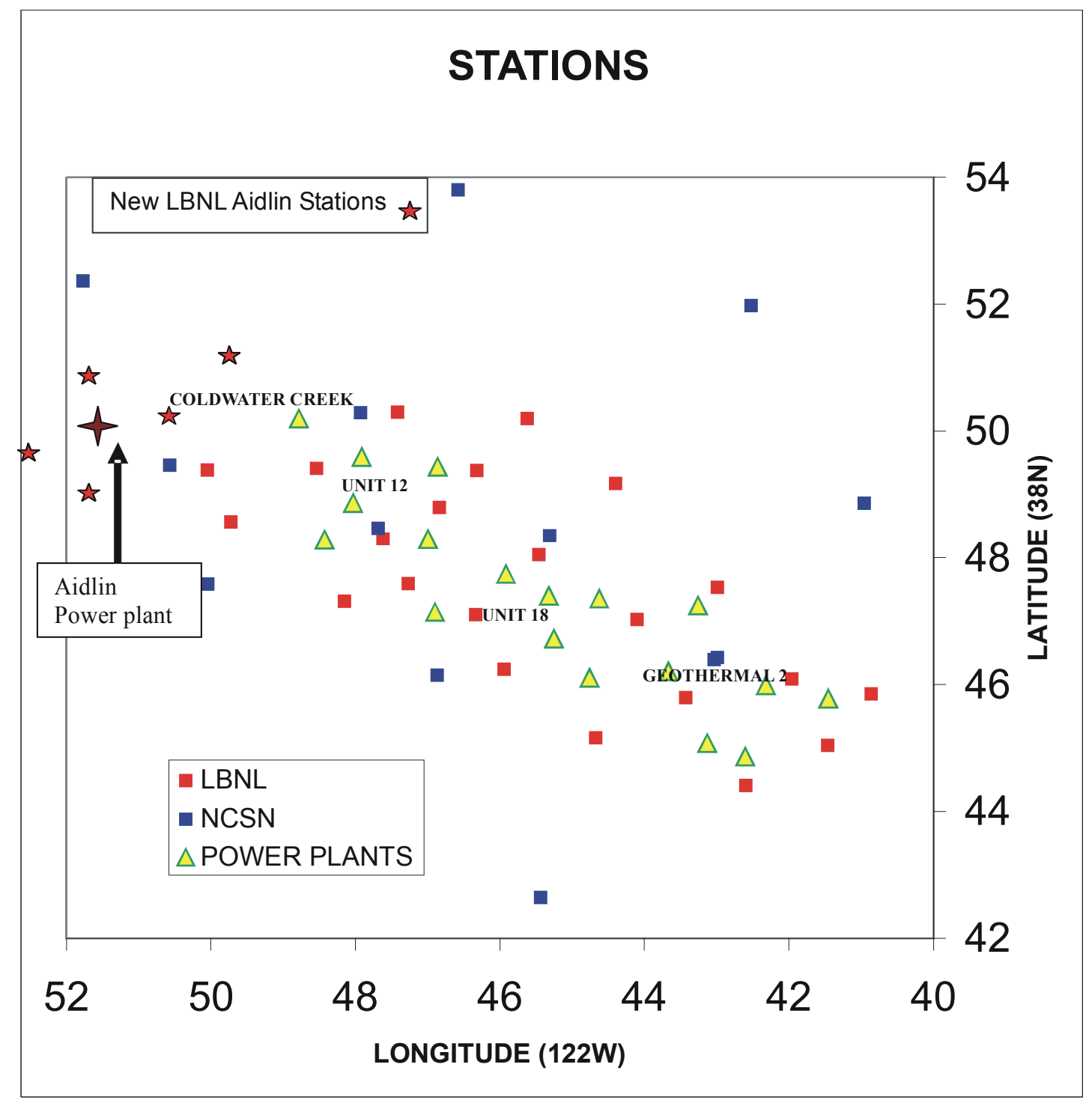

Figure 1. New Aidlin stations relative to the existing LBNL array 
Other activity in this task included expanding the investigation from The Geysers to geothermal fields in Nevada and other sites. The Geysers while important is a relatively unique area. Plans were formed with Geothermics Inc. to investigate and monitor a field in Nevada that is planned for stimulation.

In addition LBNL is participating in the IEA effort on understanding seismicity from enhanced geothermal activities. A White paper was produced by LBNL and circulated to planners of the effort. The result being a workshop planned for early February of 2005 at Stanford after the Stanford geothermal workshop. The objective of the workshop is to leverage resources and knowledge to define a path forward. The workshop is intended to be an interactive exercise with all contributing in one fashion or another, i.e., a true workshop not a string of presentations. Ideally, the result of the workshop would define definite studies, synthesis of information, and/or experiments that will shed light on the cause and hopefully control of seismicity in geothermal systems.

\section{Reports and Articles Published in FY 2004}

White paper on Induced Seismicity, submitted to DOE May 2004

\section{Presentations Made in FY 2004:}

May 2004, Progress report to the Lake county seismic advisory panel.

\section{Planned FY 2005 Milestones:}

Continue monitoring Geysers area and correlating the seismicity to reservoir production parameters as a function of injection and withdrawal rates. Circulate data to the public and scientific community through the USGS and UC Berkeley Northen California Data Center -ongoing

Compare seismicity in Aidlin area in high injection periods (Nov - March) to background - ongoing.

Velocity model improvement: An updated 3-D velocity model for the expanded study area to include the Aidlin area, 2nd quarter.

Hold workshop at Stanford with international attendees to address and identify priorities associated with seismicity due to Enhanced Geothermal activities. Feb 2005

Use the improved locations and velocity model to understand the anisotropy effect on the attenuation and traveltimes, 3rd quarter

Integrate appropriate processing into routine data processing: Include the most robust processing into the automated processing stream $4^{\text {th }}$ quarter. 


\section{SYSTEMS DEVELOPMENT}




\section{Materials Field Testing}

Reporting Period: FY 2004 (October 1, 2003 to September 30, 2004)

DOE Grant/Contract \#: $\quad$ DE-AC36-99-GO10337

Performing Organization: National Renewable Energy Laboratory

1617 Cole Blvd., Golden, CO 80401

Principal Investigator: $\quad$ Keith Gawlik, (303) 384-7515, keith_gawlik@nrel.gov

Collaborating Researchers: Toshi Sugama, Brookhaven National Laboratory, sugama@bnl.gov

DOE HQ Program Manager: Dr. Leland (Roy) Mink, (202) 586-5463, roy.mink@hq.doe.gov

DOE HQ Technical Manager: Raymond LaSala, (202) 586-4198, raymond.lasala@ee.doe.gov

DOE Funding Allocation: $\quad \$ 140 \mathrm{~K}$

Cost Share Funding: $\quad \$ 150 \mathrm{~K}$ in-kind estimated by Mammoth Pacific LP, Puna Geothermal Venture, Calpine, Curran International

Project Objective: Corrosion, erosion, and fouling by scale deposits are major issues for geothermalfluid-wetted heat exchanger tubes and other plant equipment in geothermal power plants at several reservoirs. In some cases, expensive corrosion-resistant alloys are used in shell and tube heat exchangers or other components because of the need for corrosion resistance. In other cases, frequent heat exchanger retubing or equipment replacement is required to repair corroded tube bundles. Capital and maintenance costs of geothermal equipment in these environments can be reduced considerably if inexpensive carbon steel tubes could be coated with a low-cost, thermally conductive coating that provides corrosion resistance equal to that of high-grade alloy steels, thus reducing the levelized cost of generating geothermal power. Corrosion-, erosion-, and fouling-resistant coatings for carbon steel tubes have been investigated at Brookhaven National Laboratory (BNL) and the National Renewable Energy Laboratory (NREL), in cooperation with industry partners CalEnergy Operating Company, Mammoth Pacific LP, Bonnett Geothermal, Calpine, Puna Geothermal Venture, Thermochem, and Curran International. These partners have hosted field tests of the coatings at geothermal power plants, assisted in field testing, or have commercialized the coatings.

Objectives in FY04 were to complete the first set of field tests started in new locations in the previous year, maintain tests in current locations, and plan for tests at a new location. All objectives were met.

Background/Approach: The research program is developing coatings for high- and low-temperature applications. For high-temperature applications, the goal is to develop a coating with low susceptibility to hydrothermal oxidation. We found that polyphenylenesulfide (PPS) is the best polymeric material that meets this requirement. Although PPS coatings showed oxidation after exposure to acid brine at $390^{\circ} \mathrm{F}$, they played a key role in successfully protecting inexpensive carbon steel heat exchanger tubes against 
corrosion in wet, harsh, geothermal environments. Our findings suggested that PPS-coated carbon steel tubes can be used in place of expensive titanium alloys, Inconel, and stainless steels, which are frequently used in geothermal power plants. Because of its semicrystalline polymer structure, PPS has good surface hardness and smoothness. Fillers are used to further improve the hardness, thermal conductivity, and surface energy characteristics of the PPS coating.

For low-temperature applications, we are developing organometallic polymer (OMP) coatings to protect evaporative condensers and aluminum finned steel tubing sprayed with geothermal fluid or well water. Strategies to use geothermal fluid to augment heat transfer by evaporative cooling are being explored at a number of geothermal plants in new and retrofit applications. An approach considered by air-cooled plants is to spray geothermal fluid directly on the finned tubes of condensers during the summer. The finned tubing has been shown to experience severe pitting and scaling during short tests with relatively clean geothermal fluid. OMP coatings are being considered for these applications.

Status/Accomplishments: In FY04 field testing continued at all current sites and plans were made to start tests at a new site in FY05. Figure 1 shows where tests have been conducted in this and past fiscal years.

The Geysers The test of a PPS-coated caustic injection spool (Fig. 2) was completed in May at the Aidlin plant at The Geysers. The coated spool was in service for one year and it lasted twice as long as an uncoated spool. At the end of the test, liner disbondment was observed and the cause of the failure is being investigated. Further tests at Aidlin will depend on the FY05 budget. Coupon tests are planned at the caustic injection point and in the incinerator and another spool may be installed if sufficient funds are available in FY05.

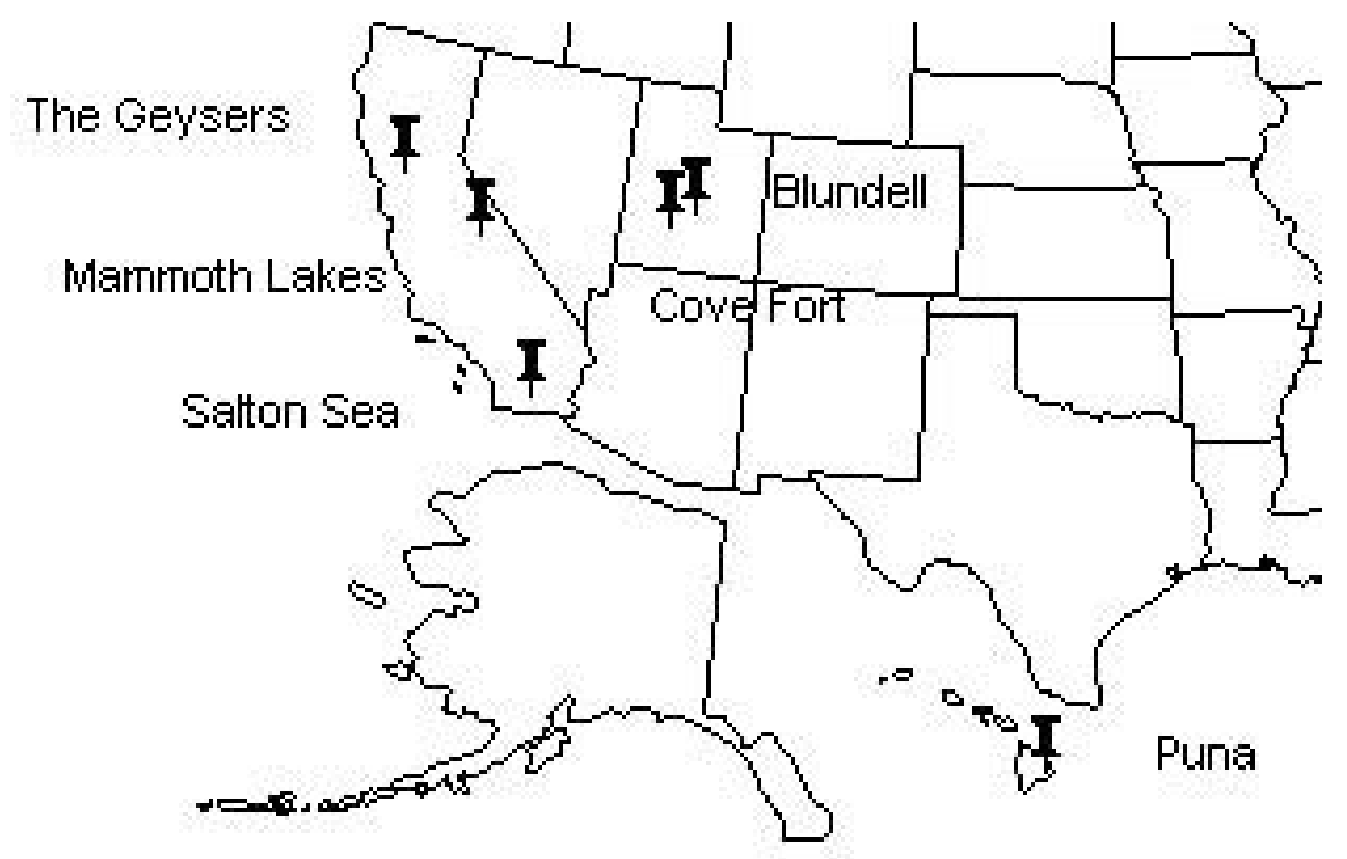

Figure 1. Map of field test locations. 


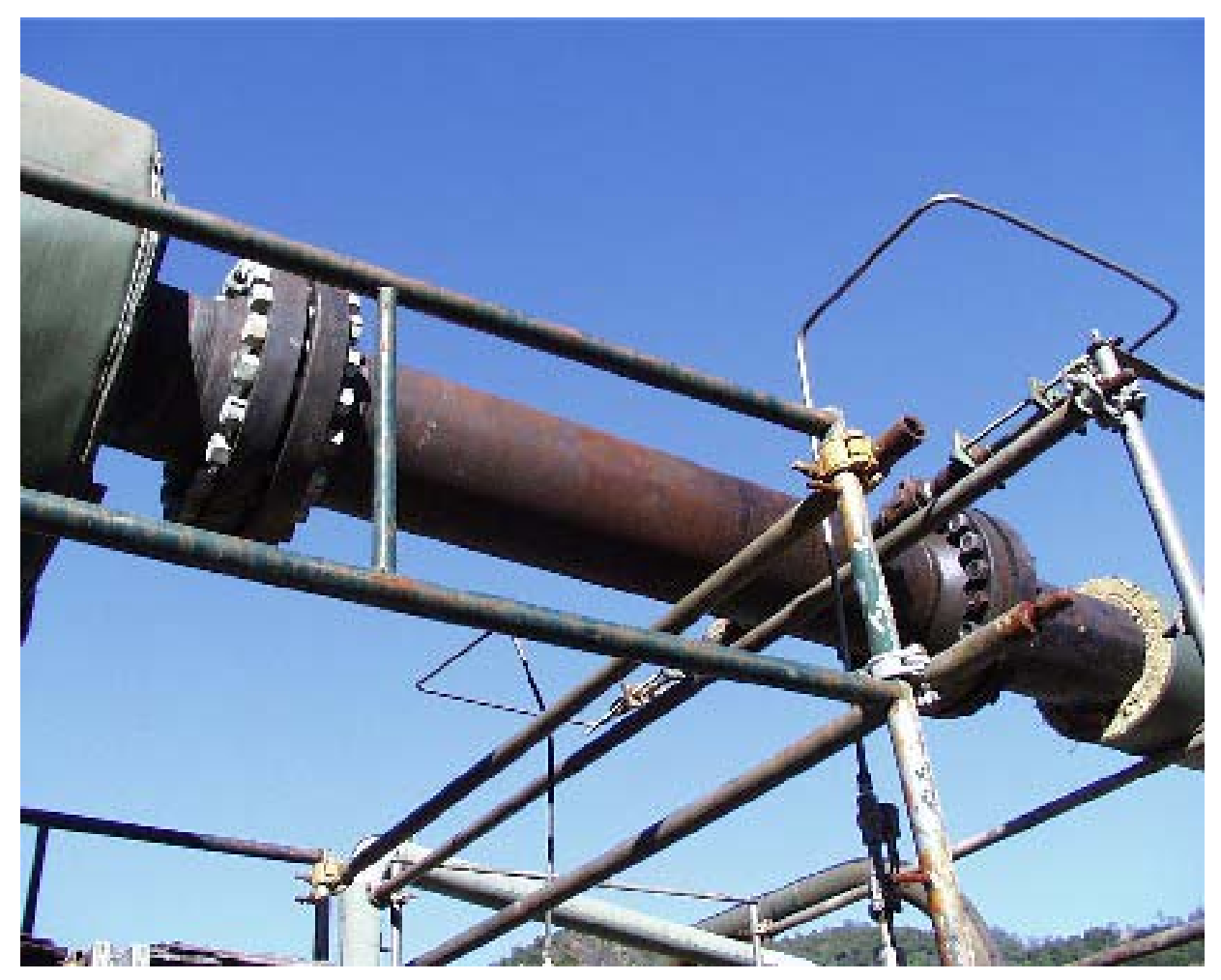

Figure 2. PPS-coated caustic injection spool installed at the Aidlin plant at the Geysers.

Mammoth Lakes Field tests of PPS and OMP coated test articles continued at this location. Tests of PPSlined heat exchanger tubes continued in two test skids installed at the Mammoth Pacific binary plant using sidestreams of production and injection fluids. Tests of 1-inch-diameter, 20-foot-long tubes have been ongoing since August 2000, and some test articles have been in the apparatus for over two years. These tests have yielded important data on long-term durability of PPS to $350^{\circ} \mathrm{F}$ production fluids, and a paper discussing the results was presented at the 2003 GRC Annual Meeting. The tests include periodic pressure washing to simulate semiannual heat exchanger cleanings that occur at the plant. PPS coatings have such a low bond strength with scale that pressures on the order of 2,000 psi are used for complete cleaning, in contrast to the 10,000 to 15,000 psi pressures required to hydroblast uncoated steel, which has a thin layer of strongly adhered scale and corrosion products even after hydroblasting. A test of two 3/4-inch-diameter, 40-foot-long PPS-lined tubes was completed in August after 13 months of exposure to injection fluids. These tubes were prepared at BNL using a different application technique than used for 20 -foot-long tubes, which better duplicates the coating process that would be used in a commercial facility. A new brine sprayer apparatus was built and installed to test OMP-coated aluminum-finned steel tubing under highly accelerated conditions (Fig. 3). The brine sprayer completely wets heated test articles and allows them to dry in 15-minute cycles. This simulates the environment brine-sprayed hydrocarbon condensers would experience. A 3.5-month-long test was completed on four test articles during which 10,000 wet-dry cycles occurred. Additional tests will be done in FY05 on other OMP formulations.

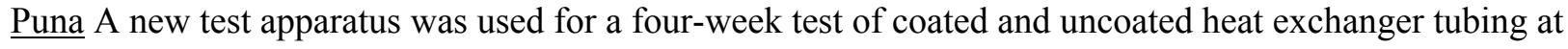
the Puna Geothermal Venture plant, where especially aggressive fluids are encountered. The test was conducted in November and a paper was presented at the 2004 GRC Annual Meeting on the heat transfer and chemical analysis results. Another test is planned for the beginning of FY05. 


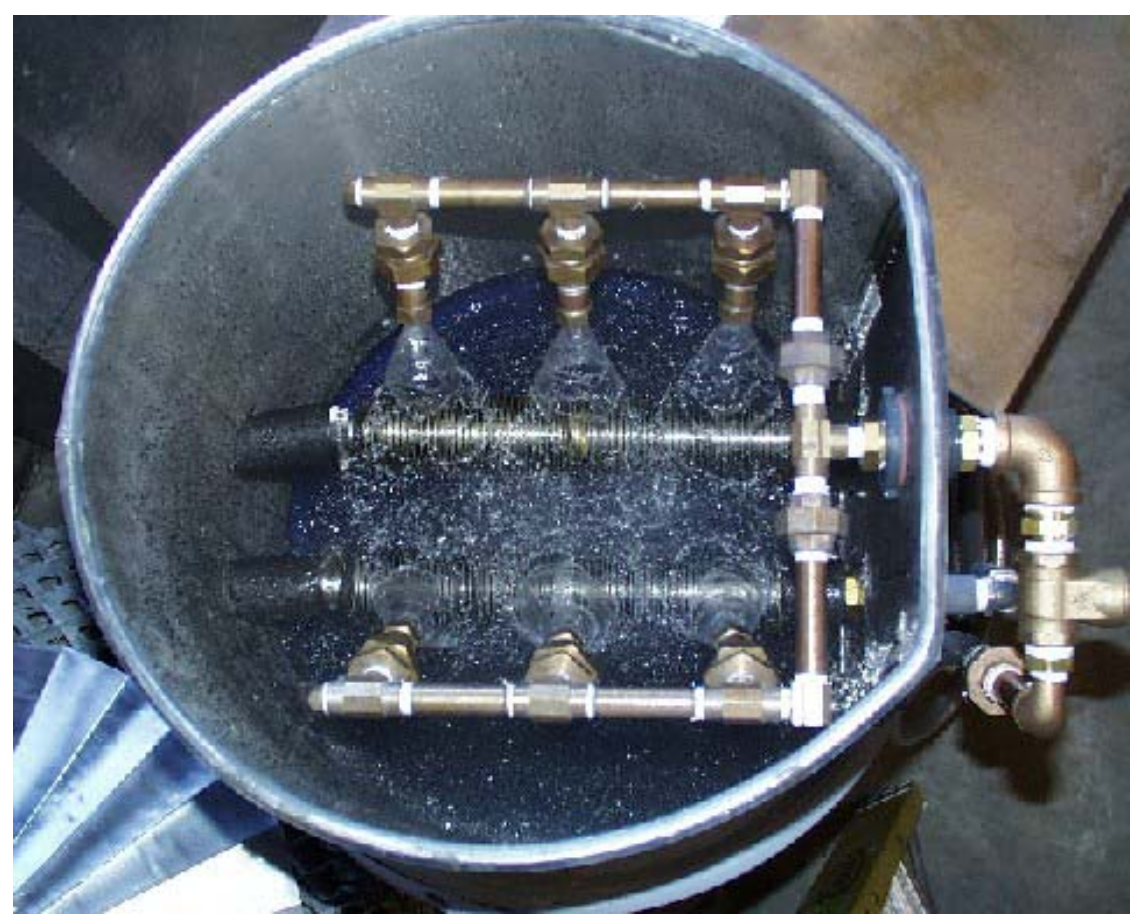

Figure 3. OMP-coated, heated, aluminum-finned tubing exposed to brine spray at Mammoth.

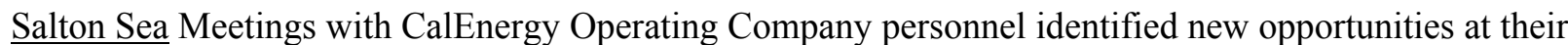
Salton Sea facilities for coating pipelines and other process equipment. Due to highly-fouling fluids that are acidified to reduce their scaling potential, expensive corrosion-resistant materials are often specified. PPS coatings have the potential to reduce material costs considerably. Talks are ongoing to define test locations and conditions. Installation of test articles, such as pipe elbows and spools, is planned for midFY05.

\section{Reports \& Articles Published in FY 2004:}

K. Gawlik, T. Sugama, "Long-term Field Testing of Polyphenylenesulphide Composite Coatings," Geothermal Resources Council Transactions, October 2003.

T. Sugama, K. Gawlik, P. Hirtz, "High Temperature Field Testing of Polyphenylenesulphide Composite Coatings," Geothermal Resources Council Transactions, August 2004.

\section{Presentations Made in FY 2004:}

The two papers described above were also presented at the meetings.

\section{Planned FY 2005 Milestones:}

Complete current exposure tests at Puna, visually inspect, perform heat transfer analysis, install new coated tubes for long term testing, ship samples to BNL

Complete current tests at Mammoth, clean \& inspect tubes, ship samples to BNL, 


\section{Advanced Cycles}

Reporting Period: FY 2004 (October 1, 2003 to September 30, 2004)

DOE Grant/Contract \#: $\quad$ DE-AC36-99-GO10337

Performing Organization: National Renewable Energy Laboratory

1617 Cole Blvd., Golden, CO 80401

Principal Investigator: Charles Kutscher, (303) 384-7521, chuck_kutscher@nrel.gov

Collaborating Researchers: Tony Yu, Laurel Swift

DOE HQ Program Manager: Dr. Leland (Roy) Mink, (202) 586-5463, roy.mink@hq.doe.gov

DOE HQ Technical Manager: Raymond LaSala, (202) 586-4198, raymond.lasala@ee.doe.gov

DOE Funding Allocation: $\quad \$ 150 \mathrm{~K}$

Cost Share Funding: $\quad$ None

Project Objective: The goal of the task is to identify and evaluate the cost-performance potential of new low-temperature power generation concepts.

Background/Approach: Many geothermal resources are at temperatures below $300^{\circ} \mathrm{F}$ and require the use of binary cycles, which are considerably more expensive than flash plants. There is a clear need to develop more efficient and more cost-effective power cycles for low-temperature electricity generation. Previous NREL analysis has focused on the Kalina cycle, but there are other innovative power generation concepts that warrant investigation. Barber-Nichols and others have proposed the use of a subatmospheric flash design to extend the applicability of flash plants down to resource temperatures as low as $250^{\circ} \mathrm{F}$. However, no study has been done to evaluate the performance and costs and determine at what resource temperatures such a system can be cost-effective. There are also other concepts that have been proposed by inventors and small companies for generation of electricity from waste heat, and these concepts have not been evaluated.

\section{Status/Accomplishments:}

- We conducted a literature search of advanced power cycle concepts. These were compiled into a spreadsheet that gave pros and cons for each concept. The concepts were culled down to the dozen most promising ideas and they were distributed to a group of experts who ranked them. The top two ideas, a pure ammonia cycle and subatmospheric flash, were then selected for analysis.

- In August 2004, we completed preliminary analyses of the two innovative geothermal power plant cycles: a sub-atmospheric flash Rankine cycle and a Rankine cycle employing pure ammonia as the working fluid. Aspen Plus and EES (Engineering Equation Solver) models were assembled for both systems, and costs were determined via Aspen-Icarus. Both concepts showed potential for 
providing lower electricity costs than current organic Rankine cycle (ORC) designs at low resource temperatures.

\section{Reports \& Articles Published in FY 2004:}

A 30-page draft report entitled, "Report on the Investigation of Innovative Low-Temperature Power Cycles for Geothermal Power Plants," by C. Kutscher, L. Swift, and T. Yu was prepared and provided to DOE. This report includes the spreadsheet of promising ideas, the analysis results for the two top ideas, and an appendix containing the results of the literature search.

Presentations Made in FY 2004: None

Planned FY 2005 Milestones:

Identification of additional analysis activities

February 1, 2005

Final report on analysis results

September 30, 2005 


\section{Advanced Heat Rejection}

Reporting Period: FY 2004 (October 1, 2003 to September 30, 2004)

DOE Grant/Contract \#: $\quad$ DE-AC36-99-GO10337

Performing Organization: National Renewable Energy Laboratory

1617 Cole Blvd., Golden, CO 80401

Principal Investigator: Charles Kutscher, (303) 384-7521, chuck_kutscher@nrel.gov

Collaborating Researchers: Eric Kozubal, Keith Gawlik

DOE HQ Program Manager: Dr. Leland (Roy) Mink, (202) 586-5463, roy.mink@hq.doe.gov

DOE HQ Technical Manager: Raymond LaSala, (202) 586-4198, raymond.lasala@ee.doe.gov

DOE Funding Allocation: $\quad \$ 185 \mathrm{~K}$

Cost Share Funding: $\quad$ \$75K in-kind estimated by Super Radiator Coils

Project Objective: The objectives of this task are to identify and develop improvements in geothermal power plant heat rejection systems, specifically by improving the performance of air-side fins used in finned tube heat exchangers. Our goal is to reduce electricity cost by 0.5 -cent per kWh.

Background/Approach: Because of the thermodynamics of operating power cycles at typical geothermal resource temperatures, approximately $90 \%$ of the heat extracted from the ground must be rejected to the environment. Water-cooled condensers are preferable from a performance standpoint; however, aircooled condensers are often used in geothermal power plants because of the lack of clean cooling water and because they avoid depletion of the geothermal resource. Air-cooled condensers account for as much as $30 \%$ of total plant capital cost, and the required fan power decreases power output by about $10 \%$. Together, this can increase the cost of electricity by $20 \%$. Thus, the cost of geothermal electricity can be reduced significantly if performance of the heat rejection systems can be improved.

NREL has developed computer models and experimental test capability to evaluate new air-side fin concepts. We have a Cooperative Research and Development Agreement (CRADA) with Super Radiator Coils (SRC), a major manufacturer of finned-tube heat exchangers, which was extended through Fiscal Year 2004. SRC has helped NREL fabricate and test transpired fin concepts as well as a new tab fin concept. In FY03 we constructed and instrumented an improved transient test rig. We designed a singletab tool that we used to produce small prototypes of tab fins and tested these fins in several configurations. We also conducted Fluent simulations to optimize the tab dimensions and built a tool to allow us to fabricate larger prototypes for steady-state testing at ITS, an independent test lab used by Super Radiator Coils. The results of our laboratory tests and computer simulations indicated that that the new tab fin concept can significantly improve the economics of air-cooled condensers. 
In FY04 our work focused on further development of the tab fin concept. We fabricated a tool that allowed us to build a test article containing tabbed circular fins on one-inch tubes. Prototypes were fabricated and tested. A detailed report was prepared to present the work to an experts' panel in early FY05.

\section{Status/Accomplishments:}

- Working with our industry partner, SRC, we conducted tests of two first-generation tab fin heat exchangers using plate fins on half-inch tubes in NREL's Advanced HVAC Test Laboratory. The test results showed the tab fins capable of providing high heat transfer rates at relatively modest pressure drops, convincing SRC to continue to pursue this technology. A test article employing tabs on plate fins with half-inch tubes demonstrated $17 \%$ more heat transfer than plain fins at the same fan power.

- We completed the design and fabrication of a pneumatic tool to punch heat transfer enhancement tabs into circular fins for use on one-inch tubes. We punched approximately 2300 fins that were used by our industry partner, SRC, to assemble a 15" x 15" x 3 rows test article. Testing of the enhanced heat exchanger was performed at Intertek Testing Services, an independent test lab, in September 2004. Measurements showed that the tabs on circular fins provided $4.5 \%$ more heat transfer than plain fins at the same fan power. Our calculations show that by further perfecting tab placement, we should be able to obtain $12 \%$ more heat transfer at the same fan power for this geometry.

- $\quad$ C. Kutscher and E. Kozubal developed a computer model of an innovative method for evaluating the performance of condenser heat transfer enhancements. C. Kutscher presented a paper on this work, "An Analytical Model for Evaluating Enhanced Fin Concepts for Air-Cooled Condensers," at the annual Geothermal Resources Council Meeting in Palm Springs, CA on August 31, 2004.

- $\quad$ C. Kutscher, E. Kozubal, and K. Gawlik prepared a 40-page report on our research and development of tab fin heat exchangers and provided the report to the technical review panel scheduled to review our work on in early FT 2005.

\section{Reports \& Articles Published in FY 2004:}

"An Analytical Model for Evaluating Enhanced Fin Concepts for Air-Cooled Condensers," by C. Kutscher and E. Kozubal, Proceedings of the Geothermal Resources Council Annual Meeting, September 2004.

\section{Presentations Made in FY 2004:}

C. Kutscher presented "An Analytical Model for Evaluating Enhanced Fin Concepts for Air-Cooled Condensers," at the annual Geothermal Resources Council Meeting in Palm Springs, CA on August 31, 2004.

\section{Planned FY 2005 Milestones:}

Complete Fluent runs on advanced patterns for circular fins Complete test on multi-row heat exchanger in NREL HVAC loop Complete final report including field test plan
April 15, 2005

August 15, 2005

October 1, 2005 


\section{Enhancement of Air-Cooled Condensers}

Reporting Period: FY 2004 (October 1, 2003 to September 30, 2004)

DOE Grant/Contract \#:

Performing Organization: Idaho National Engineering \& Environmental Laboratory 2525 North Fremont Drive, P.O. Box 1625, MS 3815 Idaho Falls, ID 83415-3815

Principal Investigator: $\quad$ Manohar S. Sohal, (208) 526-9412, Manohar.Sohal@inl.gov

Collaborating Researchers:

DOE HQ Program Manager: Dr. Leland (Roy) Mink, (202) 586-5463, roy.mink@hq.doe.gov

DOE HQ Technical Manager: Raymond LaSala, (202) 586-4198, raymond.lasala@ee.doe.gov

DOE Funding Allocation: $\quad \$ 160 \mathrm{~K}$

Cost Share Funding: $\quad$ McElroy Manufacturing, Inc., cash $\$ 3 \mathrm{~K}$ plus in-kind

Project Objective: This task supports the programmatic goal of reducing the levelized cost of power generated from geothermal energy. By improving air-cooled condenser heat transfer performance by $\sim 15 \%$, installed component cost will be lowered, reducing the cost of power.

Background/Approach: Geothermal resources utilizing binary power cycles are frequently located in regions lacking a sufficient supply of make-up water for evaporative heat rejection systems. Thus, heat is rejected directly to the ambient air using air-cooled condensers. Because air is a poor heat transfer medium, a large surface area of the condenser tubes is required. An EPRI report "Next Generation Geothermal Power Plant" prepared by Ben Holt Co. indicates the air-cooled condenser cost can be up to $\sim 25 \%$ of the total plant cost (including well field). Improving the performance of the condensers is expected to have a significant impact on reducing the cost of power generated from these plants. Investigators have identified and confirmed the potential of vortex generators on fins of air-cooled condensers to improve heat transfer performance The vortex generators (on the fins) induce swirling flow, which disrupts the formation of the boundary layer and mixes the flow between the fins. It also reduces the stagnant wake region behind a tube. This concept can reduce condenser size and cost in binary geothermal plants. The work at INEEL parallels efforts at NREL, which is using a different technology/concept to enhance air-side heat transfer performance. To date INEEL investigators have completed laboratory scale experiments, numerical work, and limited small-scale tube bundle testing.

Status/Accomplishments: During FY04, a tube bundle was prepared using circular individual (plate) fins provided by Super Radiator Coils (SRC), Richmond, VA. INEEL punched the "toe-in" vortex generators. SRC mounted the fins on the tubes, pressurized the tubes to minimize the contact resistance. SRC completed overall fabrication of the tube bundle including the headers. Supposedly the material and 
fabrication technique for the tube bundle was identical to that for the NREL bundle. Also, testing of the tube bundles provided by a CRADA partner was completed during FY04. Overall benefit of the proposed enhanced tube air-cooled condenser was quantified considering performance enhancement (increased heat transfer and pressure drop).

Reports \& Articles Published in FY 2004: Two papers were submitted for publication and accepted in the Journal of Heat Transfer.

J. E. O'Brien, M. S. Sohal, and P. C. Hallstead, "Local Heat Transfer and Pressure Drop for Finned-Tube Heat Exchangers using Oval Tubes and Vortex Generators," Accepted for publication in ASME Journal of Heat Transfer, 2004.

J. E. O'Brien and M. S. Sohal, "Heat Transfer Enhancement for Finned-Tube Heat Exchangers with Winglets," Accepted for publication in ASME Journal of Heat Transfer, 2004.

Presentations Made in FY 2004:

Planned FY 2005 Milestones:

Complete final report on the vortex generator enhancement project 


\section{Continual Removal of Non-condensable Gases for Binary Power Plant Condensers}

Reporting Period: FY 2004 (October 1, 2003 to September 30, 2004)

DOE Grant/Contract \#:

Performing Organization: Idaho National Engineering and Environmental Laboratory

Principal Investigator: $\quad$ Charles Mohr, (208) 526-9552, Charles.Mohr@inl.gov

Collaborating Researchers: Greg Mines

DOE HQ Program Manager: Dr. Leland (Roy) Mink, (202) 586-5463, roy.mink@hq.doe.gov

DOE HQ Technical Manager: Raymond LaSala, (202) 586-4198, raymond.lasala@ee.doe.gov

DOE Funding Allocation: $\quad$ \$70K (FY04)

Cost Share Funding: $\quad$ In kind, only

Project Objective: Although not typically associated with binary geothermal power plants, noncondensable gases (NCGs) are present in these plants. Most of the commercial binary plants in operation have some provision for the periodic removal of these gases. This project is testing and evaluating the use of membrane separation technology to provide for the continual removal of the gases. The system being developed takes advantage of membranes developed for other industries that separate condensable organic vapors from air. This system is intended to minimize both the adverse effect these gases have on power output and the loss of working fluid to the ambient. This project is developing technology that will reduce the cost of generating electrical power by increasing the output of binary-cycle geothermal plants without requiring significant increases in operating or capital costs. In addition, the membrane system can be designed to minimize the release of working fluid, compared to the release associated with the current purge system. This will alleviate any associated public and institutional environmental and air-quality concerns.

Background/Approach: Once the concept was formulated, data from operating plants was evaluated to establish air introduction rates and estimate the probable benefit of the technology. Concurrently the membrane performance for the specific separations involving typical working fluids was established. This was done by subcontract to Membrane Technology and Research, Inc. (Menlo Park, CA), a developer of membranes suited for this application. A prototype pilot unit was then designed and built under subcontract by MTR. The front end of the system consists of a compressor and air condenser, similar to that of existing working fluid recovery systems. It differs in that membranes are installed on the discharge of the working fluid condenser to provide additional removal of the working fluid from the vent stream, allowing the plant condenser to be vented continuously with minimal working fluid loss.

Status/Accomplishments: The prototype system testing is continuing at Mammoth Pacific (Mammoth Lakes, CA). Extensive modifications to the skid were made in early FY2004 to correct the problem of 
unreliable return of condensed working fluid to the plant condenser. The new design features an additional pressure vessel (used to accumulate condensate) and pressure-driven liquid return to the condenser rather than pumped. This rework required extensive piping changes, installation of additional control valves and instrumentation, and a rewrite of the PLC control logic program. The membranes, now about four years old, continue to function well. The unit experienced problems with water condensate (form the plant condenser) freezing in the control valves. This was fixed by heat-tracing the valves, bottoms of the vessels, and liquid return line. Results of the testing to date were reported at the 2004 GRC meeting in Indian Wells, CA. Typical performance of the system at Mammoth shows an air vent rate of 3 to 4 liters per minute with an organic content of 3 to $6 \%$. The vent rate is over 10 times the design rate, resulting in the higher than design concentration of working fluid in the vented air. However, the operator estimates the system has significantly reduced working fluid loss, compared to the purge system used previously.

Reports \& Articles Published in FY 2004: None.

Presentations Made in FY 2004:

Paper presented at the 2004 Geothermal Resources Council Annual Meeting (Indian Wells, CA).

\section{Planned FY 2005 Milestones:}

Complete long-term testing

Document test results and issue final report.
Aug 05

Sep 05 


\section{Geothermal Plant Process Monitoring}

Reporting Period: FY 2004 (October 1, 2003 to September 30, 2004)

DOE Grant/Contract \#: $\quad$ DE-AC07-99ID13727

Performing Organization: Idaho National Engineering and Environmental Laboratory

Renewable Energy and Power Technologies

2525 North Fremont Drive, P.O. Box 1652

Idaho Falls, ID 83415-3870

Principal Investigator:

Judy K. Partin, (208) 526-2822, Judy.Partin@inl.gov

Collaborating Researchers: Eric Sponsler, Brady Power Partners (ORMAT Group), sponsler@cccomm.net

DOE HQ Program Manager: Dr. Leland (Roy) Mink, (202) 586-5463, roy.mink@hq.doe.gov

DOE HQ Technical Manager: Raymond LaSala, (202) 586-4198, raymond.lasala@ee.doe.gov

DOE Funding Allocation: $\quad \$ 189 \mathrm{~K}$

Cost Share Funding: $\quad$ \$ $\quad$ K (Industry In-kind)

Project Objective: This project is directed toward DOE's goal of reducing the levelized cost of geothermal power to $3-5$ cents/kWh by 2010 through the development and verification of low maintenance instrumentation for the real-time detection and control of abatement process parameters.

Background/Approach: Geothermal plants contain gaseous, liquid, and particulate species in process streams that require abatement to minimize equipment damage, maximize performance and/or meet regulatory require-ments. These abatement processes involve the use of costly chemicals and/or the consumption of energy; and in addition, are conservatively applied, in part, because the targeted species are only measured periodically. Some examples of these processes include the over-application of iron chelate to ensure hydrogen sulfide emissions from cooling stacks remain within the regulated limits, and excessive steam washing to remove particulate and reduce chloride concentrations to levels that will not damage plant components. Continuous measurements could allow these abatement processes to be optimized and costs reduced. This project is applying new diode technologies that have been developed for the telecommunications industry in the design of robust instrumen-tation for the real-time monitoring of various stream parameters which impact operating cost and/or plant performance. Parameters targeted in prior year research included measurement of $\mathrm{H}_{2} \mathrm{~S}$ in the treated vent gas stream and $\mathrm{HCl}$ in the steam line. Currently, the project is focusing on the development of a new on-line instrument for monitoring both steam quality and purity.

The measurement of steam quality is important because of the impact that excessive moisture can have on turbine performance and maintenance costs. Moisture can be introduced into the steam line by either inadequate phase separation processes or during steam "washing" employed to reduce particulate, 
chlorides, and other chemicals to levels that are not as damaging to equipment. If too much water is added, the washing process may actually make the damage problem worse. Droplets entrained in the steam can erode turbine internals, while particulate and other contaminates dissolved or entrained in the moisture can deposit on and scale turbine components. Both scaling and erosion adversely impact turbine efficiency, which also decreases as the amount of moisture in the steam increases. Decreases in turbine efficiency reduce the power output and lower revenue streams. For a $50 \mathrm{MW}$ plant the revenue losses due to a $1 \%$ loss in efficiency can be as high as $\$ 175,000$ per year, depending upon the cost of electricity. In low-enthalpy and brine-dominated resources, the deposition of calcium carbonate, silica and other minerals is a serious concern. The formation of scale in pipelines, heat exchangers, and reinjection wells places major constraints in fluid utilization in some geothermal operations, and can result in large maintenance costs for operators. The precipitation kinetics of these minerals is generally not well understood and deposition on plant components can occur quickly without proper controls. Techniques for preventing the deposition of scale include restricting brine temperatures to above that at which supersaturation occurs and acidification of the brine phase to inhibit mineral deposition. In other approaches, chemical inhibitors are used to sequester or complex with the minerals, preventing their precipitation.

The ability to perform on-line monitoring of both the quality (moisture content) and purity (particulate loading) of geothermal fluids could lower the costs of using the resource by: reducing the loss of energy due to over-washing, allowing a more judicious use of expensive scale inhibitors, and by minimizing capital and maintenance costs due to scaling and the associated production losses during plant shutdowns for repair.

Status/Accomplishments: In FY02-03, a new instrument was developed for the in-situ monitoring of steam quality in geothermal steam. The measurement principle for the new Optical Steam Quality Monitor, pictured in Figure 1, is based upon the selective absorption of infrared energy in response to the presence of moisture. The instrumentation consists of an electronics package, containing laser diodes, beam combiners/separators, detectors and a data logger, that is fiberoptically-coupled to a pair of specially designed optical probes. The probes are aligned across the process stream of interest. This allows data to be collected in a volumetric cross section extending across the entire process stream, resulting in the collection of more representative data for higher accuracy measurements that are applicable to all flow regimes. The optical signals are collimated into a beam of radiation that is transmitted through a sapphire window and across the process stream where it is collected by an identical probe assembly and transmitted back to the electronics box for analyses. (Sapphire windows have a combination of physical, chemical, and optical properties that allow them to operate in high pressure, high temperature, and chemically caustic environments.) The probes can be located at distances up to 1 kilometer from the electronics package.

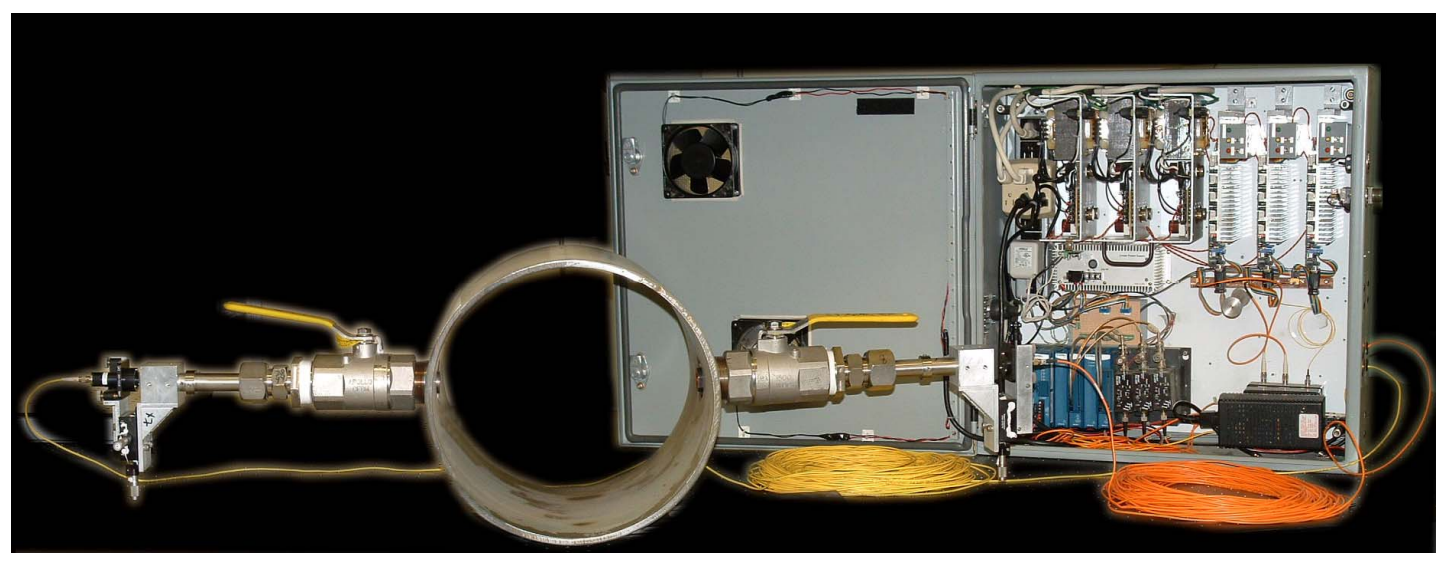

Figure 1. Monitor Instrumentation and In-situ Probes 
The stainless steel probes are designed for "hot tap" insertion into the process stream using a ball valve installation. The process flow across the windows minimizes the formation of condensate and particulate deposition without the use of active heating or gas purging. The probes can also be easily removed for cleaning or replacement without shutdown of the process stream.

In August 2003, an extended, in-situ deployment and evaluation of the Optical Steam Quality Monitor was initiated at the Brady Power Plant operated by ORMAT Nevada, Inc. near Fallon, NV. The plant was well-suited for the in-situ evaluation, since water washing is periodically used in the operation to reduce scale, providing known periodic changes in the steam quality for the instrument to track. The optical probes were installed in a turbine inlet line using aligned ball valve installations located immediately upstream of the turbine and downstream from a series of throttling valves. The optical signals, used for the determination of steam quality, were fiber-optically-coupled from the probes to the instrumentation box installed in the control room. A schematic of the installation is shown in Figure 2.

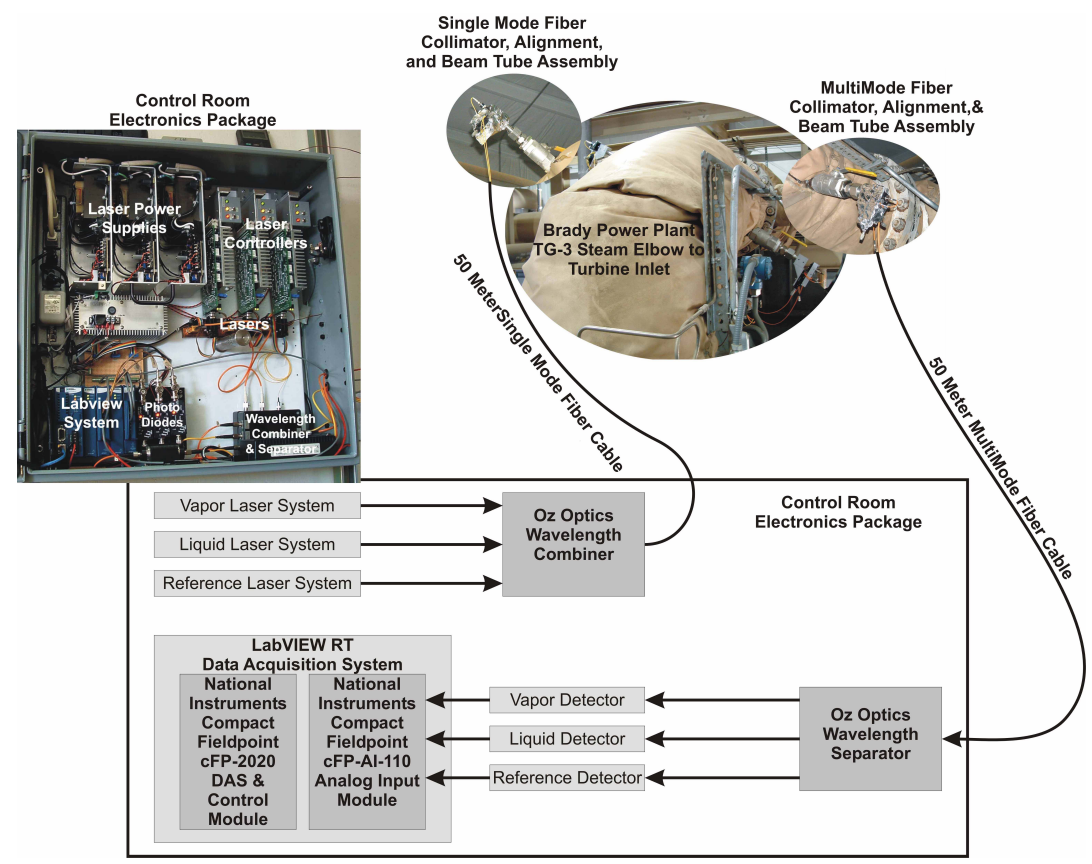

Figure 2. Steam Quality Monitor Installation Schematic

During the 150-day deployment, which concluded in January 2004, the device was able to successfully track small changes $(\sim 0.25 \%)$ in moisture content that occurred during scheduled operations such as turbine water washing to reduce scale. In addition, the monitor also demonstrated the ability to alert operators to off-normal conditions in the plant, including a problem with one of the valve seals on a water wash isolation system. The instrument operated with minimal impact to the plant operation, and while there was some fouling of the window during the extended operation, no serious maintenance issues were discovered. In fact, the optical probes were never removed for cleaning or repair during the entire deployment. The steam quality monitoring technology was licensed in August 2004 to Thermochem, Inc. (Santa Rosa, CA).

During FY-2004, the possibility of upgrading the optical steam quality instrumentation for the detection of entrained particulate was investigated. A proprietary design was subsequently developed, based upon time division multiplexing of the monitoring signals that would allow one channel of the device to serve as a particulate detector; and in particular, provide real-time data on the mass concentration of solids flowing through the sample stream. An improved self-cleaning window probe assembly was also 
conceived for use with the instrument. In addition to adding the ability to more sensitively detect particulate in process streams, the new design could result in an instrument that is less expensive to fabricate, operate, and maintain than the existing system.

The goal of the FY-2005 work is to fabricate the prototype device for detecting particulate in geothermal process streams. A suitable test site will then be selected and an in-situ evaluation of the device will be conducted and reported.

Reports \& Articles Published in FY 2004: J. K. Partin, J. R. Davidson, E. N. Sponsler, and G. L. Mines. 2004. "Deployment of an Optical Steam Quality Monitor in a Steam Turbine Inlet Line", Geothermal Resource Council Transactions, Vol.28, pp. 557-560.

\section{Presentations Made in FY 2004:}

J. K. Partin, J. R. Davidson, E. N. Sponsler, and G. L. Mines, "Deployment of an Optical Steam Quality Monitor in a Steam Turbine Inlet Line", Paper and Poster presented at Geothermal Resources Council 2004 Annual Meeting, Indian Wells, CA, August 29-September 1, 2004.

\section{Planned FY 2005 Milestones:}

In-plant testing and evaluation of the particulate monitor completed and reported. 


\section{Microbiological Research}

Reporting Period: FY 2004 (October 1, 2003 to September 30, 2004)

DOE Grant/Contract \#: $\quad$ DE-AC07-99ID13727

Performing Organization: Idaho National Engineering and Environmental Laboratory

Renewable Energy and Power Technologies

2525 North Fremont Drive, P.O. Box 1652

Idaho Falls, ID 83415-3870

Principal Investigator: $\quad$ Peter A. Pryfogle, (208) 526-0373, Peter.Pryfogle@inl.gov

Collaborating Researchers: Allen Sonneville, Calpine Corporation, asonneville@calpine.com John Avery, Calpine Corporation, johna@calpine.com

Beth Kershaw, Calpine Corporation, bkershaw@calpine.com

DOE HQ Program Manager: Dr. Leland (Roy) Mink, (202) 586-5463, roy.mink@hq.doe.gov

DOE HQ Technical Manager: Raymond LaSala, (202) 586-4198, raymond.lasala@ee.doe.gov

DOE Funding Allocation: $\quad \$ 71 \mathrm{~K}$

Cost Share Funding: $\quad \$ 3.6 \mathrm{~K}$ (Industry In-kind)

Project Objective: This project is directed at investigating the impacts of microbiological activities on the efficient operation of geothermal power production facilities and developing techniques for mitigating the costs associated with these impacts. The specific objective of the 2003-04 work is to contribute to the DOE goal to reduce the levelized cost of geothermal power to 3-5 cents/kWh by 2010 through the demonstration and validation of an on-line instrument for monitoring biofilm development. The project is developing and testing procedures for effectively using the instrument to minimize the impact of biofilm development in condenser and cooling tower systems in geothermal plants. The project goal is reduce the estimated cost of $\$ 500,000$ for $100 \mathrm{MWe}$ plant due to lost revenue, cleaning, and chemical abatement by $50 \%$.

Background/Approach: Microbial activity is an operational issue in power plants utilizing evaporative heat rejection systems. INEEL sampling studies at steam and flash-steam plants in California, Nevada and Utah have shown that cooling waters in their heat rejection systems contain significant densities of bacteria. The steam condensate utilized as cooling water make-up in these plants contains impurities such as hydrogen sulfide, ammonia, carbon dioxide, and dissolved solids that provide nutrition for microbial growth. Microbial organisms can adhere to the surfaces of critical components in geothermal heat rejection systems and develop complex structures called biofilms. The development of biofilms can impact plant performance in a number of ways. Their development on heat transfer surfaces retards the exchange of heat. The biofilms can damage equipment by direct corrosion processes, or by accelerating chemical corrosion activity. Microbial growth can also impact the effectiveness of plant chemical 
abatement systems. Investigations at the INEEL showed increased microbial activity after exposure to the iron chelate compound used in hydrogen sulfide abatement systems, indicating the compound served as a feedstock. Biofilms may also interfere with corrosion inhibitors by preventing their contact with the metallic surface.

The impediment to heat transfer due to biofilm development has the potential to significantly impact plant performance, and consequently plant revenues. Condenser temperature and pressure rise in response to this increased resistance to heat transfer, and power output declines as the associated turbine exhaust pressure rises. Experience at The Geysers indicates that the condensing pressure drops by $\sim 0.5 \mathrm{inch}-\mathrm{Hg}$ after cleaning (on a two-year maintenance cycle). Examination of fouled condensers and deployed coupons indicate the fouling is dominated by biofilm development. Assuming the fouling is linear with time and a cost of power of $\$ 0.03$ per $\mathrm{kW}$-h, the associated lost revenues approach $\$ 400,000$ annually in a $100 \mathrm{MWe}$ plant. When the power revenues associated with cleaning both the condenser and cooling tower and with tube failures are included, the impact of microbial activity on the operation of a $100 \mathrm{MWe}$ plant can exceed $\$ 500,000$ annually.

Plant operators are well aware of the impact of microbial activity, which they attempt to control and mitigate with costly chemical applications. (An operator of a small $10 \mathrm{MWe}$, flash plant has indicated that their annual expenses for biocides approach $\$ 100,000$.) In spite of the high costs, few geothermal plants have biological monitoring programs in place to detect growth problems. Most apply treatments on a predefined schedule, or in response to growth as evidenced by changes in flow parameters or film formation on coupons or other structures. In either case the operating efficiency has been impacted to some extent and larger doses of biocides may be required to eliminate the film. In addition, treatments are typically designed by the vendors selling the chemicals, who have little incentive to reduce their costs. Most biological control strategies are also geared toward reducing the number density (cells per unit volume) of the bacteria present. Work conducted by INEEL and other researchers indicate that is possible to dramatically reduce the numbers of bacteria present without having any significant impact on biofilm development.

INEEL investigators have been evaluating analyses techniques for the detection and characterization of biological growth in geothermal plant cooling water systems. In particular, the utility of a commercially-

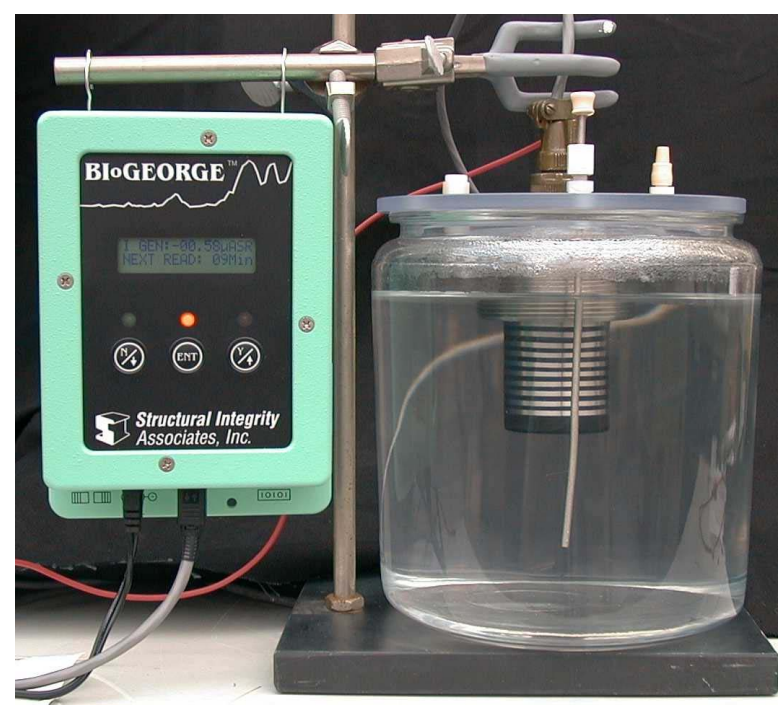

Figure 1. BIoGEORGE ${ }^{T M}$ Monitor. available electrochemical probe, the BIoGEORGE тм Biofilm Activity Monitor, that has been specifically tailored for the detection of biofilm formation, has been investigated. The monitor, pictured in Figure 1, consists of a stack of stainless steel discs comprising two identical electrodes. The electrodes are electrically isolated from each other and from the stainless steel plug that serves as the body of the probe. One electrode is polarized relative to the other for a short period of time each day to a preset DC potential. The polarization cycle creates an environment that encourages biological growth on the discs; and therefore, growth occurs on the instrument as a pre-cursor to fouling on plant components. Biofilm formation is then detected as an increase in the applied current required for achieving the preset potential. The instrument also monitors the current generated between the two electrodes when no external potential is applied. 
This current can also provide an indication of biofilm formation. The electronics for the control, data acquisition and data analyses are housed in the electronic box picture at the left of the probe.

During FY2001-02, the monitor was installed in a cooling water circulation line at the Bonnett Geothermal Plant (Cove Fort, UT) operated by Utah Municipal Power, for extended testing and evaluation. The goal of this testing was to determine if the probe, which had typically been installed in static environments, could be deployed in a flowing process stream and successfully used to collect data that could be correlated with other plant parameters, including visual observations, indicating growth problems. The results of this extended field evaluation concluded that the instrument did show promise as a real-time indicator of biofilm in geothermal plant cooling water systems. However, the operators at the Bonnett plant had some issues with its mode of operation. In particular they felt that instrument would be more valuable if the software could be modified to automatically update and display trend information on a daily basis. (Data had to be downloaded and manipulated in a spreadsheet to provide this trending information.) They also wanted to be able to determine the minimum reliable signal change, or trend, that indicated growth in their system, since that would provide the optimal control.

Using input from the Bonnett plant investigation the BIoGEORGE ${ }^{\mathrm{TM}}$ Biofilm Activity Monitor vendor, Structural Integrity (San Jose, CA), modified the data acquisition software allowing the data to be automatically updated and displayed for real-time trending. In addition, the system was configured so that data can also be accessed via a modem for remote monitoring and analyses of plant stream conditions. The testing and validation of the upgraded system was originally planned at the Bonnett plant. However with the sale and closure of this plant in early 2003, it was necessary to find another location for this testing. Calpine Corporation, subsequently agreed to host this testing at its Aidlin Unit 1 Plant located near Middletown, CA.

The monitor probe was installed in a sampling line at the Aidlin cooling tower July 15, 2003. The installation, shown in Figure 2, provided access to the condenser circulation, was designed to simulate flow velocity through the condenser tubes, and contained coupon holder for the placement of metal substrates to be used for biofilm calibration and verification purposes. In this deployment the probe was exposed to cooling water down stream of the condenser. The real-time display was placed just outside the control room at the facility in a location that can be easily viewed by operations personnel.

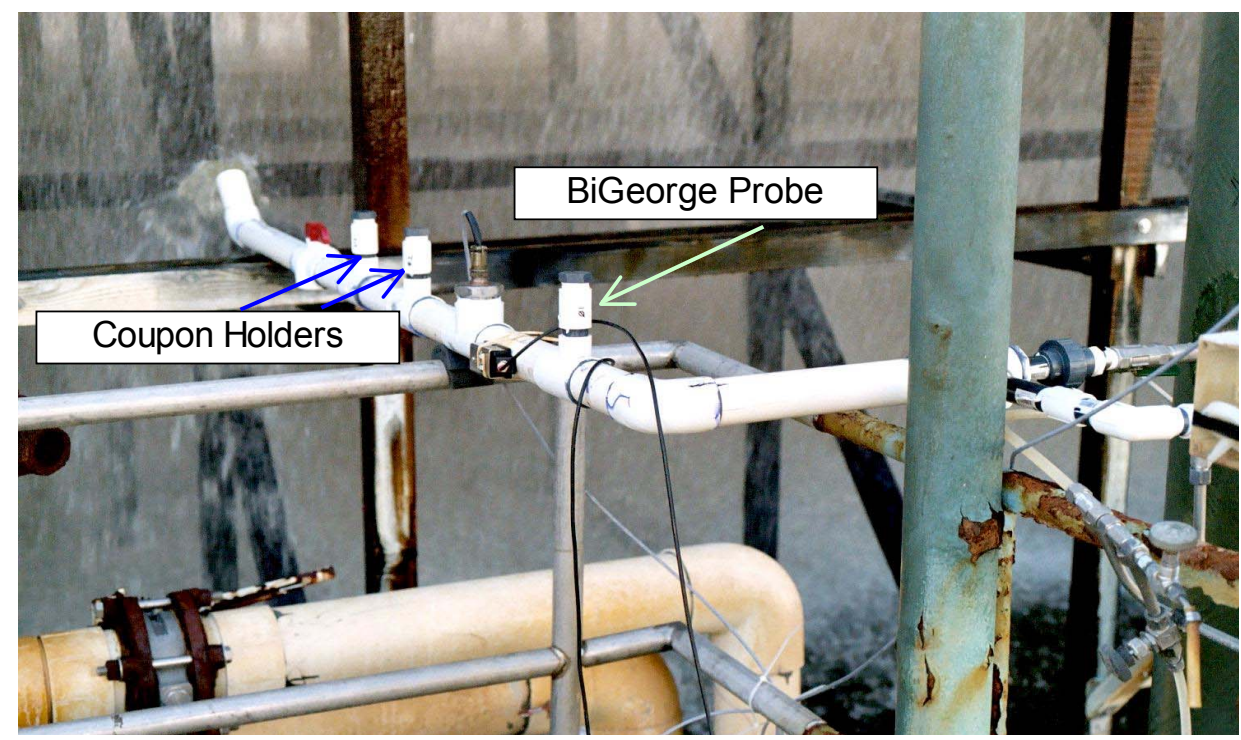

Figure 2. BIoGEORGE ${ }^{T M}$ Biofilm Activity Monitor Probe Installed at the Aidlin Unit 1 Cooling Tower. 
Status/Accomplishments: Due to the project delay caused by the Bonnett plant closure, the data collection and analyses activities were continued into FY 2004. A particular goal of this deployment was to use the BIo-GEORGE ${ }^{\mathrm{TM}}$ Biofilm Activity Monitor to determine if a significant biofilm problem existed at the plant and if so, establish its severity and the requirement for treatment. The applied current data recorded by the probe over a six-month period is presented in Figure 3. The data exhibited significantly more noise than from the previous deployment at the Bonnett Plant, although some trending is still evident. For example, it is evident that there is a change in the operation in mid-November resulting in a decrease the applied current. This is consistent with the expectation that less biofouling would occur during the winter months. (The lower evaporation rates due to cooler ambient conditions tend to flush or clean the total dissolved and suspended solids that accumulate in the cooling water systems.) The data from the BIoGEORGE ${ }^{\mathrm{TM}}$ monitor was also compared to a cleanliness factor determined from operational parameters to see how the monitor data would trend with this calculated condenser performance over the same time period. The applied current trend recorded was observed to decrease as the efficiency, or inferred cleanliness, of the condenser increased, both indicating that there was less fouling in this system.

In general, the data collected from the monitor indicated that minimal biofouling was occurring in the system. In order to confirm this indication, the coupons installed on July 12, 2003 were pulled from the test train on March 24, 2004, placed into sterile $15 \mathrm{ml}$ centrifuge tubes, and sent to the INEEL for microscopic analyses. The measurements indicated that the Aidlin coupons had approximately 30 microns of biofilm present. By comparison, similar measurements made on metal coupons deployed for one month in the cooling tower basin at Bonnett Geothermal were found to have approximately 50microns of biofilm on their surfaces. Since the Aidlin coupons had been exposed for a factor of eight times longer, this data is another indication that the Aidlin plant was not be experiencing problems with excessive biofilm formation.

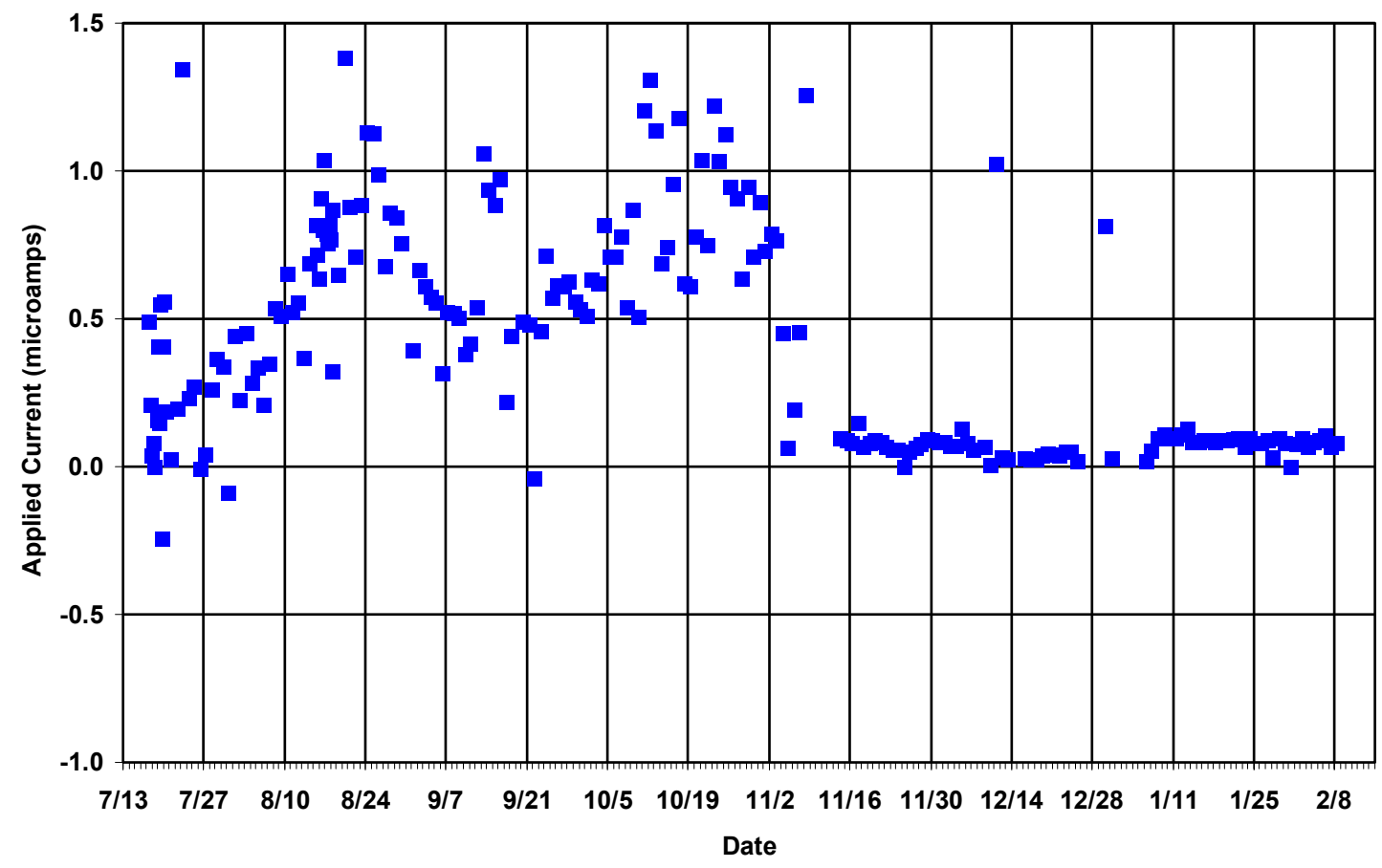

Figure 3. Data Collected by BIoGEORGE TM Biofilm Monitor at Aidlin Unit 1 (July 2003-February 2004) 
The application of the BIoGEORGE ${ }^{\mathrm{TM}}$ Biofilm Activity Monitor for predicting the on-set of biofilm development in geothermal power plant cooling water systems has been evaluated in long-term deployments at two different facilities. In both cases, the instrument has demonstrated that if it is properly deployed in the process stream, it can provide data that is valuable for assessing and monitoring biofilm problems in these facilities. A protocol for the installation, calibration, and operation of the monitor based upon these field experiences has been developed and is available to the user community.

\section{Reports \& Articles Published in FY 2004:}

P. A. Pryfogle, "Monitoring Biological Activity In Cooling Towers and Condenser Circulation Systems at Geothermal Power Plants," Industrial Water Conference Proceedings, December 9-11, 2003, Las Vegas, N.V.

\section{Presentations Made in FY 2004:}

P. A. Pryfogle, "Monitoring Biological Activity In Cooling Towers and Condenser Circulation Systems at Geothermal Power Plants," Industrial Water Conference, December 9-11, 2003, Las Vegas, N.V.

\section{Planned FY 2005 Milestones:}

Publish a reference document detailing all of the work conducted over the lifetime of the project 


\section{Geothermal Co-production of Silica and Other Commodities}

Reporting Period: FY 2004 (October 1, 2003 to September 30, 2004)

DOE Grant/Contract \#: $\quad$ W-7405-Eng-48

Performing Organization: Lawrence Livermore National Laboratory, 7000 East Ave., Livermore, CA 94550-9234

Principal Investigator: William L. Bourcier, (925) 423-3745, bourcier1@1lnl.gov

Collaborating Researchers at LLNL:

Bill Ralph, ralph2@1lnl.gov

Carol Bruton, bruton1@1lnl.gov

Other Collaborators:

John Byers, Byers Rubber Consulting, byersrc@cs.com

Robert Sullivan, Mammoth Pacific LP, Bsullivan@ormat.com

DOE HQ Program Manager: Dr. Leland (Roy) Mink, (202) 586-5463, roy.mink@hq.doe.gov

DOE HQ Technical Manager: Raymond LaSala, (202) 586-4198, raymond.lasala@ee.doe.gov

DOE Funding Allocation: $\quad \$ 21 \mathrm{~K}$

Cost Share Funding: $\quad$ \$75K from the California Energy Commission (CEC)

Project Objective: Our objective is to extract marketable silica and other commodities from geothermal fluids. If successful, our results would lower the cost of geothermal power by adding a new revenue stream from sale of byproducts. Project success would lower operations and maintenance costs by reducing silica scale formation in surface facilities and in re-injection wells.

Background/Approach: Produced geothermal brines contain large quantities of dissolved silica that often forms scale in power production facilities. During FY2004, we continued our collaboration with Mammoth Pacific LP to extract dissolved silica as a marketable byproduct. We are developing an understanding of how to produce silicas with optimum properties for commercial use by varying the precipitation conditions and characterizing the resulting silica precipitates.

The goal of our project is to develop working silica precipitation processes for geothermal sites that produce silicas with properties that match a targeted silica market. We are working with technical contacts from the rubber industry and colloidal silica distributors to help identify material properties and likely markets for our produced silicas. Once silica has been extracted from spent geothermal brines, it becomes technically feasible to extract additional metals such as lithium from the brines without interference from silica precipitates. 


\section{Status/Accomplishments:}

\section{Summary}

- $\quad$ Carried out a preliminary economic analysis of silica extraction at Mammoth Lakes

- Upgraded our field equipment to include a larger (80 vs. 20 liter) custom designed stirred reactor and a $20 \mathrm{gpm}$ reverse osmosis unit modified for use at elevated temperatures, and assembled a cross-flow filtration unit that uses ultrafiltration elements for solids capture

- $\quad$ Performed suitability tests of geothermal silicas as tire rubber binder (performed via contract with Byers Rubber Consulting of Wadsworth, Ohio)

As reported previously, we successfully extracted high-purity silica from the geothermal fluids at the Mammoth Lakes site with properties that match those of commercial precipitated silicas. Our initial tests were carried out with a leased reverse osmosis unit and 200 nanometer cartridge filters. Based on our experience with that system, we have designed and constructed a system for higher fluid throughput and higher silica recovery.

FY05 work will be targeted at using our new field equipment to recover larger masses of silica for marketing tests, improving silica yield using cross-flow filtration, and reducing the amounts of additives needed to lower operating costs.

\section{Reports \& Articles Published in FY 2004: None}

\section{Presentations Made in FY 2004:}

Bourcier, W., E. Burton, M. Johnson, W. Ralph, and C. Bruton (2004) Developing a Process for Commercial Silica and Fresh Water Production at the Mammoth Lakes, California Geothermal Site: Poster presented at Geothermal Resources Council 2004 Annual Meeting, Indian Springs, CA, August 29-Sept 1.

\section{Planned FY 2005 Milestones:}

Summary report to CEC (copy to DOE) on silica extraction process 


\section{Silica Scale Inhibition}

Reporting Period: FY 2004 (October 1, 2003 to September 30, 2004)

DOE Grant/Contract \#: $\quad$ W-7405-Eng-48

Performing Organization: Lawrence Livermore National Laboratory

7000 East Ave.

Livermore, CA 94551

Principal Investigator: $\quad$ Elizabeth Burton, (925) 422-7330, burton14@1lnl.gov

Collaborating Researchers: Carol Bruton, Bill Bourcier, Adam Wallace, Roald Leif, LLNL

DOE HQ Program Manager: Dr. Leland (Roy) Mink, (202) 586-5463, roy.mink@hq.doe.gov

DOE HQ Technical Manager: Raymond LaSala, (202) 586-4198, raymond.lasala@ee.doe.gov

DOE Funding Allocation: $\quad \$ 83 \mathrm{~K}$

Cost Share Funding: $\quad 0$

Project Objective: This project aims to provide geothermal operators with technical information that will improve silica scaling prediction and mitigation techniques in facilities and injection wells. Tools presently available are incomplete and/or inappropriately framed for geothermal industry use. Conditions favoring silica scaling will become more common with the expansion to new resources, including enhanced geothermal systems, and increasing maturity of existing geothermal resources. Declining reservoir pressure, spent brine reinjection, growth in use of lower grade geothermal resources, binary and hybrid plants, and lower pressure secondary flash or bottoming cycles will increase the need to improve silica scale management techniques and best-practice sharing across the industry.

Our project contributes to achieving two Program goals: reducing levelized costs to 3-5 cents $/ \mathrm{kWh}$, and doubling the number of states with geothermal power. Silica scaling negatively impacts plant operational costs, well performance and risk in a variety of ways that, in sum, may significantly reduce net income and curtail resource development. Improving silica scale control can reduce cost and risk by:

- $\quad$ Preventing declines in energy conversion efficiency due to scaling

- $\quad$ Expanding geothermal water usage to plant cooling operations

- $\quad$ Minimizing scale-related waste, use of scale inhibitor and dissolver chemicals, and their associated environmental impacts

- $\quad$ Decreasing frequency of facilities treatments and well workovers due to scaling

- $\quad$ Reducing operations upsets and downtime

- $\quad$ Reducing likelihood of injection well abandonment, wellbore and formation damage, particularly in enhanced geothermal systems where temperature gradients and mixing of incompatible waters may induce scaling 
Prior to FY2004, the project objectives were focused more on developing a fundamental understanding of inhibitor behavior. In FY2003, we focused more on building a basis for the underlying effects of fluid chemistry on silica polymerization and how these effects relate to observed inhibitor performance variations, and in developing a way to deploy this information to the geothermal industry. In FY2004, we focused on completing and delivering a useable silica scale prediction tool to selected trial users.

Background/Approach: Silica scaling commonly occurs in geothermal power plants. Silica scaling problems can be moderate, or so extreme that the power generation process must be specially designed to limit scaling. Even small amounts of scaling are deleterious to binary plants because of the effect on heat transfer. More efficient utilization of geothermal heat, and the use of geothermal and other water supplies for water make-up and cooling increases the risk of scaling. There are a number of chemical additives (inhibitors) that are commercially available for scale control. However, variations in fluid chemistry, different plant operating conditions, and the complex nature of silica reactions cause the effectiveness of an inhibitor to vary widely within and among geothermal fields. The growing use of brine acidification is promising with regard to scale control, but issues remain even with this technology. Scale management presently is done by qualitative case-by-case studies to test scaling potentials and inhibitor efficacy. Making scale management more systematic and predictable across the industry requires quantification of the effects of fluid chemistries and of inhibitor effectiveness for the full range of conditions found in geothermal operations.

The formation of silica scale can be broken down into four major steps: polymerization of monomeric silica, growth of polymeric silica to insoluble amorphous silica colloids, agglomeration of the colloids, and nucleation and growth of silica scale on solid substrates (e.g. piping). While thermodynamic models (e.g. TEQUIL) exist that predict the potential magnitude of scaling and qualitatively capture the overall dependence of reaction rates on the degree of disequilibrium, they do not capture the overall and stepspecific rate effects of various other solution parameters, such as sodium and fluoride concentrations, and $\mathrm{pH}$. Existing kinetic models are based on laboratory data alone, consider a limited number of chemical variables, do not explicitly include inhibitors, and are not field-validated. Thus, there is a critical need for a coupled kinetic-thermodynamic model specifically designed to address silica scaling in geothermal operations. Antiscalants, or inhibitors, intervene in the kinetics of one or more of these key steps leading to scale deposition. For example, threshold inhibitors delay the initial polymerization of monomeric silica in a supersaturated brine, and dispersive agents inhibit agglomeration of silica colloids.

In this project, we evaluated commercially available silica scale inhibitors from a variety of vendors for their application to geothermal brines of varying composition in both flash and binary plants. The approach included laboratory testing to establish and model the polymerization rates of silica in a variety of geothermal brine chemistries as well as inhibitor testing. Laboratory tests were designed to quantify: (1) the effects of a matrix of aqueous chemical variables on silica polymerization and precipitation rates, and (2) the impact of commercial scale inhibitors on rates of specific steps in the silica precipitation reaction. In addition, we built a small database of geothermal water compositions, focusing on existing or potential geothermal sites in the western U.S., using existing databases at research centers (including Great Basin Research Center, USGS, Energy and Geoscience Institute) and published literature to define ranges for chemical variables for laboratory tests. We also sought to include data from field tests in order to compare our lab data to measures of chemical inhibitor effectiveness and silica precipitation in "real" geothermal fluids under plant conditions.

Status/Accomplishments: In laboratory tests, we have quantified the effects on silica polymerization of the following set of chemical variables: $\mathrm{Na}$ at 500 and $2000 \mathrm{ppm}, \mathrm{pH}$ values from 5 to 9 , temperatures of 25 and $50^{\circ} \mathrm{C}$, and silica saturation values from 1.2 to 6 . Total initial dissolved silica concentrations were kept constant at $600 \mathrm{ppm}$. Silica was added as sodium metasilicate. The $\mathrm{pH}$ was adjusted with hydrochloric acid or sodium hydroxide and monitored throughout each run. A circulating water bath held 
solutions at constant temperature to $\pm 0.5^{\circ} \mathrm{C}$. Silica polymerization was followed over time by spectrophotometric measurements on solution aliquots using the silicomolybdate method as modified by Iler. We purchased an automated system to control and maintain $\mathrm{pH}$. Previous work identified appropriate laboratory testing protocols, and tested silica scale inhibitors from the geothermal and water treatment industry for the Dixie Valley and Coso geothermal fluids. Quantum mechanical modeling of silica polymerization and nuclear magnetic resonance measurements tracking the formation of oligomers were also conducted to better define the processes of early polymerization and predict the reactivity of aqueous silica. A technique for using hydrothermal atomic force microscopy to directly image silica deposition on metal surfaces was developed to study the influence of the substrate on silica precipitation. Work was also done to determine the effects of inhibitors on particle size and to identify the general molecular structures of inhibitors to develop an understanding of how they work. This work showed that inhibitor behavior could change dramatically with changes in fluid chemistry.

We decided to change our focus in the lab experiments in FY2003 from tests on site-specific brine chemistries to creating a baseline dataset that would allow us to isolate the specific effects of individual chemical parameters. We are using these data and applicable published data to find accurate equations for predicting silica scaling across the full range of fluid chemistries found in geothermal systems, and to provide a baseline for quantitative analysis of inhibitor performance. As an additional benefit, we can quantify the effects of $\mathrm{pH}$-modification relative to other methods of silica scale control over a range of operating conditions. To insure coverage of the full matrix of chemistries, we have assembled a geothermal fluid chemistry database, including data from operations and sites in the western U.S., to establish the ion concentration matrix for our experiments.

Lowering $\mathrm{pH}$, as would occur by $\mathrm{pH}$-modification, increases the induction time prior to polymerization and decreases polymerization rate. These results explain field experience where silica scaling has been effectively prevented by $\mathrm{pH}$-modification. However, our results also show that the $\mathrm{pH}$ effects are interdependent on other aspects of fluid chemistry. For example, polymerization rate decline caused by decreasing silica concentration is faster at higher than at lower $\mathrm{pH}$.

We have used several approaches to begin the modeling. First, we used a multiple linear regression model to predict rates of polymerization as a function of chemical variables and elapsed time. This simple model appears to be a good predictor of polymerization rates for the intermediate range of rate measurements, but is less reliable for rates measured early or near the end of each run. We examined several data-fitting mathematical packages for use in developing more accurate nonlinear predictive equations for the model, but we decided a faster and more efficient approach would be to leverage off existing codes. In FY2004, we updated the Weres et al. SILNUC model computer code for silica polymerization with our data and with new data in the literature that can extend the model to higher ionic strengths and improve and simplify the nucleation kinetic modeling.

We also examined the possible impacts that silica scaling might have in enhanced geothermal systems, and reviewed the literature on current and past EGS projects to determine what water-rock reactions had been observed and whether there were likely to be compatibility issues between injected and reservoir fluids that could cause plugging of injection wells and/or formation damage. The preliminary findings of this work were presented at the GRC Annual Meeting.

Reports \& Articles Published in FY 2004: Burton, E.A., Bourcier, W.L., Bruton, C.J., Roberts, J.J., and Carlson, S.R., 2004, Evidence for the Impact of Water-Rock Interactions on Permeability in Enhanced Geothermal Systems. Geothermal Resources Council Transactions, v. 28, in press. 


\section{Presentations Made in FY 2004:}

Burton, E.A., Bourcier, W.L., Bruton, C.J., Roberts, J.J., and Carlson, S.R., 2004, Evidence for the Impact of Water-Rock Interactions on Permeability in Enhanced Geothermal Systems

Geothermal Resources Council Annual Meeting, Indian Wells, CA, Aug. 29-Sept. 1, 2004. 


\section{Investigation of Microbial Sulfur Oxidation for the Natural Abatement of Sulfides in Geothermal Cooling Tower Basins}

Reporting Period: FY 2004 (October 1, 2003 to September 30, 2004)

DOE Grant/Contract \#: $\quad$ DE-AC07-99ID13727

Performing Organization: Idaho National Engineering and Environmental Laboratory Renewable Energy and Power Technologies 2525 North Fremont Drive, P.O. Box 1652 Idaho Falls, ID 83415-3870

Principal Investigator: $\quad$ Peter A. Pryfogle, (208) 526-0373, Peter.Pryfogle@inl.gov

$\begin{array}{lll}\text { Collaborating Researchers: } & \begin{array}{l}\text { Allen Sonneville } \\ \text { Calpine Corporation } \\ \text { asonneville@calpine.com }\end{array} & \begin{array}{l}\text { Beth Kershaw } \\ \text { Calpine Corporation } \\ \text { bkershaw@calpine.com }\end{array}\end{array}$

DOE HQ Program Manager: Dr. Leland (Roy) Mink, (202) 586-5463, roy.mink@hq.doe.gov

DOE HQ Technical Manager: Raymond LaSala, (202) 586-4198, raymond.lasala@ee.doe.gov

DOE Funding Allocation: $\quad \$ 69 \mathrm{~K}$

Cost Share Funding: $\quad \$ 5 \mathrm{~K}$ (Industry In-kind)

Project Objective: The goal of this project is to assist in lowering the levelized costs of generating geothermal power to $3-5$ cents/kWh by 2010 by reducing the cost of hydrogen sulfide abatement in geothermal process streams through the optimization of natural abatement processes.

Background/Approach: The natural abatement of hydrogen sulfide that occurs in the cooling towers has always been considered to be purely inorganic oxidation by chemical conversion. However, operators have observed changes in the degree of abatement that occur for unknown reasons and cannot be explained solely by changes in oxygen solubility or activity. Since populations of sulfur-oxidizing bacteria, including various strains of Thiobacillus, are known to exist in these process streams it is reasonable to assume that some component of this abatement is due to microbiological activity. Operators, including those at the Calpine plants at the Geysers', are interested in investigating the ability of microorganisms found in the cooling basin to metabolize and cycle sulfides to less toxic sulfur compounds. If the role of these organisms were better understood, then it might be possible to take steps, such as adding nutrients to selectively enhance growth, to increase natural abatement in the cooling tower. This could result in substantial cost savings by reducing the quantity of expensive chemicals that are currently used for sulfide abatement.

A key element of this work is to develop techniques for tracking and manipulating the microbial communities found in cooling tower basins in order to enhance sulfide-oxidation without increasing 
fouling or acid production in the systems. The hypothesis to be tested is that by performing nutrient enrichments in an oxgenated environment, such as the cooling tower, the growth of sulfur-oxidizing bacteria will be favored over other organisms that may be detrimental to the plant performance.

Status/Accomplishments: The Sonoma facility at Calpine was selected as the test site for this work since this plant was planning to use Santa Rosa wastewater as tower make-up during the summer months. The addition of the Santa Rosa wastewater as make-up may alter the water chemistry of the cooling tower basin by introducing phosphates and nitrates, which are expected in turn to increase some types of microbial activity. (These nutrients may also impact the addition of chemicals used for sulfide abatement.)

A series of experiments, based upon respirometry, were designed to investigate the ability of microorganisms found in cooling tower basins to metabolize and cycle sulfides. Respirometry is a manometric measurement of dissolved gases that are in equilibrium in a confined volume. Since microbes expire varying amounts of carbon dioxide or oxygen as they metabolize nutrients, this technique can be used to evaluate their activities in process streams. Respirometry is a well-established tool for process control in the biological treatment of wastewater. And, while it is most commonly performed on samples in a laboratory environment, it is also possible to implement as an on-line measurement.

The studies were conducted using water samples collected from the Sonoma facility cooling tower basin and then shipped to the laboratory. The experiments investigated the impact of adding phosphate and nitrate additions to existing microbial populations in the sample water and to populations of sulfatereducing (Desulfovibrio vulgaris) and sulfur-oxidizing (Thiobacillus neopolitanus) bacteria introduced into water from laboratory cultures. Data from one of these experiments using a Gibson Differential Respirometer is shown in Figure 1, where $20 \mathrm{ppm}$ additions of sodium nitrate $(\mathrm{N})$ and phosphate $(\mathrm{P})$ solutions were added to a water sample containing a natural population of bacteria.

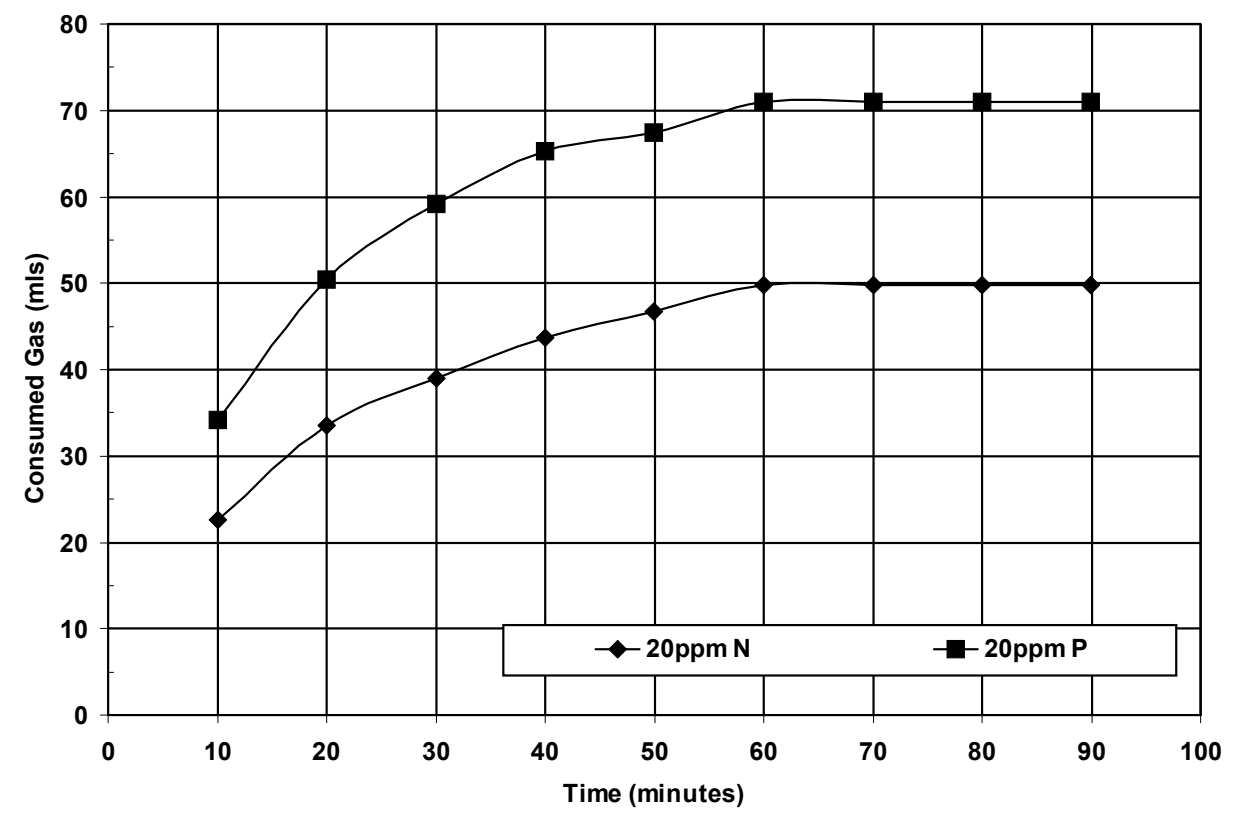

Figure 1. Respiration rate change detected in Sonoma water sample with the addition of 20 ppm nitrate (N) and phosphate $(P)$ nutrients. 
The plot shows increased microbial activity, as evidenced from increased gas consumption, when small concentrations of phosphorus and nitrogen were added. Figure 2 illustrates the impact of adding sulfides to the Sonoma water sample. In this experiment, 10\% (1-Sulfide) and 20\% (2-Sulfide) sodium solutions were added to water samples. While there were dramatic differences observed in the results of this test, there are uncertainties associated with the interpretation of the data, since sulfides can be trapped in an alkaline solution. There were, however, other indications that the addition of sulfide was affecting the natural population of microbes. The sulfate analyses indicated a slightly higher concentration of sulfate at the end of the experiment in the flasks that received sulfide additions, which is consistent with an increase sulfur oxidation due to microbial action.

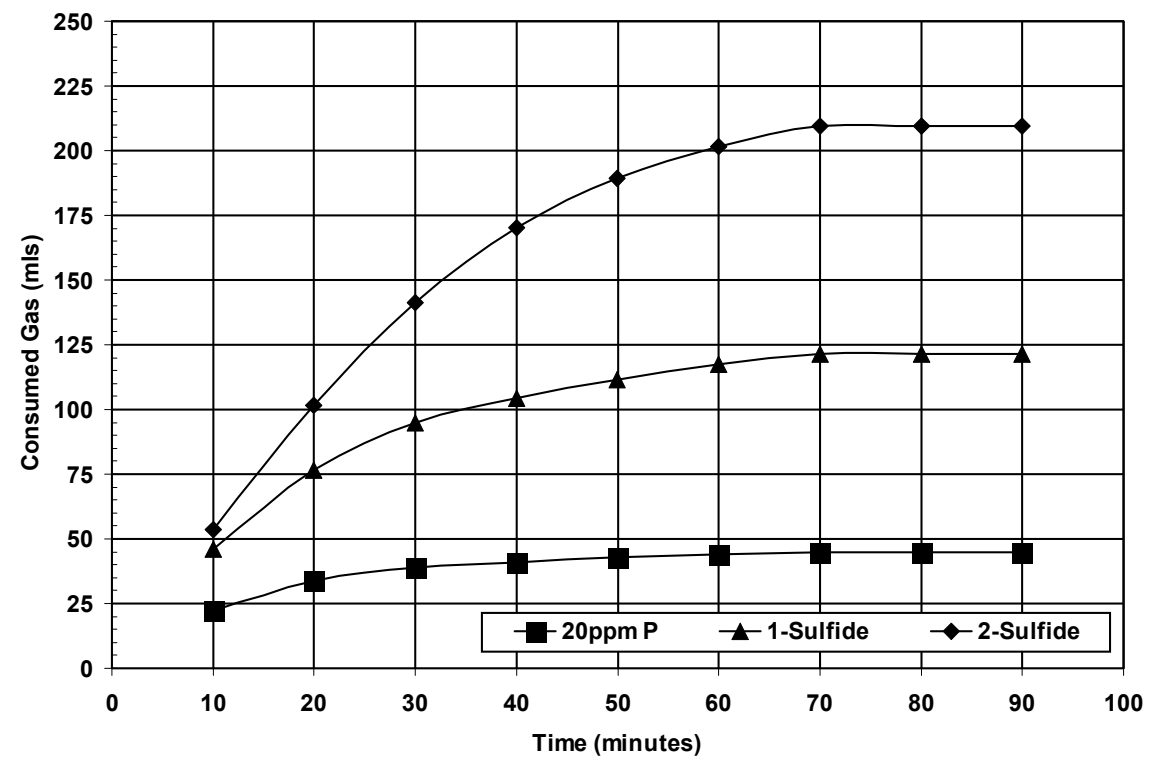

Figure 2. Respiration rate change detected in Sonoma water sample with the addition of $10 \%$ and $20 \%$ sulfide amendments compared with an (20 ppm) addition of phosphate nutrients.

The results of these experiments indicate that respirometry can be a useful method for observing the impact of nutrient additions associated with the Sonoma tertiary treated water in the cooling tower basin water. Both nitrate and phosphate additions produced detectable changes in the rate of microbial activity in the indigenous population of bacteria. There was also evidence that microbial sulfate oxidation was occurring and that the rates of this activity could be enhanced by increasing the population of sulfur oxidizing bacteria in the samples. Results from experiments taken with water samples collected at differing times also showed similar trends. Also, since the experiments were conducted on water samples collected from the basin, shipped to the laboratory, stored at $4^{\circ} \mathrm{C}$ and then tested, it is very likely that under these conditions the natural population of bacteria were stressed. Consequently, they may not be as active as the microbes would be if sampled and processed immediately. Based upon these results, the respirometric technique for tracking microbial activity in the geothermal basin is not only feasible but would be even more effective if it could be used on site and implemented as an on-line technique.

\section{Reports \& Articles Published in FY 2004: None}

\section{Presentations Made in FY 2004: None}

Planned FY 2005 Milestones: Protocol for monitoring bacterial populations in cooling tower streams Aug 05 developed and delivered to plant operators. 


\section{High-Temperature Electronics}

Reporting Period: FY 2004 (October 1, 2003 to September 30, 2004)

DOE Grant/Contract \#: $\quad$ DE-AC04-94AL85000

Performing Organization: Sandia National Laboratories

Geothermal Research Department 6211

Albuquerque, New Mexico 87185-1033

Principal Investigator: ～Randy Normann, (505) 845-9675, ranorma@sandia.gov

Collaborating Researchers: Joseph Henfling, (505) 844-6720, jahenfl@andia.gov

DOE HQ Program Manager: Dr. Leland (Roy) Mink, (202) 586-5463, roy.mink@hq.doe.gov

DOE HQ Technical Manager: Raymond LaSala, (202) 586-4198, raymond.lasala@ee.doe.gov

DOE Funding Allocation: $\quad \$ 615 \mathrm{~K}$

Cost Share Funding: $\quad \sim \$ 300 \mathrm{~K}$

Project Objective: To produce a $300^{\circ} \mathrm{C}$ logging tool NOT requiring heat-shielding. To test new hightemperature components for reliability and enhanced functionality supporting the Sandia geothermal drilling program while making this technology easy to transfer to industry.

Background/Approach: The principle program objective is to jump start the service industry into silicon-on-insulator (SOI) electronics. SOI electronics have demonstrated an operating temperature of $225^{\circ} \mathrm{C}$ for 5 -years by both Honeywell and Goodrich. To meet this high standard, most SOI components continue operating up to $300^{\circ} \mathrm{C}$. Sandia National Laboratories has demonstrated an SOI tool by logging a $240^{\circ} \mathrm{C}$ geothermal well without any heat shield for 40 hours. With two component improvements, Sandia hopes to achieve $300^{\circ} \mathrm{C}$ in 2005 while adding additional capabilities.

Sandia is providing technical assistance directly to both electronic component manufacturers and service companies while the individual companies use their own internal funding to develop new components and logging/drilling tools. This insures that DOE is maximizing their R\&D dollars. Only devices and materials unique to geothermal applications are undertaken directly by Sandia under this development effort. Two example devices in 2004 were $300^{\circ} \mathrm{C}$ high-temperature batteries and $350^{\circ} \mathrm{C}$ printed wiring boards. These are important components unique to geothermal logging and drilling tools.

Status/Accomplishments: Overall, the level of high-temperature drilling and logging activities has greatly increased over 2003. As evidence of this, the High-Temperature Electronics Conference (HiTEC) saw attendance double over the past conference, engineers at Halliburton have told Sandia to expect some high-temperature surprises in 2005 , both Paine and Kulyte have introduced new $280^{\circ} \mathrm{C}$ and $250^{\circ} \mathrm{C}$ 
pressure sensors while SemiSouth Inc. has started a product line of $300^{\circ} \mathrm{C}$ power transistors produced using $\mathrm{SiC}$, and Cissoid introduced a commercial $290^{\circ} \mathrm{C}$ voltage regulator.

The number of new components and materials is a welcome sight but unfortunately, component and material testing at Sandia has fallen behind. There are no plans for correcting this situation in 2005 . Greater care will be exercised to determine which new high-temperature components and materials benefit the overall DOE mission.

Our effort to build the first $300^{\circ} \mathrm{C}$ logging tool fell short of our expectations. The development of a $300^{\circ} \mathrm{C}$ clock oscillator by Kouros Sariri, FMI, Inc. has not completed. They are still working on the development using internal funding. Without the clock oscillator, we developed a $300^{\circ} \mathrm{C}$ analog version of the tool. This tool could be used to flow test an EGS experimental well in Australia in a joint project with Scientific Drilling Inc.; see Planned FY 05, Milestones below.

A major accomplishment was the installation of a Sandia SOI tool within a geothermal well at CalEnergy's Utah power plant. This was the first time SOI electronics and fiber optics were both tested in the same well. This is also the first time SOI electronics have seen $481^{\circ} \mathrm{F}\left(250^{\circ} \mathrm{C}\right)$ within a geothermal well.

The figure below shows the initial well profile before the well was heated. The SOI tool was placed at 1550ft. A 316L Stainless Steel wired tubing carried electric power and communication to the tool. The tubing also contained a single-mode optical fiber with a number of Bragg fiber optic temperature sensors. Ten of these sensors were placed close to the SOI tool with only a 1 meter separation between each. Later, the well heated to $481^{\circ} \mathrm{F}$ as a well head leak caused heat to be pulled up from the reservoir, $\sim 1650 \mathrm{ft}$.

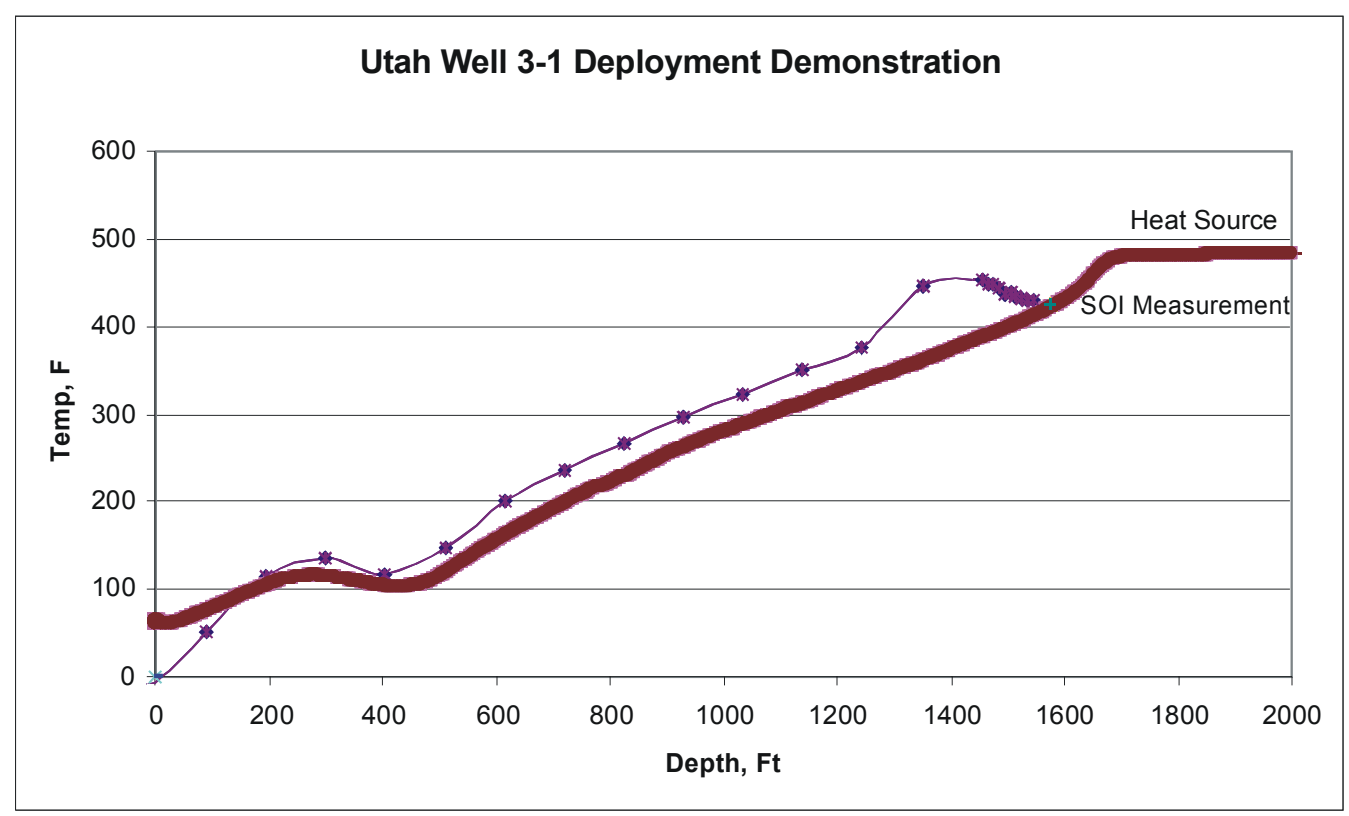

Figure 1. First data taken after tool installation within the Utah well.

The day following the measurements shown in Figure 1 above, the well heated to $481^{\circ} \mathrm{F}$ exceeding the desired long-term temperature target of $430^{\circ} \mathrm{F}$. The contracted logging company Instrumentation Services Inc. removed the tool and placed it within a slightly cooler well. During this process, the tubing broke and 
the tool fell. The tool is currently in the well. As the well is only $400^{\circ} \mathrm{F}$, the tool is not being damaged and there is hope to fish the tool out sometime in 2005.

Even with the short test, there are a number of useful outcomes. SOI tool electronics survived and continued to work even at $481^{\circ} \mathrm{F}\left(250^{\circ} \mathrm{C}\right)$. Fiber optic Bragg temperature sensors work but have a problem of localized strains creating false temperature gradients. Once such false temperature gradient is seen at $\sim 1400 \mathrm{ft}$. Investigation in to why the tube broke shows a significantly enhanced chloride interaction with the $316 \mathrm{~L}$ stainless steel around the welds. Welds are used to seal the tubing after the wires and fiber optic cables are installed.

Sandia is currently providing this information and suggested design improvements to the fiber optic cable supplier Sabeus and the wired tubing supplier BIW Cable. In the future, these services will be available to the geothermal industry.

The Sandia HT SOI tool was deployed in a Coso Naval Test Range well located only a mile away from the Coso Geothermal power plant. The tool was installed within the well at 3,100 ft using wire in tubing. At this point the nominal temperature is $192^{\circ} \mathrm{C}\left(379^{\circ} \mathrm{F}\right)$. This is the hottest location within the well. Prior to the tool going into the well, the tool was oven tested for one month at temperatures between 180 and $200^{\circ} \mathrm{C}$. The purpose of this field test is to demonstrate the increased reliability gained when using manufacturer-qualified high-temperature electronic components. Sandia is working with a large number of commercial manufacturers to build a complete logging tool using only commercially available components. We hope to continue this test for the next two years. To date, this system has been deployed for approximately $7400 \mathrm{hrs}$. The downhole reservoir monitoring system was presented in papers at the 2004 Stanford Geothermal Workshop and 2004 GRC. Reports concerning the tools design have been given to all of the major service companies and most of the smaller geothermal service companies.

\section{Reports \& Articles Published in FY 2004:}

Article: "High Temperature Downhole Reservoir Monitoring System", Stanford Geothermal Workshop, Jan 2004

Report to Service Companies and Capacitor Manufacturers: "High Temperature Downhole Reservoir Monitoring System”, High-Temperature Electronics Conference, May 2004

Article: "High Temperature Downhole Reservoir Monitoring System", High-Temperature Electronics Conference, May 2004

Article: "High Temperature Electrical Printed Wiring Boards Function at $350^{\circ} \mathrm{C}$ ", High-Temperature Electronics Conference, May 2004

Article: "Comparison of High Temperature Capacitor Testing”, High-Temperature Electronics May 2004

Article: “Aerospace R\&D Benefits Future In-Situ Reservoir Monitoring”, Geothermal Resource Council, Sept 2004

\section{Presentations Made in FY 2004:}

Presentation: "High Temperature Downhole Reservoir Monitoring System", Stanford Geothermal Workshop, Jan 2004 
Presentation: "High Temperature Downhole Reservoir Monitoring System", High-Temperature Electronics Conference, May 2004

Presentation: “Aerospace R\&D Benefits Future In-Situ Reservoir Monitoring”, Geothermal Resource Council, Sept 2004

Presentation: Drilling Engineering Association, Sept 2004 and Nov 2004

Presentation: “An Introduction to Problems Encountered with Well Instrumentation”, Dec 2004

\section{Planned FY 2005 Milestones:}

Deploy 300C tool for extended EGS well flow testing with SDI

Jan 05

Award a cost shared high-temperature battery development contract

Mar 05 


\section{Wellbore Integrity and Lost Circulation}

Reporting Period: FY 2004 (October 1, 2003 to September 30, 2004)

DOE Grant/Contract \#: $\quad$ DE-AC04-94AL85000

Performing Organization: Sandia National Laboratories

Geothermal Research Department 6211

Albuquerque, New Mexico 87185-1033

Principal Investigator: $\quad$ S.J. Bauer, (505) 844-9116, sjbauer@sandia.gov

Collaborating Researchers: Dr. Janice Hamilton, National Silicates, an affiliate of PQ Corp., Daniel Bour, Halliburton

DOE HQ Program Manager: Dr. Leland (Roy) Mink, (202) 586-5463, roy.mink@hq.doe.gov

DOE HQ Technical Manager: Raymond LaSala, (202) 586-4198, raymond.lasala@ee.doe.gov

DOE Funding Allocation: $\quad \$ 320 \mathrm{~K}$

Cost Share Funding: $\quad \$ 100 \mathrm{~K}$

Project Objective: Reduce lost circulation costs by $30 \%$ and the cost of drilling a typical geothermal well by $5 \%$ by promoting best-available wellbore integrity systems that integrate lost circulation mitigation, drilling on to the next casing point, and cementing in the next casing. To meet Geothermal Program Goals of increasing the states producing electric power from geothermal energy, reducing the cost of generating geothermal power, and increasing the use of geothermal energy, it will be necessary to reduce geothermal drilling costs. Because drilling costs occur early in the life cycle of a geothermal project, high drilling costs are a significant barrier to geothermal development. Reduction of trouble cost is the most effective way to reduce geothermal drilling costs. The Wellbore Integrity and Lost Circulation Technologies task focuses on avoiding/mitigating wellbore integrity problems. If severe lost circulation/cross flow is expected or encountered, what should be done to get the next casing string properly cemented in place at the least cost? While a technology specifically for lost-circulation control, e.g. polyurethane grouting, may be the only sure way of stopping severe cross flows, to minimize overall drilling costs, there is a need to take a broad system perspective considering how lost circulation impacts cementing, casing, well design, etc. The ultimate goal isn't lost-circulation control; it is maintaining wellbore integrity. That is, preparing the wellbore so that the next casing string can be cemented in properly. To reach this goal one should both use the best currently available technology and seek new revolutionary technologies. The tasks have been chosen to provide the driller with a "complete" and adequate set of technologies with multiple options to mitigate lost-circulation and cross-flow problems. While cement grouting of casings will continue to be a requirement, cement plugs have proven inadequate to stop lost circulation and cross flows. Reactive plug technologies (plugs which harden quickly where placed) are needed. Rigid polymers and silicate based systems were chosen for further development because of favorable properties. 
Background/Approach: New wellbore integrity technologies are needed to facilitate change in the ineffective standard practice of fixing each lost-circulation zone as it is encountered. Drilling should be focused, not on lost-circulation control, but on the bigger question, "How do we get the next casing string cemented in with minimal lost time and low additional cost?" Ideally, one would like to minimize flat lost time from lost circulation by development of a new system to deal with lost circulation "while drilling". The method is summarized as follows: To facilitate growth of this new paradigm, the task is focused on two reactive plug technology systems, polymers and silicates. We describe these as systems, because a material alone will not solve the lost circulation problem; one has to place the material in the correct spot, and have it set before being washed away, and then survive while drilling continues until the interval is cased.

One of the focused efforts in this task this year was initiating study of silicate-based grout systems. Silicates have been used to form stable grouts and cements for over 50 years because of their ability to gel and polymerize. This reaction has also been used successfully for water shutoff and to solve lost circulation problems in oil and gas drilling. In addition to their gelling action, silicates will also react with soluble metal salts, such as calcium chloride, to produce insoluble metal silicate plugs. Silica is known to be stable and environmentally benign at high temperatures. Because of these qualities, silicate plugs offer great potential for use in geothermal applications. As such, this year's work evolved into two separate laboratory-based material system studies, silicates and polymers. The polymer work was truly a secondary focus, and our desire was to complete hydrolysis evaluations of polymer grout formulations developed earlier.

\section{Status/Accomplishments:}

Recognizing the importance of minimizing trouble time caused by severe lost circulation in geothermal wells, we have studied the chemical stability of two potentially viable plugging material systems, polymers and silicates. Both materials comply with the initial needs, (1) no special handling requirements and considered non-hazardous by the DOT and EPA; (2) a low cost (3) readily pumpable; (4) controllable gel time; the reaction rate needs to be adjustable for varied conditions both at the surface and down hole; (5) controllable placement such that it has minimal water solubility and adheres well to rock surfaces through a single delivery hose; (6) hydrothermally stable for 8 weeks at geothermal temperatures (7) once placed, the grout would have to be sufficiently stiff, to drill with conventional means, and no unanticipated problems with drill bit plugging.

In the first of these system studies, we concluded laboratory work to evaluate the survival potential of organic polymer materials used for lost circulation plugs in geothermal wells. We learned early in the study that these materials were susceptible to hydrolysis wherein water molecules attacked chemical bonds, breaking them through time, and reducing the mechanical integrity of the polymers. This rendered the polymers useless in the desired range of geothermal temperatures and pressure applications. Through a systematic program in which many potential chemical combinations were evaluated, polymers were developed which tolerated hydrolysis for eight weeks at $260^{\circ} \mathrm{C}$. The polymers also meet material, handling, cost, and emplacement criteria (above). This screening process identified the most promising materials. A benefit of this work is that the components of the polymers developed can be mixed at the surface and pumped downhole through a single hose. Further strength testing is required to determine precisely the maximum temperature at which extrusion through fractures or voids causes failure of the lost circulation plug.

Specifically, for maximum hydrothermal performance, the crosslink density, types of crosslinks and the ability to perform these curing reactions under field conditions are critical to the ultimate performance of the grouting system. The selection of commercially available and competitively priced raw materials suggests that the standard polyurethane prepolymer and the variations tested will offer about two weeks 
of useful life at $135^{\circ} \mathrm{C}$. The production of aromatic polyureas or polyurethanes crosslinked with dimethacrylate monomers increases the useful life at $135^{\circ} \mathrm{C}$ to four-to-eight weeks. By incorporating a polybutadiene resin and crosslinking with dimethacrylate monomer the useful life at $135^{\circ} \mathrm{C}$ is over eight weeks. By eliminating all isocyanate reaction products and crosslinking a polybutadiene resin with dimethacrylate monomer, the useful life at $149^{\circ} \mathrm{C}$ is further extended. Testing of final compositions at $163^{\circ} \mathrm{C}, 177^{\circ} \mathrm{C}, 204^{\circ} \mathrm{C}, 232^{\circ} \mathrm{C}$ and $260^{\circ} \mathrm{C}$ also demonstrated survival from hydrolysis for eight weeks.

These new polymer grouting systems meet the previously described desired characteristics but have yet to be tested in a field-type application. Such work should be considered in the future.

In the second of these material system studies, we began work on development and demonstration of a silicate-based advanced treatment method through a lab program (with PQ Inc, world leader in silicate manufacturing). which systematically simulates downhole lost circulation conditions in order to better understand a field deployment. We began with a screening study to assess the potential of several chemicals known to react with $\mathrm{N}$ sodium silicate ${ }^{1}$ to form plugs and then determine the stability of these plugs at $200^{\circ} \mathrm{C}$. Stainless steel bombs were used, which became pressurized at high temperatures. Initial experiments determined whether it was necessary to dilute the silicate to obtain the hardest, most solid plug that retained stability and integrity over time.

\begin{tabular}{ll}
\hline N Sodium Silicate without dilution & Diluted N Sodium Silicate $(\sim 25 \% \mathrm{v} / \mathrm{v})$ \\
Calcium Chloride $10 \%$ & Calcium Sulfate $-7.5 \%$ Plaster of Paris Powder \\
Sulfuric or Nitric Acid $20 \%$ & Citric Acid $20 \%$ \\
Hydrochloric Acid $20 \%$ & Hydrochloric Acid $50 \%$ \\
Sodium Bicarbonate $10 \%$ & Acetic Acid $20 \%$ \\
\hline
\end{tabular}

This work evolved into studies which included effects of temperature on the reaction, effects of temperature and pressure, and long term stability with a focus on calcium silicate hydrate plugs.

Looking ahead, the high temperature grout system will meet all of the above criteria and facilitate a significant time savings to drilling operations, because it can be placed through the drill string. In this method, the calcium silicate hydrate plugs would be placed as follows. A measured amount (for the volume determined from the hole diameter and stand-off height) of the mixture for filling the backed off section of hole, with encapsulated $\mathrm{CaCl}_{2}$ and $\mathrm{N}$ sodium silicate could be placed by pumping the constituents down the interior of the drill pipe. The size of coated pellets must be less than 1/3 the drill-bit port diameter. Alternatively if particle size risked bridging the nozzles, the drill pipe could be tripped and runback in open-ended with a drillable tailpipe if deemed necessary. The pumping/flow rate would have to be such that all of the plug mix exited the drill bit before melting of the encapsulant occurred.

Temperature determinations, coupled with pumping/flow rates would need to be part of this grout system such that the plug forming reaction did not happen inside the drill string. If the downhole conditions had been determined to be excessively hot, perhaps water could be pumped down the drill string for a short time period to cool the drill pipe. The mixture, once delivered, would be heated (by the downhole heat), the encapsulant would melt, and the plug would be formed, sealing the loss zone (Figure 1). It may be necessary to chase this mixture with water (or another fluid) to provide a backpressure to drive the plug a short distance into the formation. It is envisioned that this plug material would flow a short distance into the formation, because the plug-forming reaction is thermally activated. If the drill hole already has water

\footnotetext{
${ }^{1}$ The $\mathrm{N}$ sodium silicate used in all the experimentation is obtained as a $37.5 \%$ solution in water and has a silicate to alkali $\left(\mathrm{SiO}_{2}: \mathrm{NaO}_{2}\right)$ weight ratio of 3.22 .
} 
in it, the calcium silicate hydrate plug material will sink to the hole bottom, because it is more dense than water. The drilling could commence in a short time because the plug sets immediately.

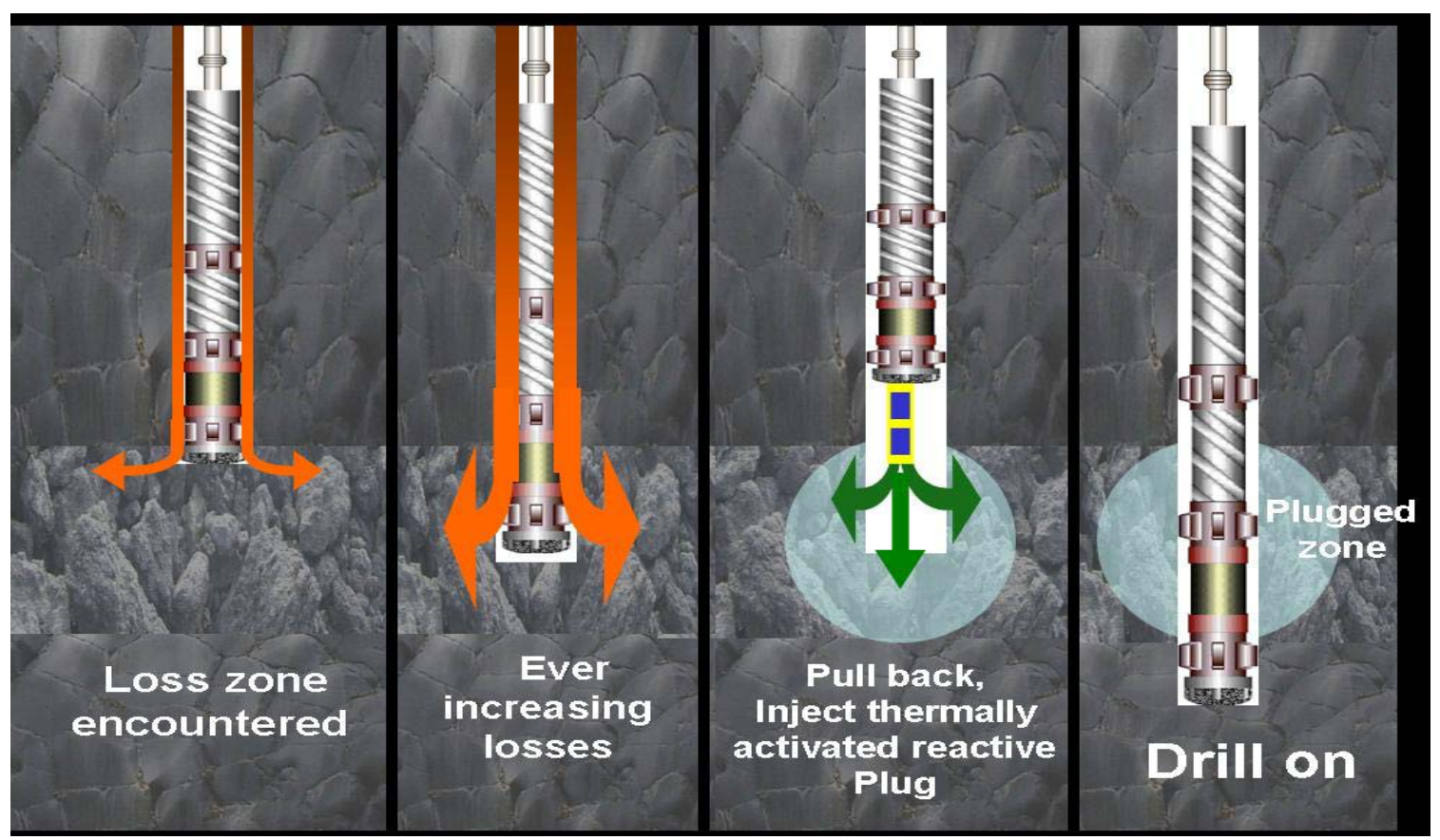

Figure 1. Placement scenario using through drill string delivery system.

\section{Reports \& Articles Published in FY 2004:}

Polymer Grouts for Plugging Lost Circulation in Geothermal Wells, SAND2004-5853, A. J. Mansure and S.J. Bauer, Dennis Galbreath, Green Mountain International, Inc, Sandia National Laboratories, Albuquerque, NM 87185

Comments on High Temperature Plugs: Progress Report on Polymers and Silicates, S. Bauer1, D. Galbreath2, J. Hamilton3, A. Mansure1, 1Sandia National Laboratories, 2Green Mountain International Inc., 3National Silicates, an affiliate of the PQ Corporation, Geothermal Resource Council, Palm Desert, CA, August 2004.

\section{Presentations Made in FY 2004:}

Comments on High Temperature Plugs: Progress Report on Polymers and Silicates, S. Bauer1, D. Galbreath2, J. Hamilton3, A. Mansure1, 1Sandia National Laboratories, 2Green Mountain International Inc., 3National Silicates, an affiliate of the PQ Corporation, Geothermal Resource Council, Palm Desert, CA, August 2004.

\section{Planned FY 2005 Milestones:}

Report on demonstration of cost saving/best-available technology to geothermal drilling (e.g., tremmie pipe, reverse placement, sodium silicate/cement plug placement, or cementing well completion job with operator) Report on bench-scale and field testing (with Halliburton) of newly developed silicate hydrate grout system 


\section{Hard-Rock Drill Bit Technology}

Reporting Period: FY 2004 (October 1, 2003 to September 30, 2004)

DOE Grant/Contract \#: $\quad$ DE-AC04-94AL85000

Performing Organization: Sandia National Laboratories

Geothermal Research Department 6211

Albuquerque, New Mexico 87185-1033

Principal Investigators: $\quad$ David W. Raymond, 844-6359, dwraymo@sandia.gov

Jack L. Wise, 844-8026, jlwise@sandia.gov

Collaborating Researchers:

DOE HQ Program Manager: Dr. Leland (Roy) Mink, (202) 586-5463, roy.mink@hq.doe.gov

DOE HQ Technical Manager: Raymond LaSala, (202) 586-4198, raymond.lasala@ee.doe.gov

DOE Funding Allocation: $\quad \$ 918 \mathrm{~K}$

Cost Share Funding:

Project Objective: Improve drill-bit hardware and control mechanisms to substantially increase penetration rate and bit life, thereby achieving corresponding reductions in the cost and risk associated with geothermal exploration and production drilling.

Background/Approach: Hot, hard, abrasive, and fractured rock formations are characteristic of geothermal energy production sites. A combined doubling of both penetration rate (ROP) and bit life relative to current conventional capabilities (ROP $\sim 5 \mathrm{~m} / \mathrm{hr}$; bit life $\sim 50 \mathrm{~m}$ or $10 \mathrm{hr}$ ) would yield an estimated $15 \%$ reduction in overall geothermal well costs. Such an improvement in economy promises a substantial increase in viably exploitable geothermal resources. The combined benefits of the anticipated decrease in drilling cost and increase in resource availability are fully consistent with the goals of DOE's Geothermal Energy Program, namely: (1) supplying electrical power and/or heat to more U.S. homes and businesses, (2) reducing the generation cost of geothermal power, and (3) increasing the number of States with geothermal electric power facilities.

Since the introduction of PDC cutters and bits in the 1970s, Sandia has worked with industry to extend this technology to drilling in harder (i.e., geothermal) formations by (i) identifying and correcting design and operational problems, and (ii) conducting field validation studies. Sandia's in-house laboratory capabilities include the Hard-Rock Drilling Facility (HRDF) and the Linear Cutter Test Facility (LCTF). These resources are supplemented, as needed, by outside laboratory and field-test facilities. The Sandiadeveloped PDCWEAR code computationally simulates bit performance and wear, supporting the generation of new bit designs. Active industry and/or university participation in each task contributes additional expertise and capabilities while maintaining program focus on commercial needs and interests. 
The FY04 effort built upon prior-year work by means of continuing technical activities to accomplish the four distinct, but complementary, tasks described in the following paragraphs.

Task A. PDC (Polycrystalline Diamond Compact) Cutter Development and Testing: This task has been undertaken to create a database that identifies optimal cutter configurations for hard rock by showing the influence of design parameters on wear and durability. New cutter materials and designs are produced and validated for geothermal drilling applications. During FY04, Sandia and U S Synthetic Corporation (USS) continued their joint cutter-parameter studies that involve the specification, manufacture, and testing of samples with unique combinations of geometric features, material composition, and processing history. The cutters are fabricated at USS, and then tested at both USS and Sandia using their complementary laboratory facilities to measure drop-impact damage and granite-log abrasion resistance (at USS), and linear cutting forces and rotary drilling performance in blocks of Sierra White Granite (at Sandia).

Task B. Self-Induced Bit Vibrations: Sandia has pursued the development and demonstration of systems that reduce axial and torsional chatter damage to bits during geothermal drilling. This approach includes (1) development of computational models to investigate the interaction between drillstring properties, bit design, formation properties, and operating conditions that contribute to bit vibrations; (2) development and testing in conventional facilities (i.e., existing Hard-Rock Drilling Facility) and advanced simulation facilities (under development) to experimentally investigate vibration phenomena, provide data to validate model development, and demonstrate and qualify advanced technology; and (3) development of advanced tools to mitigate bit vibrations. The synergistic coupling between computational modeling and laboratory testing validates our understanding of the mechanisms contributing to drillstring vibrations. The products of these developments are downhole hardware and control methodologies that will allow the application of PDC bits to geothermal production drilling.

Task C. PDC Bit Development and Testing: Working with multiple corporate partners, Sandia has conducted an ambitious field-test program to evaluate and document the hard-rock drilling capabilities of state-of-the-art drag bits that have been supplied by different vendors. These "best effort" bits were developed under the Sandia/industry CRADA (Cooperative Research and Development Agreement) that was established in FY02 to promote the adoption of improved bit technology by the geothermal drilling community. Activities for this task have simultaneously accomplished (1) a demonstration of baseline and state-of-the-art drag bits, and (2) a proof-of-concept test for Sandia's Diagnostics-While-Drilling (DWD) system.

The CRADA-based drilling has been carried out in three successive phases at the GTI Catoosa Test Facility, which features a well-characterized lithology with significant hard-rock intervals. Drilling for all three phases was conducted in the same lithologic interval, using the same bottomhole assembly (BHA) behind the bit. Phases 1 and 2 involved drilling with a conventional, widely known drag-bit design that was run, respectively, without (Phase 1) and with (Phase 2) surface and downhole data feedback to the driller from the DWD system. In Phase 3, each industry partner supplied a proprietary "best effort" bit and an engineering team for a field demonstration in conjunction with Sandia. Each industry team monitored and applied real-time DWD data to control the operation of its bit.

Task D. Mudjet-Augmented PDC Bit: Sandia has worked toward improved use of the hydraulic energy at the bit by integration of passively pulsating, cavitating nozzles that augment the rock reduction process. Prior to FY04, Sandia developed a demonstration bit and conducted full-scale laboratory testing at elevated wellbore pressures that validated the benefit of these nozzles. In FY04, laboratory testing was conducted by Sandia to characterize the nozzle/cutter/rock interaction process and guide the design of a second-generation mudjet-augmented PDC bit. Additionally, alternate processes to fabricate diamondcoated orifices for passively pulsating/cavitating nozzles were addressed. 
Status/Accomplishments: Task-by-task accomplishments during FY04 are summarized below.

Task A. PDC (Polycrystalline Diamond Compact) Cutter Development and Testing: Linear-cutting tests were completed on Sandia's LCTF for six additional lots $(13-18)$ of PDC test cutters. These tests yielded extensive 3-axis (X, Y, and Z) measurements of the time-resolved and mean cutting-force components for different cutting depths in a planar rock surface. Force data were also acquired for cutters from all six lots during engagement-angle tests, which involved the incremental deepening of a single groove in the rock via successive passes by the same cutter. In addition, rotary-drilling tests commenced on Sandia's HRDF, where the performance of cutters from two lots (13 and 14) was fully characterized by the end of FY04. Drilling evaluations for the remaining four lots carried over into the first quarter of FY05. Data from the latest tests augment the previously documented results for cutter lots $1-12$, which were investigated during FY01 and FY02. The test results from these parameter studies show that changes in cutter geometry and composition can have dramatic (factor of 10+) consequences for cutter drilling, wear, and impact performance.

Task B. Self-Induced Bit Vibrations: Sandia has developed a Prototype Controllable Damper to mitigate the damaging effects of axial and rotational vibrations on the integrity of the bit and drillstring. This downhole tool incorporates magnetorheological (MR) fluid in a damping module to introduce the requisite damping for stability. In FY04, Sandia tested the Prototype Controllable Damper in the HardRock Drilling Facility. The drilling tests demonstrated drilling stability across an operating range that had previously resulted in catastrophic failure of the PDC cutters on the bit. Data analysis, however, indicates the maximum controllable range of the Prototype Controllable Damper was not achieved in the prototype hardware. Sandia has executed a Non-Disclosure Agreement with Lord Corporation, a commercial manufacturer of MR fluids, regarding technical advances in controllable fluid technology and drillstring dynamics applications. Sandia attended an MR technology workshop, sponsored by Lord Corporation, along with personnel from research and industry. The MR module incorporated in the tool was evaluated using lessons learned from the workshop. In FY05, the MR module in the Prototype Controllable Damper will be reconfigured. This tool will be tested in a Sandia vibration facility and then returned to the HardRock Drilling Facility for additional drilling tests.

Sandia initiated development of an advanced computational modeling code to evaluate candidate concepts for controlling drillstring vibrations in the field and to guide selection of design parameters for field-grade tools. This code is based upon a wave-propagation algorithm, developed at Sandia, for analysis of extensional waves in drillstrings. An approach has been developed for a Drilling Dynamics Simulator, an advanced test facility to simulate the dynamic compliance of a field drillstring within the laboratory. Prototype hardware has been purchased to demonstrate the approach in FY2005. The demonstration will use our computational models to drive the Drilling Dynamics Simulator prototype hardware, allowing an evaluation of the Prototype Controllable Damper in a simulated drilling environment.

Task C. PDC Bit Development and Testing: Sandia fulfilled its obligations under CRADA No. SC02/01655, "Advanced Drag Bits for Hard-Rock Drilling," by analyzing and documenting the field results obtained during Phases 1 and 2 for a conventional drag bit, and during Phase 3 for the "best effort" bits provided by the industry partners. These results were reported in two separate GRC Transactions articles. The first article (GRC Transactions, Vol. 27) detailed the Phase 1 and Phase 2 results, providing baseline data demonstrating that the application of DWD-based drilling control can contribute significantly to extended bit life. The second article (GRC Transactions, Vol. 28), which won the "Best Paper" award for the Drilling Session of the GRC 2004 Annual Meeting, showed convincing evidence that deployment of an advanced bit design in conjunction with DWD can lead to major improvements in rate of penetration (factor of $1.4+$ ) and bit life (factor of 2+) relative to a conventional bit design operated without benefit of DWD. These performance improvements correlate with a reduction in the bit specific energy, which is a measure of the work required to advance the bit through a volume of rock. 
Task D. Mudjet-Augmented PDC Bit: Sandia completed single-cutter testing to evaluate the interaction between low-pressure nozzles and hard, non-porous rock. The results from the interaction testing were combined with the earlier results from a demonstration bit incorporating this technology and a final report was prepared. This report also summarizes the development of an approach to direct sinter polycrystalline diamond material within the throat of the nozzle orifice. This technology development is imperative for the successful deployment of these nozzles to survive the cavitation environment inherent in the passively, pulsating nozzles. The report is being circulated to industry to spawn commercialization of the technology.

\section{Reports \& Articles Published in FY 2004:}

Wise, J. L., J. T. Finger, A. J. Mansure, S. D. Knudsen, R. D. Jacobson, J. W. Grossman, W. A. Pritchard, and O. Matthews, "Hard-Rock Drilling Performance of a Conventional PDC Drag Bit Operated With, and Without, Benefit of Real-Time Downhole Diagnostics," Geothermal Resources Council Transactions, Vol. 27, October 2003, pp. $197-205$.

Mansure, A. J., J. T. Finger, S. D. Knudsen, and J. L. Wise, "Interpretation of Diagnostics-While-Drilling Data," Paper No. SPE 84244, SPE Annual Technical Conference and Exhibition, Denver, CO, October 2003.

Raymond, D. W., and Grossman, J. W., "Development and Testing of a Mudjet-Augmented PDC Bit," SAND Report (number pending), January 2004.

Wise, J. L., T. Roberts, A. Schen, O. Matthews, W. A. Pritchard, G. Mensa-Wilmot, S. Ernst, R. Radtke, R. Riedel, and J. Hanaway, "Hard-Rock Drilling Performance of Advanced Drag Bits," Geothermal Resources Council Transactions, Vol. 28, August 2004, pp. $177-184$.

\section{Presentations Made in FY 2004:}

Wise, J. L., "Hard-Rock Drilling Performance of a Conventional PDC Drag Bit Operated With, and Without, Benefit of Real-Time Downhole Diagnostics," oral and poster presentation at the GRC 2003 Annual Meeting, Centro de Convenciones y ExpoCentro, Morelia, Michoacán, Mexico, October 12 - 15, 2003.

Wise, J. L., "Drag-Bit CRADA Results," oral presentation at the DWD TAC Meeting, Stress Engineering Services, Inc., Houston, TX, May 6, 2004.

Wise, J. L., "Hard-Rock Drilling Performance of Advanced Drag Bits," oral and poster presentation at the GRC 2004 Annual Meeting, Hyatt Grand Champions Resort \& Spa, Indian Wells, CA, August 29 September 1, 2004.

Raymond, D. W., "Magneto-Rheological Fluid-Based Damper for Drilling Applications," oral presentation at Lord Corporation, Cary, NC, October 30, 2003.

\section{Planned FY 2005 Milestones:}

Test the Prototype Controllable Damper with a reconfigured magneto-rheological (MR)

fluid module and show the system can be regulated to introduce the appropriate level of

damping.

Complete linear-cutting and rotary-drilling lab tests on prototype shear cutters with

functionally designed microstructures. 


\section{Diagnostics-While-Drilling (DWD)}

Reporting Period: FY 2004 (October 1, 2003 to September 30, 2004)

DOE Grant/Contract \#: $\quad$ DE-AC04-94AL85000

Performing Organization: Sandia National Laboratories

Geothermal Research Department 6211

Albuquerque, New Mexico 87185-1033

Principal Investigator: Douglas A. Blankenship, (505) 284-1230, dablank@sandia.gov

Collaborating Researchers: A. J. Mansure, ajmansu@sandia.gov

S. D. Knudsen, sdknuds@sandia.gov

R. D. Jacobson, rdjacob@sandia.gov

D. S. Drumheller, dsdrumh@sandia.gov

J. A. Henfling, jahenfl@sandia.gov

DOE HQ Program Manager: Dr. Leland (Roy) Mink, (202) 586-5463, roy.mink@hq.doe.gov

DOE HQ Technical Manager: Raymond LaSala, (202) 586-4198, raymond.lasala@ee.doe.gov

DOE Funding Allocation: $\quad \$ 1740 \mathrm{~K}$

Cost Share Funding:

$\$ 300 \mathrm{~K}$, in-kind participation of operators and service companies in providing technical advice, conference facilities, data-reduction consultation, drill bits for field testing, and rig time.

Project Objective: The principal cost barriers to meeting DOE Geothermal Program goals are three: exploration for new geothermal resources, well construction for access to them, and power-plant operating and maintenance costs (including remedial treatment of production and injection wells). Reduced drilling cost is a critical component in breaking each of these barriers. When exploration is limited by drilling cost for example, it not only means that fewer potential reservoirs can be identified but it places a heavy expense at the front end of a project, years before it can be amortized by the revenue stream. The objective of the Diagnostics-While-Drilling (DWD) program is to provide a dramatic impact on the cost of geothermal drilling. Specifically, the DWD program is directed toward providing real-time information of downhole drilling conditions, thus adding capabilities to the drilling system and enabling a reduction of drilling flat-time and increased performance while drilling.

Background/Approach: DWD addresses drilling improvement both by reducing the cost of conventional drilling processes and by providing a revolutionary new capability - a closed feedback loop that carries data up and, eventually, control signals down between the driller and tools at the bottom of the hole. Upcoming data will give a real-time report on drilling conditions, bit and tool performance, and imminent problems. DWD will reduce costs, even in the short-term, by improving drilling performance, increasing tool life, and avoiding trouble. Cost analyses have shown that DWD technology can potentially reduce the 
bus-bar cost of geothermally generated electricity by $5 \%$ to $25 \%$, depending on well depth, well productivity, and the type of geothermal reservoir.

The industry data transmission standard now is mud pulse telemetry, but this technology only communicates one way from the bit to the surface, has a very slow data transfer rate, and will not work in geothermal conditions - high-temperature regimes, vapor-dominated wells, or underbalanced drilling operations. The principal criterion that will shape design of the DWD data transmission system is the data rate that we wish to transmit. Real-time drilling control that considers a number of downhole measurements requires a data rate higher than mud pulse, so we can either choose a technology that provides a higher data rate or we can perform much of the data processing downhole and just transmit a "status report" signal at a low data rate. Downhole data-processing has three major disadvantages: reaction time is too long to respond to down hole conditions that can damage bits in seconds; there is a risk to expensive, sometimes fragile tools in a high-shock, high-pressure, high-temperature environment; and processing algorithms must be chosen before the tool goes in the hole, losing the flexibility of changing data processing on the fly as drilling conditions change. In order to support the goals of the DWD program, it is for these reasons, we have chosen a high data-rate system.

Status/Accomplishments: The principal accomplishments in FY04 included fielding of the DWD system with support from an industrial partner, the development of new and more capable system for displaying real-time data, and design progression of a high temperature DWD system. Efforts also continued in working with industry on the marrying of DWD capabilities with alternative telemetry systems.

Security DBS, a Halliburton Company, requested that the DWD program provide support for its hardrock bit-technology development program. Two separate drilling tests were preformed in both hard statigraphic and granitic basement rocks at the Gas Technology Institute test facility in Catoosa, OK. The DWD system was a critical part of the Security DBS test plan, which required real-time, high-speed, downhole monitoring of the drilling operations. Security DBS supplied a 50 percent share of the rig time charges as well as the costs for drill bits, and bit engineering and analysis that are associated with this effort. The request from Security DBS was a strong endorsement of the utility and value of the DWD system; anecdotal comments from test engineers included "I can't imaging doing these tests without DWD”. In addition to providing industry valuable bit performance data, the testing partnership allowed continued testing of evolving DWD components and provided an opportunity to gain additional experience with the DWD system under difficult field conditions.

A critical component of the DWD system is the sub-system used to display data in real-time to the driller and/or engineer at the surface. A new integrated data display system (IDDS) was developed to improve the data processing and display capabilities of the original data display system. The IDDS is a major upgrade from the original data system. The new system has the ability to synthesize data from a variety of disparate data sources and allow viewing, storage, and reviewing in a common environment, on a single data acquisition computer. For example, the new system allows the real-time overlay of telemetry based data from the DWD sub with simple analog data obtained from surface based measurements, while also allowing contemporaneous annotations to be entered into a common data file. The new integrated data display system requires significantly less hardware that the original system and operates on a common Windows operating system using LabView ${ }^{\circledR}$ as the development platform. The aforementioned field test efforts with Security DBS allowed the system to be exercised in a real-world environment; the system performed admirably. Figure 1, provided below, shows a typical IDDS display.

Options were evaluated for a second-generation, high-high temperature DWD tool and designs for this tool were evaluated. A design temperature $225^{\circ} \mathrm{C}$ was selected because it appears feasible to maintain most of the functionality of the current low-temperature tool. However, design of a DWD sub for elevated temperature necessitates certain compromises. The inherent accuracy, resolution, and efficiency of many 
high temperature sensors and components are reduced relative to their low temperature counterparts. Also, high temperature components are larger than low temperature versions; the current low temperature tool is about 2.4-m-long; the high temperature tool is expected to be nearly $5 \mathrm{~m}$ in length. In addition to the change in temperature capabilities, the second-generation tool will also include design elements that remove the historically problematic "clamshell" covers. The new tool will continued to sense loads with a reduced diameter, strain-gaged section but will be protected with a keyed sleeve held in place with a service connection; thus eliminating the possibility of the clamshells detaching during drilling. To the extent feasible, bolted fasteners through the body of the tool will be eliminated to mitigate possible washout issues in the tool body. Critical electronic components were evaluated for high temperature operation. These evaluations were performed from $20^{\circ} \mathrm{C}$ to $225^{\circ} \mathrm{C}$ and evaluated drift and noise associated with included sensors as well as board level components.

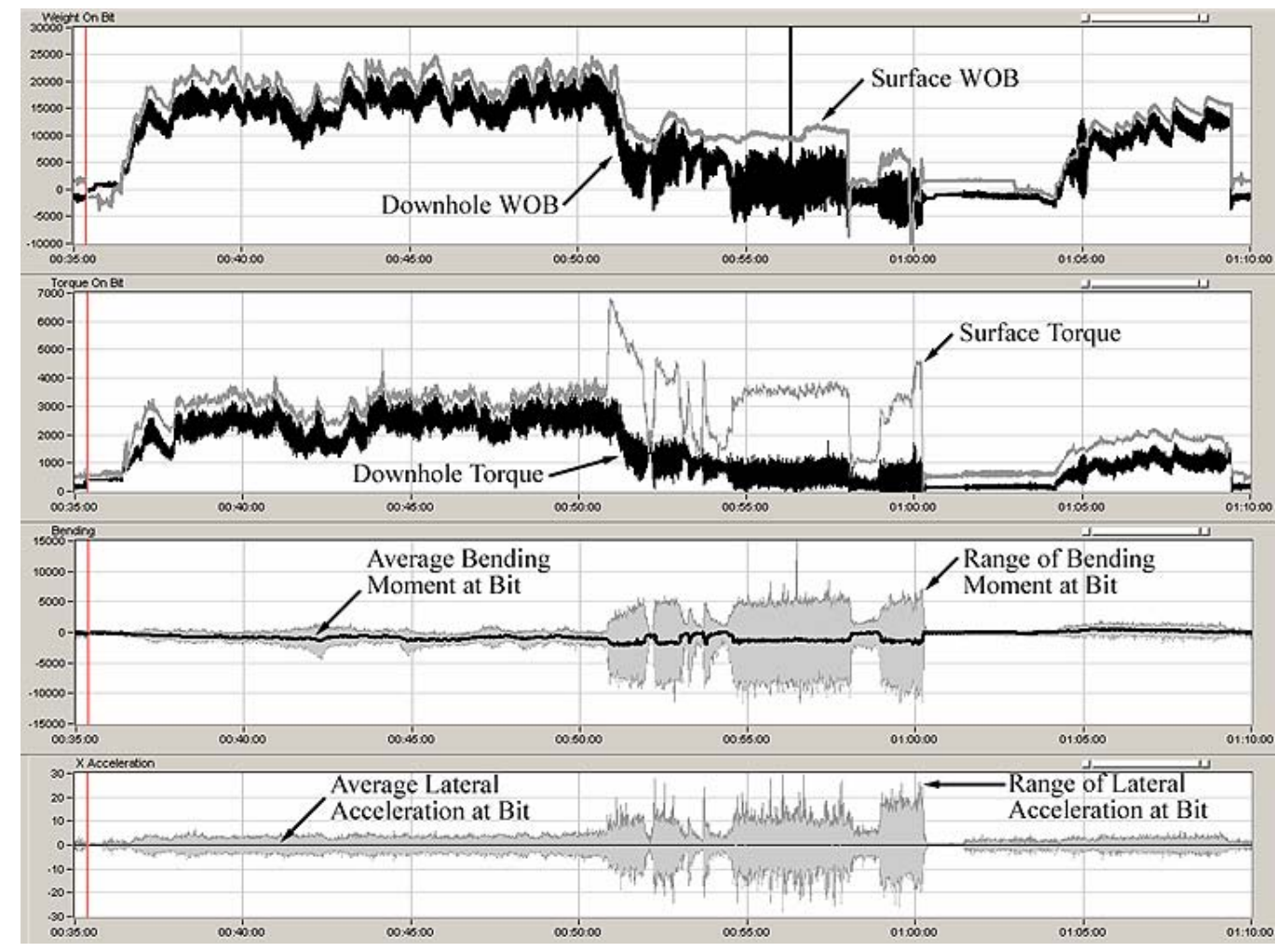

Figure 1. Typical Display from the Integrated Data Display System.

Necessity ditcates the data transmission link between the DWD sub and the surface continue to be the wet-connect wireline system. The wireline is a conventional single-conductor cable with connections that can be made and broken while immersed in drilling fluid and with an electrical swivel that allows the lower part of the cable to rotate relative to the upper part while maintaining electrical continuity. This wireline system has at least two major advantages in addition to its commercial status: the downhole electronics can be powered from the surface, obviating the need for downhole batteries, and the wireline can be quickly extracted from the drill string for any required maintenance or repair. During the drilling tests to date, performance of the wireline system has been adequate. Most problems, whether data dropouts or complete loss of signal, have been associated with the electrical swivel. Sandia continues to work with the company that manufactures the swivels, and improvements continue. This wireline system will also be used with the high temperature version of the DWD system. Notwithstanding the requirement to continue with wet-connect wireline, interaction with companies developing wired pipe telemetry systems continued. A cross-over sub was designed to allow the DWD measurement sub to interface 
mechanically and electrically with the IntelliPipe system being developed by NovaTek and Grant Prideco. A field test using IntelliPipe to transmit DWD data is planned for FY05.

\section{Reports \& Articles Published in FY 2004:}

Blankenship D. A., A. J. Mansure, J. T. Finger, S. D. Knudsen, and R. D. Jacobson, August/September 2004, Update on a Diagnostics-While-Drilling (DWD) System to Assist in the Development of

Geothermal Wells," Geothermal Resources Council Transactions, Vol. 28

Wise, J. L., Mansure, A. J., and Blankenship, D. A., Hard-Rock Field Performance of Drag Bits and a Downhole Diagnostics-While-Drilling (DWD) Tool, accepted for publication in the World Geothermal Congress Proceedings, 2005.

\section{Presentations Made in FY 2004:}

Blankenship D. A., A. J. Mansure, S. D. Knudsen, R. D. Jacobson, J. A. Henfling, and D. S. Drumheller, DWD Status Update, Meeting of the DWD Technical Advisory Committee, Stress Engineering Services Facilities, Houston, TX, May 2004.

Blankenship D. A. and A. J. Mansure, Diagnostics-While-Drilling, Sandia Technology Symposium, Sandia National Laboratories, Albuquerque, NM, September 2004.

Geothermal Resource Council presentation as noted above.

\section{Planned FY 2005 Milestones:}

Identify site for DWD geothermal drilling test Dec 04

Qualify high temperature components in laboratory tests Mar 05

Complete fabrication of high temperature DWD tool to be used in drilling test June 05 Perform DWD test in high temperature well 


\section{Advanced Drilling Concepts}

Reporting Period: FY 2004 (October 1, 2003 to September 30, 2004)

DOE Grant/Contract \#: $\quad$ DE-AC04-94AL85000

Performing Organization: Sandia National Laboratories, Geothermal Research Department 6211

PO Box 5800, Albuquerque, NM 87185-1033

Principal Investigator: $\quad$ A.J. Mansure, (505) 844-9315, ajmansu@sandia.gov

Collaborating Researchers: S. Bauer and N. Warpinski

DOE HQ Program Manager: Dr. Leland (Roy) Mink, (202) 586-5463, roy.mink@hq.doe.gov

DOE HQ Technical Manager: Raymond LaSala, (202) 586-4198, raymond.lasala@ee.doe.gov

DOE Funding Allocation: $\$ 330 \mathrm{~K}$

Cost Share Funding: $\quad 0$

Project Objective: Achieve more than incremental reductions in geothermal well costs by investigating emerging (technologies being developed elsewhere by industry but not yet tested for geothermal) and potentially "game changing" (revolutionary) technologies. Focus will be on technologies needed for future geothermal wells including Engineered Geothermal System (EGS) wells. Evolutionary drilling and completion technology improvements can achieve the objective "By 2010, develop and implement nearterm improvements to drilling processes for geothermal applications to reduce costs by $25 \%$ " and thus support cost reductions in hydrothermal geothermal power costs to 5 cents per kilowatt-hour by 2010 . But to achieve the objective of "By 2020, develop the long-term revolutionary drilling advances needed to allow drilling twice today's depths for the same cost, particularly in Engineered Geothermal System (EGS) environments," will require Advanced Drilling Concepts.

Background/Approach: Cost-effective well construction requires integrating various functions including casing the well, maintaining wellbore integrity, removing the cuttings, etc. Only by considering the overall drilling system, alternate methods for enhancing well construction can be evaluated. Many potential component technologies have been evaluated in the past, including lasers, water/mud jets, arcs, flame jets, explosives, hammers, projectiles, rock melters, and coiled tubing. In general, the evaluation was done in the context of currently developed geothermal resources rather than the geothermal resources of the future, the focus of this project.

Wellbore construction must be evaluated as a system in context: what is the drilling stratigraphy (rock mechanical properties), completion, and lift mechanism (natural flow, submersible pump, etc.)? All of these must be known to design a well and evaluate applicable technologies. Historically, completion of EGS systems has been envisioned as stimulation by hydrofracturing basement rocks. There are other 
drilling stratigraphies with geothermal potential such as deep sedimentary basins. A necessary first step is to establish drilling stratigraphic targets considering how the reservoir will be engineered.

The evaluation of Advanced Drilling Concepts builds upon past work: "Advanced Drilling Systems Study" (SAND95-0331 by Pierce et al.). That work has been updated, added to, supplemented with additional economic analyses, and done in context. Input from industry has been sought to identify new developments and concepts. Evaluation of emerging technologies is being done through cooperation with industry. The advanced concept must be a complete system, not just a component. Potential impacts of changing one component on performance of other parts of the system are evaluated - e.g., does changing the rock reduction have a positive/negative impact on wellbore integrity?

In addition to approaching the problem of prioritizing Advanced Drilling Concepts from the technology perspective, data in the Wellcost Database is being reviewed to identify what are current cost drivers of well construction, e.g., the relative importance of trouble costs, tangible costs, rock reduction costs, wellbore integrity costs, etc.

Status/Accomplishments: To demonstrate that it is possible to significantly reduce geothermal well construction costs, both past and future geothermal drilling costs have been analyzed. Figure 1 compares both recent geothermal and oil \& gas well costs to the costs of wells drilled in the 1970's ("Advances in Geothermal Drilling Technology: reducing cost while improving longevity of the well," Geological Society of Nevada, Symposium 2005, by Mansure \& Bauer). The figure shows that, not only are recent geothermal wells less expensive than geothermal wells drilled in the 1970's, the ratio of geothermal to oil $\&$ gas well costs has been reduced. This is in spite of the fact that geothermal well diameters are increasing and oil \& gas well diameters are decreasing. Even though geothermal drilling costs are decreasing, there is still significant opportunity to reduce cost further. Review of data in the Wellcost Database shows that typically problems during drilling of the well contribute $30 \%$ to the cost of a geothermal well in developed areas; in undeveloped areas, where there is of course no data, the costs of trouble will be even more.

Reduction in Drilling Costs (Geothermal vs. Oil \& Gas)

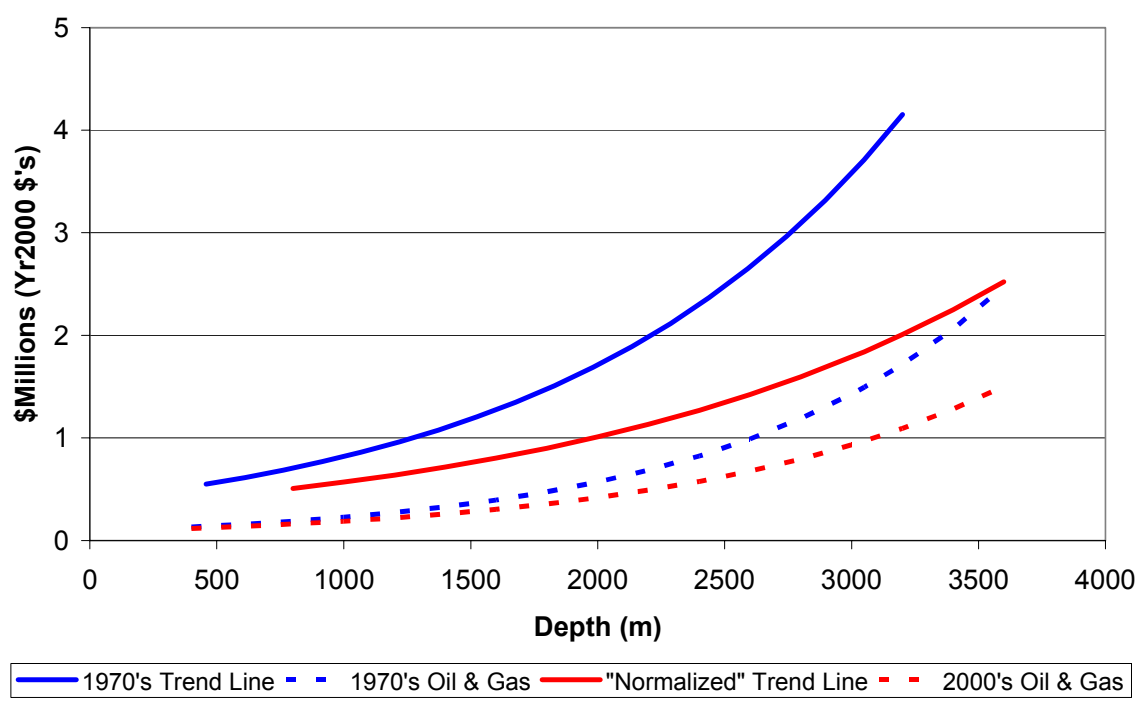

Figure 1: Comparison of both recent geothermal (solid red) and oil \& gas well costs (dashed red) to the costs of wells, geothermal (solid blue) and oil \& gas (dashed blue) drilled in the 1970's. 
Future geothermal drilling costs have been analyzed based on a "trouble-free" 20,000-foot EGS geothermal well drilled using state-of-the-art technology. This work showed that the cost of such a well divides into three almost equal parts: 1) rock reduction \& removal, 2) permanent well stabilization (casing), and 3) other. Thus the perfect rock reduction \& removal technology, one that is free, has an infinite rate-of-penetration, and does not wear out, would reduce the cost of the well by one third. Costs of casing the well include the steel, the cement, rig time to run the casing and pump the cement, cementing tools, and service charges. Other costs include management costs, location costs, well control, fuel, transportation, directional control, wellhead, logging, testing, etc.

From these cost analyses it is clear that to achieve a reduction in geothermal drilling by a factor of two or more, one must address more than one technology issue, that is, focusing on just rock destruction or permanent wellbore stabilization is inadequate. Other geothermal drilling costs can be reduced indirectly by achieving cost savings through streamlining operations by standardizing and simplifying the well construction, minimizing the footprint and equipment, reducing the time to construct the well, etc; through technology improvements.

Material costs (steel, cement, etc) tend to be higher for geothermal wells than for oil \& gas wells (see Figure 2 for a comparison of oil \& gas and geothermal casing costs). For a geothermal well with $95 / 8$ inch casing, the steel costs as much as $\$ 54$ per foot and the cement $\$ 5$ per foot. Thus these material costs alone are a significant part of a $\$ 113$ per foot goal of drilling twice as deep for the same cost. Thus the need to consider "game changing" technologies that reduce the cost of permanent well stabilization.

Based on the need to address both rock destruction and permanent wellbore stabilization, and on the need to improve the current state-of-the-art through near-term technology advances, as well as to break out of the evolutionary mind set, potentially advanced concepts technologies have been synthesized into a list of high-priority near-term and long-term opportunities:

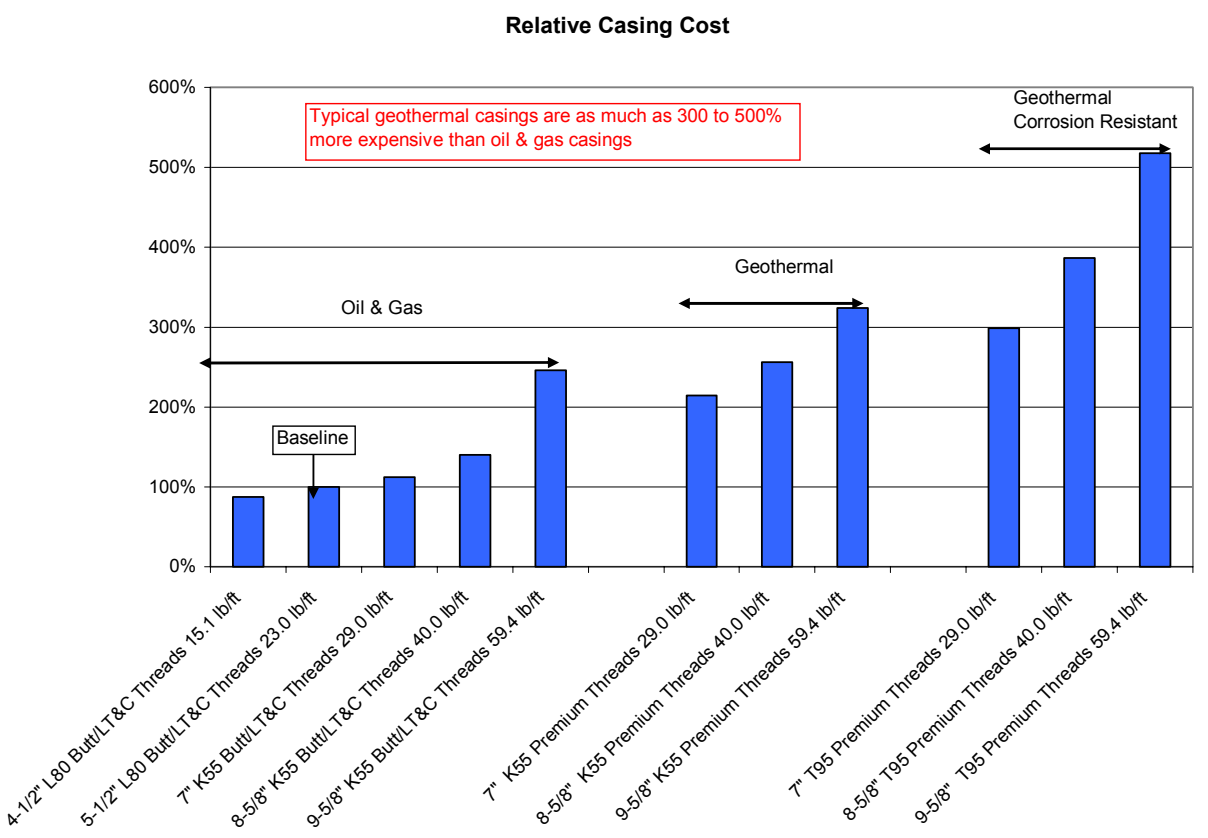

Figure 2: Comparison of Oil \& Gas and Geothermal casing costs considering 5 1/2 inch baseline well casing. 
Near-term technologies (ones that could be prototyped in 5-years):

- $\quad$ Advanced Wellbore Designs (e.g. monobore).

- $\quad$ Casing Drilling.

- Innovative Wellbore Drilling Hydraulics System (e.g. Dual-Tube Reverse-Circulation).

- $\quad$ Particle Impact Drilling.

- Percussion Drilling.

- $\quad$ Cold Water Zone Shutoff Using Expandable Tubulars.

Long-term opportunities (ones that will require more than 5 years to prototype):

- $\quad$ Advanced Wellbore Stabilization (can we eliminate the need for casing using casing lining concepts?).

- $\quad$ Alternative "Casing" Materials (can we eliminate steel?).

- $\quad$ Chemical Dissolution Drilling.

Advanced Drilling Concepts can be emerging and "game changing" technologies. Emerging technologies are technologies being developed elsewhere by industry but not yet proven for geothermal drilling. Emerging technologies includes technologies such as Percussion Drilling that are not new in concept, but for which there have been recent developments. Casing Drilling, Particle Impact Drilling, Percussion Drilling, and Expandable Tubulars are emerging technologies. Advanced Wellbore Stabilization, Alternative "Casing" Materials, and Chemical Dissolution Drilling are "game changing" technologies.

Work on establishing the context within which Advanced Drilling Concepts are evaluated has included establishing a baseline well design and target mechanical stratigraphies. Cost analyses of Advanced Drilling Concepts must be done based on actual well designs. Well design is a function of lithology, completion, and lift mechanism. A baseline well design has been established for a deep 20,000 ft well drilled into basement rock.

The lithology assumed for the baseline well is that, for the upper portion of the well where wellbore integrity may be a problem, "water well" technology can be used and that, for deeper drilling, the rock is competent minimizing drilling problems (that is deep drilling is assumed to be relatively trouble free). The diameter is large enough for the well to be self-pumping, supplemented by a charge pump for EGS systems. Also, the wellbore is large enough to allow a variety of completion options (multi-leg, open hole, cased, or slotted liner).

Work on mechanical stratigraphies began with a draft of lithology and completion targets. Drilling conditions considered, included Geysers, Coso, Dixie Valley, Basin \& Range, Imperial Valley, Hawaii, Deep Sedimentary Basins, Cascades, and Deep Basin \& Range. This range of resource was considered to allow advanced drilling concepts to be evaluated both for hydrothermal and EGS resources. Factors included are Lithology, ROP, Well Control, Bit Life, Hole Stability, Directional Control, Lost Circulation, and Casing \& Cementing Problems. These factors were considered for the conductor pipe; surface, intermediate (if required), \& production casings; and completion.

Currently, we propose to classify future drilling targets not by reference to a specific location, but by mechanical stratigraphy (this classification is being reviewed):

1. Sedimentary (e.g. Imperial Valley)

2. Sedimentary overburden crystalline basement (e.g. Cooper basin)

3. Volcanics - interbedded consolidated \& unconsolidated (e.g. Hawaii, Coso) 
4. Crystalline basement (e.g. Fenton Hill)

5. Metamorphic complex (e.g. Geysers)

6. Fractured/faulted - alternating volcanics \& sediments (e.g. Basin \& Range).

Currently the Advanced Drilling Concepts considered most promising for work in FY05 are Percussion Drilling, Expandable Tubular Cold Water Zone Shutoff, and Particle Impact Drilling.

Reports \& Articles Published in FY 2004: None

Presentations Made in FY 2004: None

Planned FY 2005 Milestones:

Complete Feasibility Study on Selected Emerging Technology

(e.g., Expanded Tubular Shutoff of Cold Water Influx Zone)

Jul 05

Complete report on "Game Changing" Geothermal Drilling Technologies

Sep 05 


\section{Acid Resistant Cements}

Reporting Period: FY 2004 (October 1, 2003 to September 30, 2004)

DOE Grant/Contract \#: $\quad$ DE-AC02-98CH10866

Performing Organization: $\quad$ Brookhaven National Laboratory, Upton, N.Y. 11973

Principal Investigator: $\quad$ Toshifumi Sugama, (631) 344-4029, sugama@bnl.gov

Collaborating Researchers: Lance Brothers, Halliburton, Lance.Brothers@halliburton.com

Todd. R. Van de Putte, CalEnergy, todd.vandeputte@calenergy.com

DOE HQ Program Manager: Dr. Leland (Roy) Mink, (202) 586-5463, roy.mink@hq.doe.gov

DOE HQ Technical Manager: Raymond LaSala, (202) 586-4198, raymond.lasala@ee.doe.gov

DOE Funding Allocation: $\quad \$ 120 \mathrm{~K}$

Cost Share Funding: $\quad$ \$200K (in-kind)

Project Objective: The purpose of this work is to 1) modify the cost-effective sodium silicate-activated slag cements developed in the previous FY with fly ash F as an industry byproduct that makes it possible to incorporate the anti-acid zeolite phase into the cement bodies, 2) investigate a potential of air-foamed low-density calcium silicate phosphate $(\mathrm{CaP})$ cement slurry for replacing $\mathrm{N}_{2}$ gas-foamed conventional cement slurries, and 3) also to conduct post-field test analyses of $\mathrm{CaP}$ cement being emplaced by Halliburton in Coso's geothermal wells. The primary goal of this program is to formulate commercial cements with superior acid-resistant properties that show less than a $5 \mathrm{wt} \%$ loss after 30 days immersion in 5,000 ppm $\mathrm{CO}_{2}$-laden $\mathrm{H}_{2} \mathrm{SO}_{4}$ brine $(\mathrm{pH}<1.2)$ at temperatures up to $200^{\circ} \mathrm{C}$. A secondary goal is to design an air-foamed $\mathrm{CaP}$ cement slurry with a density of $<1.22 \mathrm{~g} / \mathrm{cc}$ and uniform dispersion of microsize fine discrete air-bubble cells. This hardened foam cement is required to posses a good adherence to steel casing and an ability to protect the casing against corrosion.

The highly concentrated $\mathrm{CO}_{2}$ and $\mathrm{H}_{2} \mathrm{~S}$ environments encountered in the upper regions of the wells $\left(\sim 3,800 \mathrm{ft}\right.$. below ground surface) at temperatures up to $200^{\circ} \mathrm{C}$ occasioned the former research objective of acid resistance. The latter was related to dealing with the problem of lost circulation caused by circulating conventional slurry of typical density, 1.9 to $2.0 \mathrm{~g} / \mathrm{cc}$ under a high hydrostatic pressure. Severe acid erosion and an insufficient protection of casing against corrosion lead to downtime or even failure of the wells, and the requirement for expensive time-consuming remediation involving redrilling and recementing operations. Thus, the improved cements would not only significantly extend the useful lifetime of the well casing, but also would save in excess of $\$ 150,000$ per well in avoided remedial operations. Wells completed with the improved cement are projected to have service lifetimes of 20 years, thereby improving the efficiency and lowering the costs of energy-extracting operations at the plants. 
Background/Approach: Based upon the data over the past several years, the cementitious materials to be developed were required to meet the following criteria: 1) maintenance of pumpability for at least 3 hours; 2) compressive strength, $>500$ psi at 24 hours; 3) water permeability, $<0.1$ millidarcy; 4) bond strength to steel casing, $>100 \mathrm{psi}$; 5) carbonation rate, $<5 \%$ after 1 year in brine at $300^{\circ} \mathrm{C}$ containing $40,000 \mathrm{ppm} \mathrm{CO} \mathrm{CO}_{2} ; 6$ ) fracture toughness, $>0.08 \mathrm{MN} / \mathrm{m} 3 / 2$ at 24 hours; 7) resistance to acid, $<5 \mathrm{wt} \%$ loss after 30 days in $5,000 \mathrm{ppm} \mathrm{CO}$-laden $\mathrm{H}_{2} \mathrm{SO}_{4}(\mathrm{pH},<1.2)$ at temperatures up to $200^{\circ} \mathrm{C}$; and 8) cost, $<\$ 15 /$ bag.

In 2001, Halliburton's commercial CaP cement known as "ThermaLock ${ }^{\circledR}$ " which won the prestigious "Research and Development (R\&D) 100 Award" in 2000, was originally developed at BNL as a $\mathrm{CO}_{2-}$ resistant material for cementing steel well casings to geologic formations in mild acid ( $\mathrm{pH} \sim 4.5), \mathrm{CO}_{2}-$ rich $\left(>40,000 \mathrm{ppm} \mathrm{CO}\right.$ ) brine environments at temperatures up to $320^{\circ} \mathrm{C}$. The Unocal Corp, Halliburton Corp, and Japan Petroleum Exploration Corp. have used this cement to complete nearly twenty-four geothermal wells in Japan, Indonesia, and the United States. In 2002, the $\mathrm{N}_{2}$ gas-foamed "ThermaLock" cement was used in the Coso geothermal wells containing a highly concentrated $\mathrm{H}_{2} \mathrm{~S}$ and $\mathrm{CO}_{2}$ brine, and also has become increasingly popular for completing geothermal, oil, and gas wells worldwide. The original $\mathrm{CaP}$ cement met all criteria, except for items 6 and 7. So, in developing the advanced $\mathrm{CaP}$ cement, we focused on improving two properties, acid resistance and toughness. Regarding the former issue, our experiments showed that among the four crystalline reaction products, hydroxyapatite (HOAp), boehmite, hydrogrossular, and Na-P type zeolite, responsible for strengthening the $\mathrm{CaP}$ cement and enhancing its resistance to $\mathrm{CO}_{2}$, the HOAp phase was susceptible to acid erosion. In efforts to look for ways to protect the HOAp phase and minimize its erosion by acid, we assessed the usefulness of a hightemperature silanol-terminated polydimethlysiloxane (PDMS) additive possessing an excellent thermal stability, high water-repellency, great flexibility, and outstanding resistance to acid. The PDMS protected the cement in two ways: it considerably reduced the formation of calcite, which was generated by the carbonation of the cement and it abated the rate of reaction of HOAp with acid. Consequently, there was a weight loss of only $7.8 \%$ after a 20 -day exposure. However, the new concern in using the PDMS was the increase in the cement's cost, making it more than three times as expensive as the original cement. Regarding the improvement of toughness, our approach was to incorporate strong fibrous materials into it. Among the ceramic- and carbon-based fibers, the milled carbon microfibers $(\sim 7.5 \mu \mathrm{m}$ diam. $\mathrm{x} 100-200$ $\mu \mathrm{m}$ long) offered a great fracture toughness of $0.068 \mathrm{MN} / \mathrm{m} 3 / 2$ by incorporating $14 \mathrm{wt} \%(21.8 \mathrm{vol} . \%)$ fibers, corresponding to its increase by 3.1-fold over that of the non-reinforced cement.

In early 2002, Halliburton applied this fiber-reinforced cement as the anti-corrosive internal lining material to the geothermal wellhead pipe in a CalEnergy power plant. In FY2003, the emphasis was directed towards developing the low cost (less than $\$ 15 / \mathrm{bag}$ ), acid-resistant cements and investigating the effectiveness of various setting retarders in extending the pumping time of $\mathrm{CaP}$ cement. In the former subject, using an inexpensive, abundant granulated blast furnace slag (BBCS) as a by-product from steel manufacturing, a new type of cement was synthesized through an alkali-activating reaction between the BBCS and the sodium silicate solution with $\mathrm{SiO}_{2} / \mathrm{Na}_{2} \mathrm{O}$ ratios of 3.22. The estimated cost of this sodium silicate-activated slag (SSAS) cement was $\sim 25 \%$ less than that of the conventional well cements. The $200^{\circ} \mathrm{C}$-autoclaved SSAS cement displayed an outstanding compressive strength of more than $80 \mathrm{MPa}$ and a minimum water permeability of less than $3.0 \times 10^{-5}$ darcy. Yet there was only $8 \%$ loss in weight of SSAS cement after a 15-day exposure to the hot $\mathrm{CO}_{2}$-laden acid. After dissolving sodium silicate in water, its hydrolysis led to the formation of two hydrolysates, monosilicic acid and sodium hydroxide. The hydroxyl anion in the sodium hydroxide hydrolysate acted as an alkali activator for slag, and the monosilicic acid hydrothermally reacted with $\mathrm{Ca}$ in the activated slag to form calcium silicate hydrate. Thus, the free $\mathrm{Na}$ ions appeared to remain in this cementitious structure. In attempting to transform nonreacted $\mathrm{Na}$ ions into a Na-intercalated crystal hydration product such as the zeolite phase which is relatively inert with reactions with acid, our attention will be concentrated on incorporating the Class $\mathrm{F}$ fly ash generated from the coal-combustion power plants into the sodium silicate-activated slag cement 
system because the mullite phase in the fly ash will react with $\mathrm{Na}$ to form zeolite. Regarding the setting retarders, the citric acid significantly contributed to enhancing the setting temperature and to extending the thickening time of $\mathrm{CaP}$ cement slurry. The set-retarding activity of citric acid was due to the uptake of $\mathrm{Ca}^{+}$ions from the calcium aluminate reactant (CAR) in $\mathrm{CaP}$ cement slurry by carboxylic acid groups within the citric acid. This uptake led to the precipitation of a Ca-complexed carboxylate compound as a set-retarding barrier layer on the CAR grains' surfaces.

Status/Accomplishments: In FY 2004, the program was divided into the following three tasks. Our first task was to develop a cost-effective sodium silicate-activated slag/Class F fly ash (SSASF) blend cementitious material as advanced acid-resistance cement. The second was to assess the potential of airfoamed low-density $\mathrm{CaP}$ cement slurry for replacing $\mathrm{N}_{2}$ gas-foamed cement slurry. Our third task was devoted to monitoring the integrity of $\mathrm{N}_{2}$ gas-foamed $\mathrm{CaP}$ cement emplaced in the Coso geothermal wells nearly two years ago.

In the first task, the SSASF blend cements were prepared by varying two parameters, the $\mathrm{SiO}_{2} / \mathrm{Na}_{2} \mathrm{O}$ mol. ratio in the sodium silicate activator, and the slag/fly ash weight ratio, and then autoclaving them at $100^{\circ}$, $200^{\circ}$, and $300^{\circ} \mathrm{C}$. The usefulness of the autoclaved SSASF cements as acid-resistant geothermal well cements was evaluated by exposing them for 15 days to $90^{\circ} \mathrm{C} \mathrm{CO}_{2}$-laden $\mathrm{H}_{2} \mathrm{SO}_{4}(\mathrm{pH} \mathrm{1.1)}$. Among the combination of these two parameters, the most effective one in inhibiting acid erosion consisted of 50/50 slag/fly ash ratio cement and $2.50 \mathrm{SiO}_{2} / \mathrm{Na}_{2} \mathrm{O}$ ratio activator. The weight loss by acid erosion of this cement was less than 7\%. The major contributor to such minimum acid erosion was the zeolite phase formed by interactions between the mullite in fly ash and the $\mathrm{Na}$ ion liberated from the activator. Further characteristics of this cement included a long setting time for its slurry of $\sim 1770 \mathrm{~min}$ at room temperature, a water permeability ranging from $2.4 \times 10^{-4}$ to $1.9 \times 10^{-5}$ Darcy, and a compressive strength from 4.0 to $53.4 \mathrm{MPa}$ after autoclaving at $100^{\circ}-300^{\circ} \mathrm{C}$ for 24 hours. This information strongly suggested that the incorporation of more zeolite phases into the cement would increase its resistance to acid. To develop zeolite-rich $\mathrm{CaP}$ cement, attention will be paid to investigating the usefulness of any other aluminum silicate-based additives, such as metakolin and amorphous aluminum silicate compounds.

Regarding the second task, in pumping and circulating a cement slurry of typical density, 1.9 to $2.0 \mathrm{~g} / \mathrm{cc}$, used in geothermal wells, there is considerable risk of creating undesirable fracture zones in a weak unconsolidated rock foundation with very fragile gradients due to the high hydrostatic pressure that is required to circulate such dense slurry, thereby causing the problem of lost circulation. Thus, it is very important to use cement slurry with the lowest density responsible for reducing this hydrostatic pressure, so minimizing the possibility of experiencing lost circulation. There are three ways to prepare low-density slurries with calcium aluminate phosphate $(\mathrm{CaP})$ geothermal well cement: First is to incorporate pressureand high temperature-resistant hollow ceramic-shelled microspheres, with a density of $\sim 0.7 \mathrm{~g} / \mathrm{cc}$ and a particle size of $75-200 \mu \mathrm{m}$, into the slurry; the second is to disperse fine $\mathrm{N}_{2}$ gas bubbles created by injecting highly pressured $\mathrm{N}_{2}$ into a slurry containing the foaming additive; and, the third is to introduce small, fine air bubbles into the slurry by adding a foaming reagent to it. Although the $\mathrm{N}_{2}$-foamed CaP cement slurry has offered very promising results thus far, the third method using a simple foaming reagent was thought of as the most cost-effective and inexpensive technology because it eliminated the use of expensive ceramic microspheres and the time-consuming, complicated $\mathrm{N}_{2}$-injection process.

The air-foamed low-density CaP cement slurry was prepared by mixing it with chemical foaming reagent at room temperature without any pressure, followed by autoclaving at $200^{\circ} \mathrm{C}$. When the porosity, compressive strength, and water permeability of the autoclaved $\mathrm{CaP}$ foam cement made from a $1.22 \mathrm{~g} / \mathrm{cc}$ slurry density was compared with those of $\mathrm{N}_{2}$ gas-foamed Class $\mathrm{G}$ cement made from a slurry of similar density under high pressure and hydrothermal temperature at $288^{\circ} \mathrm{C}$, the $\mathrm{CaP}$ cement revealed some advanced properties, such as a higher compressive strength and lower porosity. However, one 
shortcoming was an increase in water permeability because of the formation of an undesirable continuous porous structure caused by coalesced air bubble cells, suggesting that an appropriate lesser amount of foaming reagent be used to create a conformation in which fine discrete air-bubble cells are uniformly dispersed throughout the slurry. For non-foamed cement, three major factors contributed to protecting carbon steel against corrosion: 1) good adherence to steel, reflecting a high extent of coverage by the cement layer over the steel's surfaces; 2) retardation of cathodic corrosion reactions; and, 3) minimum conductivity of corrosive ionic electrolytes. However, adding an excessive amount of foaming reagent did not offer as effective corrosion protection as that of non-foamed cement. Based upon the above information, our work now will shift to developing new types of a chemical foaming reagent along with a corrosion inhibitor for an air-foamed cement.

Correspondingly, another critical issue of the casing's corrosion concerned the generation of fissures in the cement adhering to the casing caused by an irregularly pulsating super heated fluid or steam. Thus, work to evaluate the bond durability at interfaces between cement and carbon steel casing by hot-cold cycling testing will be required.

For our third task, BNL evaluated the $\mathrm{N}_{2}$ gas-foamed cement specimens after exposure for 18 months in Halliburton's designed in-house environment $\left(\sim 10,000 \mathrm{ppm} \mathrm{CO}_{2}\right.$ and $\mathrm{pH} \sim 3.5$ at hydrothermal temperature of $170^{\circ} \mathrm{C}$ ) similar to the Coso wells at 3,700 ft.-casing depth. The evaluation included their compressive strength, water permeability, and phase identification. The obtained data were compared with that of the unexposed ones to judge whether the required properties of the exposed-foamed cement still remained unchanged. The test data revealed a very encouraging result; namely, there were no significant changes in mechanical and physical properties for the 18-mo.-exposed specimens. The compressive strength fell slightly from 2885 psi for unexposed specimens to 2725 psi for exposed ones, yet its value was far higher than that of $500 \mathrm{psi}$ as material criteria. The water permeability of $7.4 \times 10-4$ Darcy was almost the same as that of the unexposed ones. The XRD analysis showed that the 18-mo.-old cement had three major crystalline phases, hydroxyapatite $\left[\mathrm{Ca}_{5}\left(\mathrm{PO}_{4}\right) 3(\mathrm{OH}), \mathrm{HOAp}\right]$, analcime $\left(\mathrm{NaAlSi}_{2} \mathrm{O} 6 . \mathrm{H}_{2} \mathrm{O}, \mathrm{AN}\right)$, and cancrinite $\left[\mathrm{Na}_{5}(\mathrm{AlSi}) 1_{2} \mathrm{O}_{24} \mathrm{CO}_{3.3} \mathrm{H}_{2} \mathrm{O}, \mathrm{CAN}\right]$, which are responsible for strengthening the foamed cement. Since the $\mathrm{CAN}$ phase was formed by reactions between $\mathrm{AN}$ and $\mathrm{CO}_{2}$, it was possible to assume that some retrogression of the compressive strength was more likely to be associated with the in-situ $\mathrm{AN} \rightarrow$ CAN phase transition, rather than its acid erosion. It was expected that this phase transition would be continued with an extending exposure time. Although any other assessments such as the adherence of cement to casing and the corrosion protection of casing by cement were not encompassed in this evaluation, we concluded that the $\mathrm{N}_{2}$ gas-foamed CaP cement remained in effect thus far.

\section{Reports \& Articles Published in FY 2004:}

T. Sugama and L.E. Brothers, "Sodium Silicate-activated Slag for Acid-resistant Geothermal Well Cements", Advances in Cement Research, 16, No.2, (2004) 77-87.

T. Sugama, L.E. Brothers, and T.R. Van de Putte, "Acid-resistant Cements for Geothermal Wells: Sodium Silicate-activated Slag/Fly Ash Blend”, Advances in Cement Research, (in press).

T. Sugama, L.E. Brothers, and T.R. Van de Putte, "Air-foamed Calcium Aluminate Phosphate Cement for Geothermal Wells", Cement and Concrete Composites, (accepted in publication).

\section{Presentations Made in FY 2004:}




\section{Planned FY 2005 Milestones:}

Complete report describing the results from acid resistance tests for slag cement

Feb 05

Complete report on corrosion inhibitors \& foaming reagents for low-density CaP slurry

May 05

Evaluate bond durability at cement/casing interfaces

July 05 


\section{Power Plant Database}

Reporting Period: FY 2004 (October 1, 2003 to September 30, 2004)

DOE Grant/Contract \#: $\quad$ AC07-99ID13727

Performing Organization: Idaho National Engineering \& Environmental Laboratory

Renewable Energy \& Power Technologies

2525 North Fremont Drive, P.O. Box 1625

Idaho Falls, ID 83415-3870

Principal Investigator: Ｇreg Mines, (208) 526-0260, Gregory.Mines@inl.gov

Collaborating Researchers:

DOE HQ Program Manager: Dr. Leland (Roy) Mink, (202) 586-5463, roy.mink@hq.doe.gov

DOE HQ Technical Manager: Raymond LaSala, (202) 586-4198, raymond.lasala@ee.doe.gov

DOE Funding Allocation: $\quad$ \$110K (FY04)

Cost Share Funding: $\quad \$ 0$

Project Objective: The objective of this task is to implement methods developed to evaluate the impact of new power plant technologies on cost of power. Methodologies being developed provide representative capital and operating costs for conventional types of power plants used with liquid-dominated, hydrothermal resources (binary and flash steam). These methods are subsequently used to quantify the benefits of technologies that improve performance and/or lower costs. Efforts will help direct research activities and priorities, and as such contribute to the goal of reducing the cost of electrical power from geothermal resources. As part of this task, support is provided on an as requested basis to DOE and other laboratories to evaluate the potential cost and performance benefits of selected technologies. In FY2004, the work scope for this task specifically included examining the potential benefits of a new technology, as well as an on-going research activity within the program

Background/Approach: Sustaining the viability and future growth of the domestic geothermal industry is contingent upon reducing the costs associated with the generation of electrical power. Historical costs, in terms of $\$ / \mathrm{kW}$ installed, provide a valuable perspective on capital costs of geothermal plants, as well as trends in cost reductions. It is difficult however to use the total installed plant cost to assess how technology advances to specific energy conversion system components impact this cost. To do so, one must know the contributions of individual components and systems to the total cost, as well as their installation costs. Obtaining historical costs in sufficient detail to provide this assessment requires one have access to information that is generally considered proprietary and has limited access. In addition, very few plants have been built domestically in the last decade; the costs that are available are dated and will not necessarily reflect true current costs. 
To account for the limitations of the historical data, INEEL investigators are working to establish methods of deriving current installed capital costs in sufficient detail to allow the impacts technology advances on power production costs to be evaluated. The methodology being developed utilizes a process simulator (ASPEN Plus) to both evaluate the impact of technology advances on conversion cycle performance and to size individual components. The impact on both component and plant capital costs (equipment and installed costs) is established using data obtained from a cost estimating software (ICARUS Process Evaluator, or IPE). Equipment specifications and operating data from existing plants have been used to assure that the ASPEN plant performance models properly simulate both plant and component performance. IPE derived cost estimates have been "calibrated" using both proprietary cost information from existing plants, as well as industry review for comment and concurrence. This process of model refinement and verification is an ongoing process that is done whenever new data becomes available. The emphasis in this activity has been on the performance and costs of binary power plants.

Status/Accomplishments: Previously the methodology using the ASPEN simulator models and the IPE software was used to derive the installed capital costs for binary power plants using an isobutane working fluid. This methodology has been "calibrated" using operating data from power plants and proprietary cost information.

In FY2004, cost and performance projections for binary plants using an isopentane working fluid were prepared and sent to industry for review and comment. This study provided insight as to the combined effect of plant and well field development on the cost of power for lower temperature resources $\left(300^{\circ} \mathrm{F}\right.$ and lower). If the wells are shallow and the associated well field development costs are low $(<\sim 30 \%$ of the total project cost), there can be a cost advantage to using less efficient conversion systems that have lower capital costs.

The potential impact of using a velocity pump reaction turbine as a geothermal total flow expander with lower temperature resources was examined in FY2004. With this device, the two-phase expansion occurs only in the outer-rotor nozzle where droplet accelerations normal to the flow direction are minimized. This should reduce the effect of droplet impingement on rotor blading and the associated adverse impact on efficiency (with axial-flow, impulse total flow devices). Prior work examined the potential benefit when using these expanders with higher temperature resources $\left(\sim 360^{\circ} \mathrm{F}\right)$. This work indicated that isentropic expander efficiencies as high as $77 \%$ might be achieved with these devices. In the current study, the potential impact on performance as evaluated for resources between $200^{\circ}$ and $350^{\circ} \mathrm{F}$. The performance comparison between a total flow cycle with this expander and other technologies is shown in the figure below. 


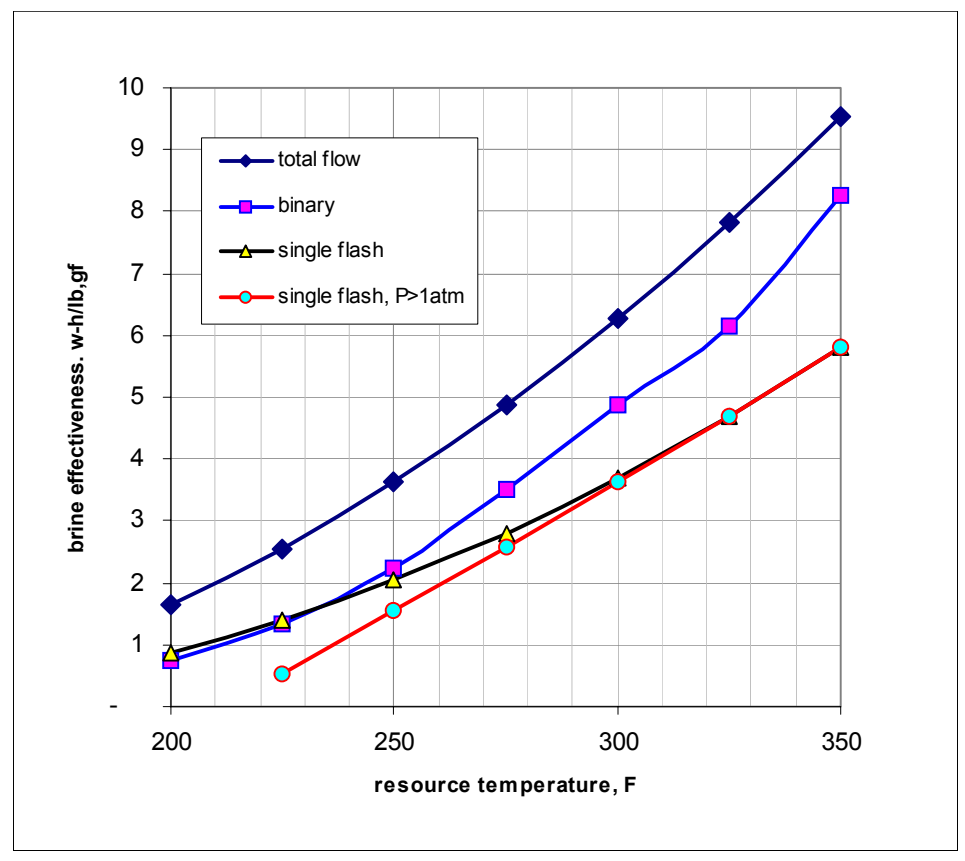

These results, which assume a total flow expander efficiency of $77 \%$, indicate a significant performance advantage for the total flow cycle, especially at the lower resource temperatures. This performance advantage occurs because the cycle removes most of the energy from the brine (the effluent temperature is approaching the ambient temperature). Because of concerns relative to the temperature dependence of mineral precipitation, this cycle will likely not be appropriate for resources having temperatures above $\sim 280^{\circ} \mathrm{F}$. It may be appropriate for lower temperature resources that do not have the same potential for mineral precipitation. The performance advantage shown in the figure above is dependent upon the expander efficiency. If the expander efficiency attained is $45 \%$ (instead of $77 \%$ ), the total flow cycle would perform similar to the binary and sub-atmospheric flash cycles. Any additional future work on this cycle will include the evaluation of the efficiencies projections developed in the prior work. If the basis for these projections is reasonable, a technology development effort would be proposed to validate the projections and resolve technical and cost issues associated with geothermal applications.

During FY2004, an evaluation of the impact of applying coatings to the heat exchanger tubing surfaces exposed to geothermal fluids in binary power plants was conducted. This work examined current industry practices and evaluated the impact of the coating application on component size and plant performance. The coatings being developed would be applied to carbon steel tube surfaces to provide corrosion protection from aggressive geothermal fluids. Because coatings add thermal resistance to the transfer of heat, their benefit is dependent upon both their thermal conductivity and their thickness. Based upon published results of work with the coatings, the thermal resistance of the coatings ( 5 mil thick) is approximately equivalent to typical geothermal fluid fouling factors. Carbon steel is predominately used as the tubing material in geothermal heat exchangers in existing binary power plants. Unless the coatings are non-fouling and the design geothermal fluid fouling factor is greater than that of the thermal resistance coatings, the required surface area will increase when the coatings are used. Although reported results indicate a resistance to fouling, the coatings do not appear to be totally fouling resistant. As a consequence, heat exchangers using the coatings will be larger and more expensive (due to size and expense of applying coatings). Although there is likely not to be any reduction in capital costs, the coatings may beneficially impact operation costs by reducing tube failures and increasing intervals between heat exchanger cleanings. Cost impacts are being evaluated and will be reported to DOE in FY2005. 
Because of funding limitations, the license to the ICARUS Process Evaluator software has lapsed. Prior to losing access to the software, several plant cost analysis runs were made under different component size scenarios. In FY2005, this information will be used to develop cost correlations that will allow cost projections to be made in a spreadsheet format.

Reports \& Articles Published in FY 2004: None

Presentations Made in FY 2004: None

Planned FY 2005 Milestones:

Complete integration of binary plant capital cost correlations and performance models into spreadsheet 


\section{Cost Database and Simulators}

Reporting Period: FY 2004 (October 1, 2003 to September 30, 2004)

DOE Grant/Contract \#: $\quad$ DE-AC04-94AL85000

Performing Organization: Sandia National Laboratories

Geothermal Research Department 6211

Albuquerque, New Mexico 87185-1033

Principal Investigator: $\quad$ Stephen Bauer, (505) 844-9116, sjbauer@sandia.gov

Collaborating Researchers: Craig Tyner

DOE HQ Program Manager: Dr. Leland (Roy) Mink, (202) 586-5463, roy.mink@hq.doe.gov

DOE HQ Technical Manager: Raymond LaSala, (202) 586-4198, raymond.lasala@ee.doe.gov

DOE Funding Allocation: $\$ 80 \mathrm{~K}$

Cost Share Funding: None

Project Objective: The expanded thrust of this project will include systems analysis activities that will subsume ongoing work and will included analyses of drilling system requirements, costs, performance, limitations, needs, and R\&D priorities. Specifically, they support continuing development, improvement, and independent validation of drilling cost/performance sub-models (for incorporation into overall geothermal system models); staying current with industry needs and directions (regular, structured interactions with industry and industry groups); staying current with ties to other applications (finding and applying/adapting available technologies) to get more interest, cost-sharing, and markets than geothermal alone can bring. In this regard, the leveraging of our activities and sharing of information (to take advantage of, for example, oil \& gas developments; high-temperature electronics applications for DoD, NASA, and others; and grout materials for the mining industry) will be critical to maximizing our progress; integration with other program elements, including system cost and performance models, but also well development needs and requirements of various geothermal applications (EGS, exploration, direct use and geothermal heat pump drilling, etc.); and, quantitative assessment of R\&D cost vs. risk vs. payoff to help prioritize $R \& D$ activities.

The key objective has been to provide a means to focus drilling related research in a manner intended to decrease short- and long-term costs by DOE and operators. Cost statistics are used to focus DOE research through development of metrics which "value" the products of research and development activities. This systems approach gives DOE and industry the cost-analysis capability to predict costs in various drilling situations and either refine their drilling practices or pursue appropriate new technology. An ever present activity is to obtain, analyze, and document U.S. geothermal drilling costs in a database that is updated annually. 
Background/Approach: A detailed understanding of drilling costs and their sources is necessary to focus efforts on work that has the highest payoff for the geothermal industry. In an effort to define field costs for typical geothermal wells, Sandia has collected more than 30 well-cost files from three different geothermal fields. These files, which are all in the electronic database format RIMBase, include not only new production wells drilled from surface, but workovers, abandonments, and injection wells. We also have access to many (hundreds) of paper well files that are not in electronic format. The RIMBase files have been summarized, and some paper well files have been translated into spreadsheet format, all aimed toward finding a standard way to display and analyze well costs.

There are two distinct ways to reduce drilling cost - eliminate abnormal, or "trouble", costs and improve performance in standard operations. Analysis of the available well data to date has yielded statistics on "average" and "optimum" wells in two different fields. The "average" well represents the cost for a typical well, based on actual cost per foot for the various components of the drilling process. The "optimum" well eliminates trouble cost from the average well and assumes the best demonstrated drilling performance (rate of penetration and bit life) for that field. Comparison of optimum and average wells shows where important cost savings are available through trouble avoidance and improved (or consistent) drilling performance.

\section{Status/Accomplishments:}

We have developed a simplified cost model for geothermal drilling. The intent of the model is to capture actual drilling cost data in a model that will allow us to estimate present and future drilling costs for a wide variety of conditions, as a function of a multitude of parameters (formation characteristics, drilling and completion technologies, well size, etc.). While capturing the appropriate detail for general use will take quite a while, we have applied the model to a "reference" hydrothermal well that can be used to assess how well our R\&D progress compares to DOE geothermal drilling metrics. The simplified cost model takes the form:

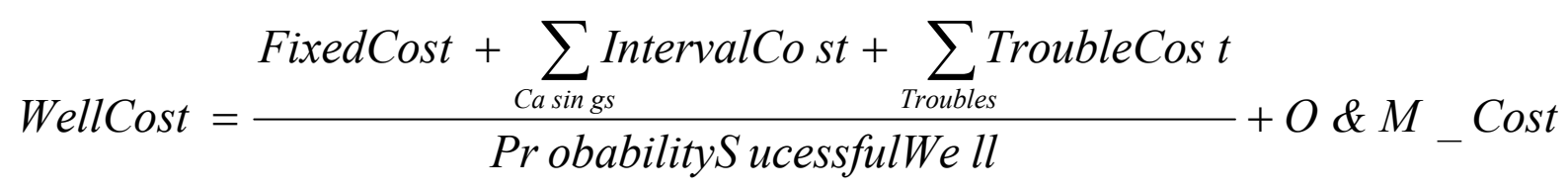

The model successfully was applied to a "reference" geothermal well and then used to evaluate the costs ascribed through cost savings which resulted from R\&D efforts.

Similarly, a scaled-down well drilling costing model for use in evaluating drilling costs for advanced concepts has been developed. The information necessary for the model includes costs associated with: (1) Well configuration: for example, the well profile in depth, hole diameter, and casing diameter, as well as casing details as to weight, grade and threaded connection (2) Prespud and mobilization: including mob and demob, as well as waste disposal and cleanup; (3) Location specific, for example site prep, cellar construction, conductor, etc.; (4) Daily Operations, including, rig day rate, fuel, power, (5) Interval costs (for planned \# of intervals), depths, bit performance, fluids, trouble, testing and completion, (6) Through production. Outputs are presented in a general manner as well as AFE format. The model has been verified through limited application of costing for previously completed cost analyses using other cost models.

The lithology (rock type) and the rate of penetration (ROP) in drilling geothermal wells for a specific drilling area have been studied (Figure 1). This work included two efforts, developing an understanding of the lithology, and examining the details of the ROP in those lithologic units. The analysis shows there is a very complex relationship between rock type and ROP. Perhaps, since all rocks at this locale are 
considered similar from a driller's perspective, the initial goal of the work, using this site as a case study, was a poor choice. There was no first-order dependence of lithology in this area on ROP. The initial intent of the analysis was left unaccomplished; there is insufficient data to relate ROP to an intrinsic rock property. If additional data in the form of, quartz content, compressive strength, velocity data, etc. becomes available, the goals of the intended analysis could possibly be completed.

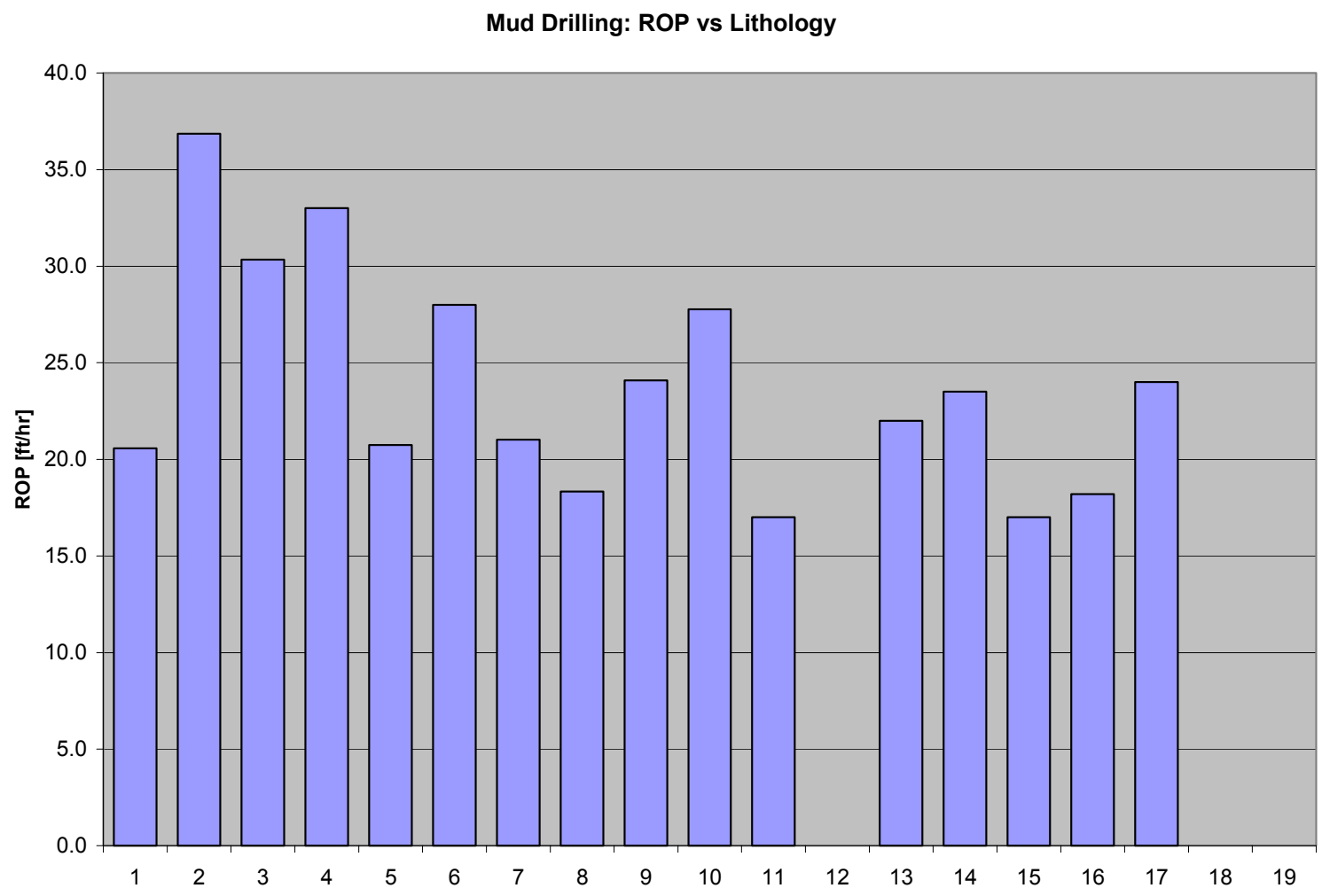

Figure 1. Rate of penetration versus differing lithologies.

\section{Reports \& Articles Published in FY 2004:}

"Wellcost Light, Simplified Analysis Method to Determine Geothermal Drilling Costs", B. Livesay, November 2003.

“Wellcost Metrics Analysis” C. Tyner, July, 2002

"Lithologic Considerations in Rate of Penetration", S. Bauer and D. Johnson, November, 2004.

Presentations Made in FY 2004: None

Planned FY 2005 Milestones (if funded in FY05):

Report on integration of additional well cost data into existing data base Jun 05 Report on development of drilling system analysis model 


\section{KEY WORD INDEX}

2D, 103, 104

2-D, 37, 38, 100

2-D, 113

$3 \mathrm{D}, 27,28,33,112,113,116,119$

3-D, 25, 29, 35, 36, 37, 38, 40, 115, 127

acid, 43, 132, 156, 159, 182, 183, 184, 185, 186

Aidlin, 109, 110, 111, 125, 126, 127, 132, 133,

$134,149,150$

air-cooled condenser, 139, 140

air-cooled condensers, 137, 138, 139

Aspen, 136

ASTER, 4, 5, 6, 8

binary, 44, 133, 135, 139, 141, 154, 155, 187 ,

$188,189,190$

biofilms, 147

Bonnett, 131, 149, 150

Bradys, 4, 5, 16, 17, 18, 19, 63

brines, 42, 43, 67, 152, 155

BTC, 90

Buena Vista, 31

Buffalo Valley, 4, 55, 56, 62, 74

Calpine, 109, 111, 124, 125, 131, 147, 149, 158, 159

capillary, 105, 106

Carson Desert, 62, 80

Casing, 96, 180

cement, $67,165,168,179,182,183,184,185$, 186

circulation, $35,67,68,71,79,114,149,165$, $166,167,182,184$

$\mathrm{CO}_{2}, 43,44,51,52,53,54,109,110,111,182$,

$183,184,185$

coating, 131, 133, 134, 189

Coldwater Creek, 109, 110

composite, 31

condenser, 138, 139, 141, 142, 147, 148, 149, 150

condensers, vii, 132, 133, 137, 139, 148

conductivity, 18, 21, 27, 30, 31, 96, 118, 132, 185,189

Corrosion, 131

Coso, 13, 17, 33, 48, 73, 103, 104, 121, 122, $156,163,180,182,183,184,185$

Cove Fort, 7, 67, 149

darcy, 100, 183

Desert Peak, 5, 16, 17, 18, 74, 112, 113, 114, $115,117,118,120$

Dixie Meadows, 6, 7, 9, 47
Dixie Valley, 7, 8, 9, 11, 12, 14, 20, 21, 22, 23, $31,32,46,47,49,50,52,67,74,156,180$

drilling, vii, viii, ix, 35, 62, 70, 102, 103, 114, $161,162,165,166,167,168,169,170,171$, $172,173,174,175,176,177,178,179,180$, 191, 192, 193, 194

DWD, 170, 171, 172, 173, 174, 175, 176

EGS, vii, viii, 5, 16, 25, 26, 41, 59, 61, 62, 66, $67,68,89,93,94,95,99,100,102,109,113$, $117,118,119,120,121,122,125,156,162$, $164,177,178,179,180,191$

electromagnetic, 27, 29

EM, 21, 22, 27, 29

faults, $6,7,8,10,11,12,14,15,18,28,35,36$, $37,38,49,61,62,63,67,72,74,75,102$, $112,113,114,116,125,126$

Fish Lake, 4, 6, 66, 67

fouling, 131, 134, 146, 148, 150, 159, 189

fractures, viii, $11,12,35,47,71,72,73,90,99$, 102, 106, 107, 113, 117, 120, 121, 126, 166

Ft. Bidwell, 28

geochemical, vii, 4, 40, 46, 49, 52, 54, 55, 56, $66,67,68,79,89,109,111,116,117$

Geochronology, 114

GEOFLUIDS, 43

GEOHEAT, 43

GEOMECHANICS, 102

Geysers, 27, 33, 34, 109, 110, 111, 124, 125, $127,132,133,148,158,180,181$

GIS, 7, 8, 18, 56, 61, 62, 63, 64, 112, 113

GPS, viii, 11, 13, 15, 30, 31, 40, 56, 61, 62, 63, $64,65,74,75,76,77$

gravity, 11, 17, 18, 61, 62, 67, 113, 116

Great Basin, 3, 8, 29, 31, 39, 40, 57, 58, 61, 62, $63,64,65,68,74,76,77,78,79,80,81,112$, $114,115,155$

$\mathrm{H}_{2} \mathrm{~S}, 143,182,183$

HARD-ROCK, 169, 170, 171, 172, 176

$\mathrm{HCl}, 109,143$

HDR, 90

heat exchanger, 131, 132, 133, 138, 189

heat exchangers, vii, 95, 131, 137, 138, 144, 189

heat transfer, 90, 95, 99, 100,132, 133, 134, $138,139,140,147,148,155$

helium, 46, 47, 48, 49, 50, 110

HFR, 89, 90, 93

Hot Springs Flats, 17 
Hot Springs Mountains, 17, 112, 113, 114, 115, 116

HRDF, 169, 171

HSZ, 112

Humboldt, 31, 40, 76, 112, 115

hydraulic, 59, 67, 102, 103, 118, 170

hydrothermal, viii, 3, 4, 8, 10, 11, 12, 13, 23, 32, $41,42,43,44,49,51,52,61,67,68,71,73$, $90,95,99,131,156,167,177,180,184,185$, 187,192

hyperspectral, 3, 4, 5, 6, 7, 8, 53

ICARUS, 188, 190

Imperial Valley, 68, 180

Indonesia, 7, 32, 71, 73, 183

injection, viii, 17, 27, 35, 41, 42, 59, 67, 71, 90, $95,99,100,104,109,110,111,117,118$, $119,124,125,126,127,132,133,152,154$, $155,156,173,184,192$

InSAR, 10, 11, 13, 15, 16, 17, 18, 19

in-situ, 103, 105, 125, 144, 145, 146, 185

interferograms, 13, 17, 18

IPE, 188

ISOTOPES, 46

Kilauea, 27, 28

LCTF, 169, 171

Long Valley, 11, 48

lost-circulation, 165,166

magnetotelluric, 20, 23, 29, 32

Mammoth, 131, 133, 134, 142, 152, 153

map, 3, 4, 6, 7, 9, 13, 21, 23, 28, 31, 33, 35, 47, $56,57,62,63,71,74,76,77,78,113,115$, 116

matrix, 90, 91, 92, 95, 99, 100, 122, 155, 156

Meager Mountain, 70

Medicine Lake, 70

MEQ, 27, 33, 113, 116, 124, 125

microbial, viii, 53, 147, 148, 159, 160

microearthquakes, 33

modeling, viii, ix, 7, 10, 11, 19, 25, 26, 27, 28, $33,36,38,41,42,43,54,57,67,85,86,88$, $89,90,92,99,102,113,156,170,171$

models, viii, 20, 23, 24, 29, 35, 36, 41, 42, 43, $44,48,49,52,66,67,70,85,86,88,103$, $106,113,136,137,155,170,171,188,190$, 191,192

MT, viii, 20, 21, 22, 23, 24, 25, 27, 28, 29, 30, $31,32,86,88$

MT/DC, 21

multiphase, 89

multispectral, 3, 4, 6, 7, 8

$\mathrm{N}_{2}, 44,111,182,183,184,185$
NBMG, 56, 57, 61

optical, 3, 106, 144, 145, 146, 162

PDC, 169, 170, 171, 172

permeability, viii, 12, 21, 33, 35, 41, 46, 71, 86, 87, 90, 94, 99, 100, 105, 106, 107, 108, 117, $118,119,120,125,183,184,185$

PEST, 85,86

$\mathrm{pH}, 42,43,45,155,156,182,183,184,185$

polymerization, 155,156

polymers, 166

pore, 103,118

porosity, $87,90,184$

power plant, viii, 7, 37, 57, 135, 137, 151, 162, $163,183,187$

power plants, vii, $57,62,125,131,132,137$, $141,147,155,183,187,188,189$

PPS, 131, 132, 133, 134

Precipitation, 90

Railroad Valley, 6, 63

reinjection, 16, 18, 19, 90, 144, 154

reservoir, 11, 16, 17, 18, 19, 20, 23, 35, 36, 37, $41,42,43,44,46,47,63,67,70,71,72,85$, $86,88,89,94,95,99,100,102,103,105$, $109,111,112,113,124,127,154,156,162$, $163,174,178$

reservoirs, viii, $33,34,35,41,51,52,89,90,92$, $95,97,105,112,113,115,131,173$

resistivity, viii, 20, 21, 22, 29, 31, 32, 72, 73, 118

respirometry, 159,160

Roosevelt, 48, 49, 73, 80

ROP, 169, 180, 193

Rye Patch, 35, 36, 37, 56

saline, 3, 43, 72, 90

Salt Wells, 63

Salton, 13, 67, 68, 69, 73, 134

Santa Rosa, 109, 111, 125, 126, 146, 159

Saturated, 92

scale, viii, $3,4,6,8,10,13,18,28,48,53,63$, $67,74,75,113,122,123,131,133,139,144$, $145,146,152,154,155,156,168,170$

scaling, 21, 41, 42, 43, 90, 132, 134, 144, 154, 155,156

Seismic, 13, 35, 36, 38, 40, 124

Senator Fumeroles, 21, 22

shear-wave, viii, 33

silica, 67, 90, 120, 144, 152, 153, 154, 155, 156

Silver Peak Range, 6, 8, 9

Smoke Creek, 62

Soda Lake, 80

SP, 27, 28, 86, 88 
starved, 95

steam, viii, 42, 67, 72, 105, 106, 107, 109, 111, $143,144,145,146,147,185,187$

Steamboat, 4, 48, 67

Stillwater, 12, 21, 22, 31, 47, 49, 80

STRAIN, 10, 12, 74

SULFIDES, 158

S-waves, 33, 37

TELEVIEWER, 121

TEQUIL, 43, 155

Tet $^{-1}, 85,86,87,88$

TETGEO, 85, 86, 88

TetGeo- 1,86

TETRAD, 85, 86

thermodynamic, 42, 155

titanium, 132
TOUGH2, 52, 90, 92

TOUGHREACT, 89, 90, 92, 93

tracer, 7, 52, 86, 87, 89, 90, 91, 93, 94, 95, 96, 97, 98

tube, 80, 131, 137, 139, 148, 163, 189

Tubing, 96

Two-phase, 95

USGS, 14, 56, 61, 62, 63, 121, 123, 124, 125 , 127,155

vapor-dominated, 71, 90, 93, 174

Vibrations, 170, 171

wavelength, 4, 15, 37, 119, 120

WBHX, 95, 97

well-cost, 192

workovers, 154, 192 


\section{PRINCIPAL INVESTIGATORS}

Arehart, G. B

Bauer, S. J.

165,191

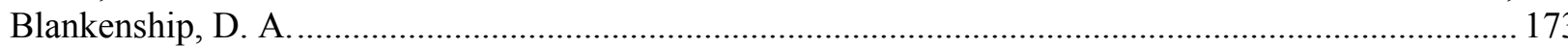

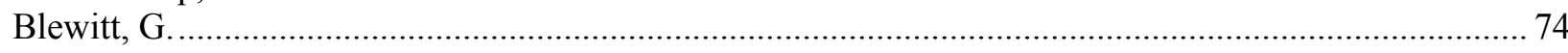

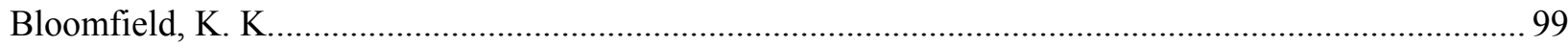

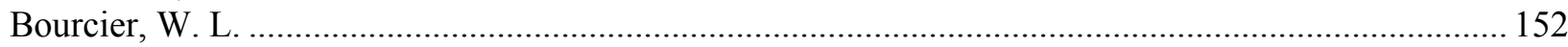

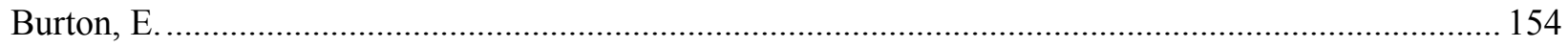

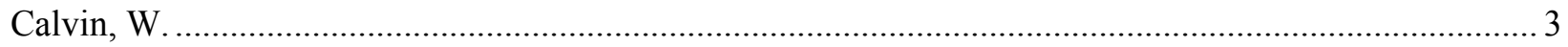

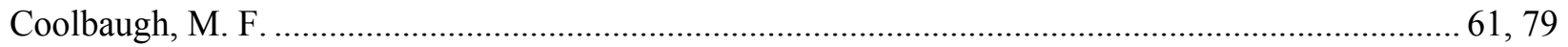

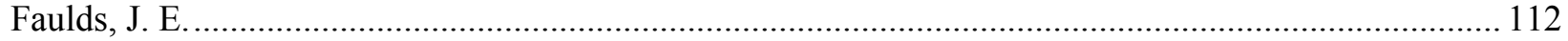

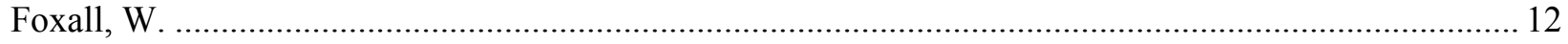

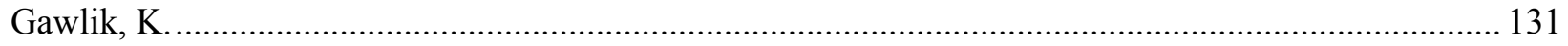

Ghassemi, A.

Horne, R. N.

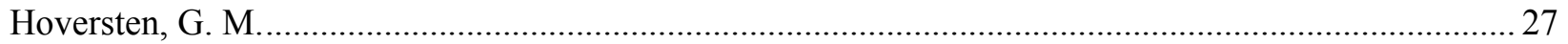

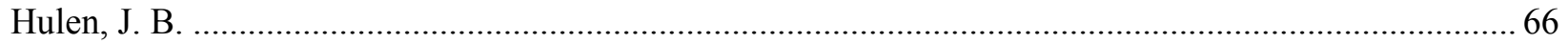

Kennedy, B. M.

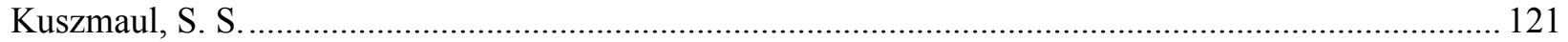

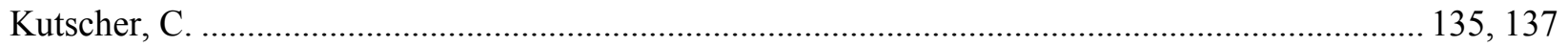

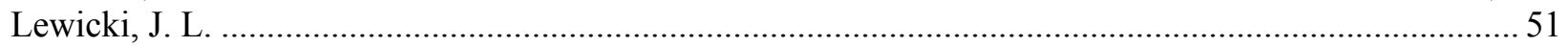

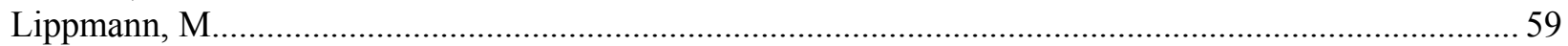

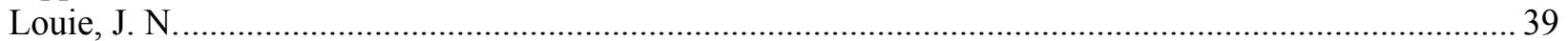

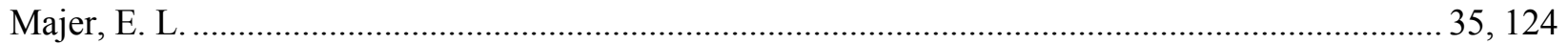

Mansure, A. J. .

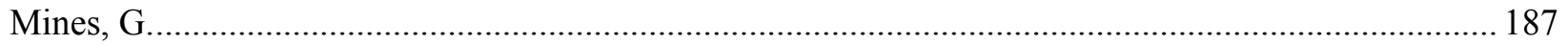

Mohr, C .

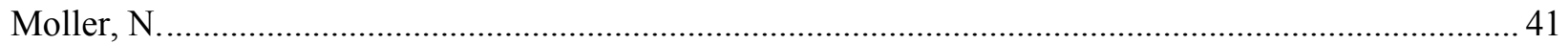

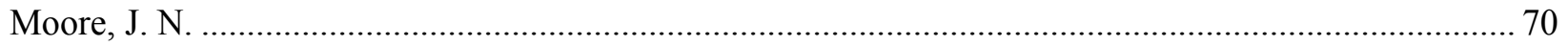

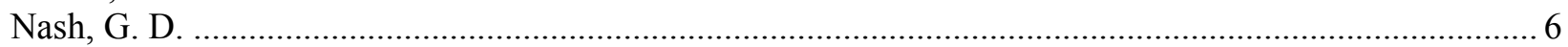

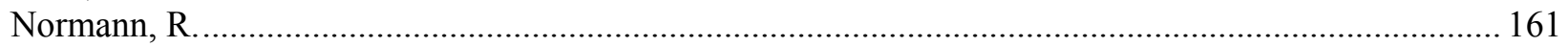

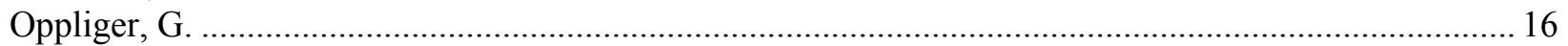

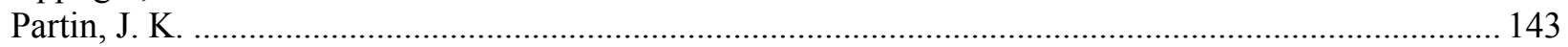

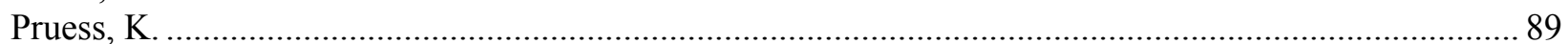

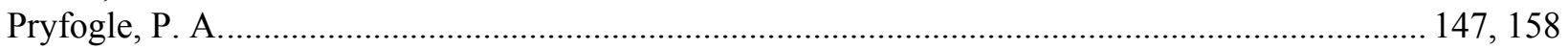

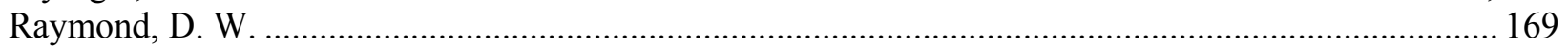

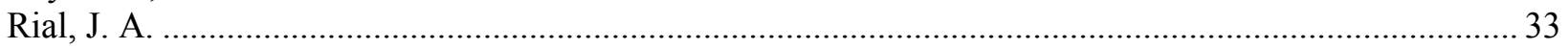

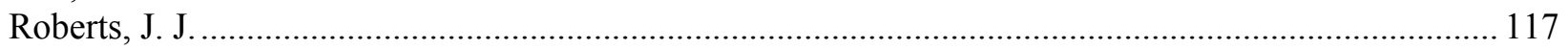

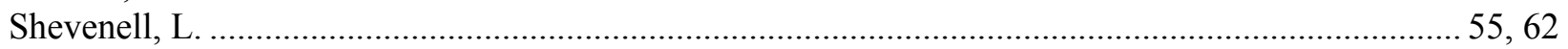

Shook, G. M.

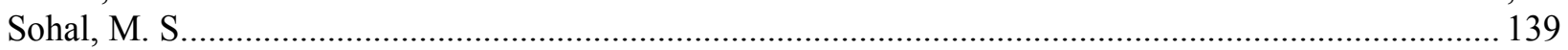

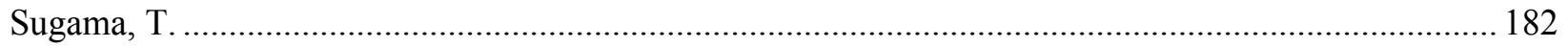

Vasco, D. W

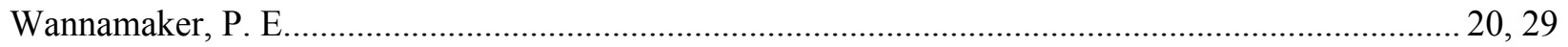

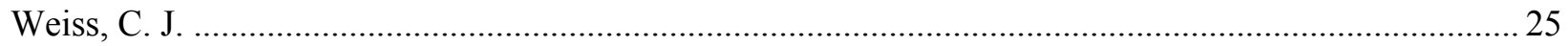

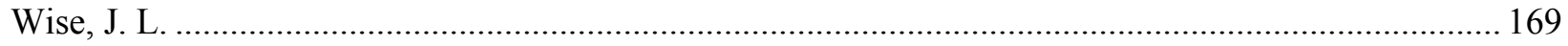




\section{COLLABORATING RESEARCHERS}

Allis, R

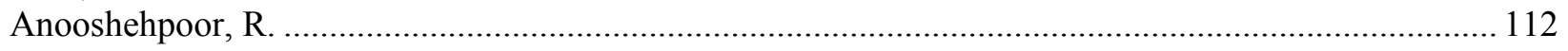

Avery, J.

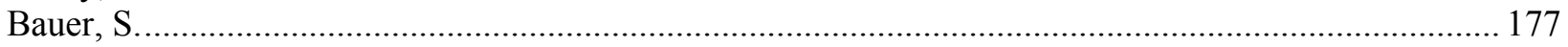

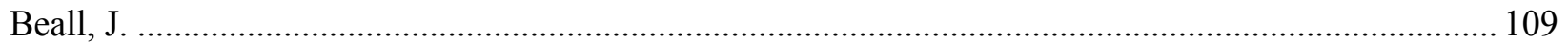

Berard, B .

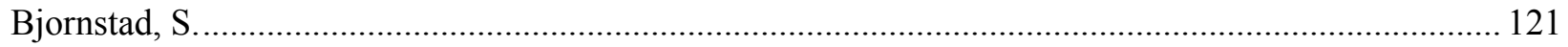

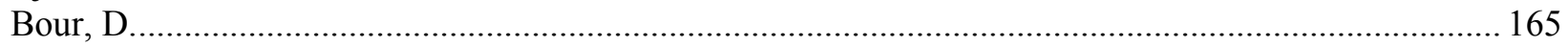

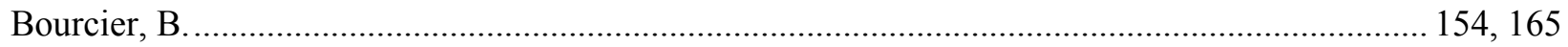

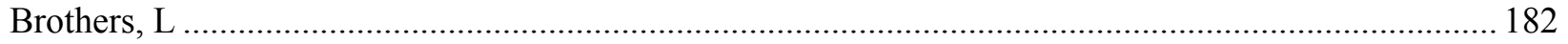

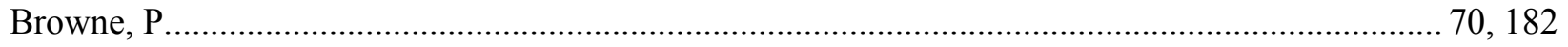

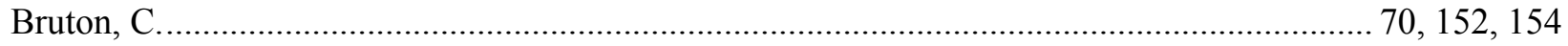

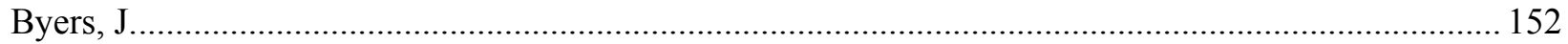

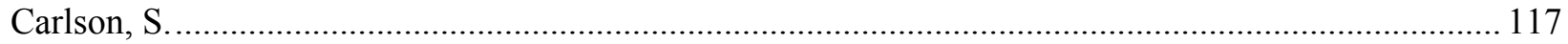

Cheng, A.

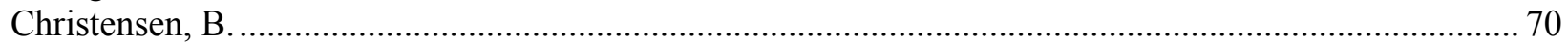

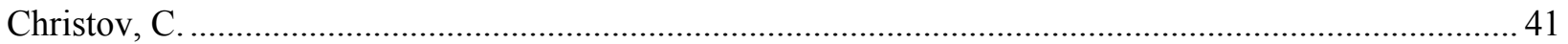

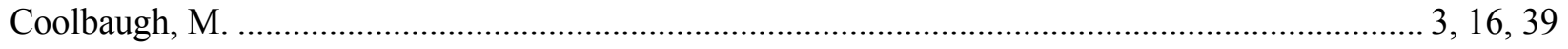

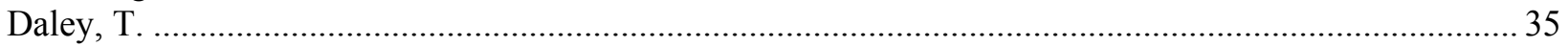

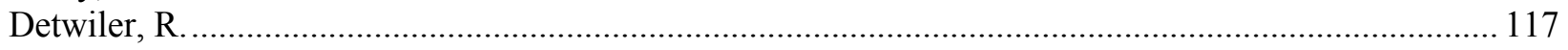

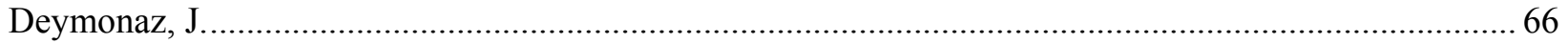

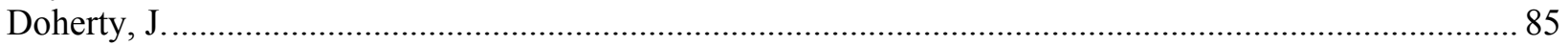

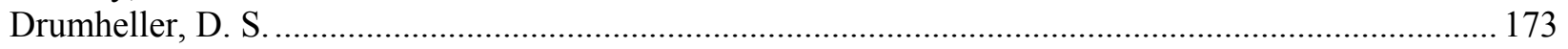

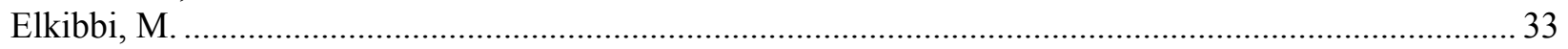

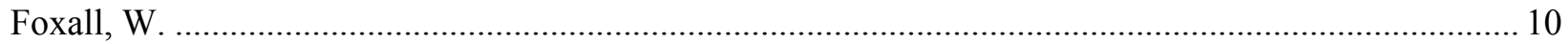

Garside, L

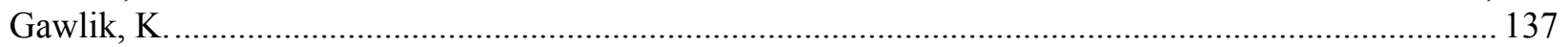

Gritto, R .

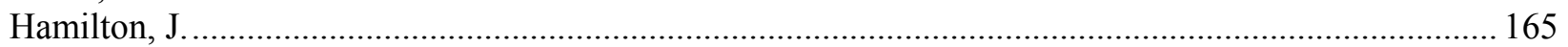

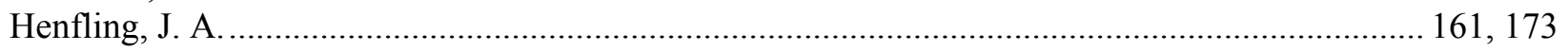

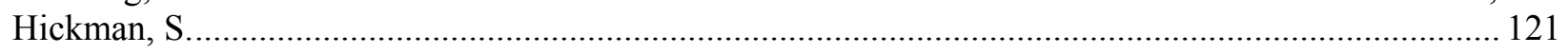

Hulen, J.

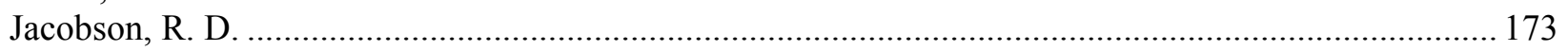

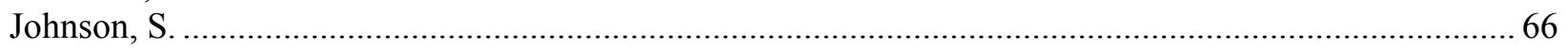

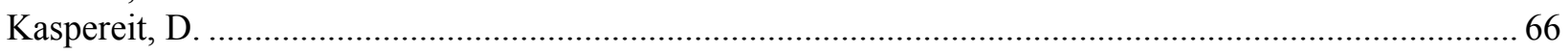

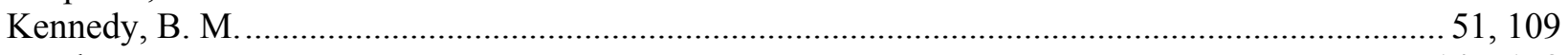

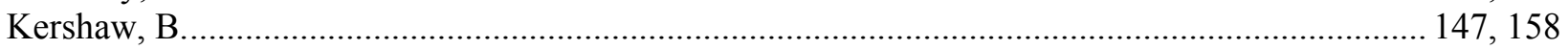

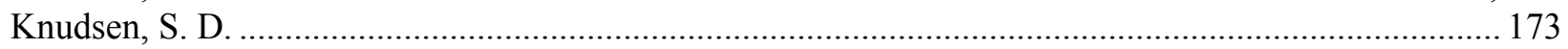

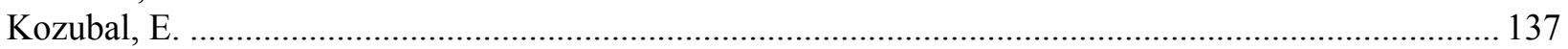

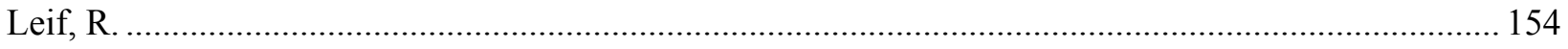

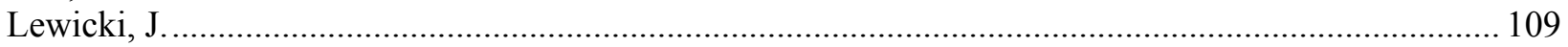

$\mathrm{Li}, \mathrm{K}$.

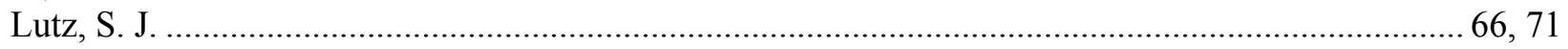

Mansure, A. J.

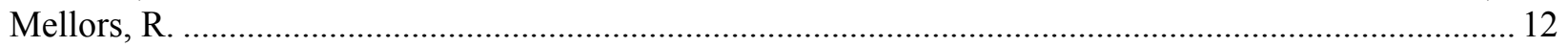

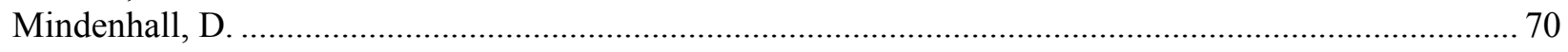

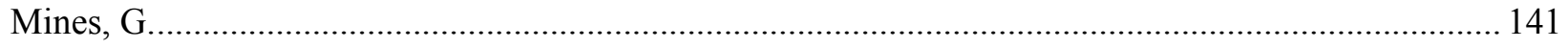

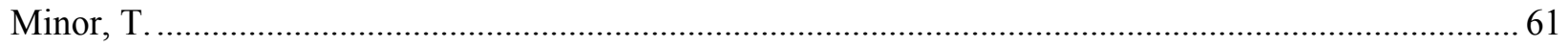




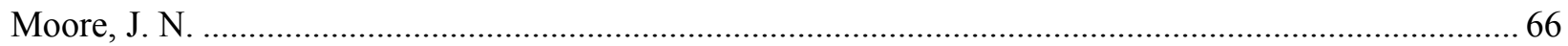

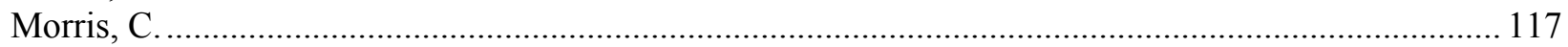

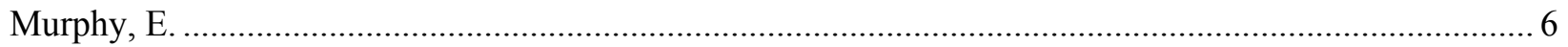

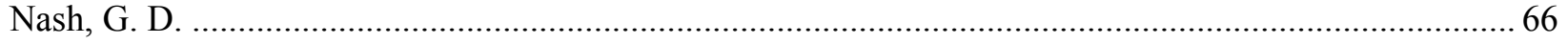

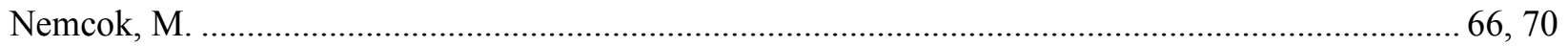

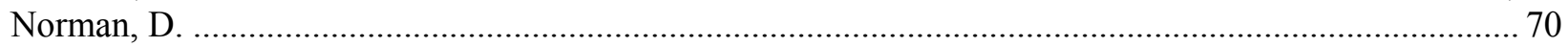

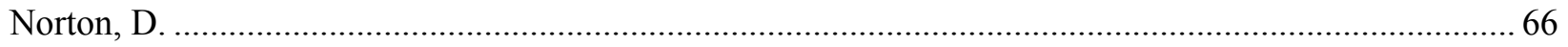

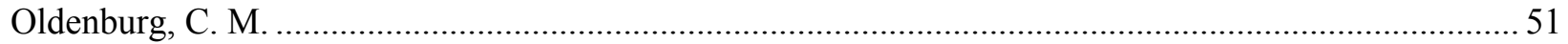

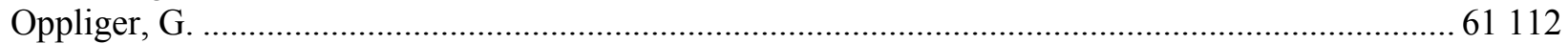

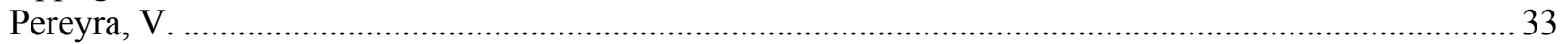

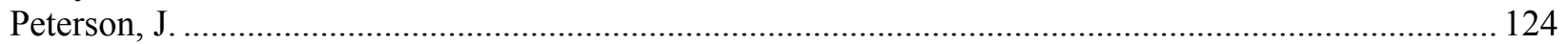

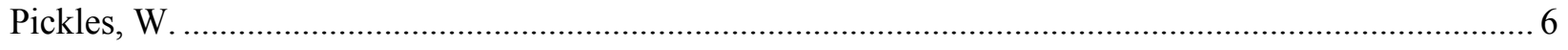

Pope, G. A.

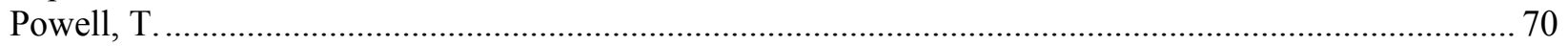

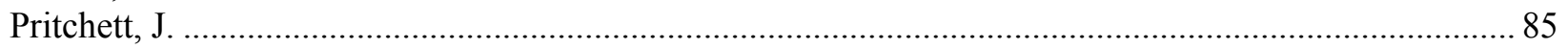

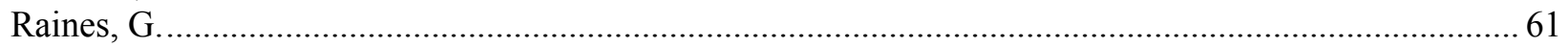

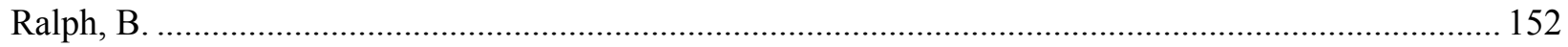

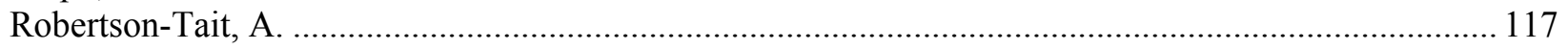

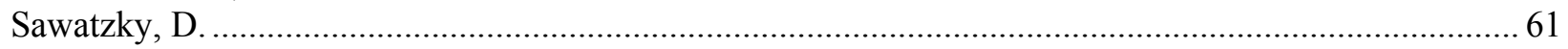

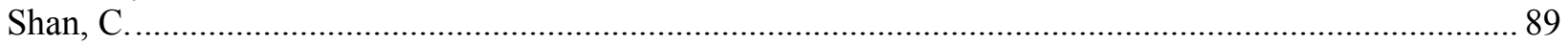

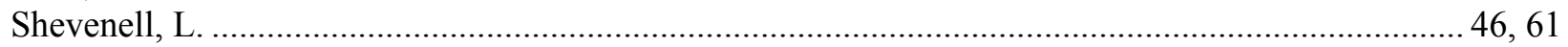

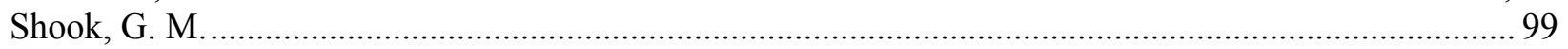

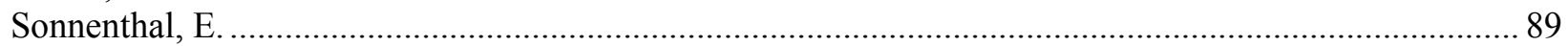

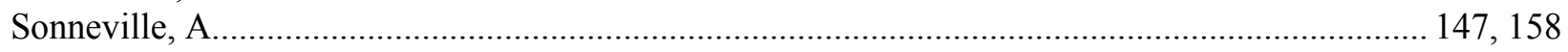

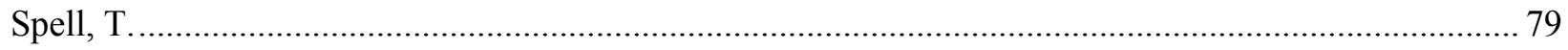

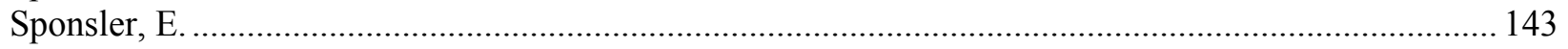

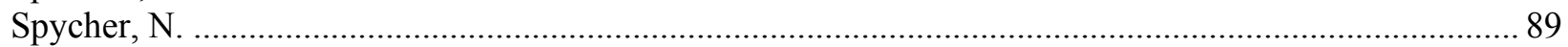

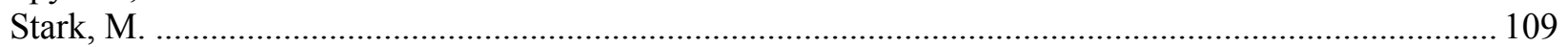

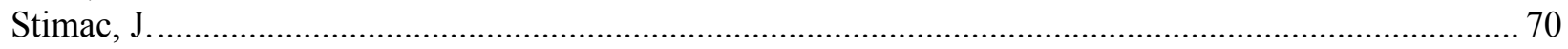

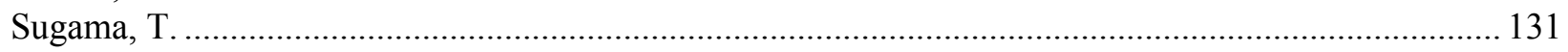

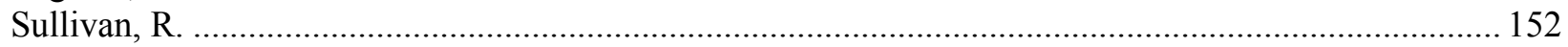

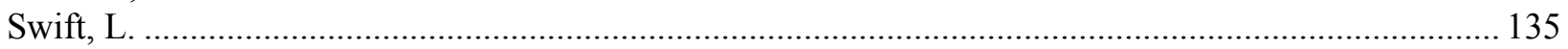

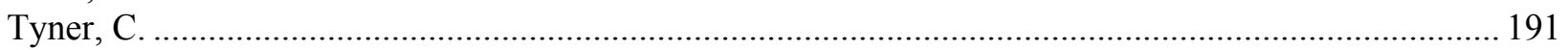

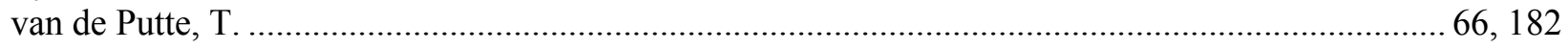

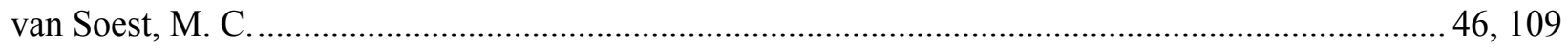

Vasco, D

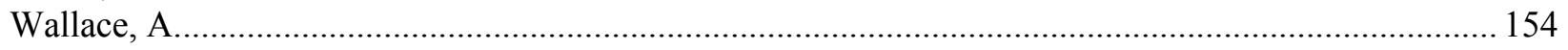

Warpinski, N.

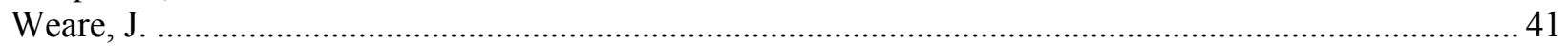

$\mathrm{Xu}, \mathrm{T}$.

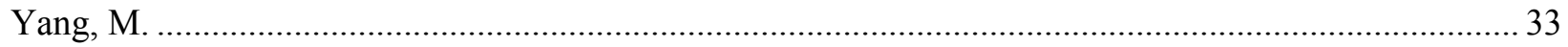

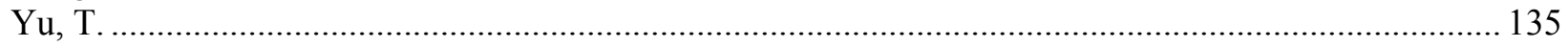

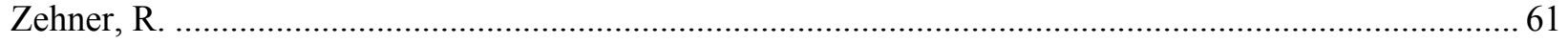




\section{PERFORMING ORGANIZATIONS}

Brookhaven National Laboratory.

131,182

Idaho National Engineering and Environmental Laboratory

$85,94,99,141,143,147,158,191$

Lawrence Berkeley National Laboratory $.10,27,35,46,51,55,59,89,92,93,109,124$

Lawrence Livermore National Laboratory $12,117,152,154$

National Renewable Energy Laboratory $131,135,137$

Sandia National Laboratories $25,121,161,165,168,169,173,176,177,191$

Stanford University 105

University of California, San Diego

University of Nevada, Reno. $3,16,39,55,61,62,64,74,79,112$

University of North Carolina at Chapel Hill 33

University of North Dakota 102

University of Utah. $20,29,66,70$ 
